\title{
Numerical Modeling of Hydraulic Fracture Propagation and Comparison with Microseismic Data at a Field Site
}

\author{
Carter Lawrence Hulcher \\ West Virginia University, chulcher@mix.wvu.edu
}

Follow this and additional works at: https://researchrepository.wvu.edu/etd

Part of the Civil Engineering Commons

\section{Recommended Citation}

Hulcher, Carter Lawrence, "Numerical Modeling of Hydraulic Fracture Propagation and Comparison with Microseismic Data at a Field Site" (2019). Graduate Theses, Dissertations, and Problem Reports. 4016. https://researchrepository.wvu.edu/etd/4016

This Dissertation is protected by copyright and/or related rights. It has been brought to you by the The Research Repository @ WVU with permission from the rights-holder(s). You are free to use this Dissertation in any way that is permitted by the copyright and related rights legislation that applies to your use. For other uses you must obtain permission from the rights-holder(s) directly, unless additional rights are indicated by a Creative Commons license in the record and/ or on the work itself. This Dissertation has been accepted for inclusion in WVU Graduate Theses, Dissertations, and Problem Reports collection by an authorized administrator of The Research Repository @ WVU.

For more information, please contact researchrepository@mail.wvu.edu. 


\title{
NUMERICAL MODELING OF HYDRAULIC FRACTURE PROPAGATION AND COMPARISON WITH MICROSEISMIC DATA AT A FIELD SITE
}

\author{
Carter Lawrence Hulcher
}

\author{
Dissertation submitted to the \\ Benjamin M. Statler College of Engineering and Mineral Resources \\ at West Virginia University \\ in partial fulfillment of the requirements for the degree of \\ Doctor of Philosophy in \\ Civil and Environmental Engineering
}
Hema J. Siriwardane, Ph.D., Chair
John Quaranta, Ph.D.
Radhey Sharma, Ph.D.
Udaya Halabe, Ph.D.
H. Ilkin Bilgesu, Ph.D.

Department of Civil and Environmental Engineering

\author{
Morgantown, West Virginia \\ 2019
}

Keywords: Numerical Modeling, Hydraulic Fracturing, Marcellus Shale, Microseismicity

Copyright 2019 Carter Hulcher 


\section{ABSTRACT \\ NUMERICAL MODELING OF HYDRAULIC FRACTURE PROPAGATION AND COMPARISON WITH MICROSEISMIC DATA AT A FIELD SITE}

\section{Carter Lawrence Hulcher}

A hydraulic fracturing site in Morgantown, West Virginia, USA was selected to be a research site for the Marcellus Shale Energy and Environment Laboratory (MSEEL) project which was funded by the U.S. Department of Energy (DOE). The overall objective of the MSEEL research project is to evaluate and improve technologies to enhance shale gas recovery with minimal impacts on the environment. The field site has two previously drilled wells and two newly drilled wells for extracting natural gas. A separate exploratory well (or "science well") was also drilled and includes a geophone array to extract important seismic/microseismic event information, which can then be used to help determine hydraulic fracture geometries.

The main objective of the current research work was to perform numerical modeling of all hydraulic fracturing operations at both of these newly drilled wells at the MSEEL site and perform model calibration based on a statistical methodology and available microseismic data. Available geologic, geomechanical, and treatment data was utilized to build the numerical model for all stages at both of these wells and comparisons were made with available microseismic data. There are 28 hydraulic fracture stages at one well and 30 stages at a second well. These 58 stages were individually numerically modeled and a statistical methodology and available microseismic data was utilized to calibrate the model. Results show a good match between estimates/measurements and model calculations of height, length, and surface pressure. 


\title{
$\underline{\text { Committee Members }}$
}

\author{
Dr. Hema J. Siriwardane (Chair) \\ Dr. John Quaranta \\ Dr. Radhey Sharma \\ Dr. Udaya Halabe \\ Dr. H. Ilkin Bilgesu
}




\section{ACKNOWLEDGEMENTS}

I would like to take this opportunity to thank those who helped me in my graduate studies over the past six years. I would first like to thank the extraordinary chair of my committee, Dr. Hema Siriwardane. His supervision and exceptional support throughout my research work have been critical, and without it none of this work would have been possible. I would also like to thank Dr. John Quaranta, Dr. Radhey Sharma, Dr. Udaya Halabe, and Dr. H. Ilkin Bilgesu for serving on my examination committee, reading and reviewing my research, and helping me on my journey to achieve my goal of earning my Ph.D. I would like to acknowledge the help provided by Dr. Antarpreet Jutla on the statistical method used in this paper, as well. I would also like to thank the entire MSEEL team for sharing research data collected at the MSEEL site.

I gratefully acknowledge the financial support provided through a graduate research assistantship by West Virginia University (WVU) through a project funded by the United States Department of Energy (DOE). I also acknowledge the financial support provided by the Statler College of Engineering's Fundamentals of Engineering Department, and the Department of Civil and Environmental Engineering at West Virginia University. These groups have given me the opportunities to study, perform research, and teach, which have been invaluable life experiences for me. Additionally, I want to thank those who have worked with me in geomechanics research over the years, including Dr. Raj Gondle, Dr. Sai Varre, Andrew Dietz, Hari Nambu, and Zainab Jawad.

Last, but certainly not least, I want to thank my wife, Abbé, parents, Janet and George, my uncle, Jim, and my entire extended family for their limitless support of me throughout my many years in college. Without their continuous love and financial support, none of this work would have been possible. 


\section{TABLE OF CONTENTS}

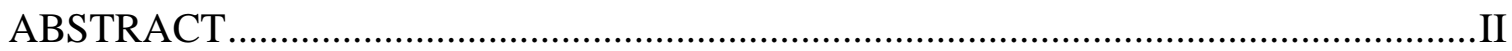

ACKNOWLEDGEMENTS ............................................................................. IV

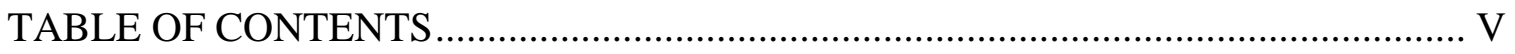

LIST OF FIGURES ................................................................................. VII

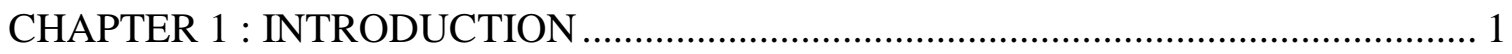

1.1 Marcellus Shale Energy and Environment Laboratory ........................................ 1

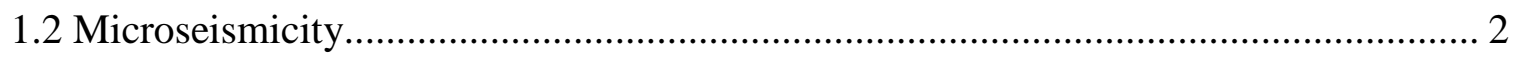

1.3 Hydraulic Fracturing and Its Importance for Energy Extraction ............................ 6

1.4 Fluid Flow through Porous Media ...................................................................... 19

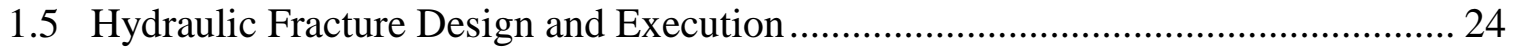

1.6 Data Acquisition and Evaluation Methods for Hydraulic Fracturing ...................... 30

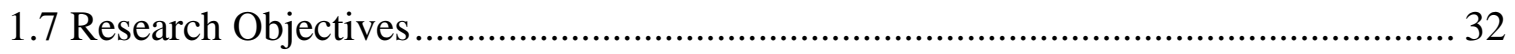

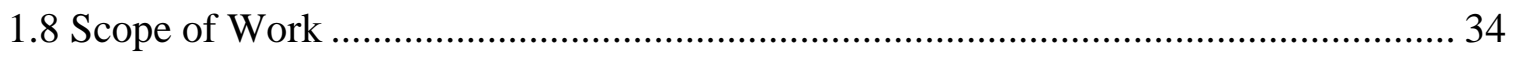

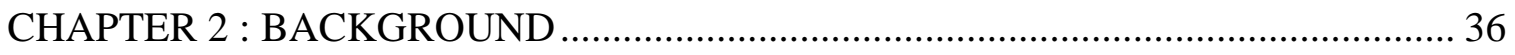

2.1 Background Research on Microseismicity ...................................................... 36

2.2 Background Research on Hydraulic Fracturing ................................................ 42

2.3 Other Studies involving Microseismic Monitoring and Hydraulic Fracturing ........... 49

CHAPTER 3 : DESCRIPTION OF THE HYDRAULIC FRACTURING FIELD SITE 55

3.1 Location of the Hydraulic Fracturing Field Site .............................................. 55

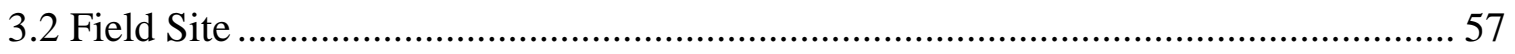

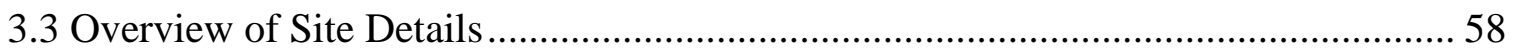

CHAPTER 4 : MATHEMATICAL DETAILS OF THE NUMERICAL MODEL ......... 73 
4.1 Numerical Model Utilized in this Study

4.2 Two-Dimensional and Pseudo-Three-Dimensional Hydraulic Fracturing Models .... 74

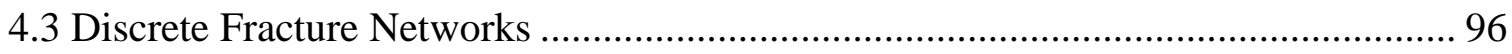

CHAPTER 5 : NUMERICAL MODELING OF HYDRAULIC FRACTURING ......... 100

5.1 Objectives of Numerical Modeling .............................................................. 100

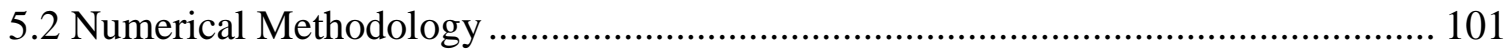

5.3 Numerical Modeling Construction and Results ............................................... 104

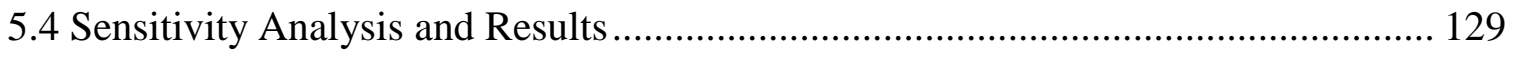

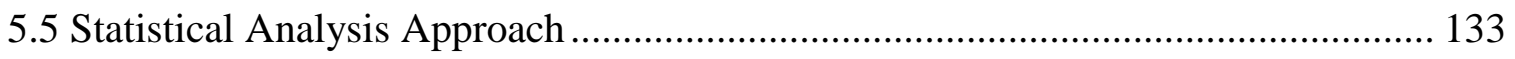

5.6 Statistical Analysis of Numerical Modeling Results ........................................ 140

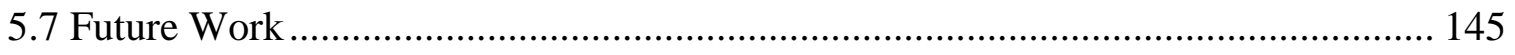

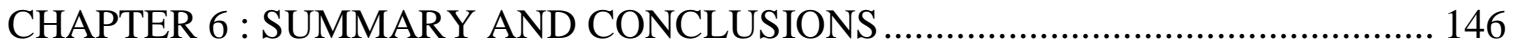

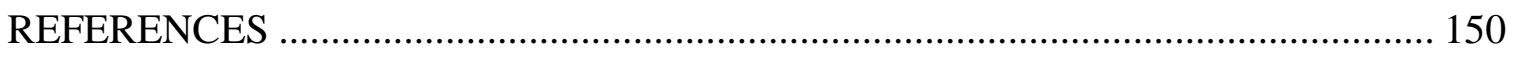

APPENDIX A - NUMERICAL MODELING RESULTS FOR STAGES 11-28 AT

WELL MIP-3H AND ALL STAGES AT WELL MIP-5H....................................... 165 


\section{LIST OF FIGURES}

Figure 1.1: Coulomb Failure (Modified from: Committee on Induced Seismicity Potential in Energy Technologies, 2013).....

Figure 1.2: Unconventional Hydrocarbon Resources Around the World (WV GIS

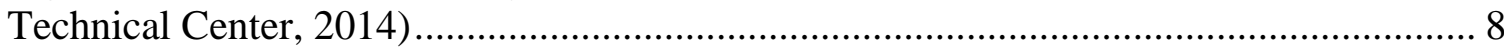

Figure 1.3: Structure Map of the Marcellus Formation (U.S. Energy Information

Administration, 2016)

Figure 1.4: U.S. Energy Production History and Projections from 1990 through 2050

(U.S. Energy Information Administration, 2018).

Figure 1.5: Wet/Dry Gas Boundary in the Marcellus Shale (Marcellus Center for

Outreach and Research, 2010) 13

Figure 1.6: Marcellus Shale Thickness Map (Marcellus Center for Outreach and

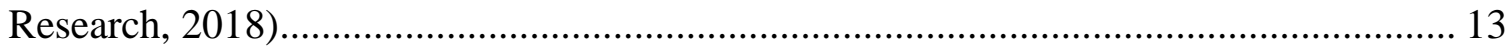

Figure 1.7: Simplified Horizontal (a) and Vertical (b) Well Configurations ................... 16

Figure 1.8: Drilling Rig Components (OSHA, 2019) .................................................. 26

Figure 3.1: 3D Block Model Showing MSEEL Well Locations in Relation to the Surrounding Morgantown, WV Area (Modified from: MSEEL Database Development

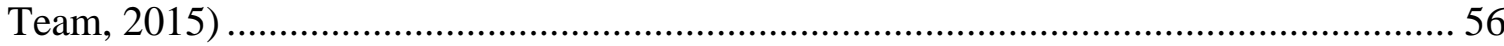

Figure 3.2: MSEEL Project Site Well Production through 02/28/2019 (MSEEL, 2019). 59

Figure 3.3: Sample Simplified Geologic Column for MSEEL Project Site (not to scale) 60

Figure 3.4: Sample Simplified Geologic Column from MSEEL Project Site Showing the

Marcellus Shale and Surrounding Layers (not to scale) ................................................... 61

Figure 3.5: Typical Injected Fluid Volume versus Time Plot for Well MIP-3H.............. 65

Figure 3.6: Typical Injected Slurry Rate versus Time Plot for Well MIP-3H................... 66

Figure 3.7: Typical Injected Slurry Volume versus Time for Well MIP-3H.................... 66

Figure 3.8: Typical Injected Cumulative Proppant Mass versus Time for Well MIP-3H 67

Figure 3.9: Typical Injected Fluid Volume versus Time Plot for Well MIP-5H.............. 68

Figure 3.10: Typical Injected Slurry Rate versus Time Plot for Well MIP-5H................ 68

Figure 3.11: Typical Injected Slurry Volume versus Time Plot for Well MIP-5H .......... 69

Figure 3.12: Typical Injected Cumulative Proppant Mass versus Time Plot for Well MIP$5 \mathrm{H}$

Figure 3.13: VSI Geophone (Schlumberger, 2004) ...................................................... 71

Figure 3.14: MIP-3H, MIP-5H, and MIP-SW Well Configuration .................................... 72

Figure 4.1: Symmetric Fracture Wing Diagram ………………………………………... 75

Figure 4.2: Fracture Model Width Profiles (from Meyer, 1986) ...................................... 82 
Figure 4.3: Length Profile for PKN, GDK, and P3D Fracture Models (Meyer, 1986) .... 83

Figure 5.1: MIP-3H Wellbore Measured Depth vs TVD with Geologic Strata (Northeast

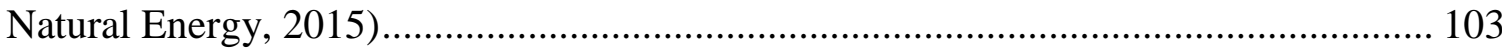

Figure 5.2: Wellbore Cross-Section used for Well MIP-3H in the Numerical Model ... 105

Figure 5.3: Typical Slurry Rate vs Time - Measured and Model Calculations - MIP-3H

Figure 5.4: Typical Cumulative Slurry Volume vs Time - Measured and Model

Calculations - MIP-3H

Figure 5.5: Typical Proppant Concentration vs Time - Measured and Model Calculations

- MIP-3H

Figure 5.6: Typical Cumulative Proppant Mass vs Time - Measured and Model

Calculations - MIP-3H 108

Figure 5.7: Typical Slurry Rate vs Time - Measured vs Model Calculations - MIP-5H 109

Figure 5.8: Typical Cumulative Slurry Volume vs Time - Measured and Model

Calculations - MIP-5H

Figure 5.9: Typical Proppant Concentration vs Time - Measured and Model Calculations

- MIP-5H.

Figure 5.10: Typical Cumulative Proppant Mass vs Time - Measured and Model

Calculations - MIP-5H....

Figure 5.11: Typical Randomly Selected Stage Numerically Modeled using Log-Derived Geomechanical Rock Properties - Additional Field Data was Available to Include an Extra Layer Named "Underlying Strata". 112

Figure 5.12: Hydraulic Fracture Geometry for Stage 10 - MIP 3H. 115

Figure 5.13: Cumulative Proppant Mass for Stage 10 - MIP 3H................................ 116

Figure 5.14: Cumulative Slurry Volume for Stage 10 - MIP 3H................................ 116

Figure 5.15: Surface Pressure versus Time for Stage 10 - MIP 3H............................ 117

Figure 5.16: Side View of Calculated Hydraulic Fracture and Measured Microseismic Events and Magnitudes for Stage 7 - MIP 3H

Figure 5.17: Side View of Calculated Hydraulic Fracture and Measured Microseismic Events and Magnitudes for Stage 8 - MIP $3 \mathrm{H}$

Figure 5.18: Side View of Calculated Hydraulic Fracture and Measured Microseismic Events and Magnitudes for Stage 9 - MIP 3H ....

Figure 5.19: Side View of Calculated Hydraulic Fracture and Measured Microseismic

Events and Magnitudes for Stage 10 - MIP 3H.

Figure 5.20: Overview of Calculated Hydraulic Fracture Geometries, Measured Microseismic Events, and Entire Wellbore for Stage 7 through Stage 10 - MIP 3H 
Figure 5.21: Top View of Calculated Hydraulic Fracture Geometries, Measured Microseismic Events, and Nearby Wellbore for Stage 7 through Stage 10 - MIP 3H ... 120

Figure 5.22: Orthogonal View of Calculated Hydraulic Fracture Geometries, Measured Microseismic Events, and Nearby Wellbore for Stage 7 through Stage 10 - MIP 3H ... 120

Figure 5.23: Calculated vs Available Estimated* Hydraulic Fracture Heights for wells MIP-3H and MIP-5H 126

Figure 5.24: Calculated vs Available Estimated* Hydraulic Fracture Lengths for wells MIP-3H and MIP-5H ......

Figure 5.25: Numerical Model Calculations versus Measurements for Surface Pressures Wells MIP-3H and MIP-5H

Figure 5.26: Estimated* Microseismic Heights vs. LSBC Calculated Primary Hydraulic

Fracture Heights - Wells MIP-3H and MIP-5H. 141

Figure 5.27: Estimated* Microseismic Lengths vs. LSBC Calculated Primary Hydraulic Fracture Lengths - Wells MIP-3H and MIP-5H

Figure 5.28: Measured Surface Pressures vs. LSBC Calculated Surface Pressures - Wells MIP-3H and MIP-5H 143 


\section{LIST OF TABLES}

Table 1.1: Permeability Range for Various Reservoir Types (Modified from King, 2012)

Table 1.2: Pressure Gradient and Dimensionless Pressure Functions for Various Flow Regimes (for radial flow) (Valko \& Economides, 1995) ............................................ 22

Table 5.1: Heat Transfer Data Used in Numerical Modeling ...................................... 113

Table 5.2: Primary Hydraulic Fracture Geometries - Stage 1 through Stage 10 - MIP 3H

Table 5.3: Calculated Fracture Geometry Data - MIP-3H.......................................... 121

Table 5.4: Calculated Fracture Geometry Data - MIP-5H........................................ 122

Table 5.5: Microseismic Event Cloud Geometry Estimate* Data - Well MIP-3H ....... 124

Table 5.6: Microseismic Event Cloud Geometry Estimate* Data - Well MIP-5H ........ 125

Table 5.7: Geomechanical/Fluid Flow Property Sensitivity Analysis Study Results Sorted by Geologic Layer and Property Changed ..................................................... 131

Table 5.8: Geomechanical/Fluid Flow Property Sensitivity Analysis Study Results Sorted by Percent Change in Fracture Height from Base Case (positive to negative) ... 132

Table 5.9: Kendall's Tau Coefficients and P Values for Height, Length, and Surface Pressure Data Sets. 


\section{CHAPTER 1 : INTRODUCTION}

\subsection{Marcellus Shale Energy and Environment Laboratory}

The work done in this research study is a part of the Marcellus Shale Energy and Environment Laboratory (or MSEEL) project. The MSEEL project is an interdisciplinary research effort with a primary objective of "provid[ing] a long-term field site to develop and validate new knowledge and technology to improve recovery efficiency and minimize environmental implications of unconventional resource development” (MSEEL, 2019). The project site is in Morgantown, West Virginia, USA at a pad that had been previously used to drill, complete, and produce natural gas from two wells.

A second site located nearby is also used as a science well to extract important data, such as seismic/microseismic event data, from the subsurface prior to and during operations at the project site. This project includes research teams from multiple disciplines at West Virginia University (WVU) in Morgantown, WV. The research work is funded by the United States Department of Energy (DOE).

The area of interest for this research work is the evaluation of hydraulic fracturing through numerical modeling of hydraulic fractures and discrete fracture networks. Numerical modeling will be used to determine the induced fracture geometries. Microseismic event data was collected by other researchers as a part of the research project. This data will be analyzed and compared with numerical modeling results as an important part of this research work. 


\subsection{Microseismicity}

Microseismicity refers to seismic events which are a result of human actions. This topic has been covered recently by various news outlets and is an important issue around the world (Busby, 2018). Researches have recognized the significance of human-induced seismic events and have begun forming databases and looking for connections between various types of human activities, such as hydraulic fracturing, and the number of induced seismic events and the magnitude of the events (Wilson et. al., 2017). Microseismic events are measured using surface and/or downhole monitoring devices. The topic of surface seismic monitoring has been reported in many locations and are detailed elsewhere (Detring and Williams-Stroud, 2013; Kumar et al., 2016; Hu et al., 2017). The topic of downhole monitoring has also been discussed extensively and is detailed elsewhere (Estrada et al., 2009; Shemeta et al., 2007).

With respect to energy technology activities, there are two primary methods in which seismic events may be induced: (1) fluid injection into and (2) fluid extraction from geological reservoirs. It is possible to induce seismic or microseismic events in the subsurface through multiple mechanisms. However, Hu et al. (2017) state that microseismic events are usually associated with the slipping of faults due to shear deformation in subsurface reservoirs. The crust of the Earth has a vast network of natural fractures and faults varying in size and overall geometry. These faults or fractures may cause movement of the rock if shear stresses overcome shear strength of the fault or fracture. When fluids are present in the fractures or faults, the shear strength is reduced. According to Coulomb failure criterion the following condition (Equation (1)) must be met 
for slip to occur on a fault or fracture (Committee on Induced Seismicity Potential in Energy Technologies, 2013):

$$
\tau=\mu(\sigma-p)
$$

where:

$\tau$ is the shear stress

$\mu$ is the coefficient of friction for the fault or fracture

$\sigma$ is the normal stress

$p$ is the pressure of the fluid in the fault or fracture

If the induced shear stress is greater than the frictional forces resisting shearing, there will be movement relative to the fault or fracture. The term, $(\sigma-p)$, is known as the effective stress.

Figure 1.1 shows the forces acting on a fracture or fault. The normal stress $(\sigma)$ is perpendicular to the fracture or fault surface, and acts to resist fracture or fault slip. The shear stress $(\tau)$ is parallel to the fault or fracture, acting to cause movement. Both the normal and shear stresses depend upon the horizontal and vertical stresses $\left(\sigma_{v}\right.$ and $\left.\sigma_{h}\right)$ and the inclination angle $(\beta)$ of the fault or fracture. The fluid pressure (p) pushes against the two rock faces, acting to open the fracture and create slip. Finally, a higher coefficient of friction $(\mu)$ of the fracture or fault, results in more resistance to slip. 


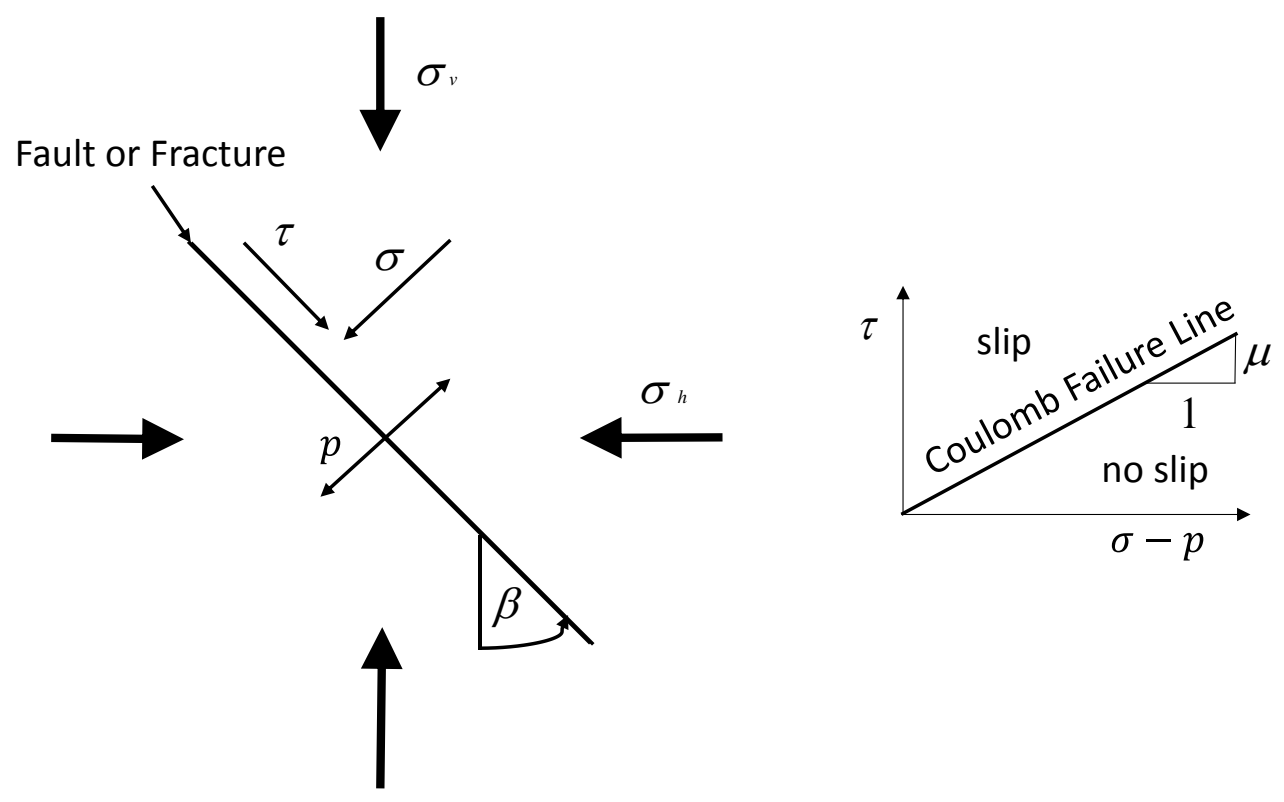

Figure 1.1: Coulomb Failure (Modified from: Committee on Induced Seismicity Potential in Energy Technologies, 2013)

There is some debate on the interpretations of microseismic events. These events capture shear failure of natural faults but have been described as less effective at capturing the tensile opening associated with hydraulic fractures (Roussel et. al., 2018). Interpretation accuracy also depends upon the location and number of wells used for observing the microseismic events, the number of devices used to capture microseismic events (called geophones), the geophone array spacing, and the depths of the geophones relative to the hydraulic fracturing interval (Veatch et. al., 2017). The monitoring of microseismic activity has been used with hydraulic fracturing activities in unconventional reservoirs for over a decade (Warpinski and Wolhart, 2016). It is also said to be very useful in optimizing hydraulic fracture treatments, evaluating completion schemes, and assessing the layout and spacing of wells in unconventional reservoirs, such as shales (Warpinski, 2013).

Seismic monitoring devices, such as geophones or accelerometers, can help to determine the locations and magnitudes of microseismic events. This information can then 
be used to extract multiple important parameters relating to hydraulic fracturing, such as fracture azimuth, fracture length, propped fracture length, fracture height, fracture complexity, stimulated reservoir volume (SRV), discrete fracture networks (DFNs), and geohazards among other parameters (Warpinski and Wolhart, 2016). Utilizing microseismic monitoring tools to evaluate the growth of hydraulic fractures is said to be beneficial in successfully treating a Marcellus shale well (Fontaine et al., 2008). Microseismic mapping can be useful in inferring vertical fracture growth confinement, azimuthal propagation preference, and ensuring that hydraulic fractures do not penetrate sources of potable water (Veatch et. al., 2017). In reference to this research work, microseismic data will be used with computed hydraulic fracture data for comparative analysis purposes. 


\subsection{Hydraulic Fracturing and Its Importance for Energy Extraction}

Hydraulic fracturing involves the injection of fluids and proppant down a wellbore at high injection rates in order to fracture targeted formations. In shale formations, the fluid utilized is often water mixed with a very small percentage of chemical additives. These formations generally contain valuable sources of energy, such as oil and gas, which need to be extracted using the hydraulic fracturing technology due to the low formation permeability. These hydraulically-induced fractures create a communication pathway between the energy resources in the formation and the wellbore. In order to keep the induced hydraulic fractures open, proppant is injected along with the fluid. Proppant is generally a small sand-type material, which may or may not be coated with an artificial resin to increase its strength, depending upon the depth of the formation. The propped fractures are ideally able to create a high permeability pathway for energy resources in the target formation to be able to travel from within the formation to the wellbore and, subsequently, to the ground surface. In order for a hydraulically-induced fracture to continue propagating through a formation, it must impart a tensile stress beyond the leading edge of the fracture (Veatch et. al., 2017). Propagation is halted when the stress-intensity at the tip of the hydraulically-induced fracture is lower than the critical stress-intensity of the formation (Savalli and Engelder, 2005).

The first hydraulic fracturing field test occurred in Kansas in 1947 and the first commercial hydraulic fracturing operations occurred in both Oklahoma and Texas on the same date, March 17, 1949 (Veatch et. al., 2017). For approximately 70 years, hydraulic fracturing has been a key means of economically extracting oil and natural gas from subsurface reservoirs (Valko and Economides, 1995). In an early paper, it was noted that 
hydraulic fractures are able to propagate when the injected fluid pressure is greater than the least principal stress and the tensile stress of the formation through which the fracture is travelling (Hubbert and Willis, 1957). From these early days of hydraulic fracturing, the technology has undergone significant changes and updates. Over the past few decades, hydraulic fracturing has expanded significantly in its field application and is now being used in wells across the United States and around the world (King, 2012). There are numerous unconventional oil and gas fields that exist across the United States (U.S.) and the world, and Figure 1.2 shows these unconventional hydrocarbon resources. In this research work one of these fields in the U.S., the Marcellus shale, will be investigated. The first Marcellus shale well stimulation, which used a large slickwater treatment, was performed in southwestern Pennsylvania in 2004 (Fontaine et al., 2008). The Marcellus shale is one of the most widely discussed and well-known of the U.S. oil and gas fields. The Marcellus shale underlies portions of several Eastern U.S. states, including New York, Pennsylvania, Ohio, and West Virginia. The location and range of depths to the top of the Marcellus shale are shown in Figure 1.3. 


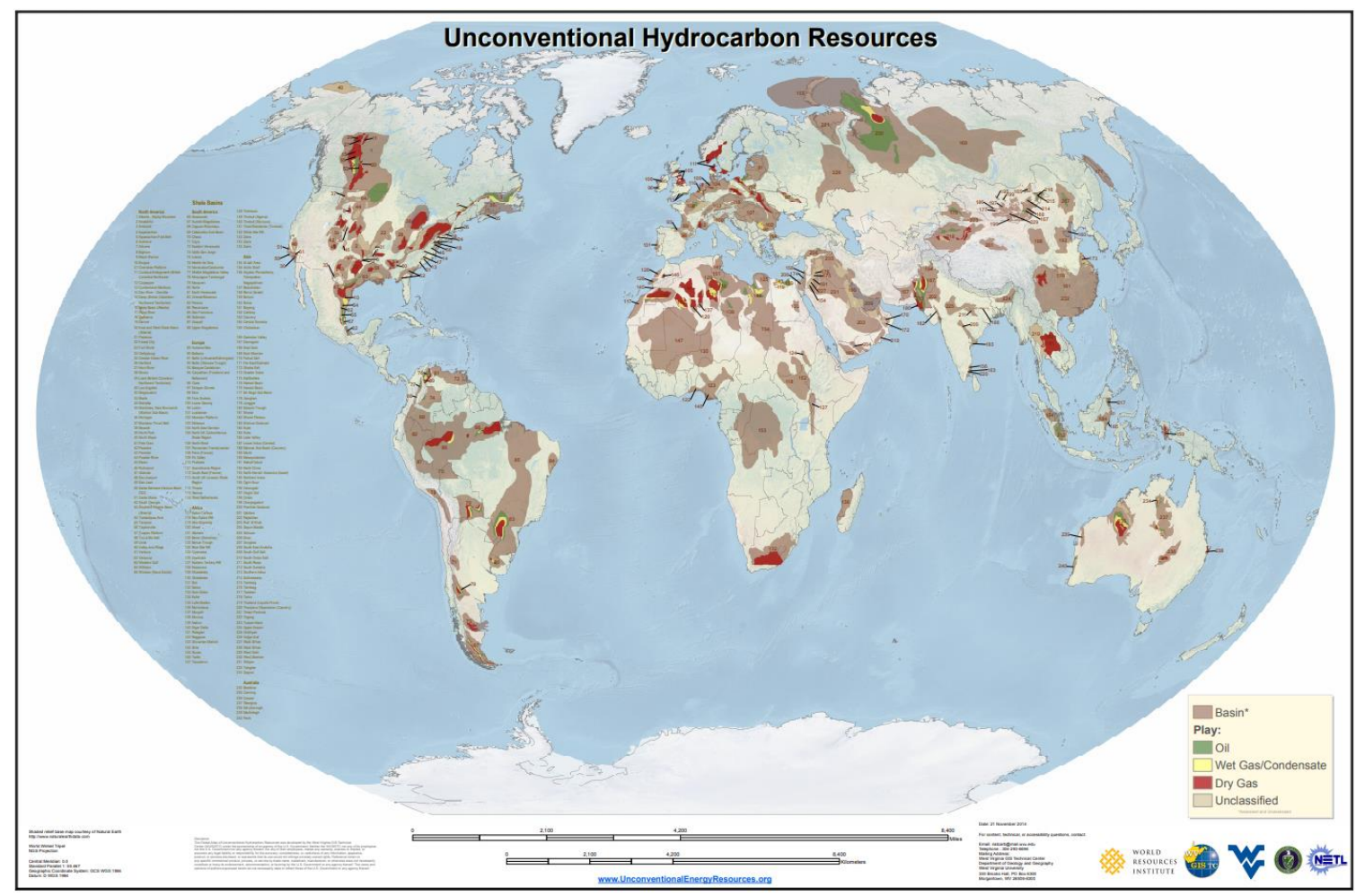

Figure 1.2: Unconventional Hydrocarbon Resources Around the World (WV GIS Technical Center, 2014) 


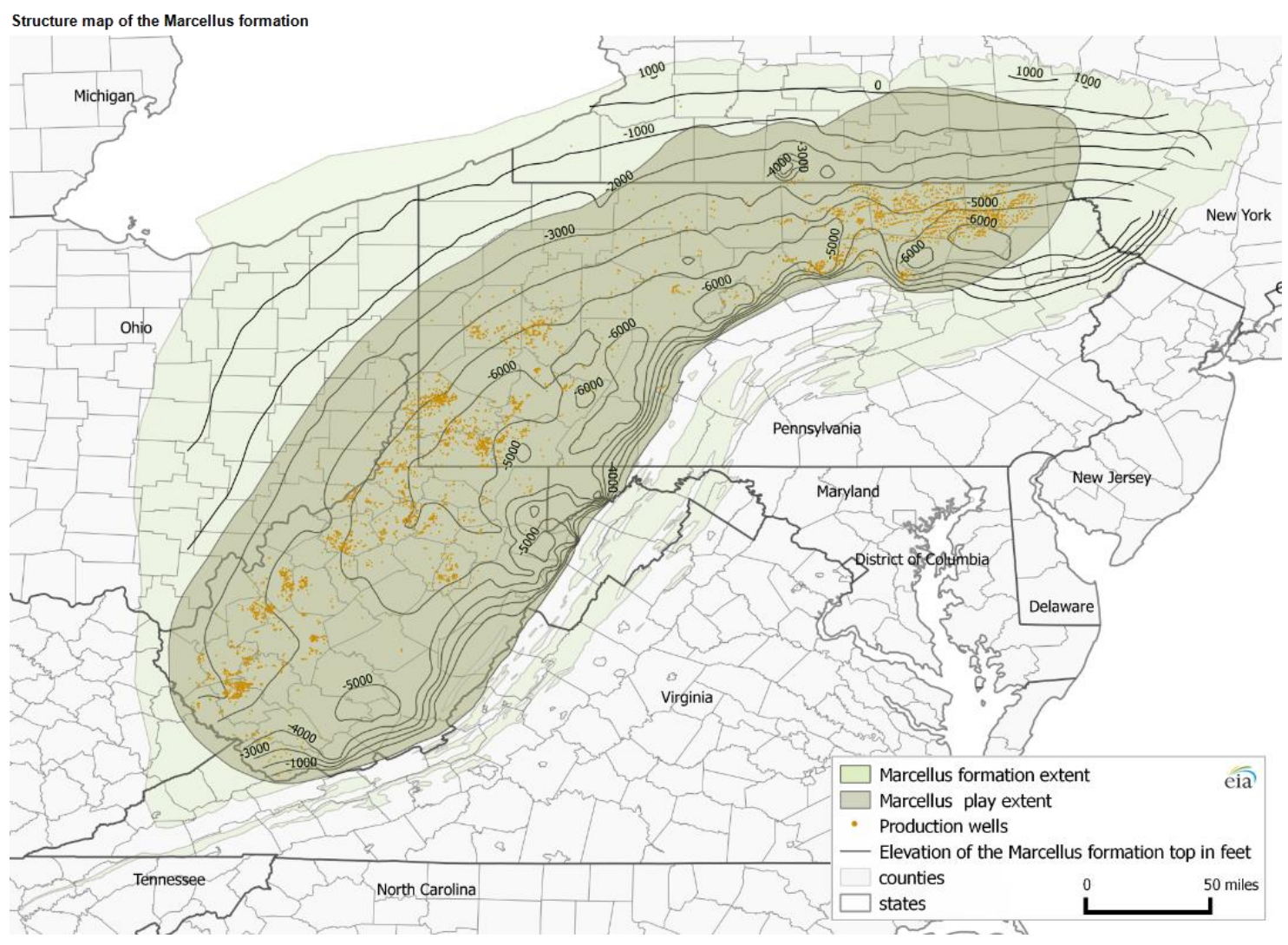

Figure 1.3: Structure Map of the Marcellus Formation (U.S. Energy Information Administration, 2016)

The formations encountered in the natural world during hydraulic fracturing operations are highly heterogeneous, and in order to determine treatment parameters, average reservoir properties are utilized. These formations and the surrounding layers are very large and remote and it is challenging to understand and represent these systems in numerical models. These issues of heterogeneity and the large size and remote location of the geologic systems is further compounded by the fact that only a small amount of the system is in the near-wellbore area (Veatch et. al., 2017). Data available for numerical modeling is scarce and costly, and this makes accurately modeling hydraulic fractures in the heterogeneous environment extremely difficult. 
The benefits of shale gas development (particular to the United States) are numerous, and include the following examples: (1) developing shale gas is extremely important to the current and future energy security of the United States, (2) in 2011, shale gas accounted for approximately $30 \%$ of the total U.S. natural gas production and natural gas is projected to rise in production in future years, (3) shale gas development has a large positive economic impact on local communities and states near where it occurs, (4) (related to the positive economic impact) shale gas creates thousands of high-paying jobs, and (5) shale gas can be developed in an environmentally responsible manner (Veatch et. al., 2017).

Natural gas extracted from shale formations such as the Marcellus are important to the current and future energy market. This is not only because the cost of natural gas has dropped by a greater margin compared to other traditional energy sources in recent years (Peters and Hertel, 2017; Jadidzadeh and Serletis, 2017), but also due to the fact that natural gas is a "greener" option. Natural gas is seen to be a significant factor in transforming the economy and achieving lower levels of greenhouse gas emissions (Considine et al., 2009). Natural gas has approximately 60 percent less carbon emissions when compared with coal, and 30 percent less carbon emissions when compared with oil (Considine et al., 2009). Figure 1.4 shows the U.S. energy production outlook through 2050. Natural gas currently accounts for the largest share of total energy production in the U.S. and is projected to account for nearly 39\% of U.S. energy production by 2050 (U.S. Energy Information Administration, 2018). Natural gas is, and is projected to continue to be, one of the most significant energy sources in the U.S. It is critical to both research as well as improve technologies associated with all aspects of the natural gas extraction process. The current 
research work aims to further this goal. According to Veatch et. al. (2017), there is enough unconventional oil and gas to last several hundred years if the right economic and social conditions allow development.

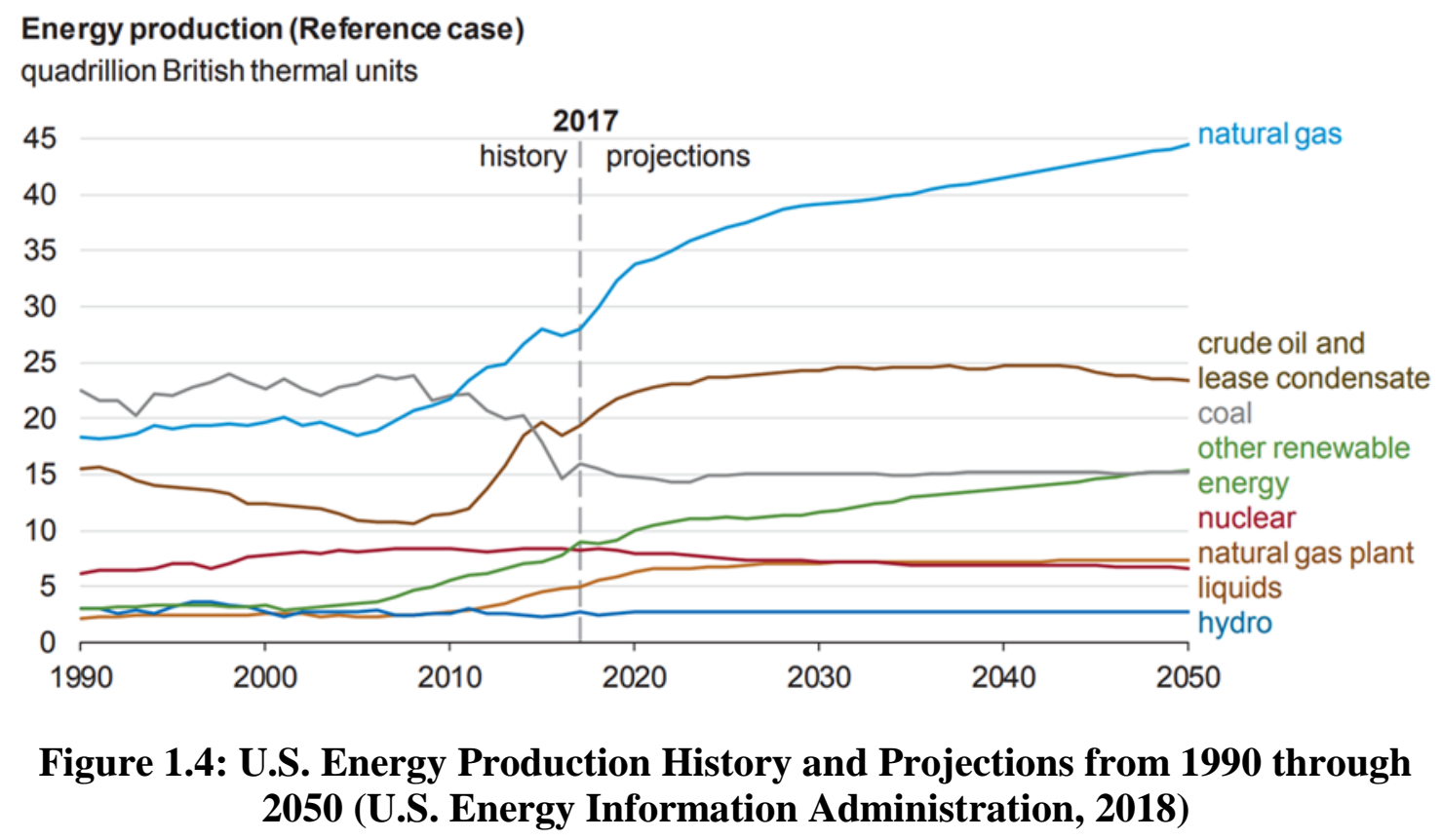

The geomechanical rock properties of the target and surrounding formations play a critical role in the propagation of hydraulic fractures. The variations between different formation layers and different horizontal regions govern vertical and horizontal height and width propagation of hydraulic fractures. The directional relative in-situ stress components influence the vertical or horizontal propagation inclination. Formation inhomogeneity and anisotropy have a strong influence on fracture propagation directional preference and fracture patterns (planar versus dendritic), especially in naturally fractured reservoirs, such as the shale reservoir involved in this study. In order to properly design a treatment for a 
given well/stage, it is necessary to have an appropriate understanding of formation properties and other in-situ parameters (Veatch et. al., 2017).

The Marcellus shale contains both wet and dry natural gasses. Whether the gas is wet or dry depends upon the thermal maturity of the gas. Thermal maturity is based on the temperatures and pressures which the gas has seen in the past. Dry gasses are more thermally mature and primarily consist of methane. Wet gasses are less thermally mature and contain methane along with natural gas liquids which can consist of ethane, butane, propane, and pentane. The methane in the wet gas must first be separated from the natural gas liquids in order to make it useable for consumers. However, this does not decrease the value of wet versus dry gas due to the fact that the natural gas liquids are valuable commodities and more than make up for the costs associated with the separation of the components (Marcellus Center for Outreach and Research, 2010). Figure 1.5 shows the wet/dry gas boundary in the Marcellus shale. The site considered in this research work is located in the dry gas region of the Marcellus shale. Figure 1.6 shows the thickness range of the Marcellus shale (Marcellus Center for Outreach and Research, 2018). The thickness of the Marcellus shale in West Virginia ranges from 0 to over 150 feet. 


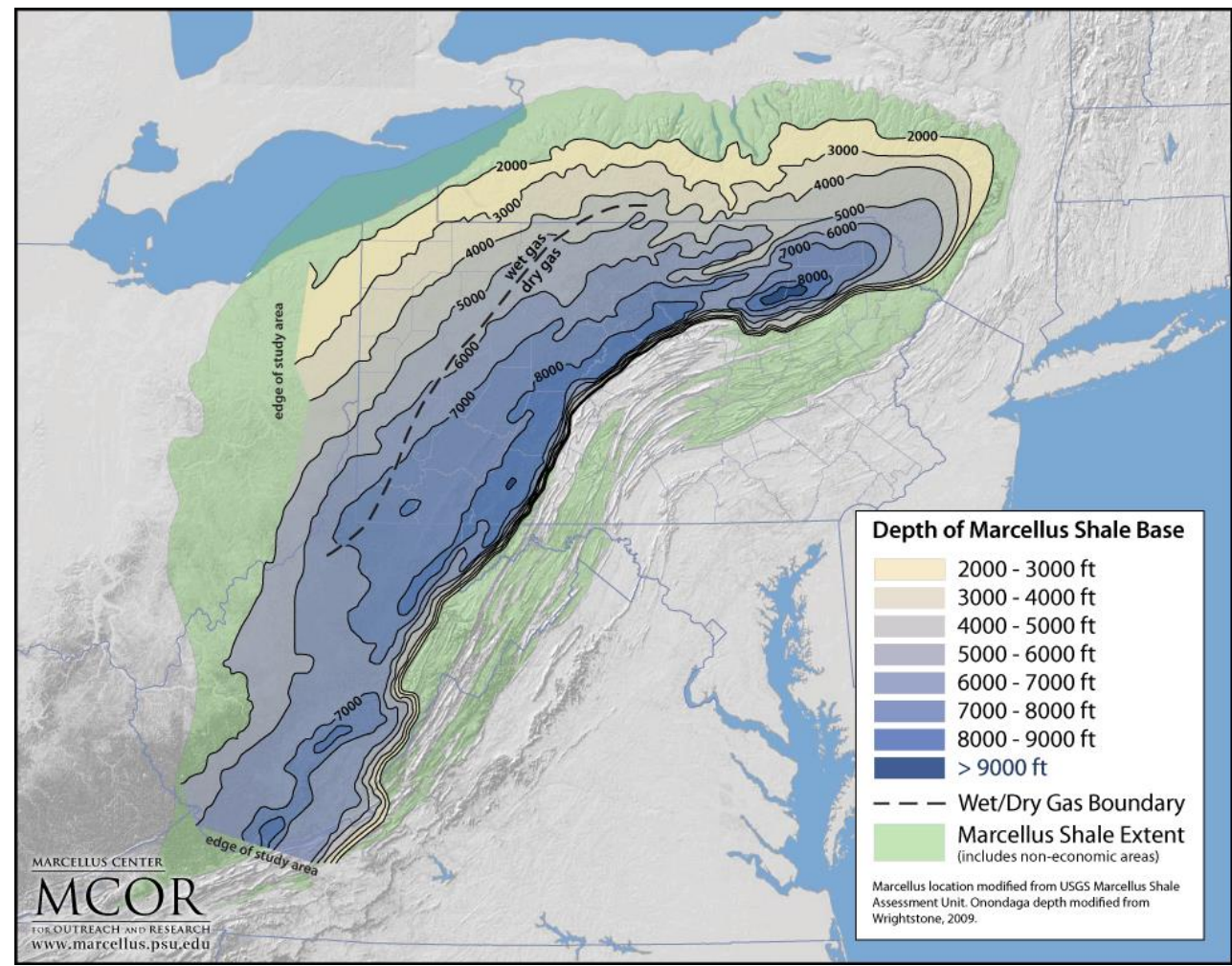

Figure 1.5: Wet/Dry Gas Boundary in the Marcellus Shale (Marcellus Center for Outreach and Research, 2010)

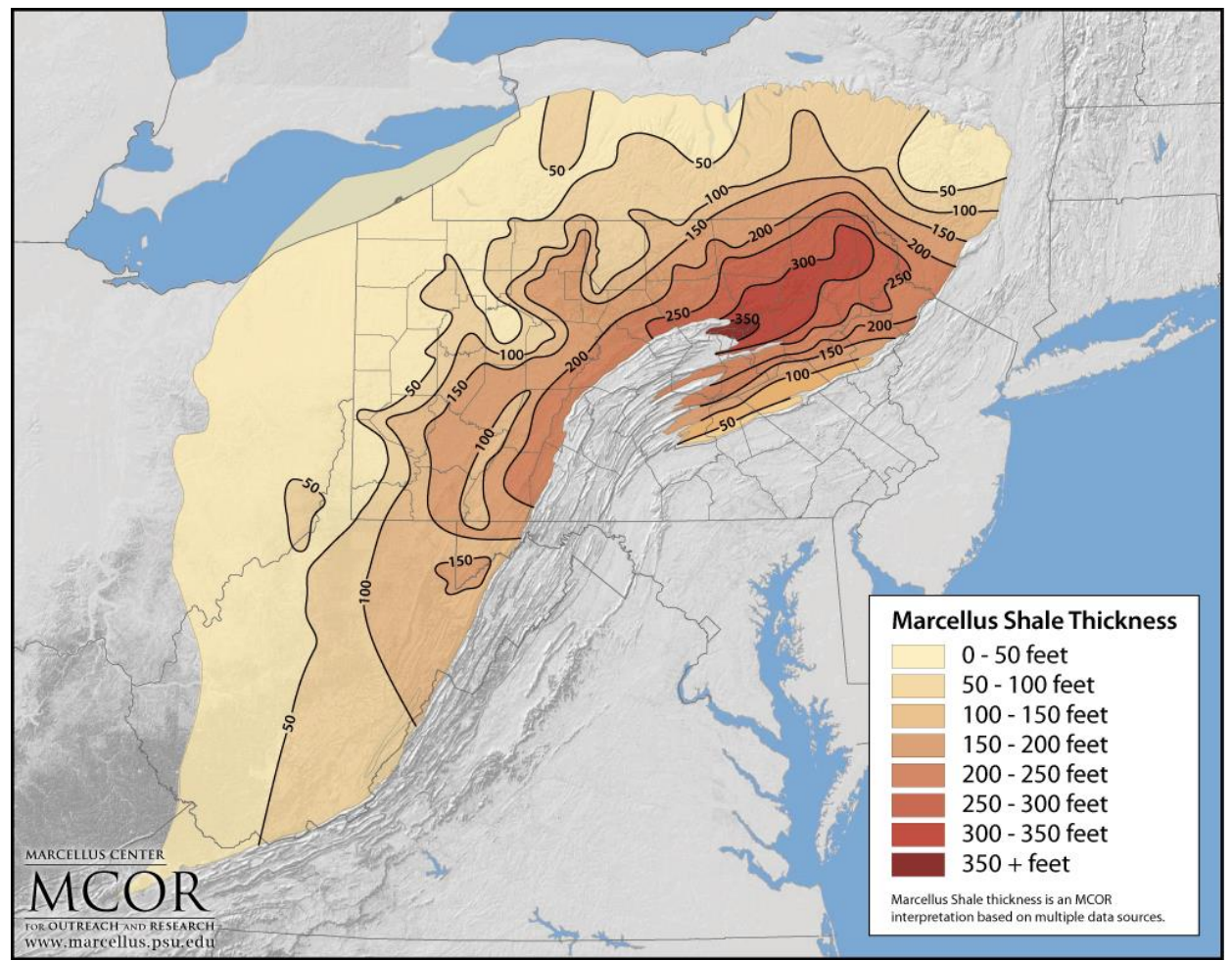

Figure 1.6: Marcellus Shale Thickness Map (Marcellus Center for Outreach and Research, 2018) 
The primary reason for using hydraulic fracturing in an oil or natural gas reservoir is economics. All hydraulic fracturing treatments must maximize the profitability of the well while using judicious practices which encompass safety, health and environmental, treatment design, and treatment execution (Veatch et. al., 2017). In conventional type reservoirs, hydraulic fracturing is not needed due to the ability of the natural resources to flow relatively easily through the geologic medium to the wellbore. Hydraulic fracturing is used in reservoirs where traditional extraction methods are not practical. These reservoirs are known as tight and unconventional reservoirs and have very low permeabilities. Permeability, in reference to the earth sciences, is the ability of a fluid to move through a porous medium. The lower the permeability, the slower fluids, such as oil and natural gas, will move through the medium. The permeabilities of these tight and unconventional reservoirs are usually less than $1 \mathrm{mD}$ (King, 2012). In many circumstances when dealing with tight and unconventional reservoirs, hydraulic fracturing may be the only feasible means of extracting the valuable oil and gasses from within the geologic media.

One significant reservoir type which falls into the tight and unconventional reservoir category is shale. Shales have some of the lowest permeabilities of any reservoir type. Permeabilities of shale reservoirs are typically less than $0.001 \mathrm{mD}$ (King, 2012). At permeabilities this low, oil and gas trapped within reservoirs move very slowly through the medium and are essentially confined within the medium for extraction purposes. If the permeability of a reservoir is low enough, hydraulic fracturing may not even be able to ensure an economic recovery of natural resources (King, 2012). The hydraulically fractured reservoir mentioned in this research work is shale. 
Development of shale reservoirs in the U.S. and around the world can be attributed to two important technologies: hydraulic fracturing and horizontal drilling (Arthur et al., 2008). Hydraulic fracturing creates fractures in low permeability reservoirs through the injection of water (usually with small amounts of chemical additives to aid in injection efficiency) and proppant at high pressure. The water helps to fracture the reservoir and transport the proppant, while the proppant acts to hold open the created fractures to allow oil and/or natural gas to flow from the reservoir into the wellbore. Horizontal drilling was developed to expose more of the wellbore to the reservoir relative to traditional vertical drilling to increase the production from the well and, thus, potential economic benefits. During horizontal drilling, the wellbore is deviated from the vertical axis at a point known as the "kick-off" point where the wellbore transitions to a more horizontal trajectory to lie in the pay zone where natural resources are located. Figure 1.7 shows simplified horizontal and vertical well configurations used in hydraulic fracturing. 


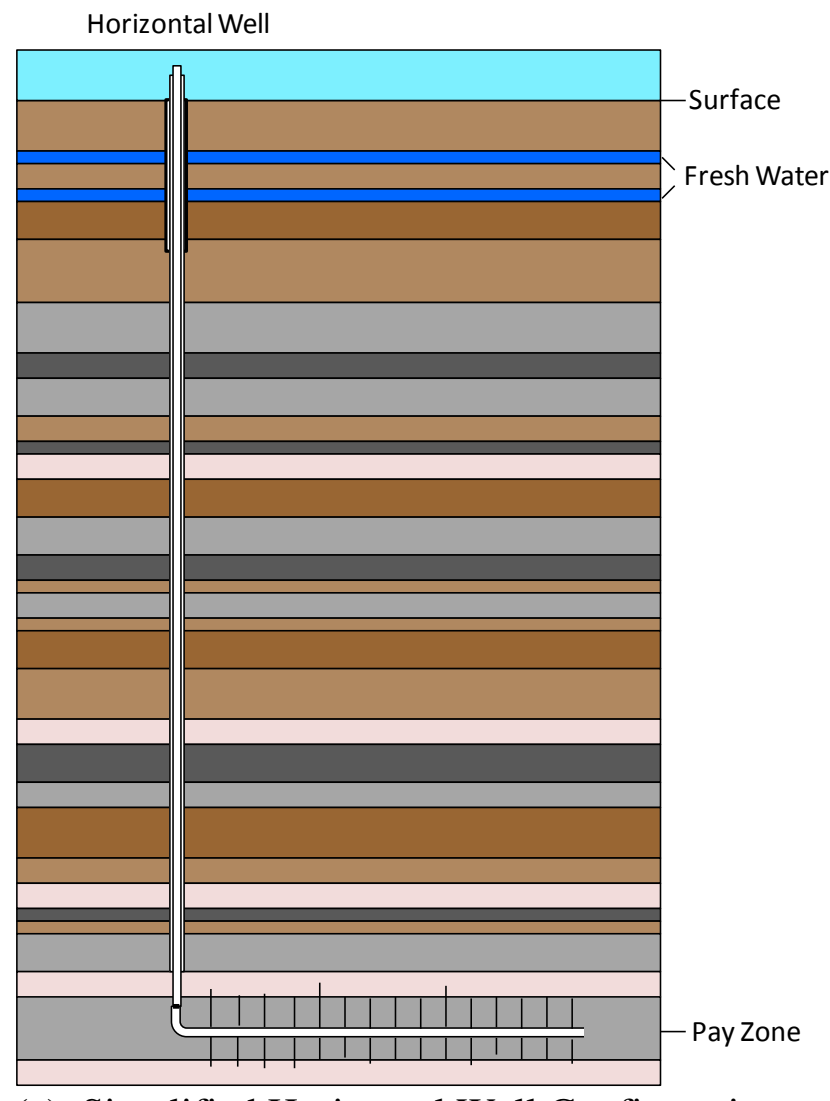

(a) Simplified Horizontal Well Configuration

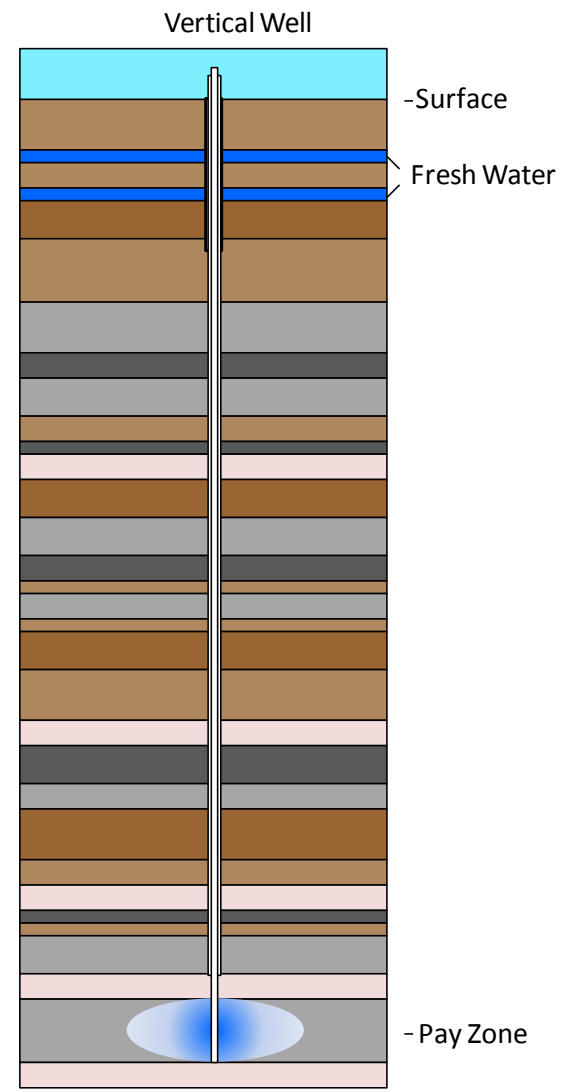

(b) Vertical Well Configuration

Figure 1.7: Simplified Horizontal (a) and Vertical (b) Well Configurations

Some of the key issues with respect to the science of hydraulic fracturing which remain to be discovered include a better understanding of (a) where fractures propagate, (b) what the fractures look like, (c) why hydraulic fractures behave like they do, and (d) how to be able to appropriately predict and determine this (Veatch et. al., 2017). So, a critical aspect of the hydraulic fracturing process is the evaluation of the treatment to determine information regarding the fracture geometry. The fracture geometry information tells the operator the effectiveness of the treatment. Fracture geometry data, such as fracture height, fracture length, and propped fracture length, can indicate the approximate potential amount of hydrocarbons that can be extracted from the target formation. The fracture 
height is also of particular concern to those interested in the integrity of groundwater resources.

Important issues with respect to the development of shale gas which need to be addressed include the following: (1) increasing the transparency of operations, (2) increasing the transparency of fracture fluid system composition, (3) improving communication between state and federal regulators, (4) protecting water quality, (5) predicting fracture height growth, (6) improving air quality, (7) managing the cumulative impacts of shale gas development, and (8) organizing for sharing best practices (Veatch et. al., 2017). Some of the aims of this study are to address the several of the aforementioned goals. Hopefully, by including information on a particular field site and the fluids used there, the transparency of hydraulic fracturing operations can be increased. Also, as a result of the work done in this study, fracture height propagation prediction will be addressed.

According to the U.S. Environmental Protection Agency (2016), an area of current uncertainty regarding hydraulic fracturing and groundwater resources is the "belowground locations of hydraulic fracturing, including data on fracture growth" (Dunn-Norman et al., 2018). Public interest has grown and could continue doing so regarding several issues including: (1) does hydraulic fracturing affect drinking water aquifers, and (2) does hydraulic fracturing cause issues with earthquakes (Veatch et. al., 2017)? In recent years, hydraulic fracturing/natural gas extraction has been found or perceived to be a threat to or located in drinking water/groundwater resources (Arthur et al., 2008; Brasier et al., 2011; Osborn et al., 2011; Rozell and Reaven, 2012; Jackson et al., 2013; Llewellyn et al., 2015; Hill and Ma, 2017; Keller et al., 2017). 
Wells completed in unconventional reservoirs do not recover as much gas per completion, so there will be a need for the drilling of tens to hundreds of thousands of new wells per year (Veatch et. al., 2017). It is, therefore, imperative to continue to evaluate the extent of hydraulic fracture growth at various sites in order to ensure the integrity of groundwater resources. Ensuring groundwater resources are not impacted by induced hydraulic fractures at field sites is a good way to show the general public the safety of these operations, in terms of a lack of wellbore to groundwater pathways. Environmental issues will continue to be important factors in the environmentally friendly development of hydraulic fracturing treatments in the future and require credible investigations which are related to specific localities (Veatch et. al., 2017). In this research work, the extent of hydraulically-induced fractures at a field site will be investigated and compared to the reported microseismic events in the Marcellus and surrounding geologic strata. 


\subsection{Fluid Flow through Porous Media}

The topic of fluid flow through porous media (such as a shale gas reservoir) is important in understanding how natural gas or oil is able to move from within a formation to a wellbore, where it can travel to the surface for resource utilization. The rate at which a fluid is able to flow through a porous medium is critical in determining the amount of natural gas or oil which can then be extracted through fracturing. In the context of oil and gas recovery, a porous medium may be defined as a geologic formation which contains void space (or pores), through which oil and gas can move. The ratio of the volume of the void space in the formation to the total (or bulk) volume of the formation is known as the porosity (denoted $\phi)$. The sizes of these voids in the geologic material typically range from about $10^{-7}$ meters to $10^{-4}$ meters in aperture. As for porosity values, these generally range from less than 0.10 to 0.40 (less than $10 \%$ to approximately $40 \%$ ). The higher porosity values can be found in some carbonate formations. The porosity of the oil or gas reservoir is very important for determining the oil or gas in place and how much can be theoretically and realistically recovered. The permeability (denoted $k$ ), describes the ability of a fluid to flow through the geologic layer. Permeability ranges of typical reservoirs and other materials can be seen in Table 1.1 . 
Table 1.1: Permeability Range for Various Reservoir Types (Modified from King, 2012)

\begin{tabular}{|c|c|c|}
\hline Reservoir Type & Permeability Range (mD) & Material Example \\
\hline Conventional & $1-1000$ & Beach Sand \\
\hline TightGas & $0.001-1$ & Brick \\
\hline Unconventional & $0.001-0.000001$ & Shale \\
\hline
\end{tabular}

Permeability can be related to the pressure gradient $(\Delta \mathrm{p})$ and the macroscopic fluid velocity $(u)$ through the following relation:

$$
u \propto k \Delta p
$$

Darcy's law is a fundamental equation which is used to describe the flow of a fluid (such as gas or oil) through a porous medium. This law relates the volumetric flow rate, fluid viscosity, and pressure gradient over a given length of flow. Darcy's law is given in radial coordinates in the following equation (Valko \& Economides, 1995):

$$
q=\frac{2 \pi r k h}{\mu} \frac{d p}{d r}
$$

where $q$ is the volumetric flow rate, $r$ is the radial distance, $k$ is the fluid permeability, $h$ is the thickness of the reservoir, and $\mu$ is the viscosity of the reservoir fluid. The following important points apply to the relation shown in Darcy's law:

- If no pressure gradient exists over a given distance, no fluid flow will occur over that distance, which is known as the hydrostatic condition.

- If there is a pressure gradient present over a given distance, fluid will flow from the higher pressure region to the lower pressure region. 
- The larger the pressure gradient over a given distance, the larger the fluid flow rate will be over that distance.

The constant rate and constant pressure solutions of the previous equation are of particular interest for the purposes of hydraulic fracturing. The general form of the constant rate solution is given as follows (Valko \& Economides, 1995):

$$
q=\frac{2 \pi k h \Delta p}{\mu p_{D}}
$$

where $p_{D}$ is the dimensionless pressure function. $p_{D}$ can be defined by three different flow mechanisms: (1) transient, which has an infinite-acting behavior; (2) steady-state, which has a constant outer boundary pressure $\left(p_{e}\right)$; and (3) psuedosteady-state, which has a noflow outer boundary condition. Table 1.2 shows the pressure gradient and dimensionless pressure functions for the different flow regimes (for radial flow). 
Table 1.2: Pressure Gradient and Dimensionless Pressure Functions for Various Flow Regimes (for radial flow) (Valko \& Economides, 1995)

\begin{tabular}{|c|c|c|}
\hline Flow Regime & $\Delta \mathrm{p}$ & $p_{D}$ \\
\hline Transient & $p_{i}-p_{b h f}$ & $-\frac{1}{2} E^{i}\left(-\frac{1}{4 t_{D}}\right)$ \\
\hline Steady State & $p_{a v g}-p_{b h f}$ & $\ln \frac{k t}{\phi \mu c_{t} r_{w}^{2}}$ \\
\hline Pseudosteady State & $p_{e}-p_{b h f}$ & $\ln \frac{0.472 r_{e}}{r_{w}}$ \\
\hline
\end{tabular}

In Table $1.2, E^{i}$ is the exponential integral, $p_{i}$ is the initial reservoir pressure, $c_{t}$

is the total system compressibility, $p_{e}$ is the outer boundary constant pressure, $p_{\text {avg }}$ is the average reservoir pressure, $p_{b h f}$ is the flowing bottom-hole pressure, $r_{e}$ is the outer boundary radius, and $r_{w}$ is the well radius.

From Equation 1.3 it can be seen that for steady state flow and pseudosteady-state flow the pressure gradient driving the flow is proportional to the logarithm of the radial distance. This means that the same amount of pressure gradient is utilized in the first meter as in the next 10 meters, 100 meters, 1000 meters, etc. If the permeability of the reservoir near the wellbore is changed (or increased through hydraulic fracturing, for example), the 
production from the well can be dramatically increased. This is especially true and important in reservoirs with very low natural permeabilities (tight formations).

In almost all drilling operations, there are some induced occurrences which decrease the permeability near the wellbore. This decrease in permeability near the wellbore is referred to as "damage," and is taken into account using a dimensionless skin effect coefficient, $s$. The dimensionless skin coefficient is simply added to the dimensionless pressure function in Equation 1.3 as shown below (Valko \& Economides, 1995):

$$
q=\frac{2 \pi k h \Delta p}{\mu\left(p_{D}+s\right)}
$$

The dimensionless skin effect coefficient is determined through a technique known as well pressure transient testing. High positive values indicate that the permeability has been severely decreased due to potential mechanical problems. A value of zero indicates no permeability change due to near wellbore damage. A negative value is rare, but is possible, and indicates that the permeability was increased in the near wellbore area due to possible chemical reactions of the formation with injected stimulation fluids (such as injected acids reacting with carbonate rock). If a negative value is found for the dimensionless skin effect coefficient, a matrix stimulation can be performed through chemical treatments to the near wellbore zone, instead of utilizing hydraulic fracturing. Hydraulic fracturing is typically performed for cases where matrix stimulation cannot be carried out economically (Valko \& Economides, 1995). 


\subsection{Hydraulic Fracture Design and Execution}

A hydraulic fracture treatment must maximize the post-treatment production and minimize the treatment costs in order to be successful. An economic principle known as the "Net Present Value," or NPV, is utilized in order to ensure that the maximum benefit is gained from the hydraulic fracture treatment (Valko \& Economides, 1995). The maximum NPV will result in the ideal fracture size. Typically, when performing the initial hydraulic fracture designs, the first step is to find the predicted fracture size using the fracture halflength or fracture wing-length. The selected hydraulic fracture numerical model then calculates the hydraulic fracture width and hydraulic fracture height. The required hydraulic fracture volume is determined by calculating the estimated fracture volume and then calculating the amount of fluid which may be lost through leakoff into the surrounding formation (Valko \& Economides, 1995). In order to calculate the required mass of proppant to keep the created hydraulic fractures open, a "ramped proppant schedule" is frequently incorporated into the treatment schedule (Nolte, 1986). The required fluid volume, mass of proppant, and time of injection are the main components that determine the total cost of the hydraulic fracture treatment. After subtracting these expected costs from the expected present value at a given time, the NPV is found for a given specified hydraulic fracture half-length. The process of finding the main components for various fracture half-lengths and the corresponding NPV for each half-length is repeated for all expected hydraulic fractures and all expected hydraulic fracture stages for each wellbore. After conducting these economic calculations, based on the projected hydraulic fracture lengths, it can be 
evaluated if the well will be economical to be drilled and if the overall venture may be profitable.

Contemporary hydraulic fracturing operations require large amounts of fluid, proppant, and pumping power for each well drilled. Hydraulic fracturing operations are capable of injecting well over 500,000 U.S. gallons of fluids, 1,000,000 lbm of proppant, and can use over 20 pumping units, each of which can produce over 2000 hhp (hydraulic horse power) (Valko \& Economides, 1995). Figure 1.8 shows an illustration of a simple drilling operation which can be used for a hydraulic fracturing treatment (Note: This is not an exhaustive list of all components used in the hydraulic fracturing process. These are many of the basic components. Mud refers to the drilling fluid mixture.). The following paragraphs briefly explain the various fracturing fluids and proppants which are commonly utilized in a hydraulic fracturing treatment. 


\section{Drilling Rig Components}

1. Crown Block and Water Table

2. Catline Boom and Hoist Line

3. Drilling Line

4. Monkeyboard

5. Traveling Block

6. Top Drive

7. Mast

8. Drill Pipe

9. Doghouse

10. Blowout Preventer

11. Water Tank

12. Electric Cable Tray

13. Engine Generator Sets

14. Fuel Tanks

15. Electric Control House

16. Mud Pump

17. Bulk Mud Components Storage

18. Mud Pits

19. Reserve Pits

20. Mud Gas Separator

21. Shale Shaker

22. Choke Manifold

23. Pipe Ramp

24. Pipe Racks

25. Accumulator

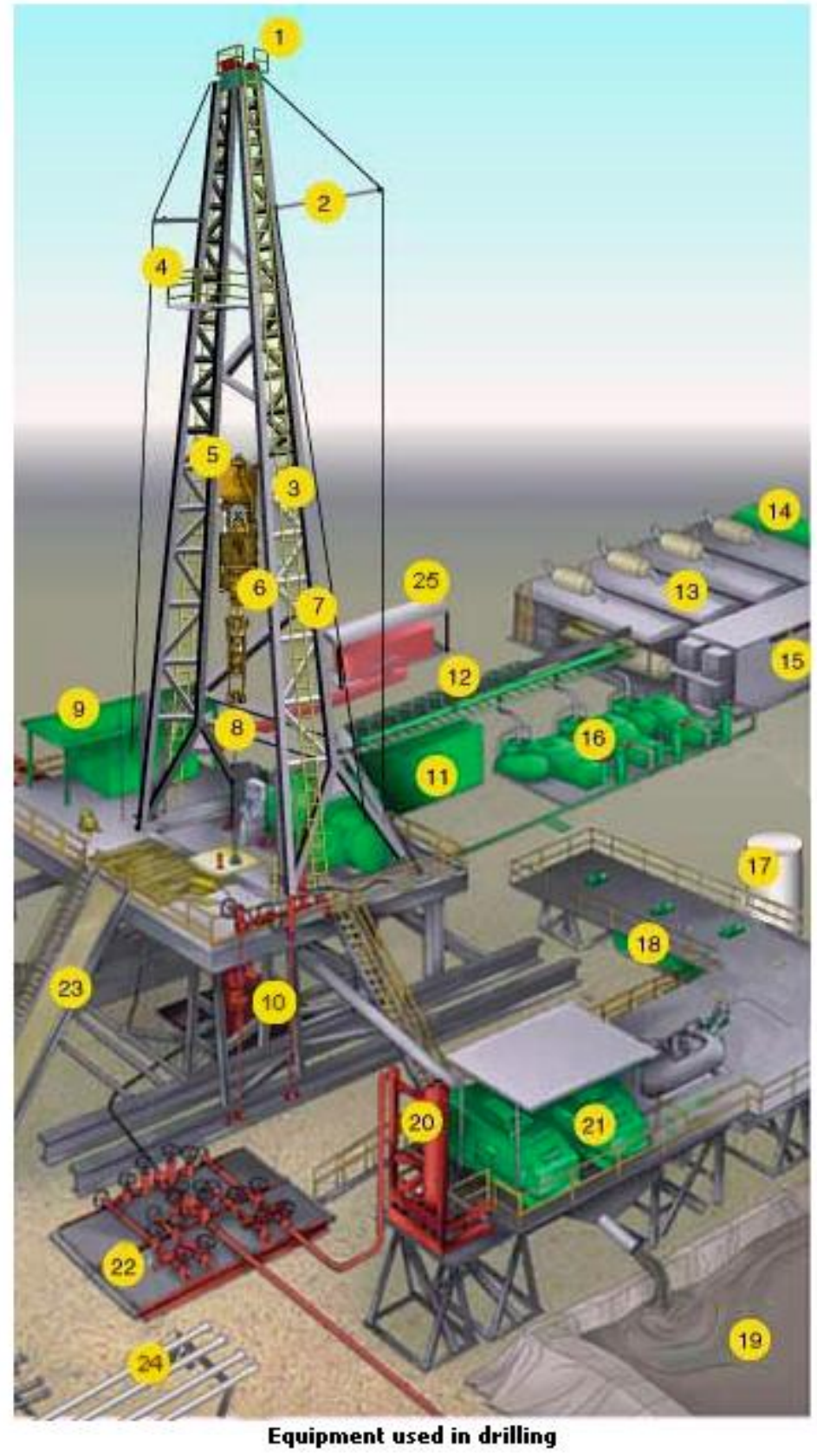

This figure was taken from

https://www.osha.gov/SLTC/etools/oilandgas/illustrated_glossary.html.

Figure 1.8: Drilling Rig Components (OSHA, 2019) 
A good hydraulic fracturing fluid has four primary goals (Valko \& Economides, 1995). The first goal is to allow the initially-created fracture to begin the breakdown process of the formation and propagate through the formation. The second goal is to aid in facilitating the transport of proppant by allowing the proppant to flow far enough into the created fractures in order to keep a sufficient fracture area open for oil and/or gas to be able to flow back into the wellbore. The third goal is to minimize the leakoff of fluid into the surrounding formation. If too much of the fracturing fluid leaks into the surrounding formation, this valuable resource is lost and the intended proppant transport and hydraulic fracture propagation may not be achieved. The final primary goal of the hydraulic fracturing fluid is to avoid any potential damage to the proppant as it is being moved through and deposited in the created hydraulic fractures. Any damage to the proppant may reduce the designed permeability of the proppant "pack" and may decrease the expected oil/gas production from the target formation.

Fluid viscosity is an essential property of any hydraulic fracturing fluid which helps it to create the necessary induced hydraulic fracture geometry. While travelling through the wellbore, the hydraulic fracturing fluid should have a lower fluid viscosity value. The lower the hydraulic fracture fluid viscosity value, the less friction pressure is created in the wellbore. This lower friction pressure caused by the pumping of the lower viscosity hydraulic fracturing fluid allows it to be pumped at a lower "treating" pressure and allows for less energy (less money to be spent on electricity-related costs) to be used in powering pumping units. However, when the hydraulic fracturing fluid enters into the induced hydraulic fractures in the target formation, a higher hydraulic fracturing fluid viscosity is required. This higher viscosity is to allow for the creation of an appropriate fracture 
geometry and adequate proppant transport (Valko \& Economides, 1995). If the hydraulic fracturing fluid viscosity is not high enough, appropriate hydraulic fracture geometries may not be created and the hydraulic fracturing operation may not be as profitable or may not be profitable at all. After the hydraulic fractures have been created and the treatment process has ended, the higher viscosity that was required for fracture creation is now detrimental to the production fluids leaving the formation and going back into the wellbore. In order to incorporate these necessary viscosity changes to the fluid at the different stages (as it goes through the wellbore, as it goes into the formation to create appropriate hydraulic fracture geometry, and as it flows back through the wellbore after the hydraulic fracture treatment is complete) various chemicals are added to the injected fluid to help achieve viscosity changes. To achieve the higher viscosity in the fractures, chemicals known as "delayed crosslinkers" may be used (Valko \& Economides, 1995). These chemicals do not increase the hydraulic fracture fluid viscosity in the wellbore. When the fluid reaches the formation, the chemical composition of the fluid is changed by the delayed crosslinker chemicals and a higher viscosity is achieved.

Hydraulic fracturing fluids are also sometimes foamed using nitrogen or carbon dioxide (Valko \& Economides, 1995). Foaming works to minimize the damage to the proppant and to help with the flowback by ensuring that cleanup of any excess material that occurs in the fracture. Foam qualities, or gas volume percentages, of 50\% to $90 \%$ have been used in the past (Valko \& Economides, 1995). Following injection, it is important to ensure that the polymer chains in the proppant pack are properly broken down so that the permeability of the induced hydraulic fracture is not decreased. In order to break down 
these polymer chains, oxidizers, enzymes, or occasionally chemicals called encapsulated breakers are added into the fracturing fluids.

After injecting the hydraulic fracturing fluids and creating the necessary hydraulic fractures in the target reservoir, the natural pressure of the reservoir acts to close the induced fractures and reduce the widths back to zero. In order to keep the fractures created by the fracturing fluids open, it is necessary to inject the proppant along with the fluids to "prop" the fractures open. These proppants are usually sands, which may or may not be coated in a resin or other material. The main criteria in selecting a proppant is by the strength and size. There are three main categories of proppant: low, intermediate and high strength. Low strength proppants are usually natural sands which fall into the 12/20 mesh to $20 / 40$ mesh range (average particle diameters range from $0.2 \mathrm{~mm}$ to $0.1 \mathrm{~mm}$ ) (Valko \& Economides, 1995). These proppants are generally used at depths below 2000 meters (less than $~ 7000$ feet), because of the lower formation stresses. Intermediate and high strength proppants are used at greater depths (3000 to 5000 meters or 10,000 to 17,000 feet) and are usually coated with a resin or other material for increased strength (Valko \& Economides, 1995). The coating helps the proppant particles to stick together, maintain a higher permeability while in the fracture, and to perform better and not be crushed under the higher formation stresses at the greater depths (Valko \& Economides, 1995). 


\subsection{Data Acquisition and Evaluation Methods for Hydraulic Fracturing}

To adequately predict hydraulic fracture propagation and conductivity through numerical modeling, data must be collected from the site where the treatment will occur. There are three primary techniques for obtaining data for use in numerical modeling. These techniques are known as well log measurements, core measurements, and well testing. Seismic techniques, such as microseismic monitoring, which is used in this study, are also sometimes used, but are very costly and primarily used in critical cases (King, 2012). Well $\log$ measurements are meant to obtain the mechanical properties of the rocks in the target formation and surrounding geologic layers (King, 2012). The primary data which is acquired from this test is the stress values in the formation and the stress contrast between the geologic layers (Valko \& Economides, 1995). Devices called "acoustic televiewers" may be lowered into drilled boreholes to send out sonic waves in order to measure their travel times and amplitudes when they reflect off of geologic layers/boundaries and they return to the device to determine the mechanical properties within the rocks (Valko \& Economides, 1995). Core measurements are also done by collecting core samples from the target reservoir. As stresses are applied to the core, fissures may appear or disappear, and by counting the number of fissures in the sample it may be possible to determine the stress anisotropy of the particular sample (Valko \& Economides, 1995).

The final data acquisition method of well testing is done while a well is in operation. The well may be analyzed for pressure and flow rate data when the well is in operation and fluid is flowing (known as drawdown), when the well is shut-in and not actively pumping fluids (known as buildup), or when the well is being observed by another well (known as 
interference). This analysis allows for the determination of several important reservoir parameters. These parameters include, but are not limited to: the skin effect, reservoir permeability, permeability anisotropy, and the types and locations of boundaries and formation heterogeneities present in the near-wellbore region. This testing can determine whether or not the formation is suitable for hydraulic fracturing, matrix stimulation, or no treatment at all. Also, after hydraulic fracturing is performed, a well test can be used to allow for the determination of hydraulic fracture half-length and fracture conductivity (Valko \& Economides, 1995). 


\subsection{Research Objectives}

The ability for predicting the extent of hydraulic fractures in a complex subsurface geologic environment is essential in order to ensure that locations of fractures are known and that the fractures do not travel into unwanted regions. The geometry of propped hydraulic fractures is a controlling factor for natural gas production rates; therefore, the prediction of hydraulic fracture growth is a critical factor when determining the economic viability of a hydrocarbon extraction operation. This research aimed to better predict hydraulic fracture heights and lengths using a novel methodology which incorporates pseudo three-dimensional (P3D) numerical modeling.

The objectives of this research were as follows:

- The primary goal of this research was to calibrate a P3D model and use a statistical approach to predict the extent of microseismic events in shale reservoirs in order to ensure both safe distances between fractures and groundwater aquifers and the efficient determination of microseismic geometric dimensions and surface pressures. Microseismic measurements are costly and the use of P3D numerical modeling to predict the extent of hydraulic fractures can save both time and money.

- Assess and develop the geologic, geomechanical, and treatment parameters based on available field data for numerical modeling of the MSEEL field site (Northeast Natural Energy, 2015). Develop a methodology for converting large amounts of measured field treatment data into smaller sections of data appropriate for numerical modeling. Use available literature to find appropriate geologic and 
geomechanical properties that are not available from field data for use in numerical modeling. Analyze available microseismic data collected by others at the MSEEL site from the VSI geophone array used to compare with computed hydraulic fracture geometries for all available stages at both wells (MIP-3H and MIP-5H) at the MSEEL project site.

- Build the numerical model from available literature and field data for the MSEEL project site. Compute primary hydraulic fracture geometries for all stages at both wells (MIP-3H and MIP-5H) at the MSEEL project site.

- Investigate any observed discrepancy between calculated hydraulic fracture geometries and reported microseismic event clouds. Potentially modify geomechanical properties in order to better match microseismic events.

- Use a statistical method to obtain a better match between field estimates and measurements with numerical model calculations. 


\subsection{Scope of Work}

The goal of this research was to calibrate a pseudo-3D numerical model and use a statistical methodology to be able to predict the extent of subsurface hydraulic fractures in shale reservoirs. Another option would be to use microseismic measurements to ascertain the extent of subsurface hydraulic fractures. However, microseismic measurements are more costly and the use of pseudo-3D numerical modeling to predict the extent of microseismic events can save time and money. The type of reservoir was constrained to a dry gas shale in this research. The numerical model which was utilized for this research was the MShale numerical model (Baker Hughes Reservoir Software, 2015), which is a part of the Meyer Fracturing Simulator suite and was originally developed by Meyer \& Associates. A unique aspect of this research is that the MShale numerical model utilizes a Discrete Fracture Network (DFN) to better model the field conditions of a naturally fractured shale network. Another unique aspect of this research is the development of a statistical methodology to correlate numerical model calculations and field estimates/measurements. As previously mentioned, this model is not fully threedimensional (3D) and is referred to as a pseudo-3D. A pseudo-3D model was chosen over a fully 3D model due to the fact that pseudo-3D models are less time/resource intensive. If a pseudo-3D model is able to predict the extent of microseismic events in a shale reservoir, this can provide valuable time/resource savings over fully $3 \mathrm{D}$ models.

This research work was focused on investigating the extent of induced hydraulic fractures at the Marcellus Shale Energy and Environment Laboratory (MSEEL) site in Morgantown, WV, USA. The site includes two wells which were numerically modeled. These wells are MIP-5H, which was stimulated first, and MIP-3H. There are a total of 30 
stages at well MIP-5H and 28 stages at well MIP-3H, with each stage containing up to five stimulated fractures. The calibration of the numerical model to predict induced fracture dimensions at the MSEEL site and the development of a statistical methodology could ensure that it is capable for use in other reservoirs. The geomechanical properties of rocks in the area near the wellbore were assessed in order to possibly match measured field conditions for the induced hydraulic fracture dimensions. The developed statistical methodology was used to better predict field estimates/measurements from numerical model calculations. 


\section{CHAPTER 2 : BACKGROUND}

\subsection{Background Research on Microseismicity}

Microseismicity has become an important topic in the modeling and evaluation of reservoirs, the hydraulic fracturing of shales, waste water injection into a variety of reservoir types, and environmental and safety discussions. A selection of recent literature on microseismicity and induced seismicity and the geomechanical aspects is presented in this section.

Warpinski et al. (1997) validated the use of microseismic data for accurately determining hydraulic fracture dimensions in a fluvial sandstone reservoir (C-Sand) at the DOE/GRI Multi-Site Project in the Piceance basin in Northwestern Colorado. The authors' comparisons were done for six different injection scenarios (5 of which were minifrac/diagnostic) into the sandstone reservoir using a variety of fluid volumes, fluid types, and rates. The fluid volumes ranged from 95 to 2118 barrels (3990 to 88,956 U.S. Gallons). The fluid types were either cross-linked or linear gels, fluid injection rates ranged from 20 to 40 barrels per minute. In five of the six injections, no proppant was included in the treatment. The only proppant injection scenario featured 250,000 lbs. of an unspecified sand. The authors were able to determine an accurate representation of the hydraulic fracture heights, lengths, and orientations through the use of an array of inclinometers, intersecting well data, and other information. The authors also state that the fracture heights calculated by models used at the time were not accurate and that additional mechanisms needed to be incorporated into the models. They go on to state that diagnostic results can be used to improve model capabilities. 
Davies et al. (2013) compiled a list of induced seismic events with moment magnitudes greater than 1.0 and investigated potential source mechanisms. The authors found that the hydraulic fracturing of shales generates only very small seismic events compared to other sources, and that very few seismic events generated from hydraulic fracturing have ever been able to be felt at the ground surface. Three mechanisms for inducing seismicity via hydraulic fracturing are suggested by the authors. These mechanisms are as follows: (1) the fracturing or pore fluid entering a fault, (2) a connection between induced hydraulic fractures and a fluid pressure pulse being transmitted to a fault, and (3) rock deformation increasing fluid pressure in a fault or in fractures connected to a fault. The authors also proposed several pathways for fluid migration in hydraulic fracturing operations. These pathways are as follows: (1) through created hydraulic fractures, (2) directly from the wellbore, (3) through the pore network of a permeable bed or along the bedding plane, and (4) through pre-existing natural fractures or small faults. The reactivated fault, which is responsible for the felt induced seismic event, may intersect the wellbore or be up to hundreds of meters from it. The authors emphasize that even though only three examples out of hundreds of thousands of hydraulic fracturing operations have been reported, the risk of felt induced seismicity at the ground surface cannot be ruled out (Davies et al., 2013).

$\mathrm{Hu}$ et al. (2017) investigated long-period long-duration (LPLD) microseismic events associated with hydraulic fracturing in the Eagle Ford shale. LPLD microseismic events are caused by fluid pressurization, resonance of fluid-filled cracks, or slow slip along weak faults. The authors observed LPLD events during hydraulic fracturing and the events tended to move away from the wellbore over time during treatment. They state that 
these events are due to "jerky" opening of fractures and the resonance of the fluid-filled cracks. LPLD event trajectory could replicate the fluid flow path of tensile fractures created during hydraulic fracturing and may be able to be used when monitoring hydraulic fracture treatments.

Detring and Williams-Stroud (2013) used a surface array to gather microseismic data in order to gain a better understanding of the subsurface structure and create subsurface fracture maps during a hydraulic fracturing operation. The authors interpreted microseismicity trends with a northeast/southwest orientation to be related to either induced or reactivated faults or fractures. Microseismicity trends found to be connecting two different wellbores in the east-northeast/west-southwest direction were interpreted to have formed due to the reactivation of faults. The microseismicity trends, which are found to be associated with faulting, can be used by engineers to predict where the faults will intersect with adjacent wells. Hydraulic fracturing treatment parameters can then be changed to avoid known geologic hazards to prevent any unwanted communication between neighboring wells. Thus, these microseismic trends can be used to provide important data, which can ultimately reduce costs in hydraulic fracturing operations (Detring and Williams-Stroud, 2013).

Palmer et al. (2013) developed a geomechanical model to predict the extent of shear failure and obtain injection permeability and porosity, among other data. The authors developed a model which identifies tensile and shear failures that occur in natural factures or other planes of weakness within rock. The model is matched with the microseismic cloud of shear failures measured in the field. This allows the authors to determine an approximation of the injection permeability and porosity, and the volume of the 
microseismic cloud. The authors state that their model may be applied to any formation which contains widespread microseismic clouds for each stage. Many tight shales, which are often hydraulically fractured, fall under this type of formation type. The authors used their model to attempt to match microseismic data obtained from the Barnett shale. Matches were able to be made from the models using weak fracture planes, which were not oriented with the plane of minimum horizontal stress. Matches were not able to be made when using traditional fractures oriented with the planes of maximum and minimum horizontal stress (Palmer et al., 2013).

Raziperchikolaee et al. (2014) developed a microscale fluid flow-geomechanicsseismicity model to determine the transport response and failure mode of microscopic cracks, which develop in Berea sandstone samples during deformation. This hydromechanical-seismic model incorporates rock grain-cement interactions as well as a rock deformation with a dynamic pore network to predict permeability. The authors were able to use their model to study the seismic source mechanism and transport behavior during joint deformation. Numerical modeling of the Berea sandstone samples was carried out, and results showed that the opening of tensile micro-cracks can occur during failure under low confining pressures, which can lead to increased permeability in joints. The authors suggest studying the effects of joint size and joint properties in order to properly select the representative element volume in future modeling work (Raziperchikolaee et al., 2014).

Westaway (2016) discussed induced seismicity from hydraulic fracturing operations in the United Kingdom from 2011. Hydraulic fracturing operations resulted in unintentional microseismic events up to 2.3 in moment magnitude. Two of the induced seismic events were large enough to be felt at the ground surface by the general public. 
This induced seismicity resulted in a negative public response and the government imposed a one year suspension on all hydraulic fracturing operations in the country. Westaway identified the following parameters as important for hydraulic fracturing operators to evaluate prior to beginning the fracturing of a formation: (1) the current state of stress in the geologic strata surrounding the injection site, (2) the possible magnitude of stress changes induced by fracturing the strata, (3) the location, size, and orientation of potential slip planes, (4) how close existing planes are to slipping, (5) the possibility of induced stresses resulting in failure along the slip planes, and (6) the magnitude of potentially induced seismic events. As there is considerable variability in the subsurface strata, it is recommended by the author that data pooling from multiple sites be used to reduce geological uncertainty at future hydraulic fracturing sites.

Warpinski and Wolhart (2016) conducted an extensive validation of various hydraulic fracturing parameters and an analysis of the source mechanisms for these parameters when used with microseismic monitoring tools. The parameters of particular interest to this research are fracture azimuth, fracture length, propped fracture length, fracture height, and fracture complexity. Source mechanisms of particular interest to this research include the discrete fracture network (DFN), potential geohazards, fracturing diversion, structural controls, and stress shadowing. The authors note that a significant amount of microseismic monitoring has been conducted and many conclusions have been made based on that monitoring, but relatively very little validation of some parameters has been extracted from data. Most validation appears to have come from planar fractures in sandstone reservoirs, as previously discussed in this section. According to the authors, shale reservoirs, like the Marcellus, have not received the same amount of validation of 
parameters such as length and height. DFNs appear to be misused with microseismic data. Often, microseismic data is used to help build and constrain DFNs; however, Warpinski and Wolhart (2016) suggest that a physical model of hydraulic fracture propagation should be used with a DFN to understand microseismic behavior. It is also noted that the effects of structural controls, stress shadowing, and other features have been minimally studied and more research is necessary to help integrate various data with microseismic results to better understand hydraulic fracture treatments. 


\subsection{Background Research on Hydraulic Fracturing}

Hydraulic fracturing has had a vital impact on the development of many low permeability geologic reservoirs in the U.S. and around the world. Without this technology, many reservoirs may still be untapped and the price for oil, natural gas and its derivatives may be much higher. A selection of recent literature on hydraulic fracturing and its geomechanical aspects is presented in this section.

Fisher and Warpinski (2012) reported hydraulic fracture height growth from thousands of treatments in the Marcellus and several other shales and corresponding water table depths. The general public has been concerned with the effects of hydraulic fracturing on groundwater resources, and one of the possible mechanisms for groundwater contamination is through communication between the wellbore and water resources. The authors looked into various mechanisms through which hydraulic fractures can be contained. These mechanisms include stress contrasts between layers, other geomechanical property contrasts between layers, weak interfaces (can blunt hydraulic fracture growth), multi-layered geologic strata, the fluid-pressure gradient, geologic faulting, and layers with higher permeability (allow for fluid leakoff). All of these containment mechanisms work together to generally keep hydraulic fracture height growth below groundwater resources. The authors looked into the real data from the various shales (Marcellus, Barnett, Woodford, and Eagle Ford) and determined that hydraulic fracture heights investigated are reasonably well contained. It is also noted that measured hydraulic fracture growth using microseismic monitoring is often less than that which is predicted by hydraulic fracture propagation models. 
Cruz et al. (2016) used 3D numerical modeling to investigate interactions between natural fractures and created hydraulic fractures in the Marcellus shale. A 3D fully coupled fracture and fluid flow simulator was utilized in two different scenarios with varied maximum horizontal stress orientations. In the first scenario, joint set $\mathrm{J} 1$ was oriented 30 degrees to the anticipated hydraulic fracture propagation direction of the maximum horizontal stress. The primary hydraulic fracture is captured and then redirected through the $\mathrm{J} 1$ joint set and reinitiates in the direction of the maximum horizontal stress. In the second scenario, the $\mathrm{J} 1$ joint set is parallel to the anticipated hydraulic fracture propagation direction of the maximum horizontal stress. In this scenario, the primary hydraulic fracture does not intersect with the $\mathrm{J} 1$ joint set due to the planar nature of the fracture. The $\mathrm{J} 2$ joint set was perpendicular to the maximum horizontal stress in both scenarios, but does not aid in capturing and redirecting the primary hydraulic fracture.

Based on modeling results and microseismic analyses, the authors suggest that the first scenario ( $\mathrm{J} 1$ oriented at 30 degrees to the maximum horizontal stress) was the most likely interaction process between created hydraulic fractures and natural fractures at the field site. Low versus high viscosity fluids were simulated to determine the effects of different viscosities on hydraulic fracture interaction with natural fractures. Lower viscosity fluids were found to create fracture complexity by arresting hydraulic fractures in natural fractures. Finally, the authors investigated microseismicity using modeled pressure distribution predictions. The reported microseismic event cloud was able to be explained exclusively by "wet" microseismic events, which are those induced by hydraulic fracture fluids (Cruz et al., 2016). 
Engelder et al. (2009) looked into J1 and J2 natural jointing in the Middle and Upper Devonian shales in the Appalachian Basin. Most of the work in this paper dealt with surface outcrops of the Devonian shales. It was determined that J1 joints, which are those joints currently oriented within a few degrees of the maximum horizontal stress, formed preferentially in Devonian black shales due to the thermal maturation of kerogen to hydrocarbons. According to the authors, the J1 joint set is most closely spaced in black shale. A second joint set, J2, is also present in the Devonian black shales and is much younger than J1. Due to its orientation, the J2 set is subjected to a higher normal stress. The authors used proprietary Formation MicroImager (FMI) images to confirm the presence of the J1 joint set at depth. It is recommended that horizontal drilling in these shales be oriented north-northwest in order to benefit from the bulk permeability anisotropy due to joint development and the permeability anisotropy developed from the normal stress in the region. $\mathrm{J} 2$ joints are also noted for their ability to deliver natural gas during hydraulic fracturing operations. These natural fractures are very important to consider when performing hydraulic fracturing treatments in Devonian black shales in the Appalachian Basin.

Geomechanical properties and their impact on the fracturing treatment in the Utica shale was investigated by Osman and Bilgesu (2015). A commercially available DFN numerical model was used in order to evaluate variations in geomechanical properties such as the Young's modulus, Poisson's ratio, horizontal stress level, and leak-off coefficient on treatment parameters. Through the simulation of cases with varying injection volumes and geomechanical and fluid-loss properties, the authors determined that the horizontal stress level, Young's modulus, and the fluid leakoff coefficient have the most impact on 
the fracture. The Poisson's ratio was determined to have an insignificant impact due to the narrow range of values for shale formations. The Stimulated Reservoir Volume (SRV) was found to be increased by low horizontal stress differentials between layers and a high Young's modulus in the layers through which the fractures propagate.

Fu et al. (2013) presented a fully coupled discrete finite element approach to modeling hydraulic fractures in shale environments with natural fracture networks. The authors developed the model in such a way as to encapsulate each physical process within its own separate module. Data sharing between the different modules represents the interactions among the physical processes. The authors chose this method of separating the physical processes in order to allow for flexibility when upgrading the processes with more complex models without impacting other modules significantly. The numerical model was validated in two ways. The first validation was against the well-established KGD model, developed by Khristianovic and Zhelton (1955) and Geertsma and de Klerk (1969). Fu et al. (2013) were able to successfully validate the numerical model using a single fracture with fluid and solid phase coupling. The second validation was against laboratory testing. A separate author, Blanton (1982), performed laboratory testing using synthetic rock blocks which included an existing fracture embedded in the sample at various angles. Water was injected into the center of each block and the interaction between hydraulic and existing fractures was observed. Nine scenarios involving different existing fracture angles were numerically simulated for comparison to the laboratory testing results. Results showed that the numerical simulation coupling strategy proposed by Fu et al. (2013) was able to sufficiently replicate the physical mechanisms involved in the interaction between the induced and existing fractures. The authors note that the validations were only 
performed for relatively simple scenarios but that more complex situations can be broken down into relatively simple scenarios. Thus, the validations in the paper provide sufficient credibility for the model.

Fontaine et al. (2008) discussed the characteristics of a "typical" Marcellus shale slickwater stimulation. The authors detail various aspects of the treatment, including its initiation, selection of proppant and proppant placement, and the conclusion of the treatment. The use of breakdown acid and proppant slugs are effective tools in reducing or eliminating neat wellbore complexities. The importance of the connection between the wellbore and the formation was emphasized due to the placement of proppant in the formation. Wellbore sweeps are seen as critical to the successful placement of proppant within a formation when using a lower-viscosity fluid. The authors also suggest that treatment parameters should be analyzed and compared with the production response in order to improve treatments in the future. Microseismic monitoring is also noted as a valuable tool in evaluating hydraulic fracture growth and enhancing reservoir development (Fontaine et al., 2008).

Davies et al. (2012) detailed the maximum reported heights of hydraulically induced fractures from thousands of different fracturing operations in a number of shale formations in the U.S. The authors also had data from natural hydraulic fractures from offshore Africa and Norway. The shales that were investigated were the Marcellus, Barnett, Woodford, Eagle Ford, and Niobrara. Based on the data sets from these shale formations, the highest reported fracture is approximately 588 meters (about 1,929 feet). The authors determined that the probability of a stimulated hydraulic fracture extending greater than 350 meters (about 1,148 feet) is approximately $1 \%$. Of the 1,170 natural hydraulic fractures 
which were imaged using 3D seismic data from offshore of West Africa and mid-Norway, the largest is approximately 1,106 meters (about 3,629 feet). It was determined that the probability of a natural hydraulic fracture extending vertically beyond 350 meters (about 1,148 feet) is approximately $33 \%$. The authors concluded that natural fractures can potentially propagate vertically higher than induced hydraulic fractures and that the microseismic measurement of fracture propagation is an essential tool for determining the separation between shallow aquifers and the target reservoir.

Zhang et al. (2017) detailed a pseudo three-dimensional (3D) model, which was developed for the evaluation of hydraulic fracture height growth in a multilayered geologic strata. This pseudo 3D model is cell-based and uses plane strain deformation in each vertical cross-section as well as two-dimensional (2D) flow assumptions. This model also intends to incorporate the effects of multiple elastic layers (modulus contrasts) on fracture growth. The authors point out that the differences between the most basic fully 3D models and 2D models is the amount of elastic coupling, descriptions of fluid flow and pressure distribution, and the ability to model fracture growth. Despite these differences, the authors note that in many situations, pseudo 3D models are able to make predictions as well as fully 3D models, and pseudo 3D models are still a good choice due to their computational simplicity. The authors compared their model to a fully 3D model called ILSA, or Implicit Level Set Algorithm, which was created by Peirce and Detournay (2008), Peirce (2015), and Dontsov and Peirce (2015). They found that for a homogenous rock layer there were some differences in both fracture size and fluid pressure, but noted that the relative errors were reasonable and fracture height predictions are similar. When comparing to a multilayer system, they found significantly slower vertical fracture growth. The authors 
concluded that their model needs further testing against fully planar simulators, which could account for modulus contrasts. 


\subsection{Other Studies involving Microseismic Monitoring and Hydraulic Fracturing}

The synthesis of microseismic monitoring and hydraulic fracturing has been an area of research for the past few decades. Various types of reservoirs have been investigated with traditional numerical hydraulic fracturing models with mixed success, depending upon the capabilities of the model and the complexities in the reservoir area. Recently, more advanced numerical hydraulic fracturing models have been developed which allow for a better understanding of the complexities of the subsurface and allow for further understanding of microseismic measurements. When dealing with shale reservoirs, such as the one in this study, it is critical to incorporate the natural fracture networks which exist in these reservoirs. More recent DFN models allow for better agreement with the natural conditions in shale reservoirs. No matter what numerical model is employed, even the newest and most sophisticated DFN models, the complications imposed by nature may exceed the limitations of the theory meant to describe them. Numerical models alone may not always be able to provide an appropriate depiction of actual hydraulic fracturing propagation behavior. Therefore, it is important to integrate hydraulic fracturing numerical models with other field measurements, such as microseismic data.

Warpinski et al. (1996) used hydraulic fracture modeling along with microseismic monitoring at the Multi-Site Project site previously mentioned, in Section 2.1, for hydraulic fracturing of a different sandstone reservoir (referred to as the B-Sand). Six unique injection scenarios were involved in this study (5 of which were minifrac/diagnostic), including the following treatment parameters: (1) fluid volumes ranging from 27 to 670 barrels (1134 to 28,140 U.S. Gallons), (2) fluid types were $\mathrm{KCl}$, linear and cross-linked 
gels, (3) injection rates ranged from 0.5 to 22 barrels per minute, (4) only one treatment scenario used proppant, and (5) incorporated 77,600 lbs. of an unspecified sand. The authors also determined in this study that microseismic mapping techniques can be used to determine important fracture geometry information, such as azimuth, height, and length. The authors used two hydraulic fracture models to attempt to match microseismic mapped fractures, including FRACPRO and a "conventional pseudo-3D simulator." Warpinski et al. (1996) determined that for the contained fractures, the models matched well; however, neither of the models exactly matched the microseismic mapped fractures for latter treatments that were not contained. A large amount of data was available for the project site, but the models in use at the time were not adequate enough to account for the complex subsurface conditions.

Daniels et. al. (2007) present three case studies which involve the integration of microseismic monitoring and hydraulic fracturing in the Barnett shale. In one of the studies, image logs were integrated with microseismic mapping in order to maximize the Effective Stimulation Volume (ESV) and the microseismic event count in real time. The ESV is determined by the number of microseismic events and the density of these events. The second study involved the integration of a sonic log with microseismic data. Through the use of the sonic log device, engineers were able to evaluate the horizontal stress anisotropy and, along with the ESV and the net fracturing pressure, could change stage spacing based on the observed horizontal stress anisotropy. In the third study, real-time microseismic event data was used to update the design of the hydraulic fracture treatment. This integration was said to allow for more of the reservoir to be contacted and production increases for the well. This study differs from the current study in that it evaluated real- 
time microseismic monitoring, occurred in a different shale reservoir, and discrete fracture modeling is not discussed, among other dissimilarities.

Zorn et al. (2017) looked into relations between microseismic response and the geomechanical properties of the various formations involved in the microseismic event cloud at a field site. The field site involved is the same that will be discussed in this research work, and details will be discussed in the subsequent chapter. The geomechanical properties that were discussed in this paper are the Young's modulus, Poisson's ratio, brittleness, lambda-rho $(\lambda \rho)$, and mu-rho $(\mu \rho)$. Geomechanical and dynamic moduli logs, along with microseismic logs, were used as a basis for the analyses the authors performed. Poisson's ratio was found to have a strong influence on the average seismic moment magnitude. Both the Poisson's ratio and Young's modulus were determined to influence the number of microseismic events and the frequency of those events. Although formations with low Poisson's ratios are believed to contain higher available organic content, the authors suggest targeting organic shale with a higher Poisson's ratio and a mid- to highlevel Young's modulus. Higher Poisson's ratios tend to indicate higher moment magnitude values. Mid- to high-level Young's moduli tend to indicate a superior ability to maintain a propped hydraulic fracture.

Shakiba and Sepehrnoori (2015) investigated applications of an Embedded Discrete Fracture Model (EDFM) in characterizing and simulating DFNs with the constraints of microseismic measurements. The authors used production data and pressure drainage in order to verify the accuracy of the numerical model DFNs. Microseismic data allowed for the development of a preliminary DFN; however, history matching has been shown to be valuable in fine-tuning numerical models. High-resolution, robust numerical models are 
preferred in order to appropriately optimize the hydraulic fracture treatment. A significant difference between the study by Shakiba and Sepehrnoori (2015) and the study presented in this paper is that the fracture network in their paper is derived directly from field microseismic data. The EDFM numerical model does not guarantee any connection between the modeled fracture planes inside the network. In the current study, the MShale numerical model features a connected discrete fracture network. There is usually some inherent uncertainty in microseismic data and it is important to be able to make necessary changes to the numerical model or its resulting data in order to account for measured differences.

Jacot et. al. (2010) used an approach of technology integration in order to maximize production and economics in a Marcellus shale well. The authors integrated minifrac, treatment, microseismic, and production data techniques along with numerical modeling in order to investigate a more efficient hydraulic fracturing strategy. The MShale numerical model was used in this study. Field data was available to the authors, from petrophysical analysis and $\log$ evaluation, which helped to develop baseline rock and reservoir characteristics. Minifrac analysis allowed the authors to define the stress, net pressure, and fluid efficiency which are used to calibrate the DFN. The microseismic field data was also used to define the extent of the DFN. In addition to these technologies, production history matching and an economic analysis could be performed in order to further calibrate the numerical model. Through the integration of the aforementioned technologies, the authors were able to obtain a reasonable match for seven stages at a field site in the Marcellus shale. The DFN and fracture geometric data found through numerical modeling were noticed to be smaller than the measured microseismic data. 
Microseismic monitoring and discrete fracture network modeling were utilized at a field site in India in a study by Stolyarov and Sookprasong (2013). The reservoir type at this location was tight and consisted of mostly shale and laminated siltstone. Microseismic monitoring via surface geophone arrays was utilized at this site in order to determine the nature of fractures at the site, post-treatment. Long and narrow lines of microseismic events would indicate that the fractures were relatively simple, bi-wing, planar fractures, while microseismic events which are shorter and wider would indicate the presence of a natural fracture network. Based on the analysis of microseismic data, it was determined that a natural fracture network was present and needed to be accounted for in numerical modeling. MShale, the same numerical model utilized in this study, was employed for use in investigating the fracture system at this site. Pressure matching was also performed at this site in order to better bring together the measurements in the field with the numerical model results.

A field site in the Barnett shale was used in a case study by Mayerhofer et. al. (2006) to look into the integration of microseismic monitoring and numerical modeling. Both horizontal and vertical wells were investigated to determine the effects of updating a numerical model using microseismic data. The authors looked into maximizing the fracture network in order to maximize the amount of hydrocarbons recovered. Treatment design parameters were investigated for the impact on gas recovery and the authors found that by doubling their initial spacing, recovery could be increased significantly. The conductivity of the fracture network, fracture face skin damage, high near-well conductivity, and network size were all investigated in a parametric study. The largest fracture network along with the densest fracture was found to be the ideal completion strategy in the Barnett shale. 
The current study focuses on the Marcellus shale, uses a different discrete fracture network solution methodology, and is focused on the primary induced bi-wing hydraulic fractures. Changes to the treatment design are also not considered in the current study. 


\section{CHAPTER 3 : DESCRIPTION OF THE HYDRAULIC FRACTURING FIELD SITE}

\subsection{Location of the Hydraulic Fracturing Field Site}

The Marcellus shale is said to be the most expansive shale in the U.S. (Kargbo et al., 2010). This shale formation was deposited over 350 million years ago in a shallow inland sea where the present Appalachian Mountains are located (Soeder and Kappel, 2009). The Marcellus shale is located underneath the U.S. states of Maryland, New York, Ohio, Pennsylvania, and West Virginia. It has been reported that estimates of the amount of gas-in-place may be in the range of recoverable 500 trillion cubic feet (Tcf), or about 14 trillion cubic meters (Engelder and Lash, 2008; Considine et al., 2009). The vast expanse of the formation, great potential for natural gas extraction, and the development and advancement of technologies, such as horizontal drilling, have all made the Marcellus shale one of the most important reservoirs in the world in recent years.

The project site discussed in this research work is located in the heart of the Marcellus shale region. The project site is referred to as the MSEEL (Marcellus Shale Energy and Environment Laboratory) site and is located in Morgantown, WV, USA. A 3D block model showing the locations of the wells in relation to the surrounding Morgantown area can be seen in Figure 3.1 (Modified from: MSEEL Database Development Team, 2015). The groundwater table depth in the area is approximately 450 feet below the ground surface. The depth to the top of the Marcellus shale formation in the area is approximately 7,576 feet below the ground surface. Figure 3.1 references the Empire State Building as a visual aid to show the depth of the Marcellus shale formation below the ground surface. As can be seen in Figure 3.1, the depth to the target formation is over five Empire State Buildings below the ground surface. 


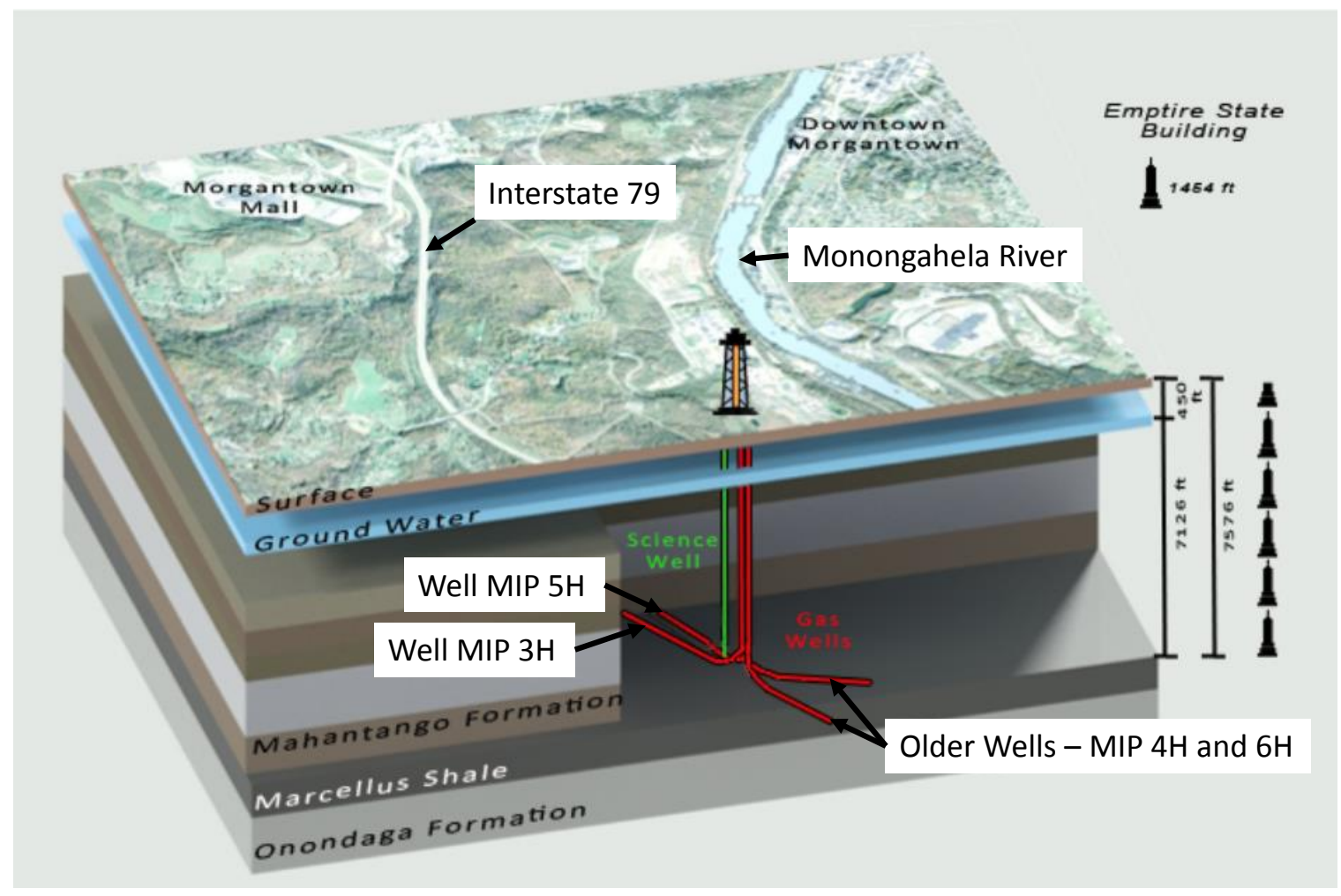

Figure 3.1: 3D Block Model Showing MSEEL Well Locations in Relation to the Surrounding Morgantown, WV Area (Modified from: MSEEL Database Development Team, 2015)

The MSEEL Project well site is located at the Morgantown Industrial Park (MIP), and the wells in this research work are MIP-3H and MIP-5H. The $\mathrm{H}$ indicates that the well is horizontal, and the numeric value is the well number. The MSEEL Project is also located on the same site where two wells were previously drilled in 2011 (MIP-4H and MIP-6H). All wells on the site have been drilled and are operated by a commercial energy company, who is also a partner on the MSEEL project. A scientific observation well (MIP SW) was also drilled by NNE in order to provide long-term monitoring. The scientific well provides the opportunity for core samples to be extracted, extensive logging, and microseismic monitoring via an array of geophones (Carr et al., 2014). Microseismic monitoring was performed by a commercial contractor. 


\subsection{Field Site}

The primary objective of the MSEEL project is "to provide a long-term field site to develop and validate new knowledge and technology to improve recovery efficiency and minimize environmental implications of unconventional resource development" (MSEEL, 2019). Hydraulic fracturing was carried out at the MSEEL site in late 2015. Numerous monitoring devices have been implemented to provide data to the team.

There are numerous secondary objectives of the MSEEL project that envelop a broad spectrum of disciplines, as MSEEL is a large project involving many researchers from various fields of study. The MSEEL team is composed of researchers from West Virginia University (WVU), a second university, and the National Energy Technology Laboratory (NETL) in Morgantown, WV, which is part of the United States Department of Energy. In no particular order, the areas of study or focus involved in the MSEEL project are: Geology, Geophysics, Petroleum and Natural Gas Engineering, Geochemistry, Hydrogeology, Environmental Science and Data Acquisition, Regional Economics, Air Quality and Air Sampling, Water Treatment and Water Quality, Public Health, Biochemistry, and Geomechanics (Carr et al., 2014).

The objective of this research work relating to the MSEEL project is to perform hydraulic fracture modeling and integrate microseismic data to improve model accuracy. An important goal of this research work will be to determine the relationship between observed microseismic activity and the preexisting faults and fracture systems (Carr et al., 2014). An existing hydraulic fracturing model will be calibrated using available data produced from the MSEEL project site. The calibrated hydraulic fracture model will then be evaluated for subsequent hydraulic fracturing at the MSEEL project site. 


\subsection{Overview of Site Details}

As previously mentioned, two wells (MIP-3H and MIP-5H) are being considered in this research study, which are located at the MSEEL project site in Morgantown, WV, USA. The vertical sections, or top holes, of the two MSEEL production wells (again, MIP3H and MIP-5H) were drilled using an air-rotary rig in June and July of 2015 (MSEEL, 2019). Air drilling has advantages over other types of drilling, such as mud drilling, as it allows for increased drilling rates and decreased formation damage, among other benefits (Zhu et al., 2010).

The horizontal portions of the production wells were drilled between September and November 2015, while the vertical science well (MIP-SW) was drilled in September 2015 (MSEEL, 2019). In October and November 2015, the production wells were completed using a variety of treatment schedules (MSEEL, 2019). Currently, both wells are being monitored for their production of hydrocarbons.

Daily and cumulative gas production data from MSEEL wells MIP-3H and MIP5H is shown in Figure 3.2. Gas began to be produced from well MIP-3H on 12/12/2015, and from well MIP-5H on 12/11/2015. At the time of writing, premade chart production data for both wells showed gas production through 02/28/2019 (Figure 3.2). As of this date, a total of approximately 3,343 MMCF (million cubic feet) of natural gas was produced by well MIP-3H and approximately 2,409 MMCF of natural gas had been produced by well MIP-5H. 


\section{Gas Production for MIP-3H, MIP-4H, MIP-5H, and MIP-6H}

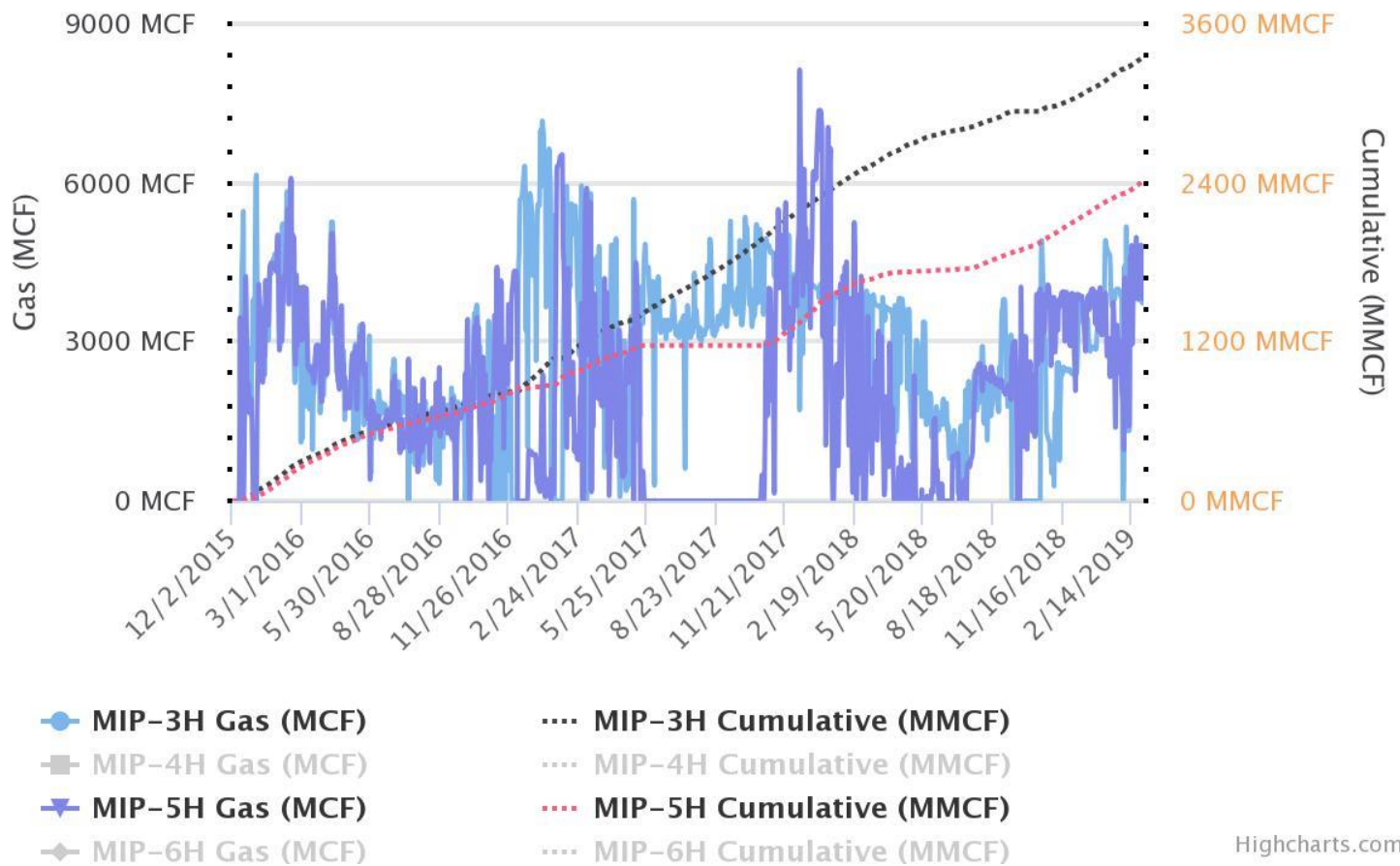

Figure 3.2: MSEEL Project Site Well Production through 02/28/2019 (MSEEL, 2019)

The perforations for wells MIP-3H and MIP-5H are located in the lower portion of the organic rich section of the Marcellus formation, as is customary with many Marcellus shale completions (Fontaine et al., 2008). Both wells were perforated at depths ranging from approximately 7,413 to 7,528 feet. Figures 3.3 and 3.4 show sample simplified geologic columns of the strata surrounding the Marcellus shale in the region where both wells are located. A limestone layer known as the Cherry Valley is present within the Marcellus shale, dividing it into Lower and Upper portions. The underlying layer of the Onondaga limestone is thought to be a good lower barrier to fracture height growth (Fontaine et al., 2008). The Onondaga limestone is the top member of the Onesquethaw Group and includes the Huntersville chert, which lies directly below (Wrightstone, 2009). 


\section{Ground Surface \\ Ground Water \\ ( 450 feet below surface)}

Marcellus and Surrounding

Formations

( $>7000$ feet below surface)

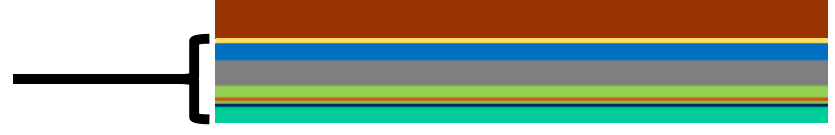

\section{Figure 3.3: Sample Simplified Geologic Column for MSEEL Project Site (not to scale)}

The Marcellus shale is bounded above by a group of gray non-organic shales known as the Mahantango/Skaneateles formation (Wrightstone, 2009). In this research work, this formation is referred to as the Hamilton shale for simplicity, as it is the uppermost member of the Hamilton group. Above the Hamilton shale/Hamilton group lies the Tully limestone. The Tully limestone layer has a higher closure stress than other shale layers in the underlying group (Starr, 2011). It is also considered to be a bounding layer for the Marcellus shale and may have been a factor in trapping hydrocarbons from the Marcellus 
shale (Zagorski et al., 2012). The Tully limestone can reach thicknesses greater than 100 feet (Wrightstone, 2009). Another non-organic shale, the Burkett, is included above the Tully limestone. Finally, a general layer simply referred to as "Overburden" is included as a top bound to the model.

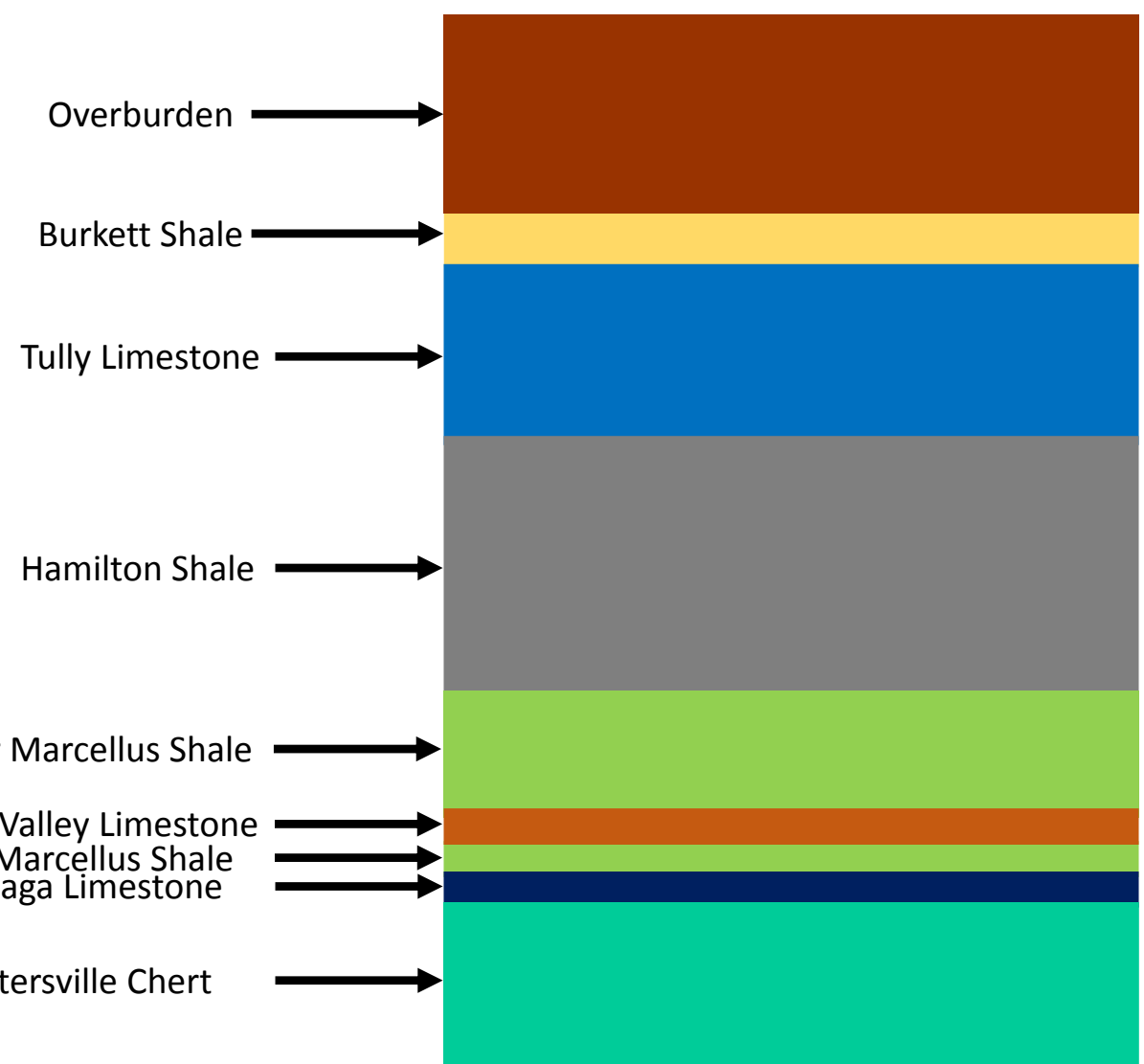

Figure 3.4: Sample Simplified Geologic Column from MSEEL Project Site Showing the Marcellus Shale and Surrounding Layers (not to scale)

Four primary steps or stages are utilized in hydraulic fracturing for each stage and each well at the MSEEL site. The first step is acidization of the perforations. The idea behind using an acid is to clean the perforations after using a perforation gun to create them. After using acid to clean the perforations, surface-treating pressure drops and a higher injection rate can then be used. The second step is the pad step, which is critical in creating a sufficient fracture network through which gas can flow from the formation to 
the wellbore. This is when most of the fracture network is created. If a large enough fracture network is not created during the pad step, pre-mature tip screen-out may occur and require modifications to the treatment schedule (Belyadi et al., 2017).

The third step is the proppant step. The fluids will be discussed first, followed by a brief discussion of proppants utilized. A slickwater fluid was used for nearly all hydraulic fracturing operations at the field site. For one of the treatment schedules used at well MIP$3 \mathrm{H}$, a second fracturing fluid was utilized in addition to the slickwater fluid. This additional fluid is a guar-free (guar refers to guar beans) viscoelastic fracturing fluid produced by Schlumberger (2014), known as Sapphire VF (Viscoelastic Fracturing) fluid. This fluid is able to outperform traditional slickwater and linear gel fracture treatments by enhancing proppant transport, improving proppant pack permeability, lowering treatment pressure, and reducing the risk of screenout among other benefits (Schlumberger, 2014).

Slickwater is composed mostly of fresh or recycled water, with fresh being preferred, and various chemical additives in small concentrations to aid in fracturing effectiveness. The particular slickwater fluid that was utilized at this field site included between 120 and 335 U.S. Gallons of friction reducer depending upon the stage. Friction reducer is considered to be the most important chemical used during slickwater hydraulic fracturing jobs because it reduces the very high friction that is developed in the pipes due to high injection pressures (about 100 barrels per minute) (Belyadi et al., 2017). A friction reducer breaker was also used for some stages at well MIP-3H in order to further reduce the viscosity of the fluid; an example of a friction reducer breaker is hydrogen peroxide. A second chemical used at the MSEEL site was a biocide, which is used to kill excess bacteria that can cause variation in the fluid viscosity and, in turn, cause pressure issues (Belyadi et 
al., 2017). Scale inhibitor was another chemical utilized at the MSEEL site. The purpose of this chemical is to prevent iron and scale from accumulating in the wellbore and/or formation which acts to increase the permeability (Belyadi et al., 2017). Corrosion inhibitor and iron control were also incorporated in stages at both well MIP-3H and well MIP-5H. The corrosion inhibitor prevents corrosion from occurring in and around the wellbore. Iron control controls and prevents the accumulation of dissolved iron in the fracturing fluid and prevents the precipitation of chemicals, which could cause the formation to be plugged off from the wellbore (Belyadi et al., 2017). Linear gel was also used for some stages. Linear gel is used to help with the proppant transport process into the formation (Belyadi et al., 2017).

Two proppants were used during hydraulic fracturing operations at both wells at the MSEEL project site. The first proppant used was a 100 mesh (no. 100 sieve; 100 openings per linear inch; each opening is $0.149 \mathrm{~mm}$ or 0.0059 inches). It is typically the smallest sized proppant used in hydraulic fracturing and is similar in size to baby powder. Hydraulic fracturing treatments typically start with 100 mesh proppant in order to seal off microfractures in the formation so that fluid leak-off will be reduced and to cover perforation erosion among other reasons (Belyadi et al., 2017).

The second proppant used at the MSEEL project site is 40/70 mesh Ottawa White sand (U.S. Silica, 2010). 40/70 mesh means that at least $90 \%$ of the particles will lie within that size range. $90 \%$ of the particles will pass the no. 40 sieve (40 openings per linear inch; each opening is $0.420 \mathrm{~mm}$ or 0.0165 inches) and will be retained on the no. 70 sieve (70 openings per linear inch; each opening is $0.210 \mathrm{~mm}$ or 0.0083 inches). $40 / 70$ mesh is typically used following 100 mesh in unconventional reservoirs like shales and creates the 
required fracture length to maximize surface area and allow for increased conductivity in induced fractures. Fracture conductivity is the proppant permeability in $\mathrm{mD}$ multiplied by the fracture width in feet (Belyadi et al., 2017).

The use of 100 mesh and 40/70 mesh proppant is the most common practice in unconventional reservoirs (Belyadi et al., 2017). This is largely due to the fact that smaller proppants are able to withstand higher stresses without being crushed in a given fracture width versus larger proppants where more proppant of smaller size can fit in the fracture. Ottawa White sand is a popular choice for hydraulic fracturing operations due to its characteristics. Ottawa White sand is a natural product and is relatively cheaper than other proppants types that are resin-coated or ceramic (Belyadi et al., 2017). It also meets American Petroleum Institute (API) recommendations for roundness, sphericity, crush resistance, acid solubility, turbidity, size, specific gravity, and bulk density (U.S. Silica, 2010).

The final step in the hydraulic fracturing process used for each stage at the MSEEL project site is the flush step. After all the proppant has been injected into the formation, the well is flushed. Flushing is the injection of only water and chemicals, such as slickwater, after proppant injection. The idea behind flushing is to push any excess proppant left in the production casing into the formation (Belyadi et al., 2017). A simple equation multiplying the casing capacity by the bottom perforation measured depth can be used to calculate the flush volume.

At well MIP-3H, a total of 28 stages were utilized during hydraulic fracturing operations. Treatment graphs for a typical stage at well MIP-3H are shown in Figure 3.5, Figure 3.6, Figure 3.7, and Figure 3.8. These graphs show the fluid volume versus time, 
slurry rate versus time, slurry volume versus time, and cumulative proppant mass injected versus time, respectively. The "slurry" is the water, chemicals, and proppant being injected together.

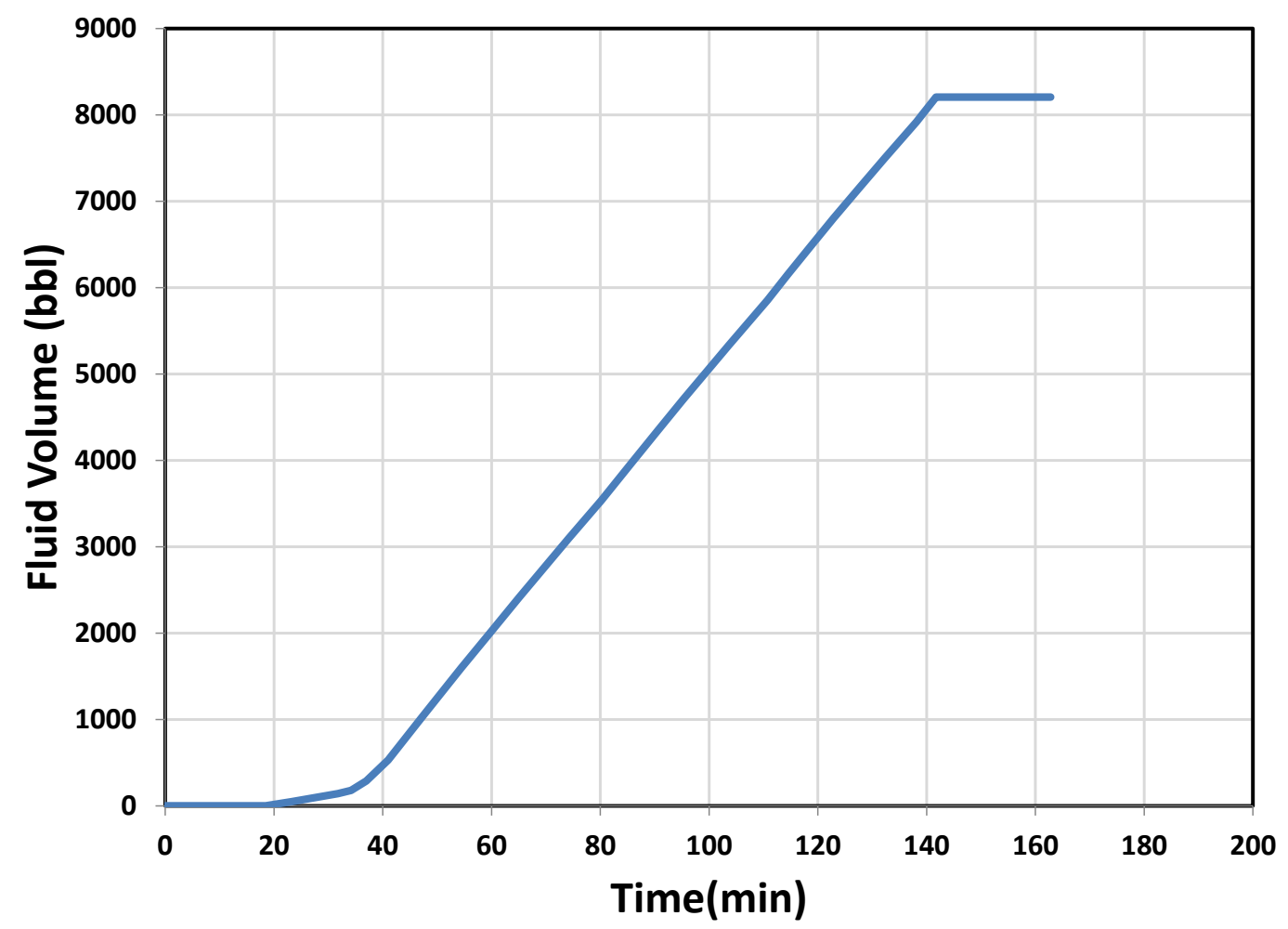

Figure 3.5: Typical Injected Fluid Volume versus Time Plot for Well MIP-3H 


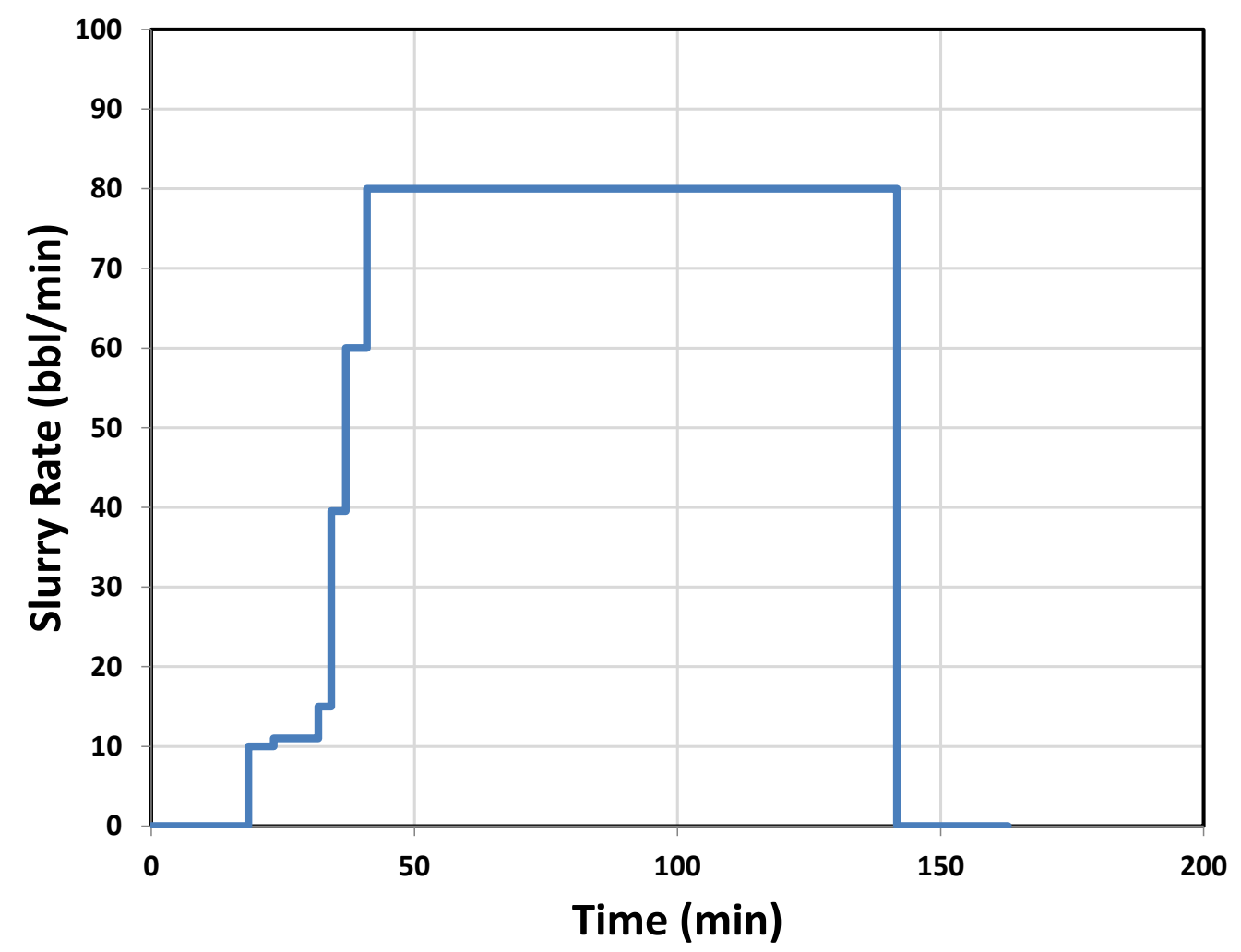

Figure 3.6: Typical Injected Slurry Rate versus Time Plot for Well MIP-3H

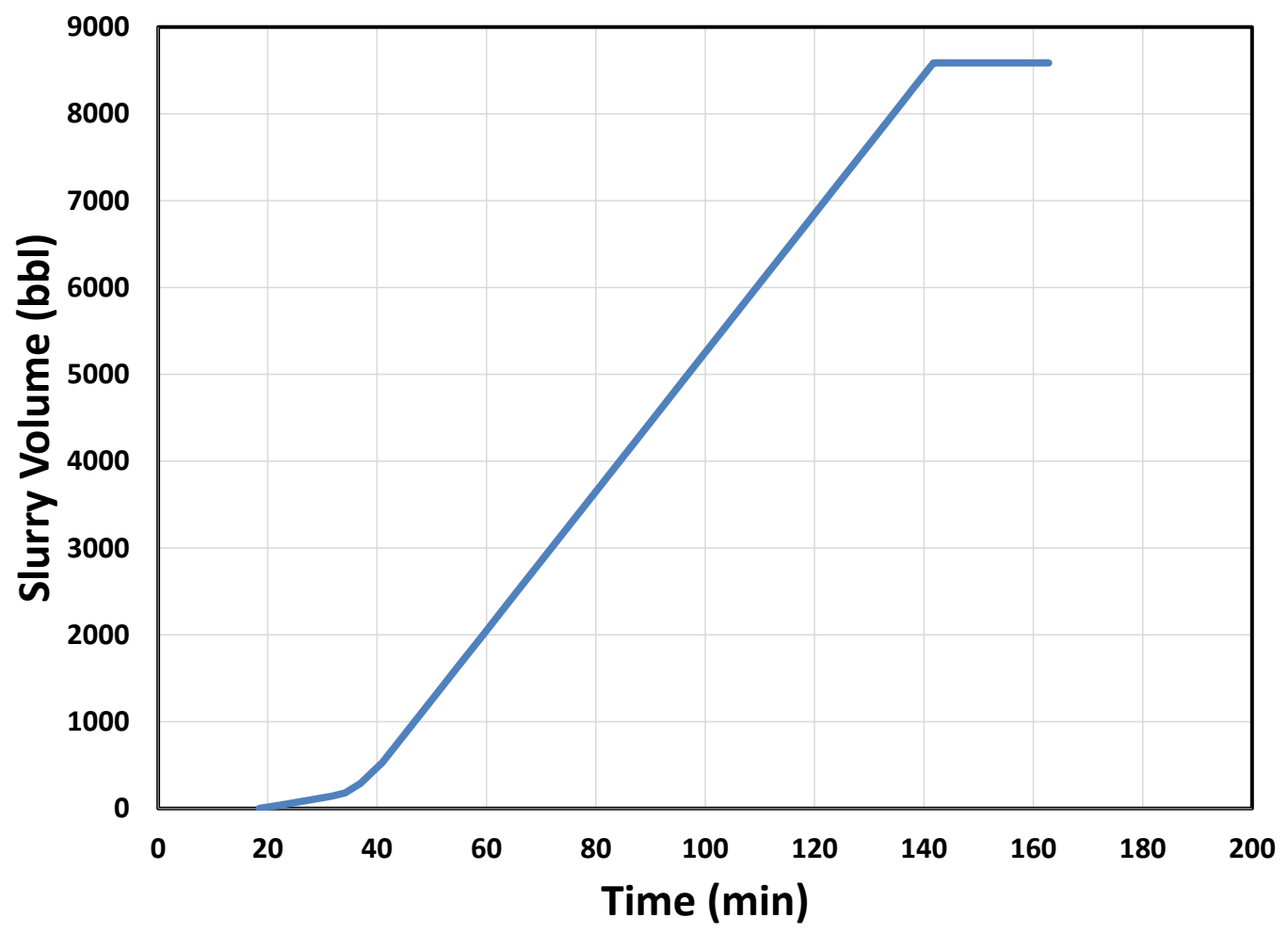

Figure 3.7: Typical Injected Slurry Volume versus Time for Well MIP-3H 


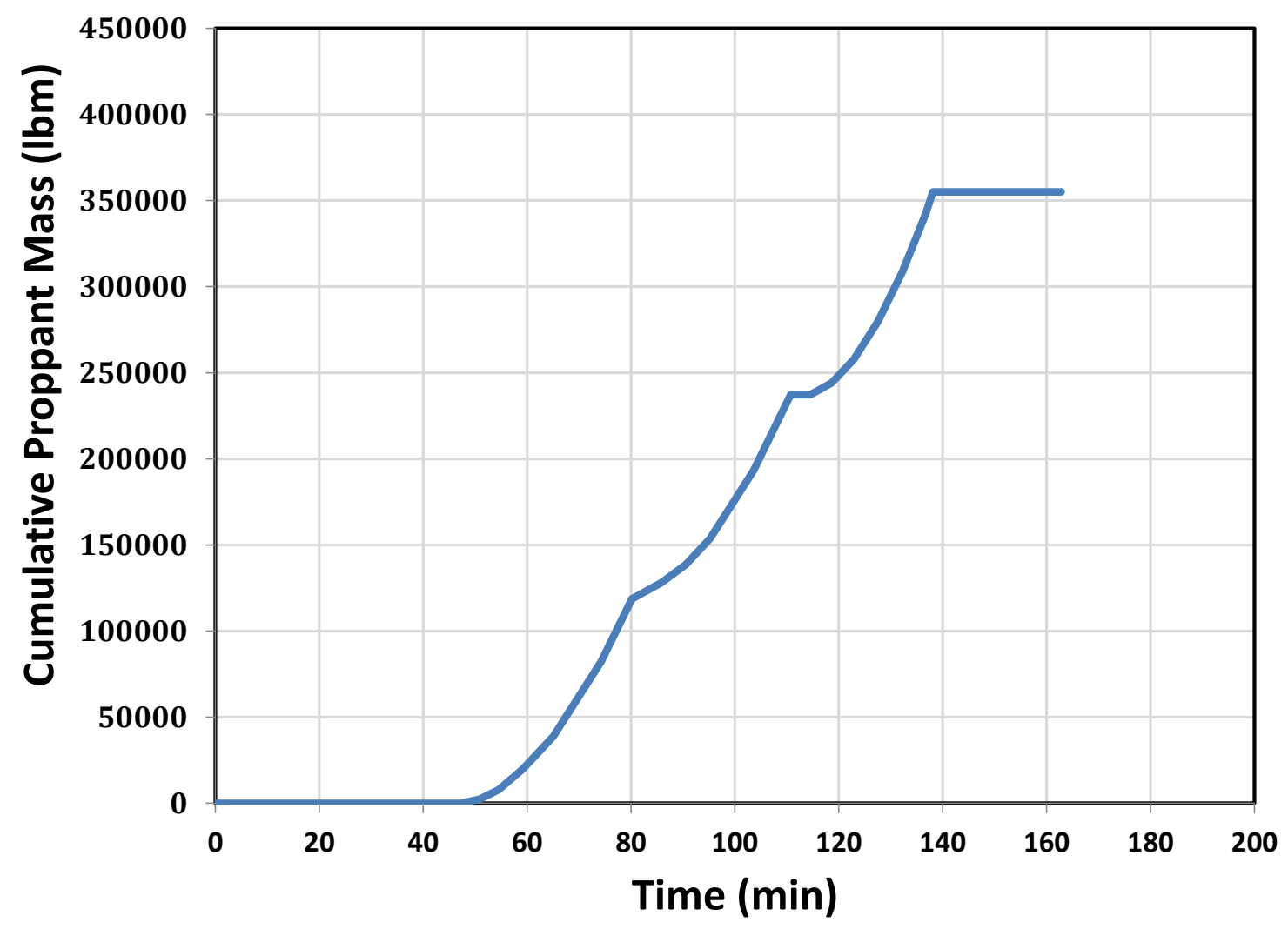

Figure 3.8: Typical Injected Cumulative Proppant Mass versus Time for Well MIP3H

At well MIP-5H, a total of 30 stages were utilized during hydraulic fracturing operations. Treatment graphs for a typical stage at well MIP-5H are shown in Figure 3.9, Figure 3.10, Figure 3.11, and Figure 3.12. These graphs show the fluid volume versus time, slurry rate versus time, slurry volume versus time, and cumulative proppant mass injected versus time, respectively. The "slurry" is the water, chemicals, and proppant being injected together. 


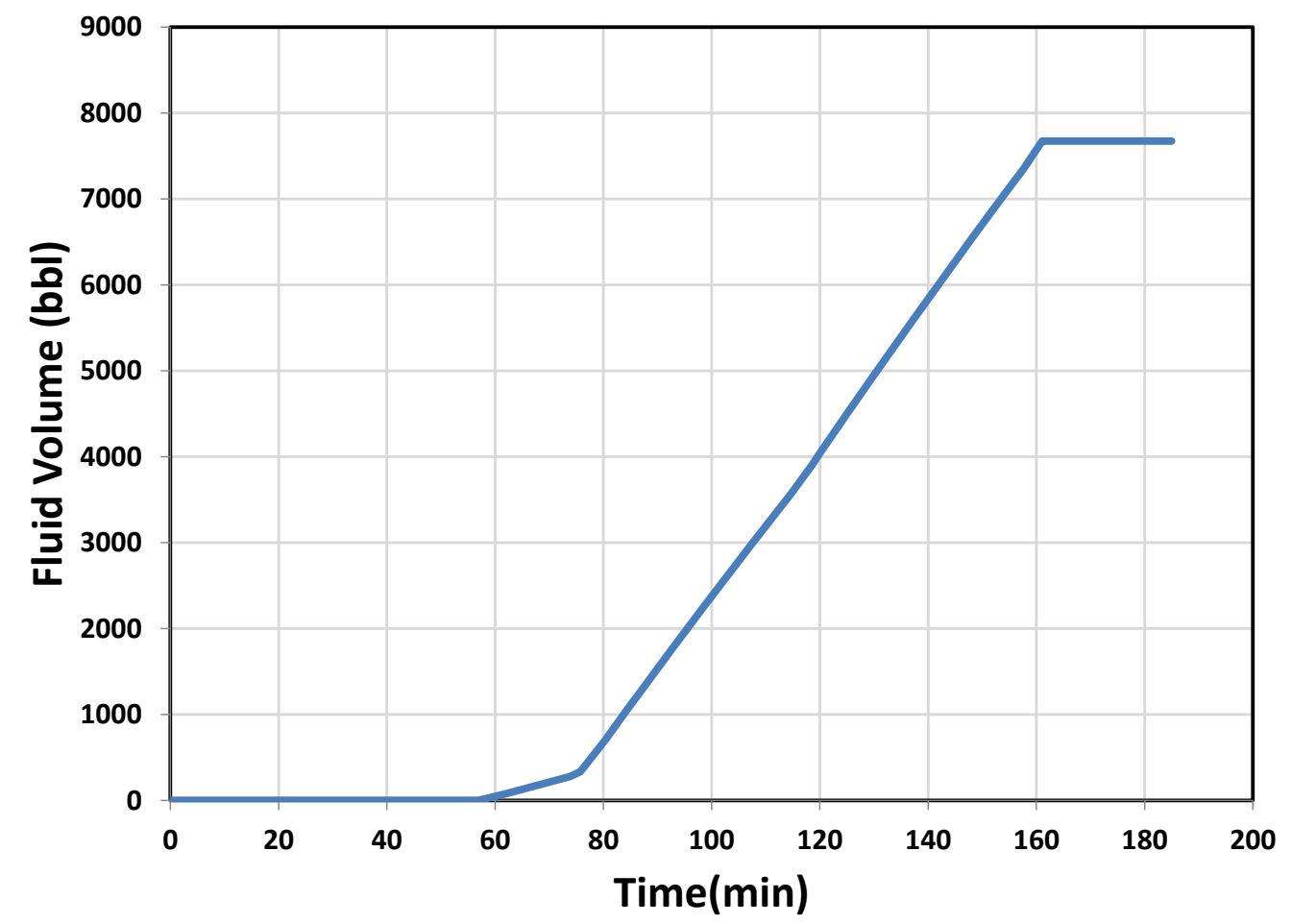

Figure 3.9: Typical Injected Fluid Volume versus Time Plot for Well MIP-5H

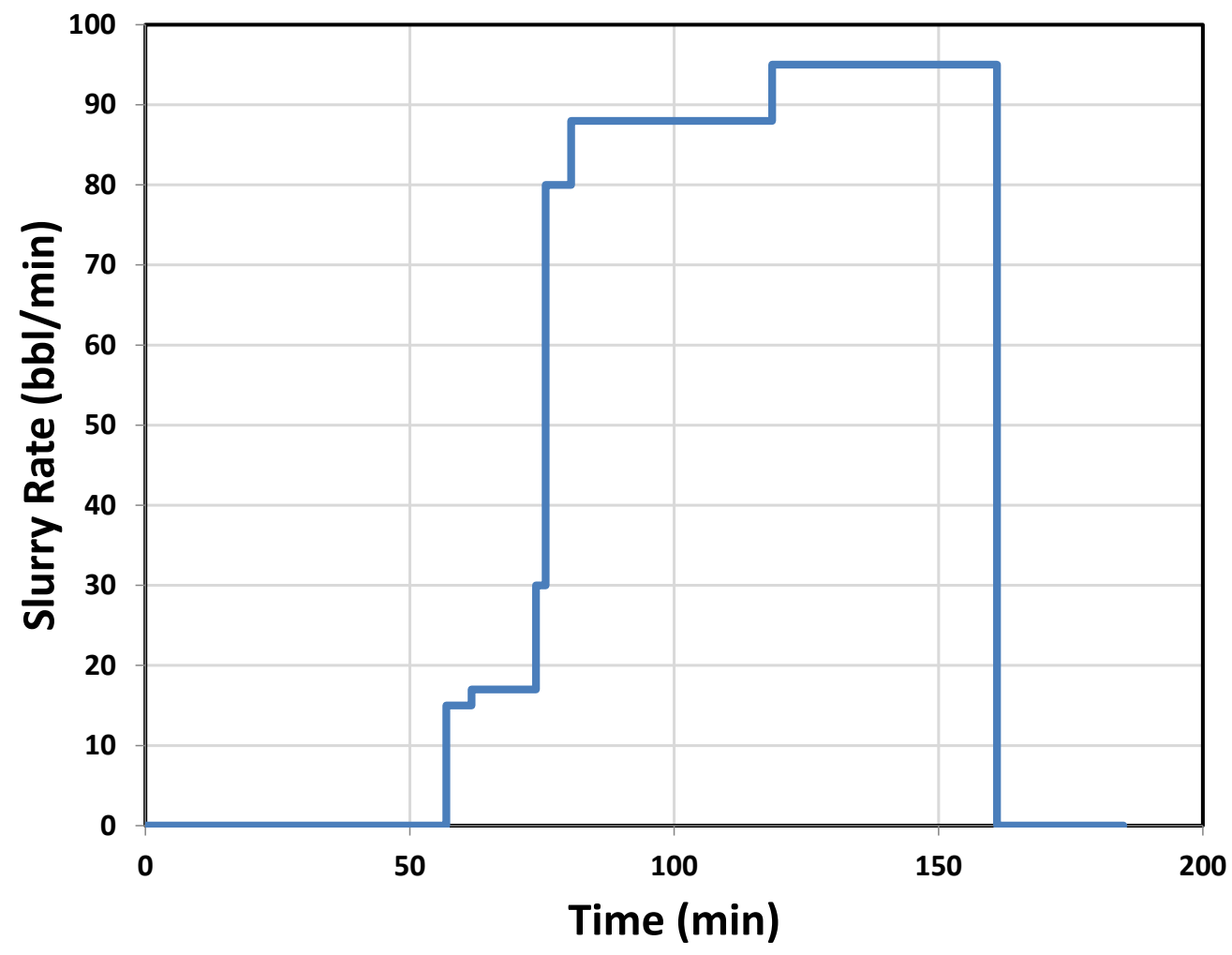

Figure 3.10: Typical Injected Slurry Rate versus Time Plot for Well MIP-5H 


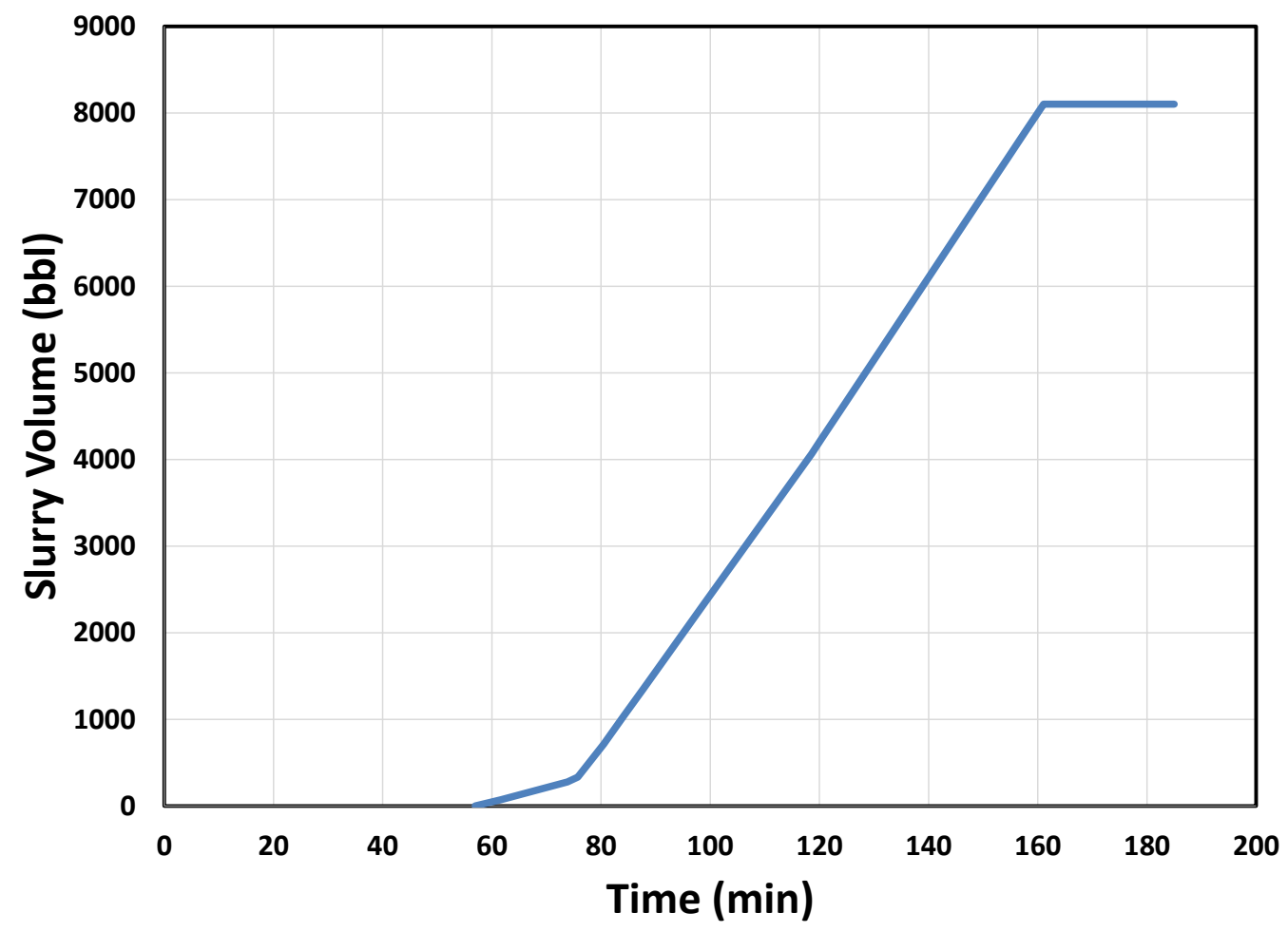

Figure 3.11: Typical Injected Slurry Volume versus Time Plot for Well MIP-5H

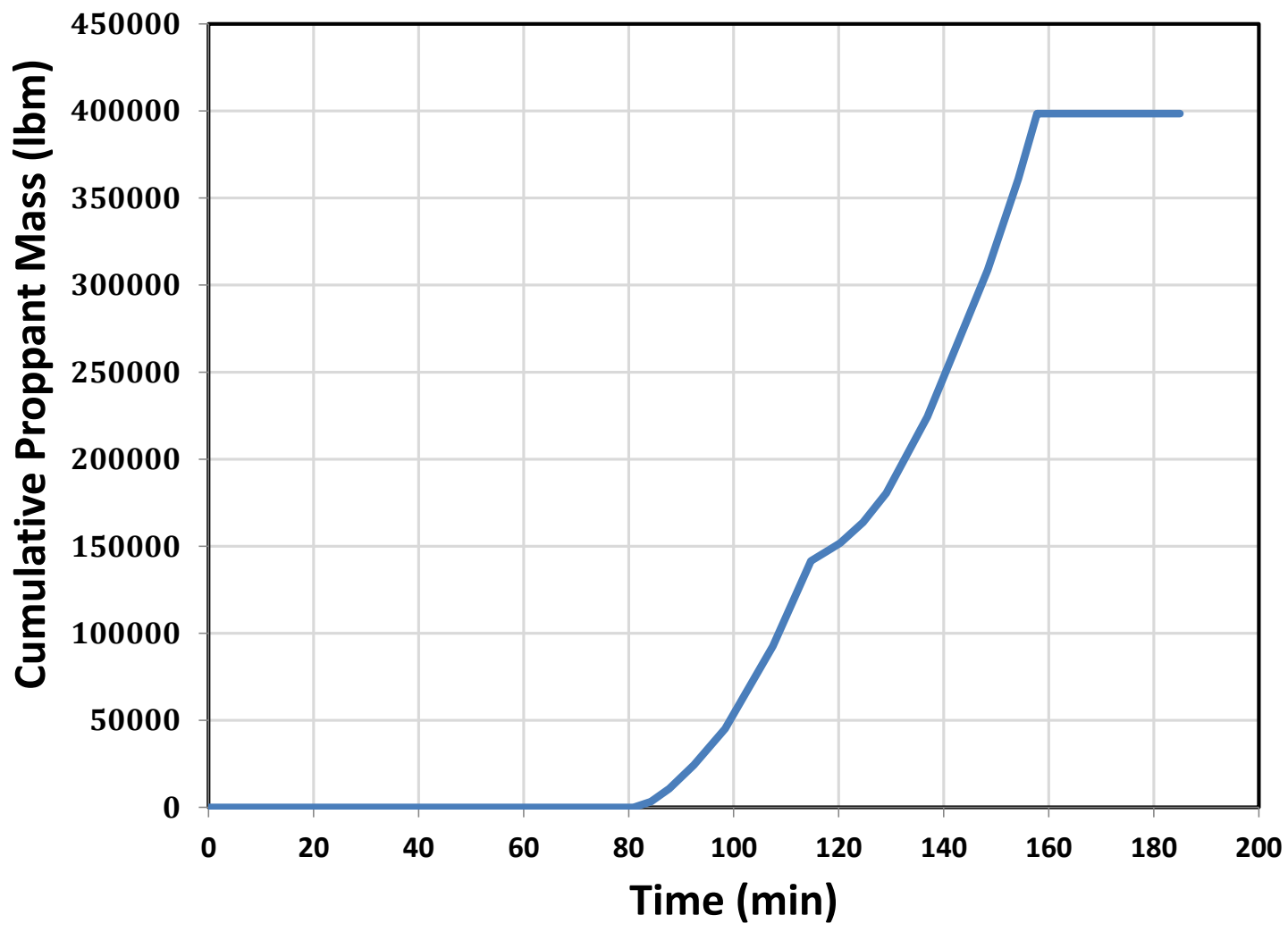

Figure 3.12: Typical Injected Cumulative Proppant Mass versus Time Plot for Well MIP-5H 
The geophone array used at the MSEEL site was supplied and monitored by a commercial contractor, and each geophone in the array is known as a Versatile Seismic Imager (VSI). The VSI devices use three-axis geophone accelerometers, which are acoustically isolated from the main body of the tool (Schlumberger, 2004). The shear wave arrival time differentials between each of the geophone receivers provide the basis for calculating the fracture shear energy release locations. Before being deployed to monitor the actual hydraulic fracturing events, each geophone's directional sensing is calibrated, either while perforating, or with what are known as "string shot detonations" in the hydraulic fracturing well. It is also possible to perform supplemental calibration using detonations at other known locations/depths (Veatch et. al., 2017).

A 12-level VSI array of geophones was used in the scientific well with a 100 foot spacing between each geophone. An image of a VSI geophone can be seen in Figure 3.13. Seismic waveforms that are produced by the acoustic reflections from geologic bedding plane boundaries are captured by the sensitive geophones and are able to be processed and analyzed by geophysicists. An array of geophones is used in microseismic monitoring versus the use of a single geophone due to the fact that "noise" is produced that needs to be reduced as much as possible. Arrays of geophones are able to successfully attenuate or reduce coherent noise patterns (Cooper, 2002). Figure 3.14 shows the geophone array in relation to wells MIP-3H and MIP-5H at the MSEEL site. Hydraulic fracturing operations at stages $7-28$ at well MIP-3H were monitored, while all stages, except 1 and 3 , at well MIP-5H were monitored. The observation well geophone array at the MSEEL site features an above reservoir array positioning. This array has the following disadvantages over one which straddles (or is above, at, and below the depth of the target reservoir) the reservoir: 
(1) less desirable viewing position, (2) more velocity effects which need to be accounted for, (3) less accurate microseismic fracture height estimate determination, and (4) less desirable hodograms (used to indicate directionality of microseismic fracture estimates) (Veatch et. al., 2017).

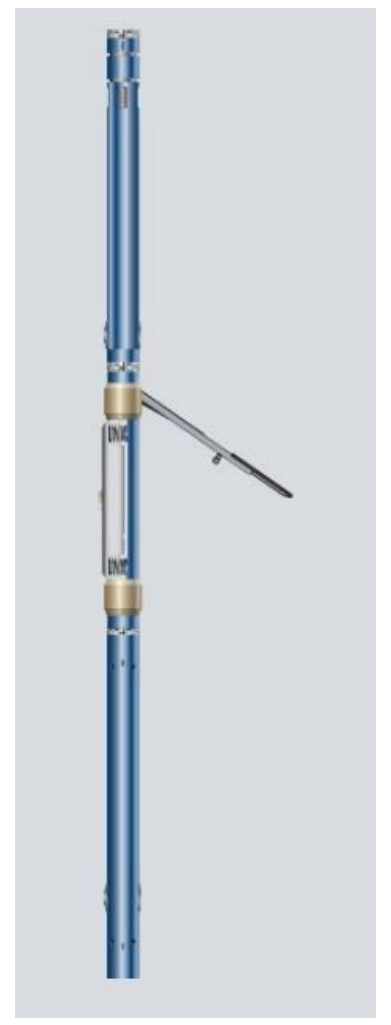

Figure 3.13: VSI Geophone (Schlumberger, 2004) 


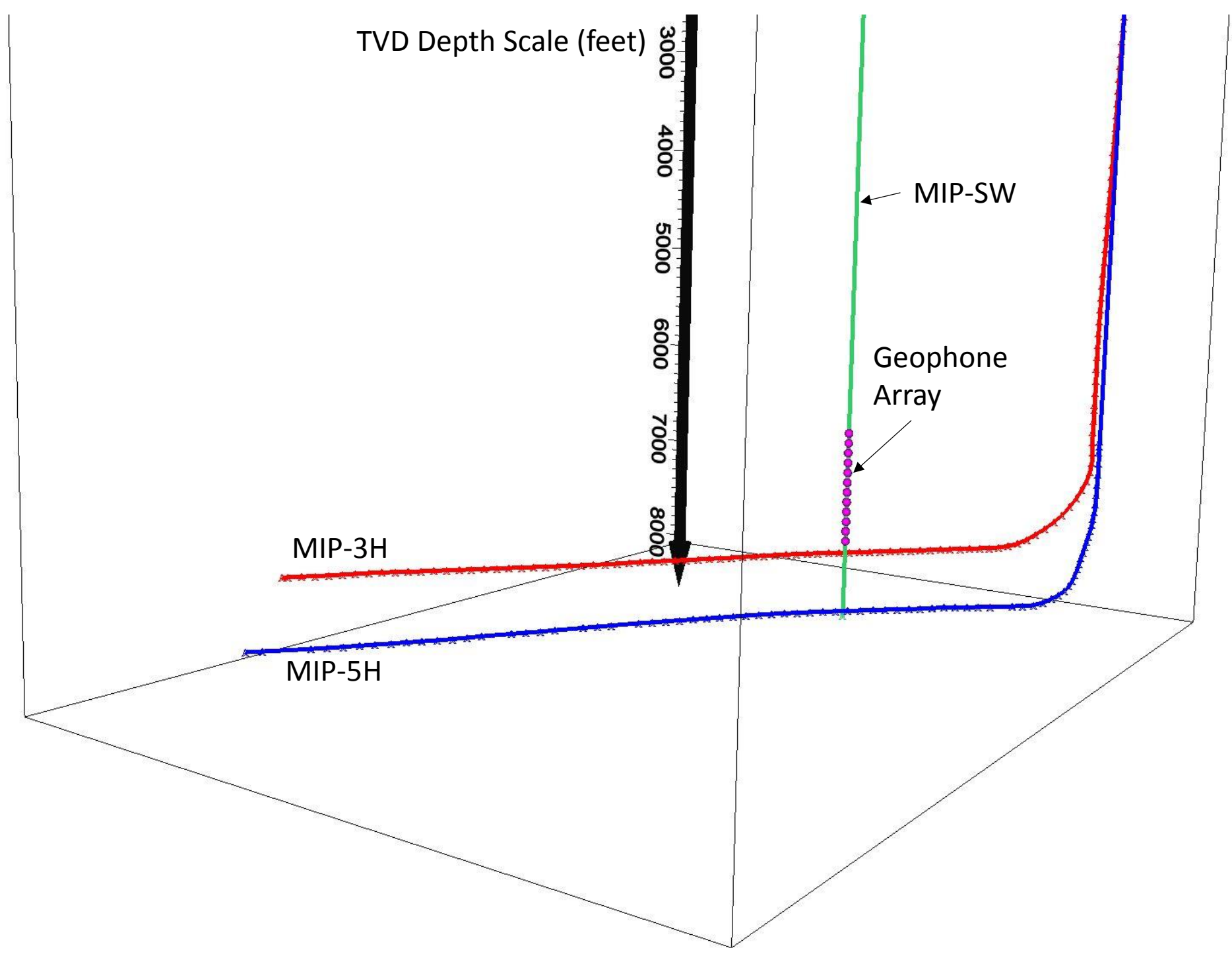

Figure 3.14: MIP-3H, MIP-5H, and MIP-SW Well Configuration 


\section{CHAPTER 4 : MATHEMATICAL DETAILS OF THE NUMERICAL MODEL}

\subsection{Numerical Model Utilized in this Study}

The numerical model utilized in this research is known as MShale, which is a part of the MFrac Suite. The MFrac numerical model was created by Bruce Meyer in the 1980's (Meyer 1986, Meyer and Hagel 1989) and is currently owned and maintained by Baker Hughes, a General Electric company (Baker Hughes Reservoir Software, 2015). The MFrac Suite includes the capabilities of performing relatively simple two-dimensional modeling, as well as more complex pseudo three-dimensional (P3D) modeling. The MShale numerical model utilized in this study includes P3D modeling with the more advanced incorporation of a DFN. More details on two-dimensional, pseudo-threedimensional, and DFN numerical models will be covered in the following sections of this chapter.

In certain types of reservoirs, two-dimensional models are adequate for modeling purposes, as they can properly take into account the subsurface conditions and provide reliable results. However, in more complex reservoirs, such as the shale reservoir being investigated in the current study, a more complex numerical model is required to account for different subsurface features. The primary subsurface feature which requires a more complex model is the natural fracture network present in the shale reservoir. The natural fractures which were formed over the millennia due to stress regime changes influence the propagation of induced hydraulic fractures and must be taken into consideration in the numerical model. The MShale numerical model is designed, as stated in the title, for shales and can properly account for the natural fracture networks in and around the reservoir. 


\subsection{Two-Dimensional and Pseudo-Three-Dimensional Hydraulic Fracturing Models}

The MFrac Suite utilizes two different two-dimensional (2D) models for analyzing hydraulic fracture propagation. These models are the Perkins-Kern/Nordgren (PKN) and Geertsma de Klerk (GDK) (also known as KGD). These are the two primary 2D models which are used in many hydraulic fracturing simulators. The P3D model formulae which are presented later in this chapter are based on a penny shape type fracture (Meyer, 1986). The PKN model was developed by Perkins and Kern (Perkins \& Kern, 1961), as well as Nordgren (Nordgren, 1972). The GDK model was developed by Geertsma and de Klerk (Geertsma \& de Klerk, 1969). These 2D models, as well as some others, and their underlying assumptions were compared by Geertsma and Haafkens (1979).

The "2D formulae are based on asymptotic behavior of more comprehensive solutions for the limiting cases of no fluid loss $(\eta=1)$ and large leak-off $(\eta \rightarrow 0) "$ (Meyer, 1986). $\quad$ P3D formulae are also shown for cases of large and no confining stresses, as these are the asymptotic limits for validation of the model. The equations presented in this chapter which govern mass conservation and fracture propagation are based on Meyer's (1986) methodology. All equations take into account a single wing fracture, as the fracture is assumed to have two symmetric wings (see Figure 4.1).

Plane strain is an adequate assumption in simplified 2D hydraulic fracturing analysis. The GDK model assumes plane strain in the horizontal plane. The PKN model assumes plane strain in the vertical plane. For longer fractures with short heights and small widths, plane strain can be assumed in the vertical plane (this is a PKN assumption). For shorter fractures with higher fracture heights and smaller widths, plane strain can be assumed in the horizontal plane (this is a GDK assumption). For more information on the 
plane strain assumptions made in the PKN and GDK models, refer to Valko and Economides (1995), Sneddon (1973), Perkins and Kern (1961), Nordgren (1972), and Geertsma and deKlerk (1969).

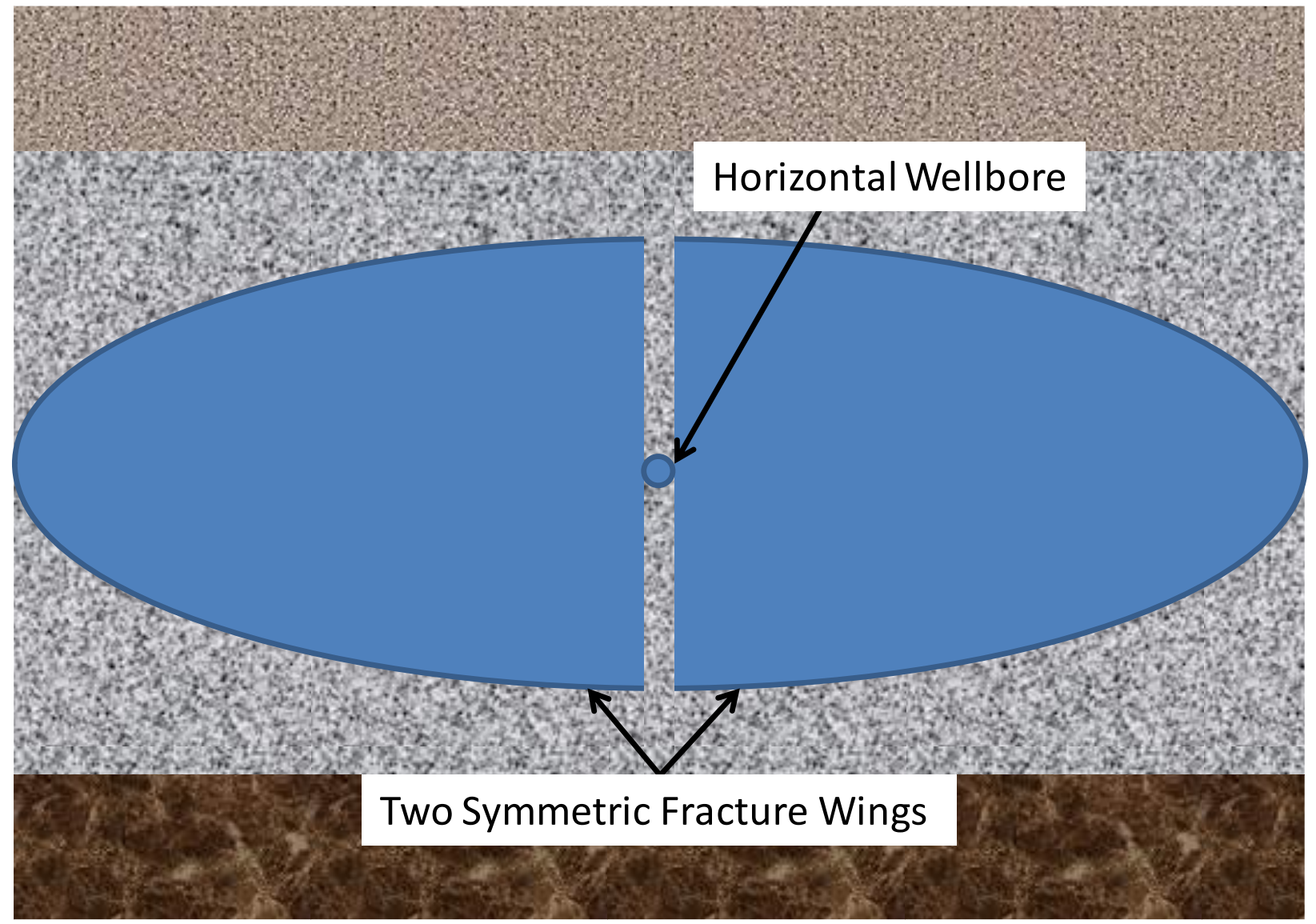

Figure 4.1: Symmetric Fracture Wing Diagram

For the conservation of mass in any incompressible slurry injection into a fracture, it is required that the following equation is satisfied (Meyer, 1986):

$$
\int_{0}^{t} q(\tau) d \tau-V_{f}(t)-V_{I}(t)-V_{s p}(t)=0
$$


where:

$V_{f}(t)=\tau_{v}(t) W_{W}(t) H_{W} L(t) \cdots G D K$

$V_{f}(t)=\Gamma_{v}(t) W_{W}(t) H_{W} L(t) \cdots P K N$

$V_{f}(t)=2 \Gamma_{v}(t) W_{W}(t) R(t)^{2} \cdots$ Penny

$V_{l}(t)=2 \int_{0}^{t} \int_{0}^{A} \frac{C(A, t)}{\sqrt{t-\tau(A)}} d A d t$

$V_{s p}(t)=2 S_{p} A(t)$

$\tau(A)=t[A / A(t)]^{1 / l_{a}}$

$t$ is time

$q$ is the single-wing flow rate

$\tau$ is the fluid loss delay time

$V_{f}$ is the single-wing fracture volume

$V_{l}$ is the volume loss due to leak-off

$V_{s p}$ is the volume loss due to spurt 
$\tau_{v}$ and $\Gamma_{v}$ are fracture volume coefficients

$W_{W}$ is the maximum wellbore width

$H_{W}$ is the total wellbore height

$L$ is the fracture half-length

$R$ is the fracture radius

$A$ is the leak-off area of a single face

$C$ is the total leak-off coefficient

$S_{p}$ is the spurt loss coefficient

$l_{a}$ is the leak-off area propagation parameter

Equation 4.1 states that the amount of fluid injected must equal the amount of fluid in the fracture and the amount of the fluid lost to the surrounding formation. Thus, the total volume of slurry injected minus the volume of slurry in the fracture, the volume of fluid lost to the formation through leak-off, and the volume of fluid lost to the formation through spurt loss must equal zero in order to correctly conserve mass in the numerical model. This equation is basically stating that what is injected into the formation must equal what is lost to the surrounding formation and what remains in the fracture (Meyer \& Bazan, 2011).

The following equations will set the stage for defining the PKN, GDK, and P3D (penny) models, which will be discussed in the upcoming sub-sections. First, in order to define the limiting cases for the PKN, GDK, and P3D (penny) models, the fracture 
efficiency parameter must be defined. This parameter is defined as the ratio of the total hydraulic fracture volume to the total volume of slurry injected. The slurry is the mix of proppant and hydraulic fracturing fluid. This relationship is shown in the following equation (Meyer, 1986):

$\eta(t)=V_{f} / \int_{0}^{t} q(\tau) d \tau$

$$
=V_{f} / q t \longrightarrow q \text { is constant }
$$

The hydraulic fracture length, $\mathrm{L}(\mathrm{t})$, and the hydraulic fracture radius, $\mathrm{R}(\mathrm{t})$, for the 2D (GDK and PKN) and P3D (penny) models are given in Equations 4.9, 4.10, and 4.11 (Meyer, 1986) for a constant injection rate and no leak-off (or a fracture efficiency of 1).

$$
L(t)=\frac{q t}{\tau_{v}(t) W_{W}(t) H_{W}} \longrightarrow G D K
$$

$$
L(t)=\frac{q t}{\Gamma_{v}(t) W_{W}(t) H_{W}} \longrightarrow P K N
$$

$$
R(t)=\left[\frac{q t}{2 \Gamma_{v}(t) W_{W}(t)}\right]^{0.5} \longrightarrow 3-D(\text { penny })
$$

where $R$ is the fracture radius (for the P3D (penny) model). 
For situations with large leak-off volumes $(\eta \rightarrow 0)$ with constant leak-off coefficients and no spurt loss, the fluid loss volume equation is given as follows (Meyer, 1986):

$$
\begin{aligned}
V_{l}(t) & =2 C \int_{0}^{t} \frac{A}{t^{0.5}} \int_{0}^{1} \frac{1}{\sqrt{1-\lambda^{2}}} d \lambda d t \\
& =\pi C A t^{0.5}
\end{aligned}
$$

where $l_{a}=1 / 2($ when $\eta=0)$

Finally, for the 2D models (PKN and GDK) and the P3D (penny) fractures, the total leak-off area for one face of a given fracture where leak-off only occurs in the pay zone (inside the target formation) is given by the following (Meyer, 1986):

$$
A=H_{p} L(t) \longrightarrow 2-D
$$

$$
A=\frac{\pi R(t)^{2}}{2} \longrightarrow 3-D(\text { penny }) \longrightarrow R<\frac{H_{p}}{2}
$$

$$
A=H_{p} R(t) \longrightarrow 3-D(\text { penny }) \longrightarrow R>>\frac{H_{p}}{2}
$$

where $H_{p}$ is the height of the pay zone. 


\subsubsection{PKN Model}

The Perkins-Kern/Nordgren (PKN) fracture propagation model features a constant height fracture and an ellipsoidal shaped width profile along the length of the fracture (Perkins \& Kern, 1961). The width profile of a PKN fracture is shown in Figure 4.2(a) (Meyer, 1986). The length profile for the PKN model is shown in Figure 4.3. The distinctive feature of the PKN model is the fact that the net pressure increases with time for a constant injection rate (Meyer, 1986). The PKN model is most applicable for use when the total fracture length is greater than the total fracture height (Meyer \& Bazan, 2011). For the PKN model, the width of the fracture at any position ( $\xi$ ) can be found using the following equation (Meyer, 1986):

$$
W(x, \xi, t)=W_{w}(x, 0, t)\left(1-\xi^{2}\right)^{1 / 2}
$$

where

$W(x, \xi, t)$ is the width at any position $\xi,\left(\xi=\frac{z}{H}\right)$

$W(x, 0, t)$ is the maximum width at any position ' $x$ '. 


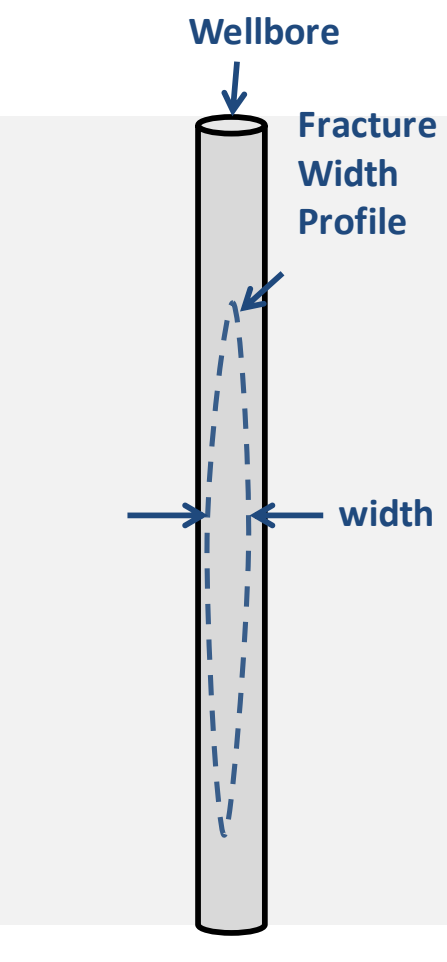

PKN Model Width Profile

(a) PKN Width Profile

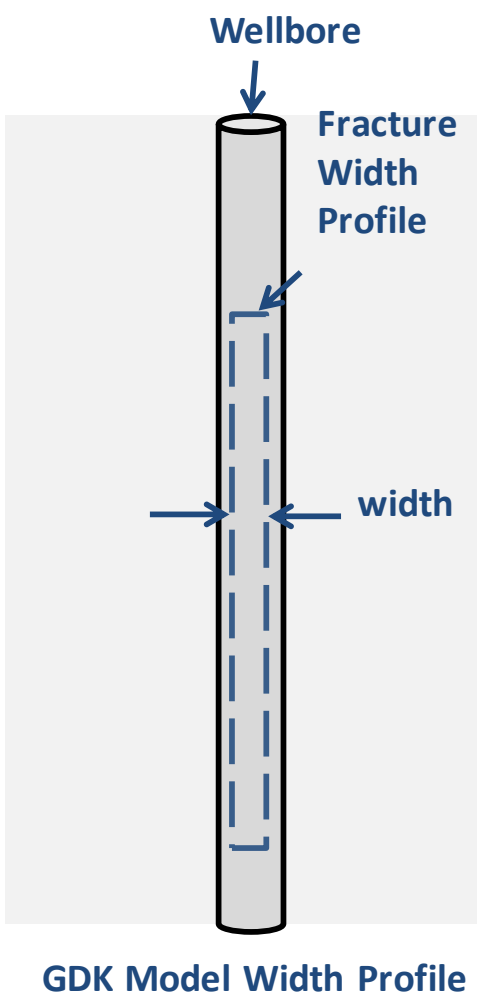

(b) GDK Width Profile

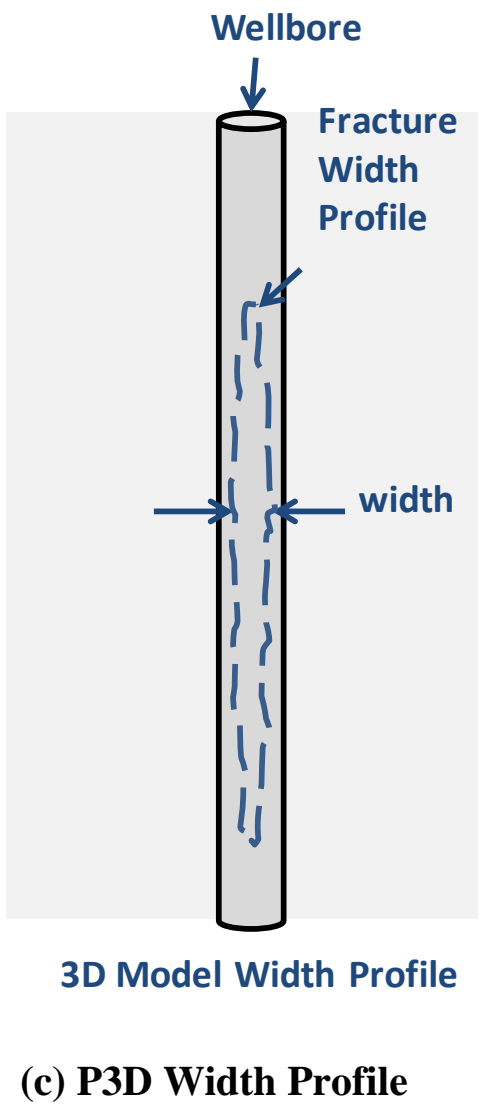

(c) P3D Width Profile

Figure 4.2: Fracture Model Width Profiles (from Meyer, 1986) 


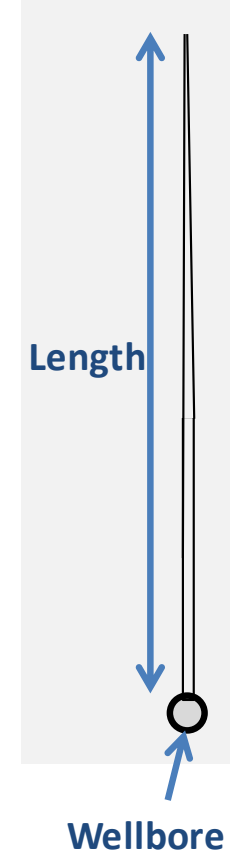

Figure 4.3: Length Profile for PKN, GDK, and P3D Fracture Models (Meyer, 1986)

The width-opening pressure relationship for the PKN model is given by the following equation (Meyer, 1986):

$$
W_{w}(x, 0, t)=\frac{\tau_{w 0}(1-v)}{G} H_{w} \Delta P(x, t)
$$

The length and width equations for cases with a leak-off coefficient value of zero are presented below, respectively (Meyer, 1986):

$$
L(t)=b\left[\frac{\frac{G}{(1-v) K_{a}}\left(\frac{Q}{H_{w}}\right)^{n^{\prime}+2}}{H_{w}}\right]^{\frac{1}{2 n^{\prime}+3}} t^{\frac{2 n^{\prime}+2}{2 n^{\prime}+3}}
$$


$W_{w}(t)=a\left[\frac{1-v}{G} K_{a}\left(\frac{Q}{H_{w}}\right)^{n^{\prime}+2} L(t)^{2}\right]^{\frac{1}{2 n^{\prime}+3}} \frac{1}{t^{2 n^{\prime}+3}}$

where

$$
\begin{aligned}
& a=\left[5^{n^{\prime}} \Gamma_{w 0} /\left(\Gamma_{f} \Gamma_{p} \Gamma_{v}\right)\right]^{\frac{1}{2 n^{\prime}+3}} \\
& b=\left[\Gamma_{f} \Gamma_{p} /\left(8 * 12^{n^{\prime}} \Gamma_{w 0} \Gamma_{v}^{2 n^{\prime}}\right)\right]^{\frac{1}{2 n^{\prime}+3}} \\
& \Gamma_{w 0}=1.0 \\
& \Gamma_{p} \cong 1 /\left(2 n^{\prime}+2\right) \\
& \Gamma_{f} \cong 3 \pi / 16 \\
& \Gamma_{v} \cong \pi / 4\left(2 n^{\prime}+2\right) /\left(2 n^{\prime}+3\right)
\end{aligned}
$$

The length and width for the PKN model with a leak-off coefficient value greater than zero are given in the following equations, respectively (Meyer, 1986):

$$
\begin{gathered}
L(t)=\frac{Q t^{1 / 2}}{2 \pi C H_{p}} \\
W_{w}(t)=a\left[\frac{1-v}{G} K_{a}\left(Q / H_{w}\right)^{n^{\prime}}\left(Q H_{w} / C H_{p}\right)\right]^{\frac{1}{2 n^{\prime}+2}} \frac{1}{t^{\prime n+4}}
\end{gathered}
$$


where

$$
\begin{aligned}
& a=\left[3^{n^{\prime}} \Gamma_{w 0} /\left(\Gamma_{p} \Gamma_{f} \pi\right)\right]^{1 /\left(2 n^{\prime}+2\right)} \\
& \Gamma_{w 0}=1.0 \\
& \Gamma_{p} \cong 1 /\left(2 n^{\prime}+2\right) \\
& \Gamma_{f} \cong 3 \pi / 16 \\
& \Gamma_{v} \cong \pi / 4\left(2 n^{\prime}+2\right) /\left(2 n^{\prime}+3\right)
\end{aligned}
$$




\subsubsection{GDK model}

The Geertsma-deKlerk (GDK) model features a constant fracture height and a vertically constant fracture width (Geertsma \& de Klerk, 1969). Figure 4.2(b) shows the GDK fracture width profile (Meyer, 1986). Figure 4.3 shows the length profile for the GDK model. The GDK model differs from the PKN model in that the net pressure decreases with time. The GDK model is most applicable for use when the total fracture length to total fracture height ratio is less than 1 (Meyer \& Bazan, 2011). Typically, the GDK model predicts greater wellbore widths and shorter fracture lengths than the PKN model does when the appropriate ratio of total fracture length to total fracture height is greater than 1 (Meyer \& Bazan, 2011). The width-opening pressure relationship for the GDK model is also different than the PKN model, and this difference is shown below (Meyer \& Bazan, 2011):

$$
\begin{aligned}
& W_{w} \propto \Delta p L / E \rightarrow G D K \\
& W_{w} \propto \Delta p H / E \rightarrow P K N
\end{aligned}
$$

For the GDK model, the width of the fracture at any position $(\xi)$ is given by the following equation (Meyer, 1986):

$$
W(\xi, t)=W_{w}(t)\left(1-\xi^{2}\right)^{1 / 2}
$$


where

$W(\xi, t)$ is the width at any position $\xi\left(\xi=\frac{x}{L(t)}\right)$

$W_{w}(t)$ is the maximum wellbore width $\left(W_{w}(t)=W(0, t)\right)$

As previously mentioned, a difference between the PKN and GDK models is the width-opening pressure relationship. More details on this difference can be found in the literature (Meyer, 1986; Meyer and Hagel, 1989). The full width-opening pressure relationship for the GDK fracture propagation model is given in Equation 4.21 (Meyer, 1986). As previously noted, this equation incorporates the length at each time step, as opposed to the height, which is used in the PKN equation (see Equation 4.17).

$$
W_{w}(t)=\frac{2 \tau_{w 0}(1-v)}{G} L(t) \Delta P(0, t)
$$

The length and width equations for the GDK propagation model with a fluid leakoff coefficient value of zero are shown below (Meyer, 1986):

$$
W_{w}(t)=a\left[\frac{1-v}{G} K_{a}\left(\frac{Q}{H_{w}}\right)^{n^{\prime}+2}\right]^{\frac{1}{2\left(n^{\prime}+2\right)}} t^{\frac{1}{\left(n^{\prime}+2\right)}}
$$




$$
L(t)=b\left[\frac{G}{(1-v) K_{a}}\left(\frac{Q}{H_{w}}\right)^{n^{\prime}+2}\right]^{\frac{1}{2\left(n^{\prime}+2\right)}} \frac{n^{\prime}+1}{t^{\prime}+2}
$$

where:

$$
\begin{aligned}
& a=\left[3^{n^{\prime}} \tau_{w 0} /\left(\tau_{f} \tau_{p} \tau_{v}^{2}\right)\right]^{\frac{1}{2\left(n^{\prime}+2\right)}} \\
& b=\left[\tau_{f} \tau_{p} /\left(16^{*} 12^{n^{\prime}} \tau_{w 0} \tau_{v}^{2 n^{\prime}+2}\right)\right]^{\frac{1}{2\left(n^{\prime}+2\right)}} \\
& K_{a}=K^{\prime}\left(\frac{2 n^{\prime}+1}{3 n^{\prime}}\right) n^{\prime} \\
& G=\frac{E}{2(1+v)} \\
& Q=2 q ; \text { two-wing injection rate } \\
& \tau_{w 0} \cong 0.785 \\
& \tau_{p} \cong 0.7046 \\
& \tau_{v}=\pi / 4 \\
& \tau_{f}=1.0
\end{aligned}
$$


The length and width equations for the GDK propagation model with a leak-off coefficient value greater than zero are presented below (Meyer, 1986):

$$
L(t)=\frac{Q t^{1 / 2}}{2 \pi C H_{p}}
$$

$$
W_{w}(t)=a\left[\frac{1-v}{G} K_{a}\left(\frac{Q}{H_{w}}\right)^{n^{\prime}+2}\left(\frac{Q}{C H_{p}}\right)^{2}\right]^{\frac{1}{2\left(n^{\prime}+2\right)}} \frac{1}{2 n^{\prime}+2}
$$

where

$$
a=\left[\frac{3^{n^{\prime}} \tau_{w 0}}{\left(\tau_{p} \tau_{f} \pi^{2}\right)}\right]^{\frac{1}{\left(2 n^{\prime}+2\right)}}
$$




\subsubsection{Pseudo 3D Model}

Planar pseudo three-dimensional (P3D) models have been used since the early 1980's and are now the industry standard. They are the most commonly used model (throughout the oil and gas industry) by producers, hydraulic fracturing consultants, and pumping service consultants. The two-dimensional simulators based on PKN and GDK, as previously mentioned, have essentially been replaced by the P3D models (Veatch et. al., 2017). The following include some of the features of P3D models, such as the one used in this study: (1) planar propagation, which is symmetric about the wellbore; (2) a continuous, ellipsoidal-shaped, concave fracture shape; (3) the vertical fracture height and width profiles are based on the in-situ stress and elastic modulus variation data given as inputs; (4) fluid properties are given as a function of time, temperature, shear rate, etc., for fluid loss to the formation, as well as fluid viscosity and rheology data; (5) one-dimensional fluid flow proppant transport is utilized; (6) post-injection proppant settling, fracture closure, and proppant concentrations are calculated in the numerical model; and (7) injection rate variations are utilized (Veatch et. al., 2017).

P3D models are capable of addressing situations where either the fracture is wellconfined by higher stress regions above and below the perforated fracturing interval of the wellbore or if there is a much higher stress regime below the perforated fracturing interval (Veatch et. al., 2017). At the MSEEL hydraulic fracturing site, the stress regime around the perforated fracturing interval is such that the stress below the interval is much higher. Thus, the P3D model is acceptable with respect to this constraint. If the geologic layers, in-situ stresses and other geomechanical rock properties, and the fluid-loss properties in 
and around the target reservoir are comparable to that given in the numerical model, then the P3D model are capable of providing acceptably reliable results (Veatch et. al., 2017). The various properties of the geologic layers in and around the target reservoir used in numerical modeling in this study are comparable to those measured in the field and the P3D model is sufficiently capable of providing reliable results. One restriction of the P3D numerical model used in this study is that calculations are limited to only symmetrical planar hydraulic fracture growth about the wellbore. Indirect hydraulic fracture growth measurements taken from microseismic measurements at the MSEEL site have shown that the growth does not appear to be symmetric about the wellbore for all stages. This may be an inconsistency between the actual fracture propagation behavior at the field site and the numerical model calculations. Also, in the numerical model, elastic rock mechanics behavior is assumed. This may not always be applicable and may result in a discrepancy.

An important note about numerical models in general is that no matter what model is used, even the most sophisticated, the inherent complexities and unknowns of the subsurface strata may exceed the bounds of the theory trying to explain them. Numerical models alone may not always be enough to provide an adequate representation of the field hydraulic fracturing behavior. However, these numerical models do give us insight into the behavior of propagating hydraulic fractures and will continue to improve as new models are developed and current models are improved upon. Numerical models also provide perspective into the effects of various design parameters on hydraulic fracture propagation behavior. In order to gain further insight into the comparisons between the numerical model calculations and the field measurements, surface pressure matching will be performed. Pressure matching of numerical model calculations against field measurements is one of 
several methods which can be useful for validating or adjusting model inputs (Veatch et. al., 2017).

The P3D fracture model uses a variable fracture height and includes different features of both the two-dimensional PKN and GDK models (Meyer, 1986). The 2D crosssectional geometry of a hydraulic fracture calculated using a P3D numerical model looks like a bullet-like shape with a concave curvature along the fracture perimeter. Regardless of the in-situ stress and elastic modulus profile prevailing in the area of the fracture, the cross-sectional geometry will have this shape (Veatch et. al., 2017). Figure 4.2(c) shows the P3D ellipsoidal fracture width profile (Meyer, 1986). Figure 2.4 shows the length profile for the P3D ellipsoidal fracture model. With most P3D models, the width and vertical height in each segment is determined by net fracturing pressure, formation elastic modulus, and fracture toughness. P3D numerical models commonly calculate the vertical height through the use of an in-fracture pressure function which will result in asymmetric vertical fracture growth (Veatch et. al., 2017).

The model used in this study takes into account varying fracture propagation in both the horizontal and vertical directions as well. If the ellipsoidal aspect ratio (the ratio of the total fracture length to the total fracture height) is greater than 1 , the solution of the P3D model approaches that of the PKN model; if the ellipsoidal aspect ratio is less than one, the P3D model solution approaches that of the GDK model (Meyer \& Bazan, 2011). More details on the P3D model can be found in the literature (Meyer, 1986; Meyer and Hagel, 1989; Meyer \& Bazan, 2011). Equation 4.24 below shows the fracture width at any radial position, $\mathrm{r}$ (Meyer, 1986): 


$$
W(r, t)=W(0, t)\left[1-(r / R)^{2}\right]^{1 / 2}
$$

where:

$W(r, t)$ is the width at any radial position, $\mathrm{r}$

$W(0, t)$ is the maximum wellbore width

$\mathrm{R}$ is the facture radius at any time, $\mathrm{t}$

The width and radius for the P3D Ellipsoidal fracture model with a fluid leak-off coefficient value equal to zero are shown below (Meyer, 1986):

$$
\begin{array}{r}
W_{w}(t)=a\left[\frac{1-v}{G} K_{a} Q^{\frac{2+n^{\prime}}{2}}\right]^{\frac{2}{3 n^{\prime}+6}} \frac{2 n^{\prime}+2}{t^{\prime}+6} \\
R(t)=b\left[\frac{G}{(1-v) K_{a}} Q^{n^{\prime}+2}\right]^{\frac{1}{3 n^{\prime}+6}} \frac{2 n^{\prime}+2}{t^{\prime}+6}
\end{array}
$$

where

$$
a=\left[3^{n^{\prime}} \Gamma_{w 0} /\left(\Gamma_{f} \Gamma_{p} \Gamma_{v}^{1-n^{\prime} / 2}\right)\right]^{\frac{2}{3 n^{\prime}+6}}
$$




$$
b=\left[\Gamma_{f} \Gamma_{p} /\left(4^{3} 24^{n^{\prime}} \Gamma_{w 0} \Gamma_{v}^{2 n^{\prime}+2}\right)\right]^{\frac{1}{3 n^{\prime}+6}}
$$

The width and radius for the P3D Ellipsoidal fracture model with a fluid leak-off coefficient value greater than zero are shown as follows for two potential fracture radius cases (Meyer, 1986):

$$
R<H_{p} / 2:
$$

$$
W_{w}(t)=\left[a \frac{1-v}{G} K_{a} Q^{\frac{n^{\prime}+2}{2}} C^{\frac{n^{\prime}-2}{2}}\right]^{\frac{1}{2 n^{\prime}+2}} \frac{2-n^{\prime}}{t 8 n^{\prime}+8}
$$

$$
R(t)=\left[\frac{Q t^{1 / 2}}{\pi^{2} C}\right]^{1 / 2}
$$

where

$$
a=\left[\frac{4(3 / 2)^{n^{\prime}} \Gamma_{w 0}}{\Gamma_{f} \Gamma_{p} \pi^{2-n^{\prime}}}\right]^{\frac{1}{2 n^{\prime}+2}}
$$


$R>>H_{p} / 2$ :

$$
W_{w}(t)=a\left[\frac{1-v}{G} K_{a} Q^{n^{\prime}}\left\{\frac{Q}{C H_{p}}\right\}^{2-n^{\prime}}\right]^{\frac{1}{2 n^{\prime}+2}} \frac{2-n^{\prime}}{t^{4 n^{\prime}+4}}
$$

$$
R(t)=\frac{Q t^{1 / 2}}{2 \pi C H_{p}}
$$

where

$$
a=\left[\frac{3^{n^{\prime}} \Gamma_{w 0}}{\Gamma_{f} \Gamma_{p} \pi^{2-n^{\prime}}}\right]^{\frac{1}{2 n^{\prime}+2}}
$$




\subsection{Discrete Fracture Networks}

The MFrac Suite includes a special numerical model for incorporating the effects of a discrete fracture network. This numerical model is known as MShale. A DFN refers to a computational model which takes into account a network of natural fractures and explicitly represents the geometry of these fractures (Lei et al, 2017). Shale formations, such as the one in this study, are naturally fractured due to their inherent geomechanical properties and the varying stress regime encountered throughout their geologic history. Ideally, this DFN is a representation of field conditions and will allow the natural fracture system to interact and propagate with the primary generated hydraulic fractures. More information on DFNs can be found elsewhere (Hyman et. al., 2016; Meyer and Bazan, 2011).

The fundamental mathematical equations for the MShale discrete fracture network model are based upon the P3D model equations presented in the previous section. The main assumptions of the model (from Meyer and Bazan, 2011) are as follows: (1) Fractures are discrete and may or may not interact with one another; (2) The primary hydraulic fracture is generated in the $\mathrm{x}-\mathrm{z}$ plane and propagates perpendicularly to the minimum horizontal stress (sometimes referred to as $S_{h \min }$ ); (3) The DFN fractures are in the y-z and x-y planes and propagate perpendicular to $\sigma_{2}$ and $\sigma_{1}$, respectively; (4) The DFN may include secondary fractures in all 3 of the principal planes; (5) The model's boundary conditions allow for the natural fracture system to create multiple hydraulic fractures; (6) Hydraulic fractures will only propagate in the secondary planes $(y-z$ and $x-y)$ if the fracture pressure driving propagation is greater than the minimum horizontal stress in the particular plane; (7) It is only possible for other hydraulic fractures (not the primary hydraulic fracture) to 
form in the same plane if a DFN in the $y-z$ plan is first created. This means that the fractures must be connected in the discrete fracture network; (8) The numerical solution for this DFN model is based on the P3D ellipsoidal equations, discussed in the previous section. The fracture's stimulated reservoir volume (SRV) and the geometric details will be ellipsoidal in shape; (9) The width and height profiles in the DFN model are also calculated from governing P3D pressure-width-height relationships; (10) The fundamental DFN model solution methodology is based on satisfying the equations of continuity, mass conservation, constitutive relationships and momentum, which are all solved numerically. More information on the assumptions of this model can be found elsewhere (Meyer and Bazan, 2011; Baker Hughes Reservoir Software, 2015).

The width-opening-pressure constitutive relationship for fractures in each of the principal planes $(\zeta)$ is taken from Perkins and Kern (1961), Meyer (1986), and Meyer and Hagel (1989) and is shown below:

$$
w_{\zeta}(x, y, z)=\Gamma_{w} \frac{2 H_{\zeta}\left(p_{\zeta}-\sigma_{\zeta}\right)}{E^{\prime}}=\Gamma_{w} \frac{2 H_{\zeta} \Delta p_{\zeta}}{E^{\prime}} \ldots \ldots \ldots \ldots \ldots
$$

Where

$w_{\zeta}$ is the fracture width

$\Gamma_{w}$ is the generalized influence function

$H_{\zeta}$ is a characteristic fracture half-height

$p_{\zeta}$ is the fracture pressure

$E^{\prime}$ is the effect elastic (Young's) modulus and $E^{\prime}=E /\left[2\left(1-v^{2}\right)\right]$

$\sigma_{\zeta}$ is the confining stress 
$\Delta p_{\zeta}=p_{\zeta}-\sigma_{\zeta}$ is the net fracture pressure for each discrete fracture in each of the three principal planes $(\zeta)$

The discrete fracture network momentum equation for a steady, incompressible laminar flow in a narrow ellipsoidal slot, where the major radius, a, is significantly larger than the minor radius, $b$, for a power-law fluid can be written as follows (Meyer and Bazan, 2011):

$$
\frac{d p}{d x}=-\left(\frac{2 n^{\prime}+1}{4 n^{\prime}}\right)^{n \prime} \frac{k^{\prime}\left(\frac{q}{a}\right)^{n \prime}}{\Phi\left(n^{\prime}\right)^{n \prime} b^{2 n^{\prime}+1}}
$$

where

$$
\begin{array}{r}
\Phi\left(n^{\prime}\right)=\int\left(1-\zeta^{2}\right)^{\mu-1} d \zeta=0.5 B(0.5, \mu)=0.5 \frac{\Gamma(0.5) \Gamma(\mu)}{\Gamma(\mu+0.5)} \ldots \\
\mu=\left(4 n^{\prime}+1\right) /\left(2 n^{\prime}\right) \ldots \ldots \ldots \ldots \ldots \ldots \ldots \ldots \ldots \ldots \ldots
\end{array}
$$

Equation 4.30 can be rewritten and solved for the net fracture flow rate (q) as follows (Meyer and Bazan, 2011):

$$
q=\left(\frac{4 n^{\prime}}{2 n^{\prime}+1}\right) \frac{\Phi\left(n^{\prime}\right) a b^{2+1 / n \prime}}{k^{\prime 1 / n^{\prime}}}\left(\frac{\Delta p}{L}\right)^{\frac{1}{n^{\prime}}}
$$

where

$\mathrm{L}$ is the length of the fluid front in the elliptical slot

The net slot flow rate, $\mathrm{q}$, for a constant cross-sectional area, given as $\pi \mathrm{ab}$, is shown below:

$$
q=\pi a b \frac{\Delta L}{\Delta t}
$$


If Equation 4.31 is substituted into Equation 4.30, the following equation is obtained:

$$
\frac{\Delta L}{\Delta t}=\left(\frac{4 n^{\prime}}{2 n^{\prime}+1}\right) \frac{\Phi\left(n^{\prime}\right) b^{1+1 / n \prime}}{\pi k^{\prime 1 / n \prime}}\left(\frac{\Delta p}{L}\right)^{\frac{1}{n \prime}}
$$

where

$\Delta \mathrm{L}$ is the change in the fluid front position over the time step $\Delta \mathrm{t}$

The relationship which governs the fluid front in terms of the slot width (or 2b) and the pressure differential $(\Delta \mathrm{p})$ is shown below (Meyer and Bazan, 2011):

$$
\Delta L \cdot L^{\frac{1}{n^{\prime}}}=\left(\frac{4 n^{\prime}}{2 n^{\prime}+1} \cdot \frac{\Phi\left(n^{\prime}\right)}{\pi}\right) \frac{\Delta t}{k^{\prime 1 / n \prime}} b^{1+1 / n^{\prime}} \Delta p^{1 / n^{\prime}}
$$

The fluid front for two different slots with two different slot widths and pressure drops can be found by modifying Equation 4.36 as follows (Meyer and Bazan, 2011):

$$
\Delta L_{2} \cdot L_{2}^{\frac{1}{n^{\prime}}}=\Psi \cdot \Delta L_{1} \cdot L_{1}^{1 / n \prime}
$$

where

$$
\Psi=\left(\left(\frac{b_{2}}{b_{1}}\right)^{1+n^{\prime}} \frac{\Delta p_{2}}{\Delta p_{1}}\right)^{1 / n \prime}
$$

Turbulent flow, time dependent cross-sectional area, DFN interaction, discrete fracture network characteristic, proppant distribution, and other underlying equations utilized in this numerical model can be found elsewhere (Meyer and Bazan, 2011; Baker Hughes Reservoir Software, 2015). 


\section{CHAPTER 5 : NUMERICAL MODELING OF HYDRAULIC FRACTURING}

\subsection{Objectives of Numerical Modeling}

The current study involves the field monitoring of hydraulic fractures through seismicity/microseismicity using an array of geophones previously described in Chapter 2. Numerical modeling of hydraulic fracturing operations in and around the Marcellus shale at the MSEEL project site is also involved in the current study. When fluids and proppant are injected into a shale reservoir, a network of hydraulically-induced fractures are created and activated. Some of these fractures are created through the hydraulic fracturing process while others are already naturally present in the shale ( $\mathrm{J} 1$ and $\mathrm{J} 2$ shale fracture sets), as discussed by Engelder et al. (2009) and Cruz et al. (2016), among many others. The creation of the fracture "network" that occurs during hydraulic fracturing operations in shale reservoirs is dependent upon many reservoir characteristics, including geomechanical properties of the reservoir itself and the surrounding geologic layers.

Numerical modeling of the hydraulic fracturing operations at the MSEEL project site provides a better understanding of the fracture network created in order to extract natural gas in the Marcellus shale. The following are some of the numerical modeling objectives for the current study:

- Compute hydraulic fracture/network dimensions and compare these to the field measurements using seismic/microseismic monitoring data.

- Compute surface/bottom-hole treating pressures and compare these with field measurements. 


\subsection{Numerical Methodology}

Pseudo three-dimensional (P3D) discrete fracture network numerical modeling was utilized to perform necessary computations in order to compare with measurements from the MSEEL project site. These models have been widely used for hydraulic fracture designs because of their ease and computational efficiency (Zhang et al., 2017). P3D models have been shown to be effective in replicating the results of more complex fully 3D models, while saving computational time (Weng, 1992; Brady et al., 1992; Adachi et al., 2007; Dontsov and Peirce, 2015; Zhang et al., 2017). Additionally, Zhang et al. (2017) states that due to the plain strain assumption, "P3D models should be used for fractures that grow more in length than in height." It can be seen from the preliminary stages presented in this chapter that both the microseismic event clouds and modeled fractures display greater fracture lengths than fracture heights. P3D models and other models based on similar assumptions and governing equations have been developed to account for naturally fractured shale reservoirs as well (Jacot et al., 2010; Meyer and Bazan, 2011; Kresse et al., 2013). A review of recently developed hydraulic fracturing models can be found elsewhere (Weng, 2015).

The numerical model for the current study was built using available field data including geologic layer data and treatment schedules. Data on layer thickness for every individual stage at the project site is unavailable. There will be some variation in the layer thicknesses at the MSEEL project site; however, for numerical modeling purposes, all layers in the vicinity of the Marcellus shale for all stages at both wells are assumed to have constant layer thickness. The only layer that changes its thickness in this model will be the 
overburden layer. This is done in order to keep the injection point at an accurate depth based on available wellbore data.

Figure 5.1 shows the cross-section of the geologic strata and the wellbore. The green area in the Marcellus shale layer is the target landing area for the wellbore. Several layers surrounding the Marcellus shale are also present in the Figure 5.1, including the Onondaga shale, Hamilton shale, and the Tully limestone. Numerical modeling was performed using a commercially available software known as MShale (Baker Hughes Reservoir Software, 2015). Mathematical details on the numerical modeling utilized for the current work can be found elsewhere and will be included in the full dissertation work (Jacot et al., 2010; Meyer and Bazan, 2011; Baker Hughes Reservoir Software, 2015). 


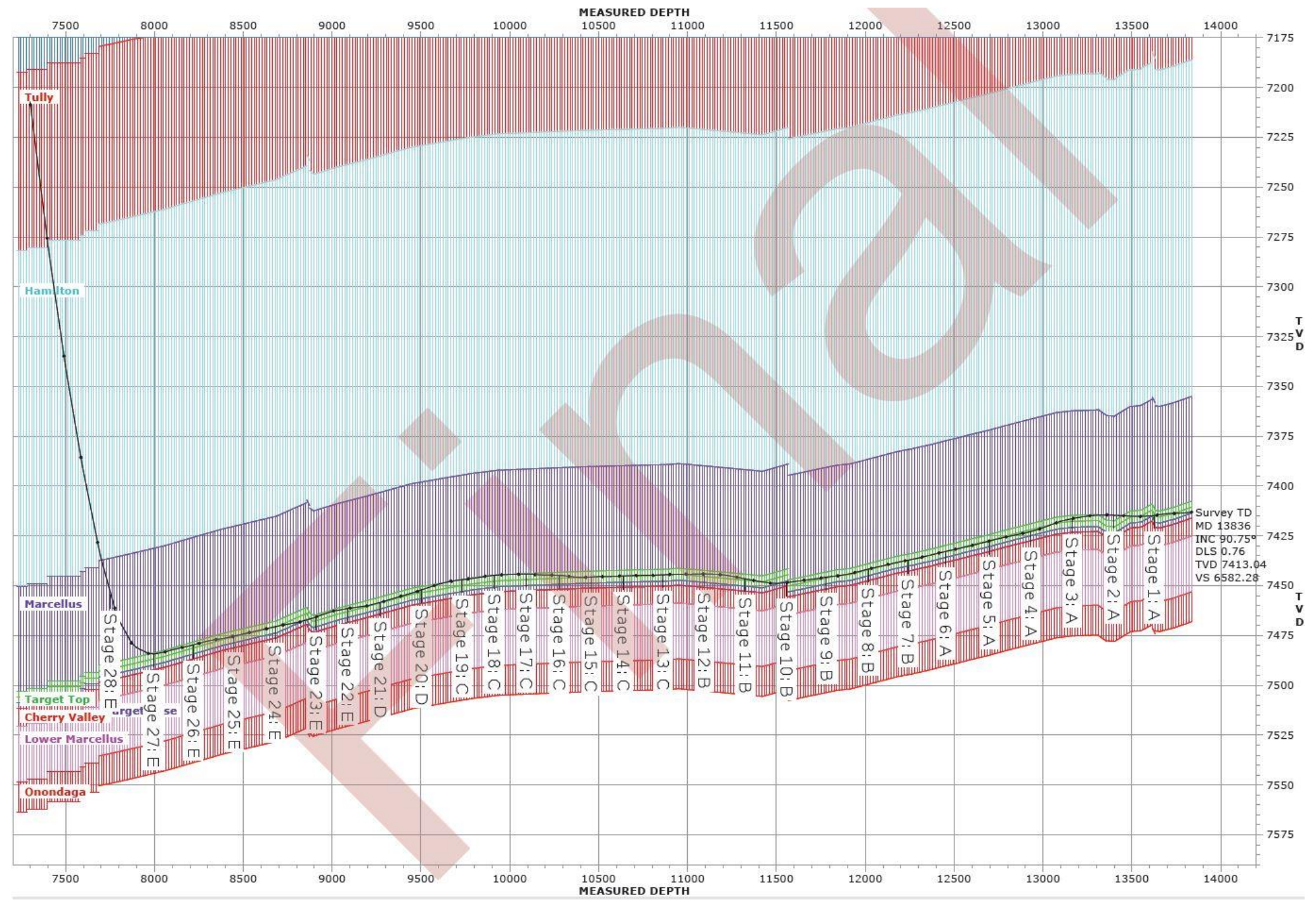

Figure 5.1: MIP-3H Wellbore Measured Depth vs TVD with Geologic Strata (Northeast Natural Energy, 2015) 


\subsection{Numerical Modeling Construction and Results}

\subsubsection{Model Construction}

The properties used in the numerical model are based on available properties obtained from the MSEEL project field site. The numerical model was built in a series of steps which each focused on a different aspect of the field site. The first step in building the numerical model was to define the options necessary for the current application of hydraulic fracturing in the low-permeability Marcellus shale formation with the available field data. A few of the numerical model options are mentioned here. A classic linear fluid loss model developed by Carter (1957) was deemed appropriate for the field application. This model assumes one-dimensional fluid loss due to the fact that the leakoff distance perpendicular to the fracture face is small compared to the fracture length. Carter's model is used for most applications and is the most commonly used model for propagating hydraulic fractures (Baker Hughes Reservoir Software, 2015). The total leakoff coefficient determines the rate at which fluid is lost to the surrounding formation. A constant fluid loss model was assumed for this application as data on the total leakoff coefficient was available. As previously mentioned, a pseudo three-dimensional planar fracture model was used with a discrete fracture network. This model will generally predict the most realistic fracture geometries when compared with two-dimensional models. An empirical model was utilized to predict the settling of proppant within hydraulic fractures. More details on this empirical model can be found in the literature (Bird et. al., 1965).

Wellbore survey data available from the field was utilized in the numerical model to accurately represent the wellbore path and depth information. Figure 5.2 shows the cross section of the MIP-3H wellbore, as used in the current study. 


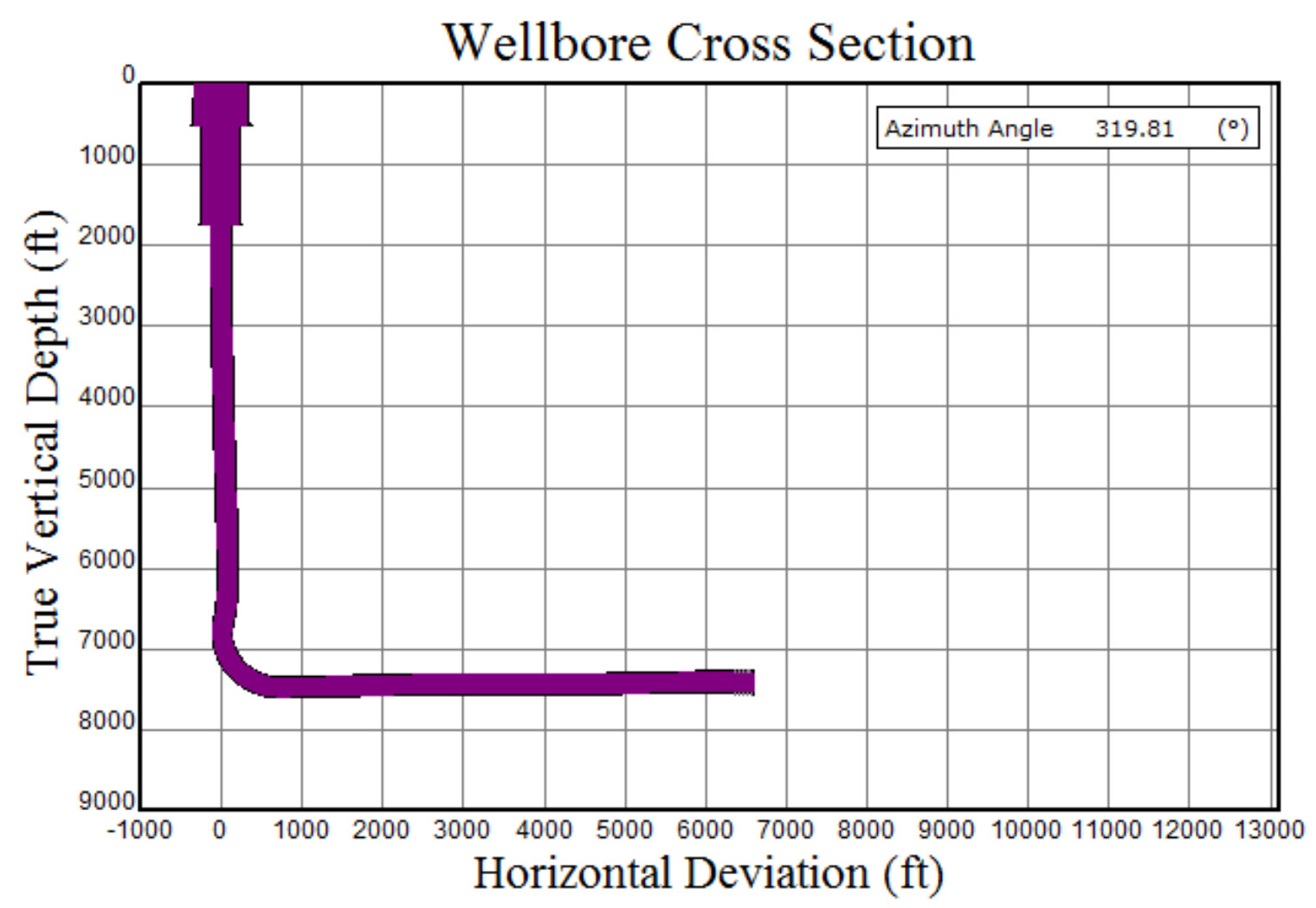

Figure 5.2: Wellbore Cross-Section used for Well MIP-3H in the Numerical Model

Perforation cluster zone data was also available from field data. The number of zones ranged from three to five per hydraulic fracture stage. The diameter of perforations utilized in the numerical model was 0.42 inches. The permeability of the pay zone in the numerical model was in the range of $3 \times 10^{-4} \mathrm{mD}$.

The development of the treatment schedule for use in the numerical model was a time-consuming task. Field data for every second of the hydraulic fracture treatment was available, including slurry rates, clean fluid rates, proppant concentrations, and cumulative proppant masses (for both the 100 mesh and the $40 / 70$ mesh proppants, as well as the total proppant masses). This field data needed to be condensed into a series of steps for input into the numerical model treatment schedule. Each step includes the current values for the slurry rate, liquid volume, time, type of stage (pad, proppant, flush, etc.), type of fluid being 
injected, type of proppant being injected, and proppant concentration, among other treatment parameters. Each of these parameters were determined from the raw data ( 10,000+ lines for each stage) for a series of approximately 20 to 40 steps (depending on the stage) for each of the 28 hydraulic fracture stages at well MIP-3H and 30 hydraulic fracture stages at well MIP-5H. An iterative process was then utilized for each stage in order to match the created numerical model treatment schedule as closely as possible with the raw field treatment data. After several iterations for each stage, the slurry rates, slurry volumes, proppant concentrations, and cumulative proppant masses were compared to ensure a good match with measured field data. Figure 5.3 shows the relation between the measured and numerical model treatment slurry rates for a typical stage at well MIP-3H. Figure 5.4 shows the relation between the measured and numerical model treatment slurry volumes for a typical stage at well MIP-3H. Figure 5.5 shows the relation between the measured and numerical model treatment proppant concentrations for a typical stage at well MIP-3H. Figure 5.6 shows the relation between the measured and numerical model treatment proppant masses for a typical stage at well MIP-3H. Figure 5.7 shows the relation between the measured and numerical model treatment slurry rates for a typical stage at well MIP-5H. Figure 5.8 shows the relation between the measured and numerical model treatment slurry volumes for a typical stage at well MIP-5H. Figure 5.9 shows the relation between the measured and numerical model treatment proppant concentrations for a typical stage at well MIP-5H. Figure 5.10 shows the relation between the measured and numerical model treatment proppant masses for a typical stage at well MIP-5H. 


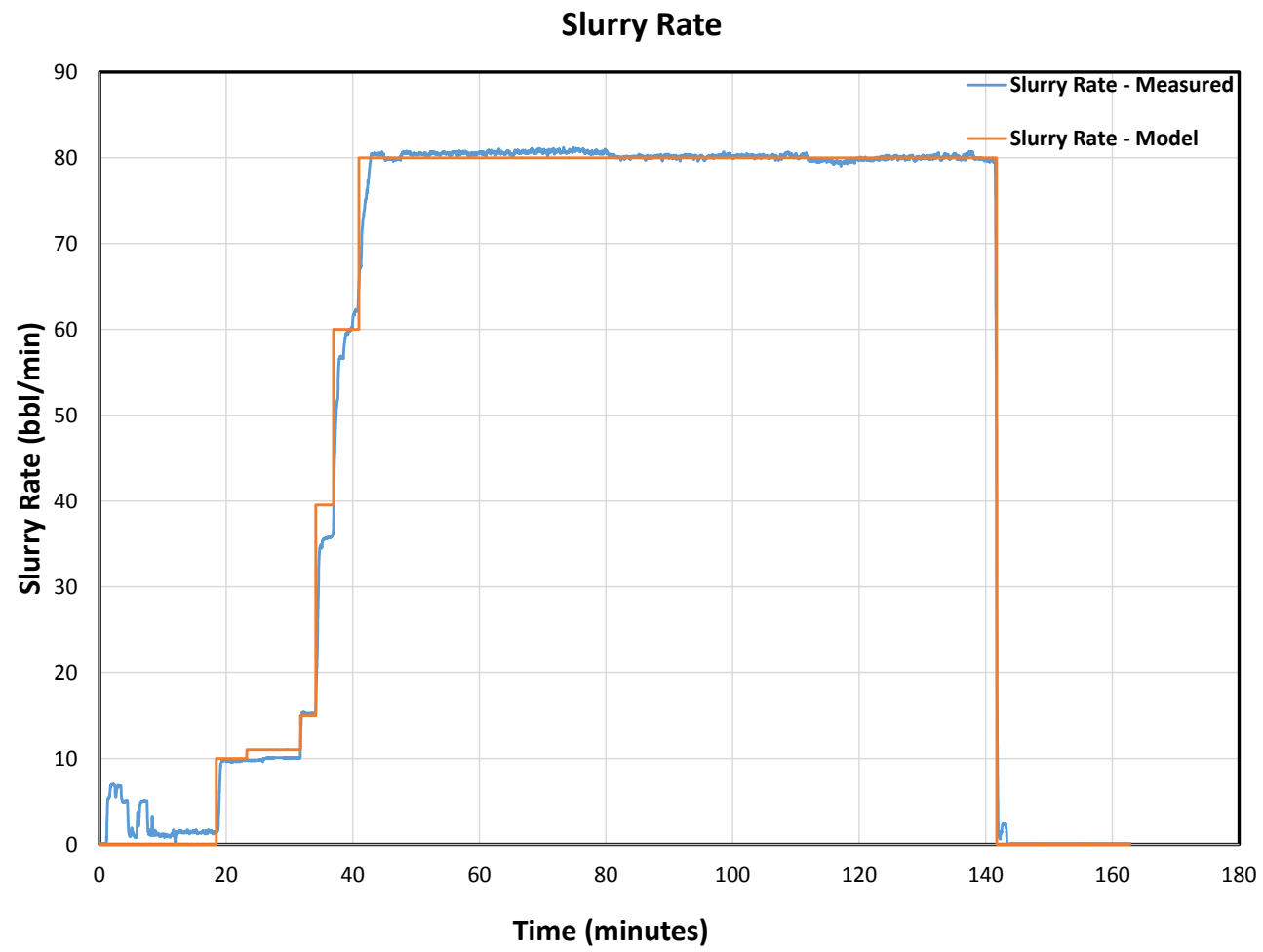

Figure 5.3: Typical Slurry Rate vs Time - Measured and Model Calculations - MIP3H

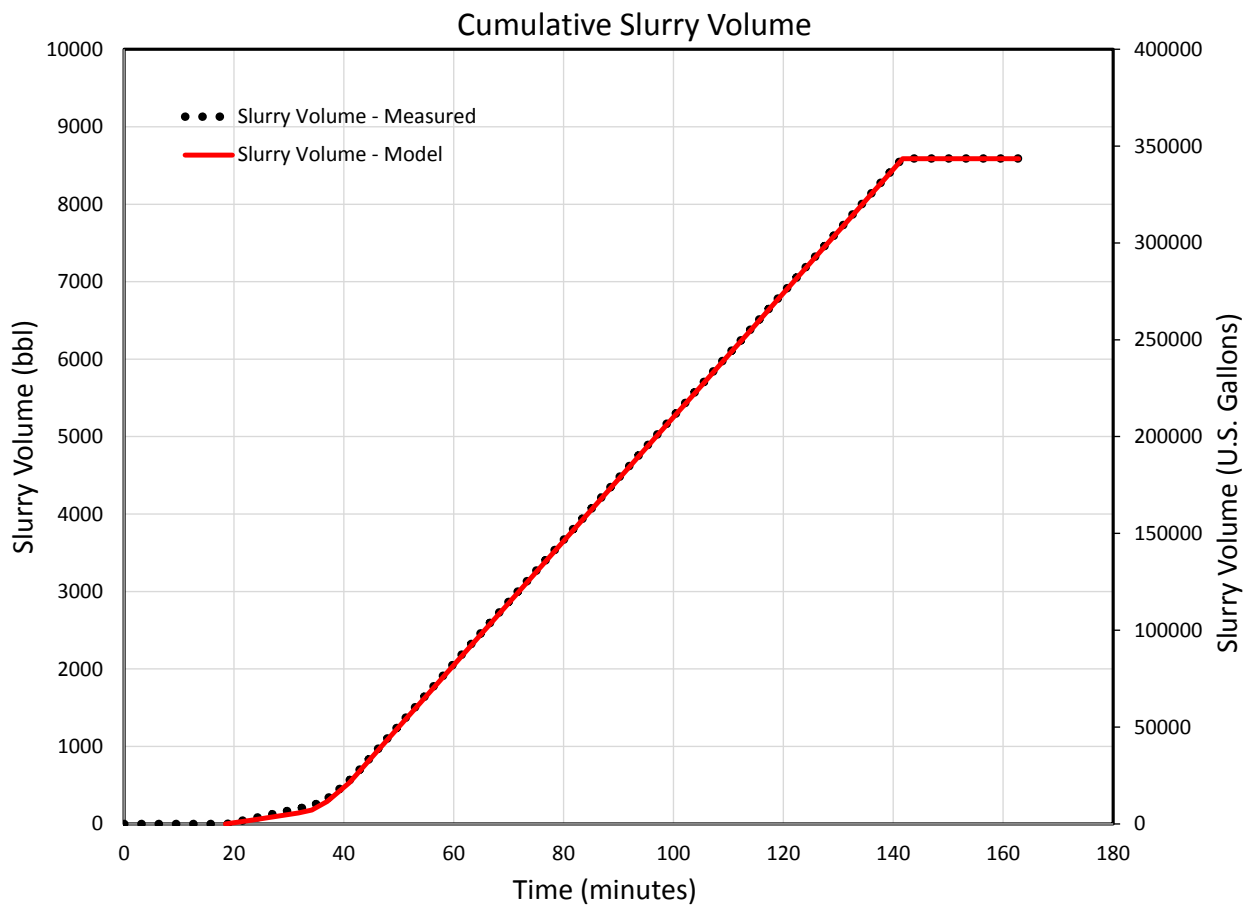

Figure 5.4: Typical Cumulative Slurry Volume vs Time - Measured and Model Calculations - MIP-3H 


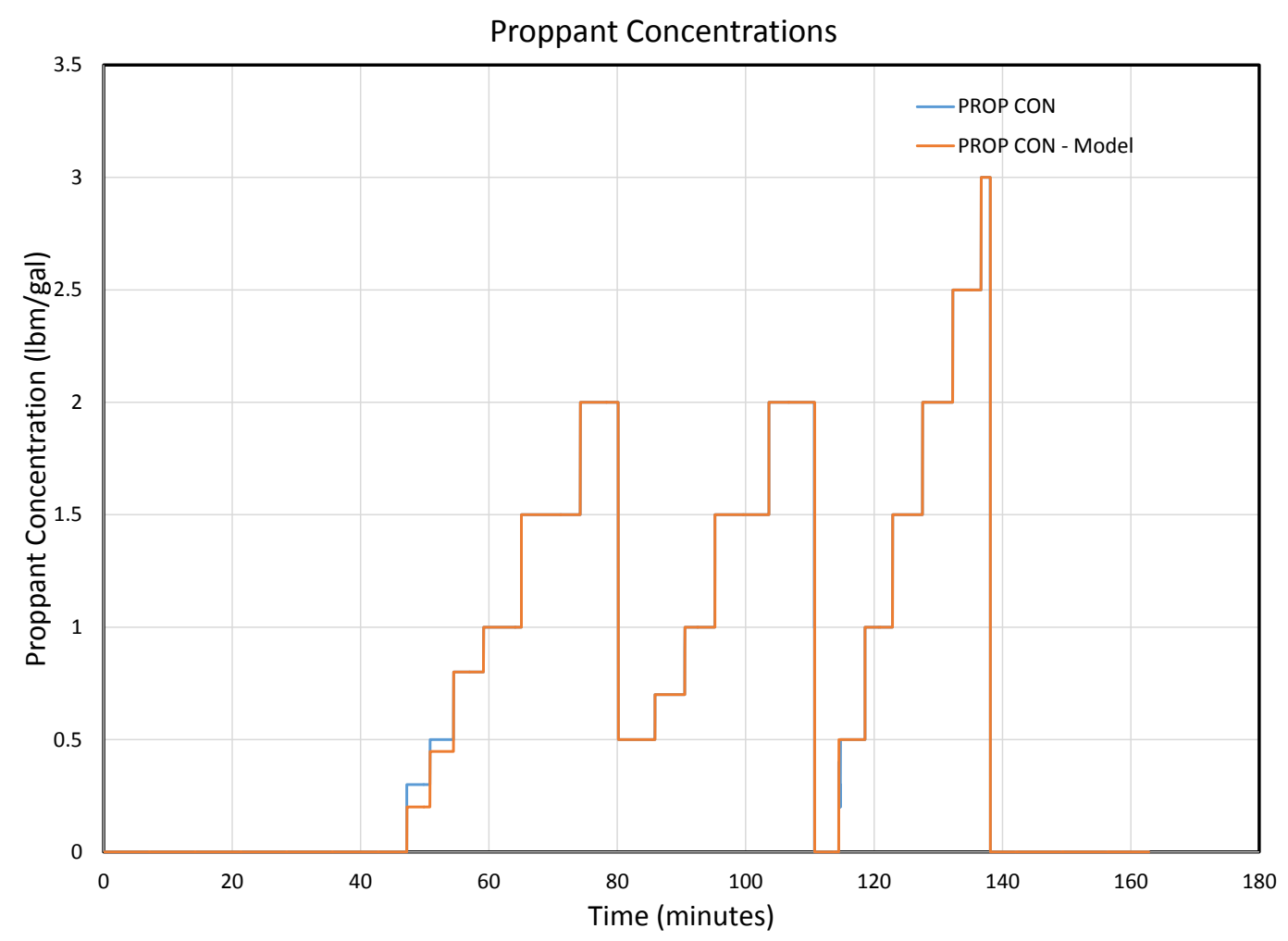

Figure 5.5: Typical Proppant Concentration vs Time - Measured and Model Calculations - MIP-3H

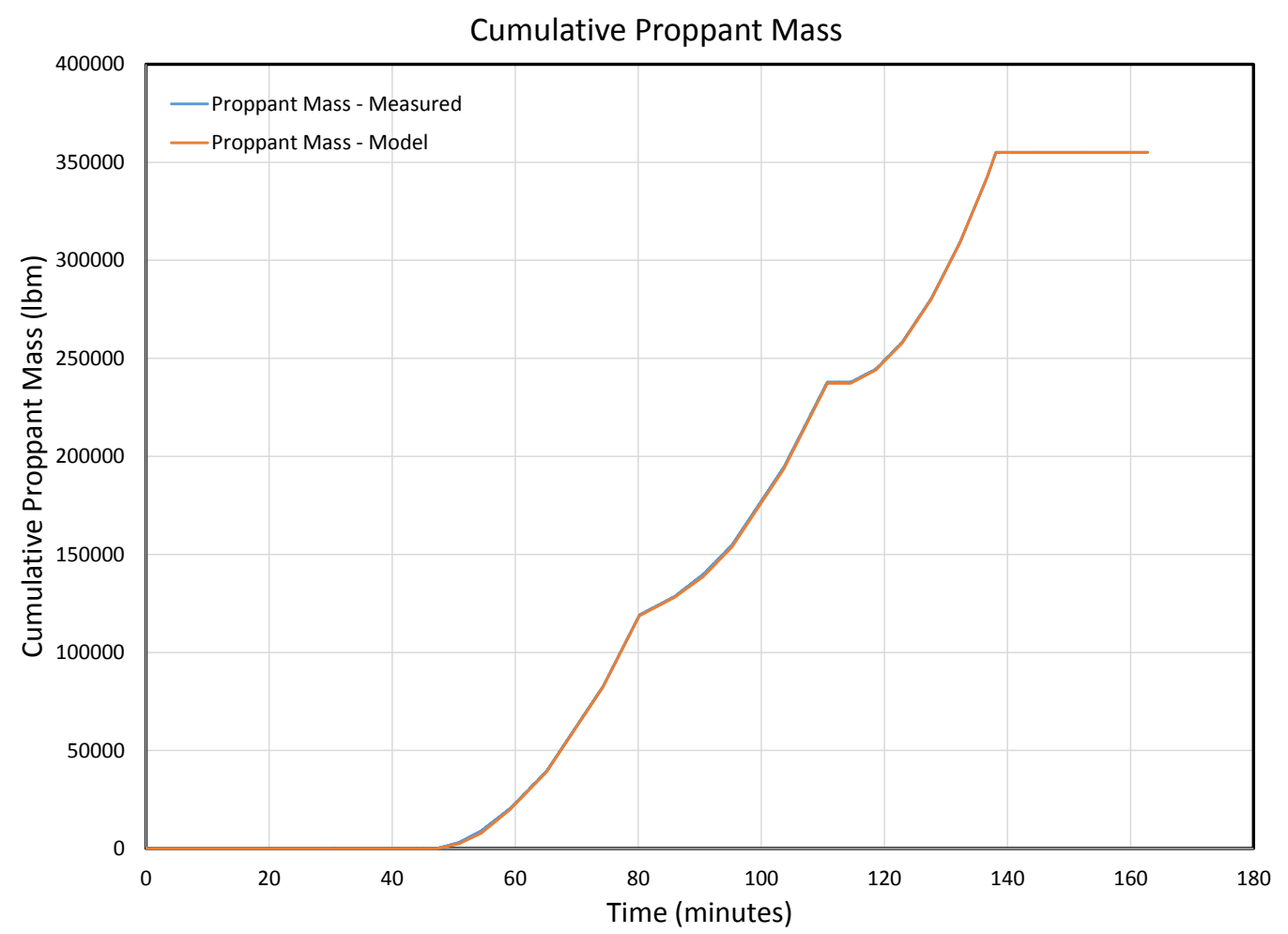

Figure 5.6: Typical Cumulative Proppant Mass vs Time - Measured and Model Calculations - MIP-3H 


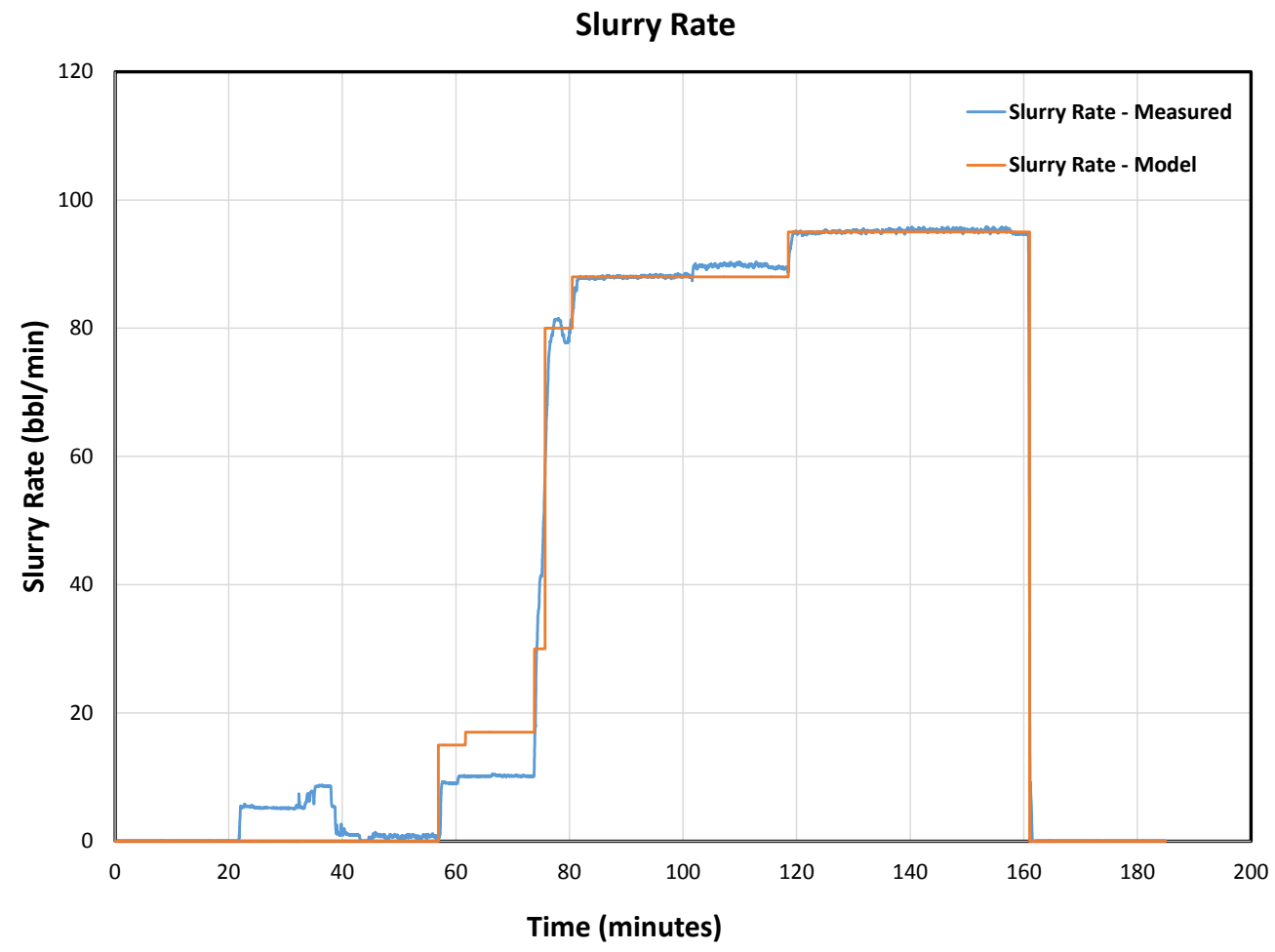

Figure 5.7: Typical Slurry Rate vs Time - Measured vs Model Calculations - MIP$5 \mathrm{H}$

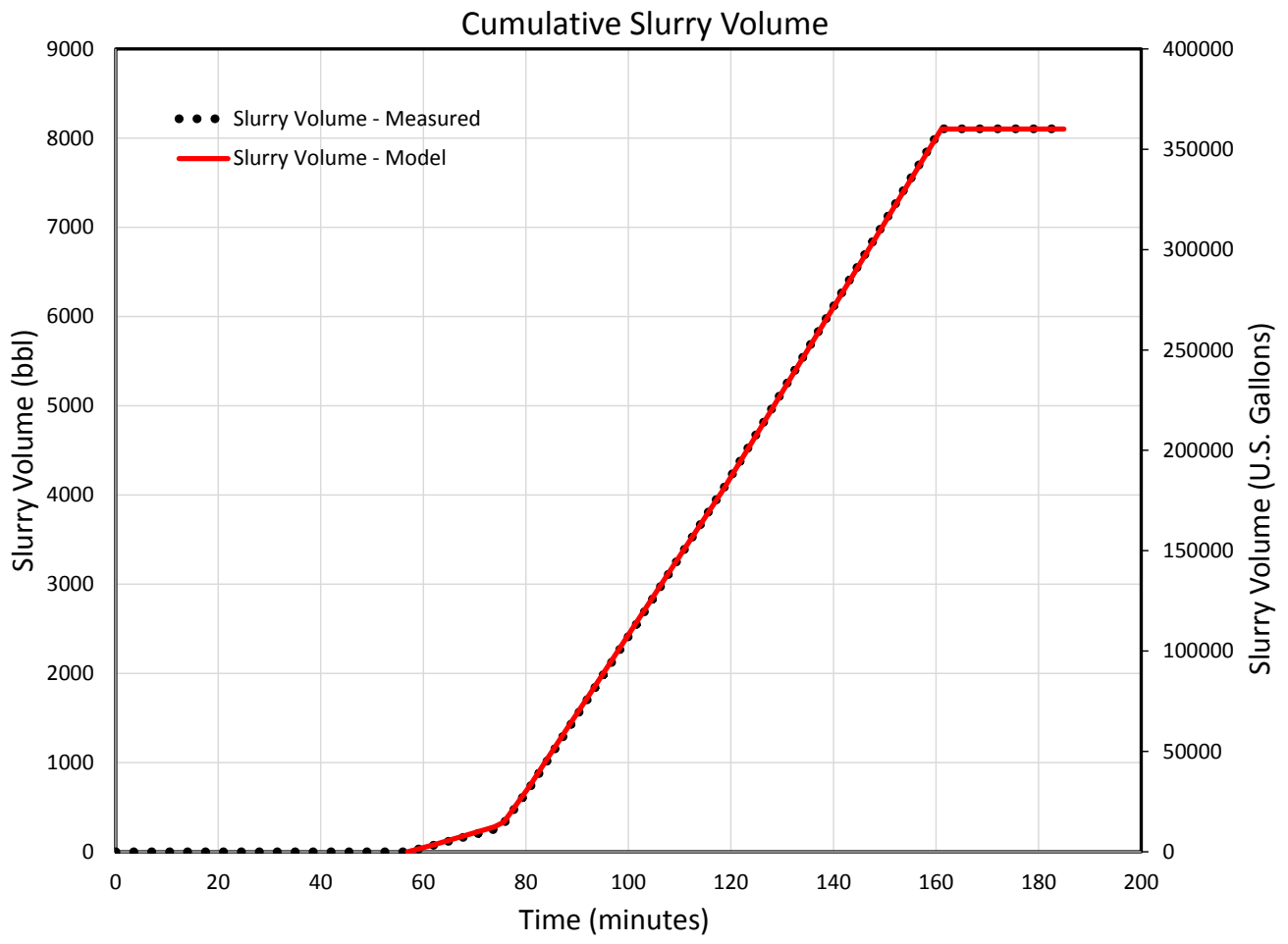

Figure 5.8: Typical Cumulative Slurry Volume vs Time - Measured and Model Calculations - MIP-5H 
Proppant Concentrations

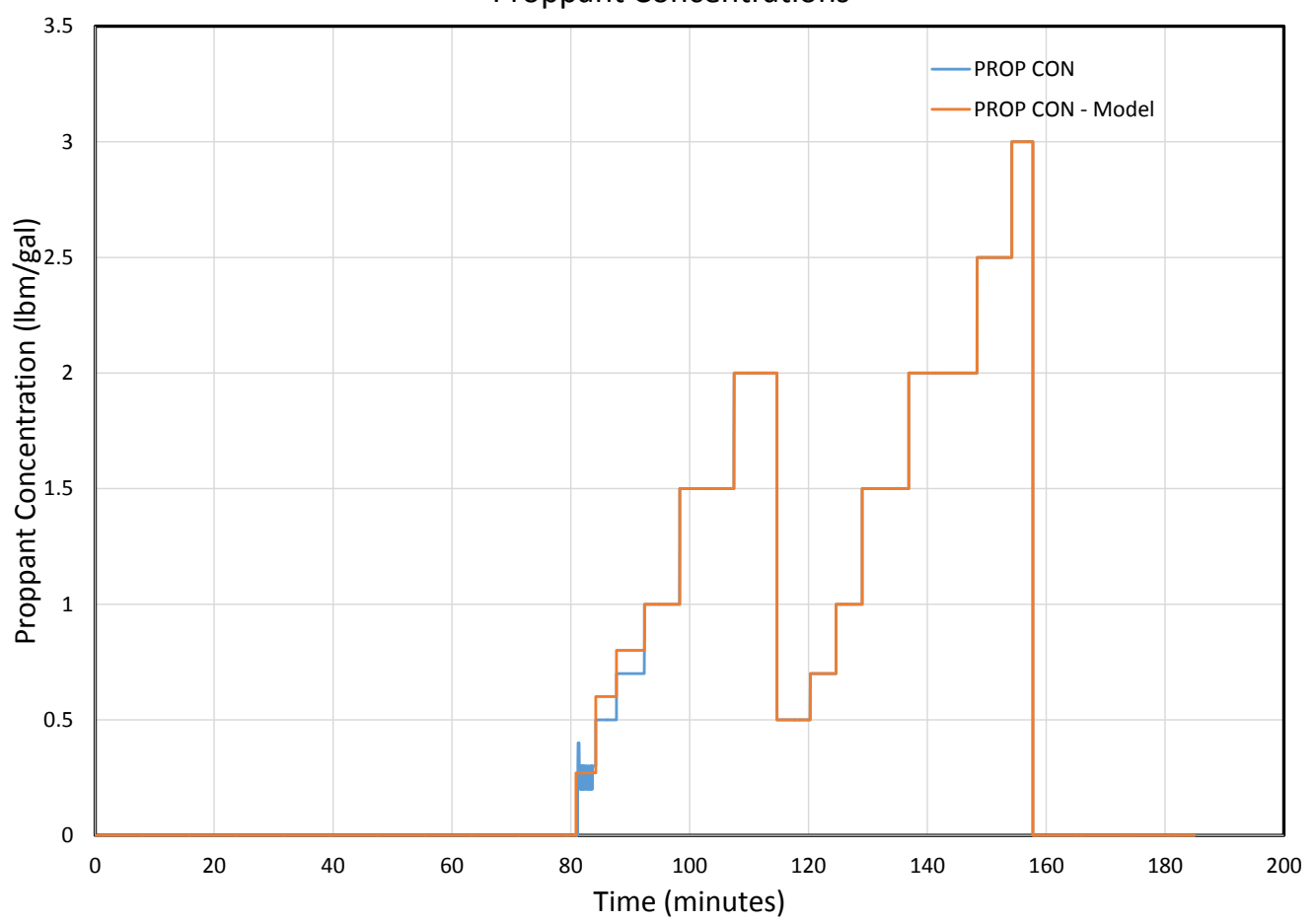

Figure 5.9: Typical Proppant Concentration vs Time - Measured and Model Calculations - MIP-5H

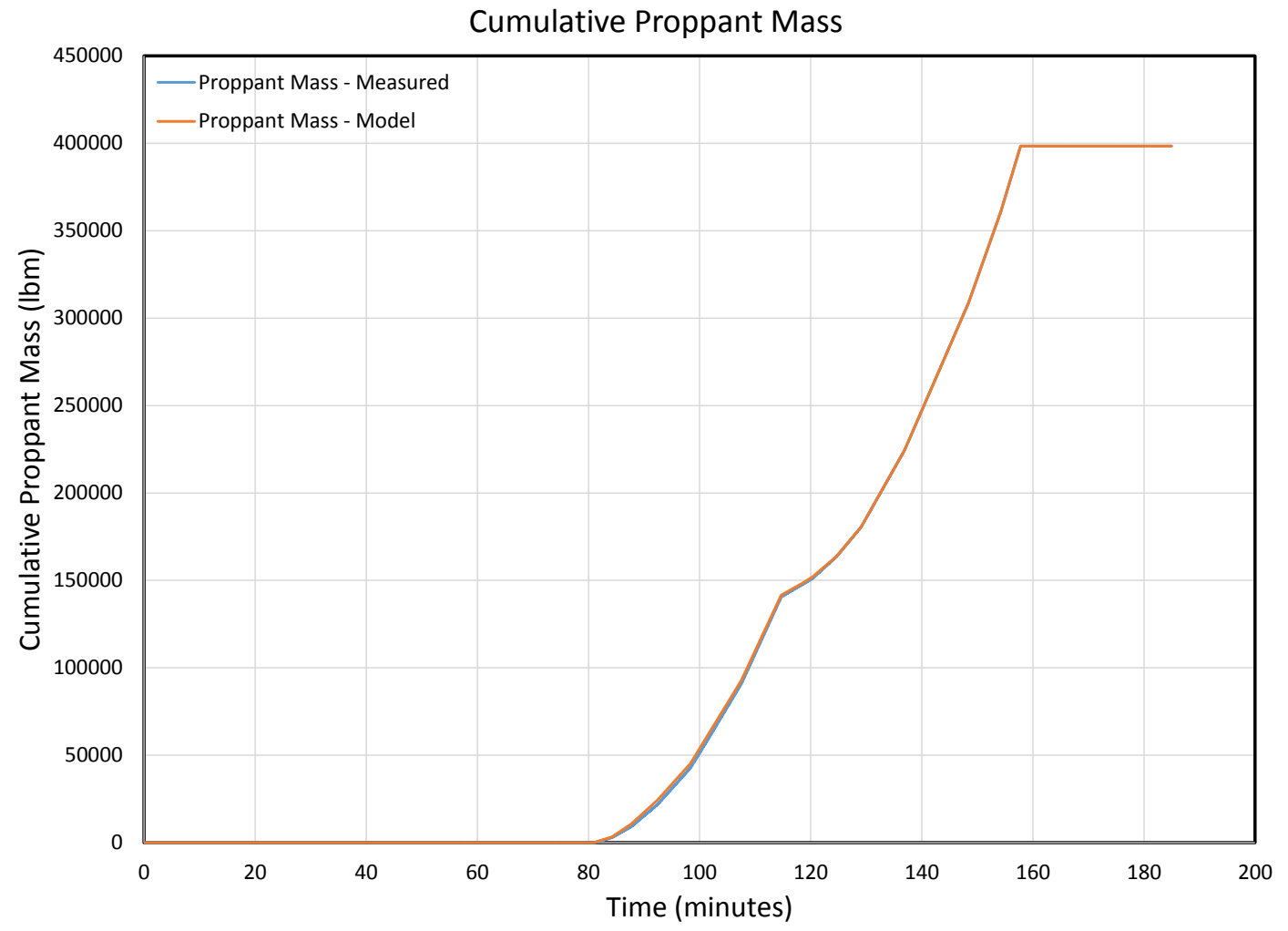

Figure 5.10: Typical Cumulative Proppant Mass vs Time - Measured and Model Calculations - MIP-5H 
The next step was to input geomechanical rock properties and the corresponding geologic layers. The layers included in the numerical modeling were those in the vicinity of the reservoir and overlying layers. These include the following layers: the overburden, Burkett shale, Tully limestone, Hamilton shale, Upper Marcellus shale, Cherry Valley limestone, Lower Marcellus shale, Onondaga limestone, and Huntersville chert. The layer in which the hydraulic fracture injection occurred is the Upper Marcellus shale layer. Geomechanical properties were available from field logs and were initially used in preliminary numerical modeling work. However, after testing with 10 randomly selected stages from both wells MIP-3H and MIP-5H it was determined that the geomechanical properties were not conducive to producing hydraulic fracture geometries which could match remotely with observed microseismic event clouds. Growth from available microseismic data showed upward hydraulic fracture growth. Typical hydraulic fracture propagation is generally upward, as well. Thus, this hydraulic fracture geometry is irregular and geomechanical rock properties taken from an in-house database based on a variety of research and literature was used for this research work. A fracture geometry from one of the aforementioned randomly selected stages used for testing using reported field estimated geomechanical log-derived properties is shown in Figure 5.11.

The final steps in building the numerical model were inputting proppant criteria and heat transfer data. Some examples of proppant criteria include the minimum number of proppant layers to prevent bridging and the minimum concentration per area to be considered a propped fracture. For the minimum number of proppant layers to prevent bridging (when proppants are unable to move further into a fracture), a value of 2 was used (Bazan, 2012). This means that for bridging to occur, the width of the fracture would have 
to decrease to twice the diameter of a proppant particle. Typically, a value of 1.5 to 3 is used in hydraulic fracturing applications (Baker Hughes Reservoir Software, 2015). The minimum concentration per area to be considered a propped fracture was set to $0 \mathrm{lbm} / \mathrm{ft}^{2}$ (Bazan, 2012). Below this concentration, the fracture will not be reported as being propped in the numerical model. This value typically ranges from 0 to $0.2 \mathrm{lbm} / \mathrm{ft}^{2}$ (Baker Hughes Reservoir Software, 2015). Heat transfer data input into the numerical model includes the following: the base fluid type, reservoir lithology, in-situ fluid type, average porosity, mean formation temperature, and injection fluid inlet temperature. This data is shown in Table 5.1 and was obtained from available field data and literature.
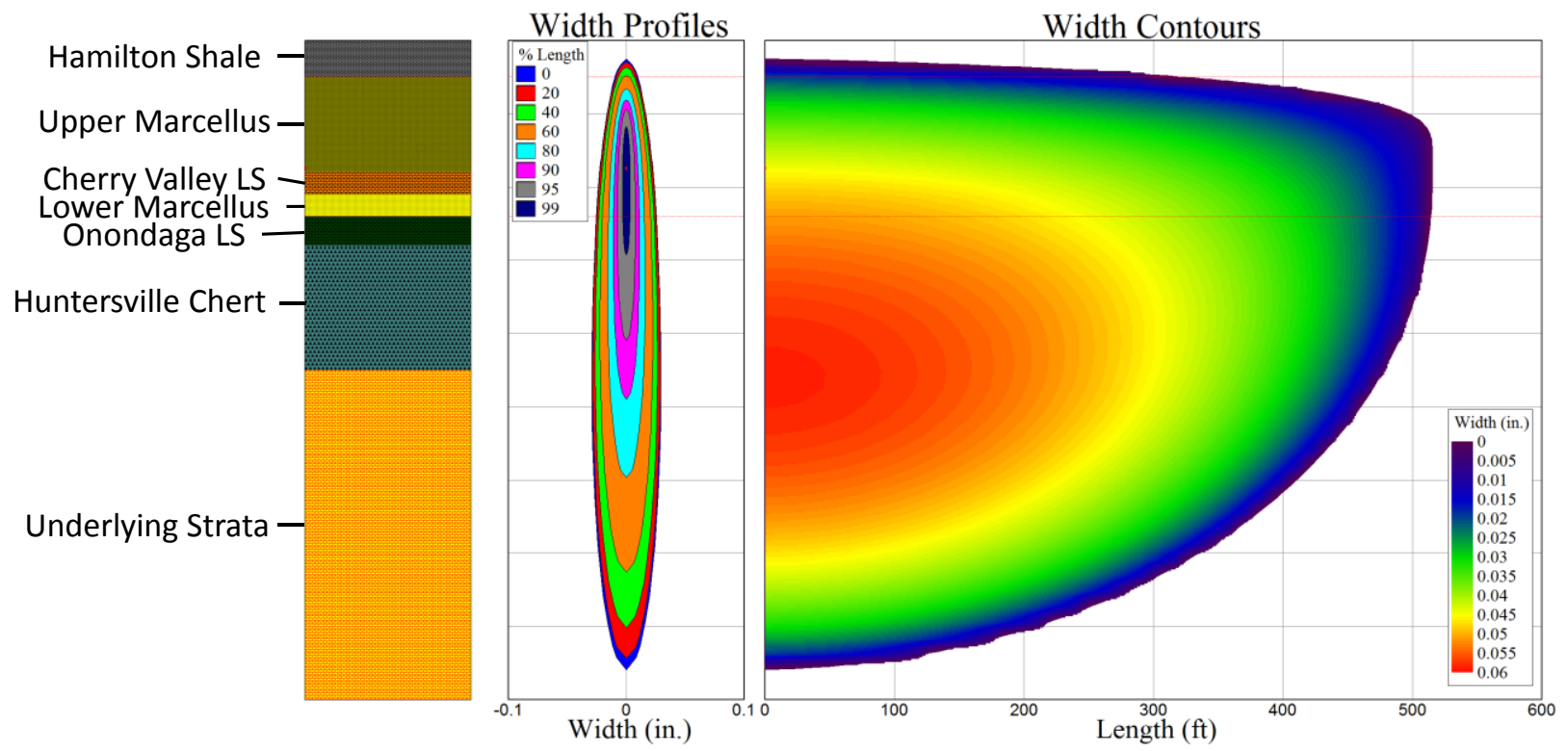

Figure 5.11: Typical Randomly Selected Stage Numerically Modeled using LogDerived Geomechanical Rock Properties - Additional Field Data was Available to Include an Extra Layer Named "Underlying Strata" 
Table 5.1: Heat Transfer Data Used in Numerical Modeling

\begin{tabular}{|c|c|c|}
\hline Property & Value & Unit \\
\hline Base Fluid Type & Water & - \\
\hline Reservoir Lithology & Shale & - \\
\hline In-Situ Fluid Type & Gas & - \\
\hline Average Porosity & 0.059 & Fraction \\
\hline Mean Formation Temperature & 161 & Degrees Fahrenheit \\
\hline Injection Fluid Inlet Temperature & 50 & Degrees Fahrenheit \\
\hline
\end{tabular}




\subsubsection{Numerical Modeling Results}

After building the numerical model, as previously described for each of the 58 stages (28 in well MIP-3H and 30 in well MIP-5H), each stage was simulated and parameters were calculated, such as the primary hydraulic fracture height, primary hydraulic fracture length, average hydraulic fracture width, and surface pressures, among other parameters. Stage 1 through 10 calculated geometric data is shown in Table 5.2. Figure 5.12 shows the fracture geometry for one of the primary induced hydraulic fractures in stage 10 of well MIP-3H. Figure 5.13 shows the cumulative proppant mass versus time (modeled vs measured), Figure 5.14 shows the slurry volume injected versus time (modeled vs measured), and Figure 5.15 shows the surface pressure versus time (modeled vs measured) for stage 10 of well MIP-3H. These figures show a good match between the numerical model and the reported data.

Microseismic data was available for four of the stages modeled in the current set shown (stages 7, 8, 9, and 10). Microseismic, well, and hydraulic fracture geometric data have been visualized in three dimensions. Figure 5.16, Figure 5.17, Figure 5.18, and Figure 5.19 show side views of calculated hydraulic fracture geometries and measured microseismic events and magnitudes for stage 7 , stage 8 , stage 9 , and stage 10 , respectively, for well MIP-3H. Figure 5.20 shows an overview of all four hydraulic fracture geometries, microseismic events, and the entire MIP-3H wellbore. Figure 5.21 shows a top view of all four hydraulic fracture geometries, microseismic events, and the nearby section of the MIP$3 \mathrm{H}$ wellbore. Figure 5.22 shows an orthogonal projection of the four hydraulic fracture geometries, microseismic events, and the nearby section of the MIP-3H wellbore. In Figure 5.16 through Figure 5.19, the measured microseismic events appear to be more prevalent 
on one side of the MIP-3H wellbore. A summary of the primary fracture half-lengths, primary fracture heights, and average primary hydraulic fracture widths for all stages at wells MIP-3H and MIP-5H are shown in Table 5.3 and Table 5.4, respectively. More details on the remaining stages at well MIP-3H and all the stages at well MIP-5H are shown in Appendix A.

Table 5.2: Primary Hydraulic Fracture Geometries - Stage 1 through Stage 10 MIP 3H

\begin{tabular}{|c|c|c|c|}
\hline STAGE & Fracture Half-Length (ft) & Calculated Fracture Height (ft) & Average Fracture Width (in) \\
\hline 1 & 705.0 & 348.0 & 0.028474 \\
\hline 2 & 647.6 & 306.7 & 0.026497 \\
\hline 3 & 659.7 & 329.9 & 0.02899 \\
\hline 4 & 684.7 & 326.9 & 0.027285 \\
\hline 5 & 594.6 & 300.1 & 0.016779 \\
\hline 6 & 698.7 & 326.5 & 0.026389 \\
\hline 7 & 687.1 & 329 & 0.027577 \\
\hline 8 & 615.5 & 355.2 & 0.021193 \\
\hline 9 & 656.7 & 335.6 & 0.029723 \\
\hline 10 & 649.6 & 332.4 & 0.03001 \\
\hline
\end{tabular}
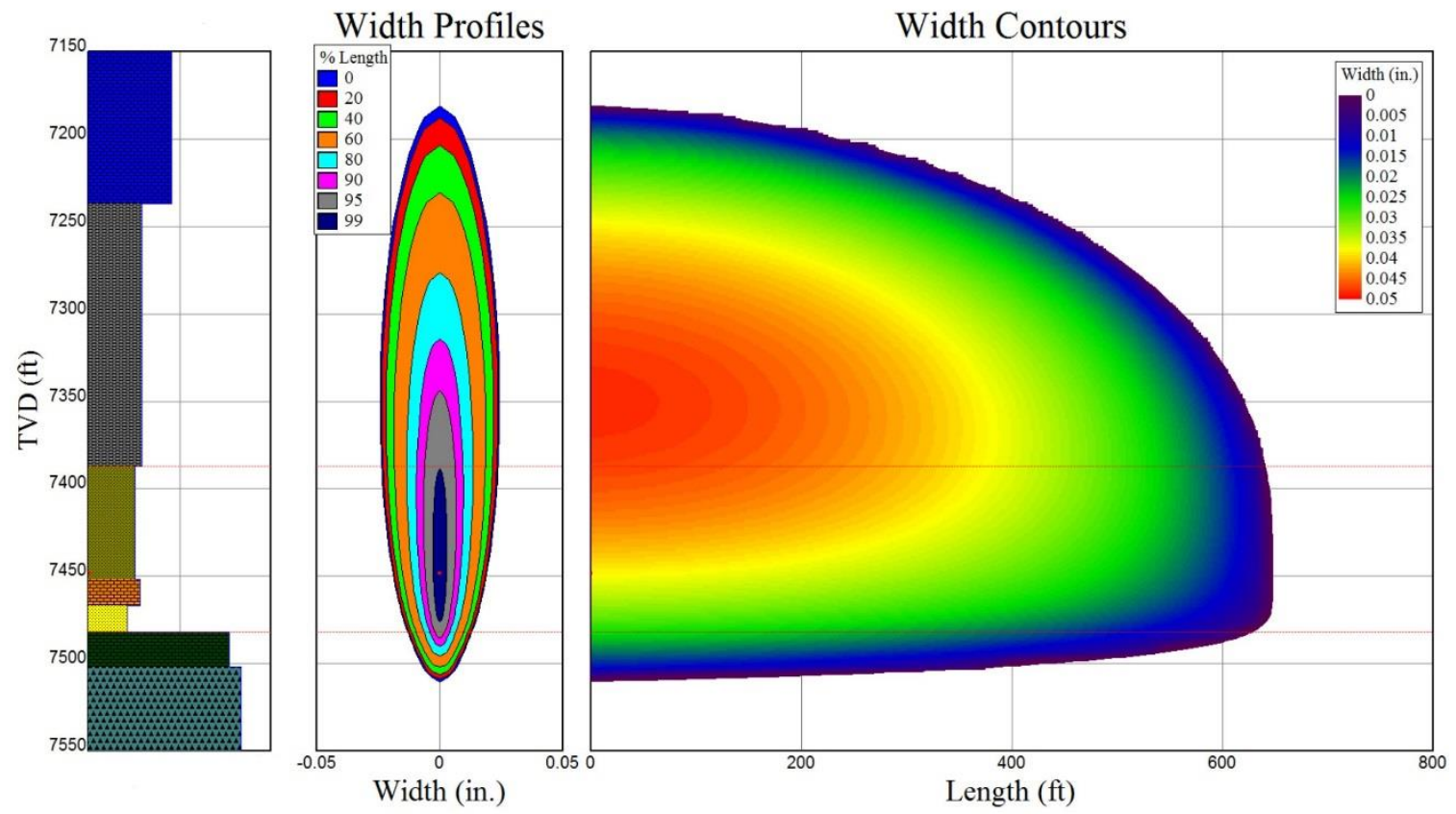

Figure 5.12: Hydraulic Fracture Geometry for Stage 10 - MIP 3H 


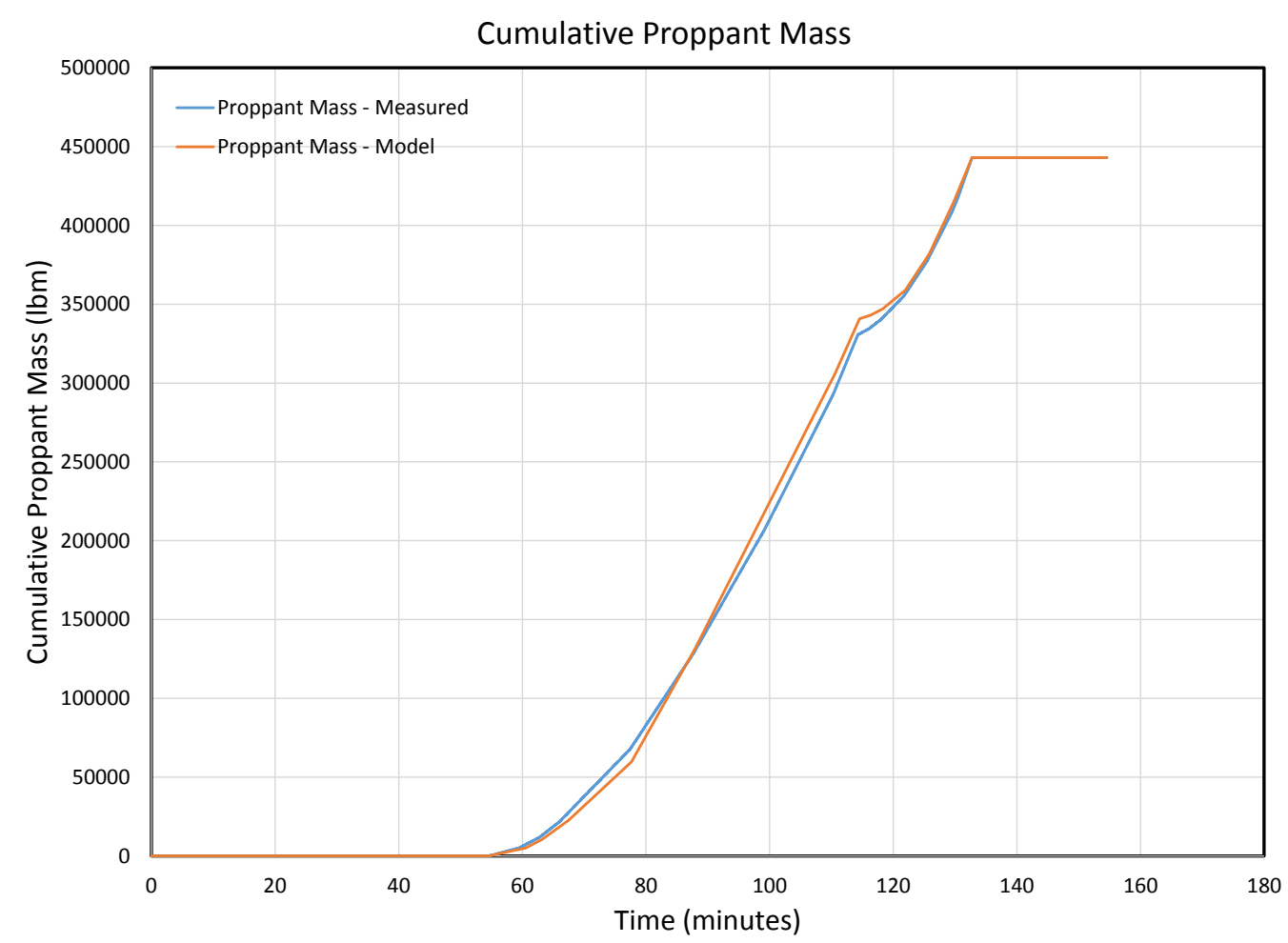

Figure 5.13: Cumulative Proppant Mass for Stage 10 - MIP 3H

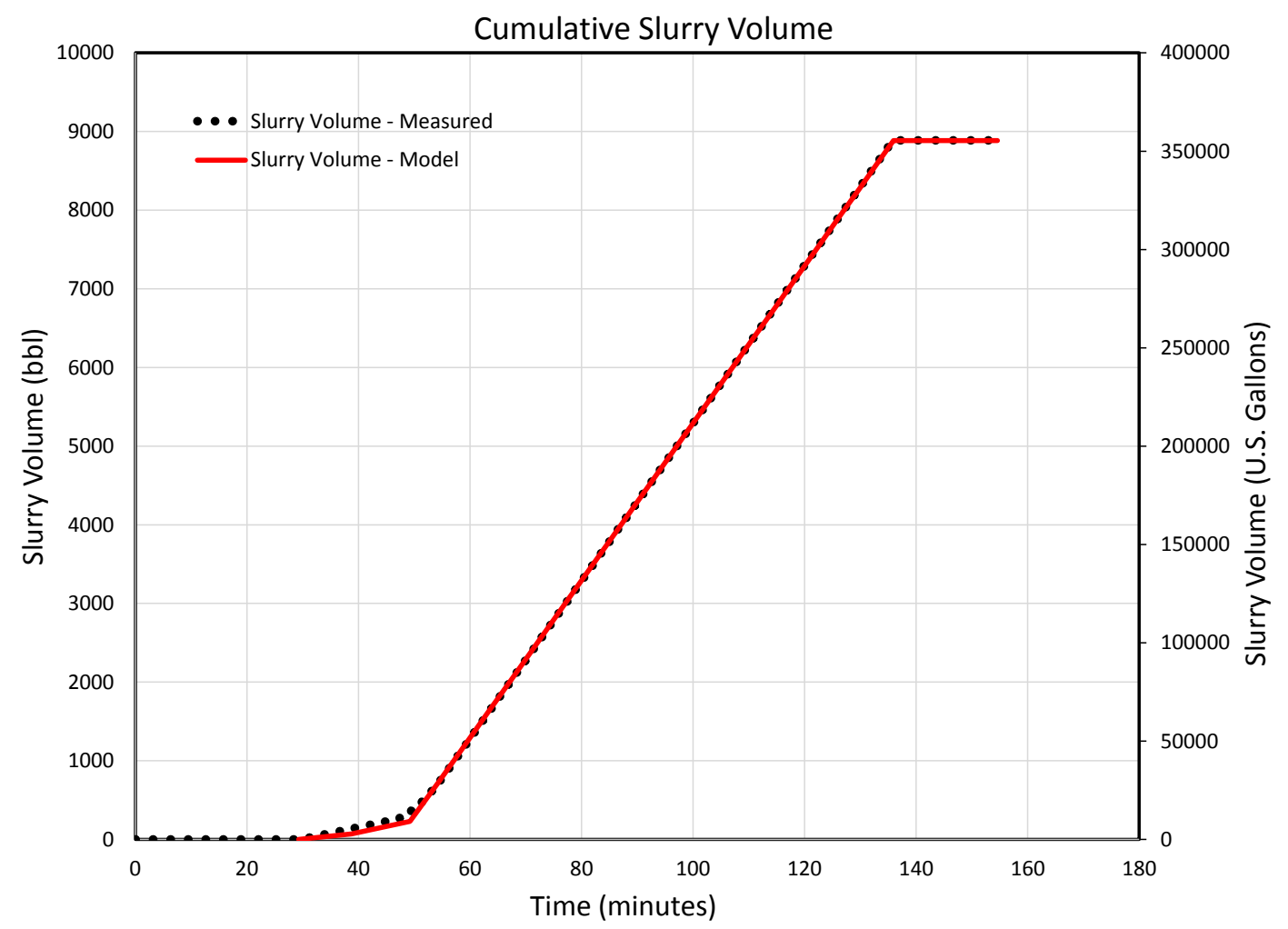

Figure 5.14: Cumulative Slurry Volume for Stage 10 - MIP 3H 


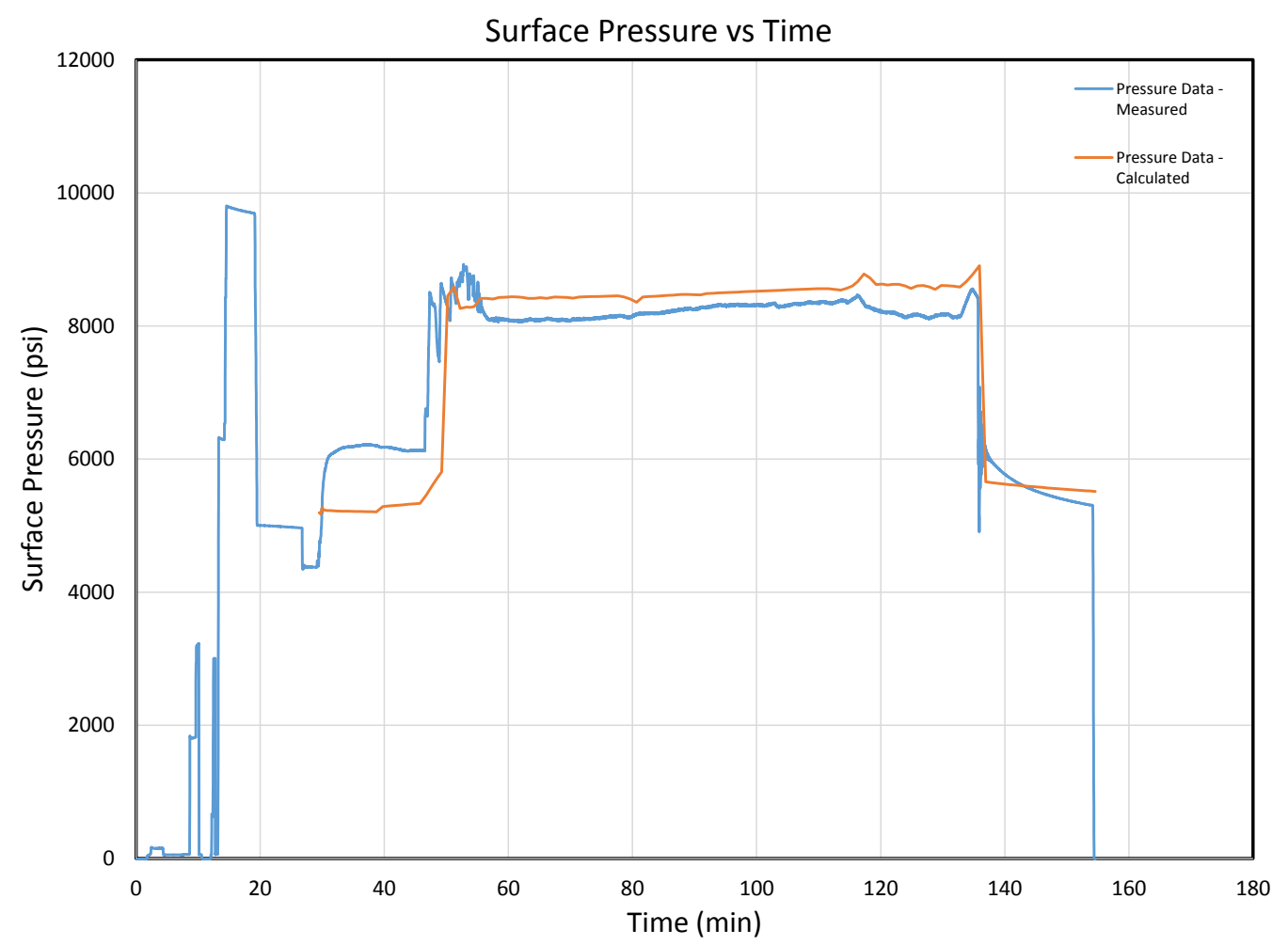

Figure 5.15: Surface Pressure versus Time for Stage 10 - MIP $3 H$

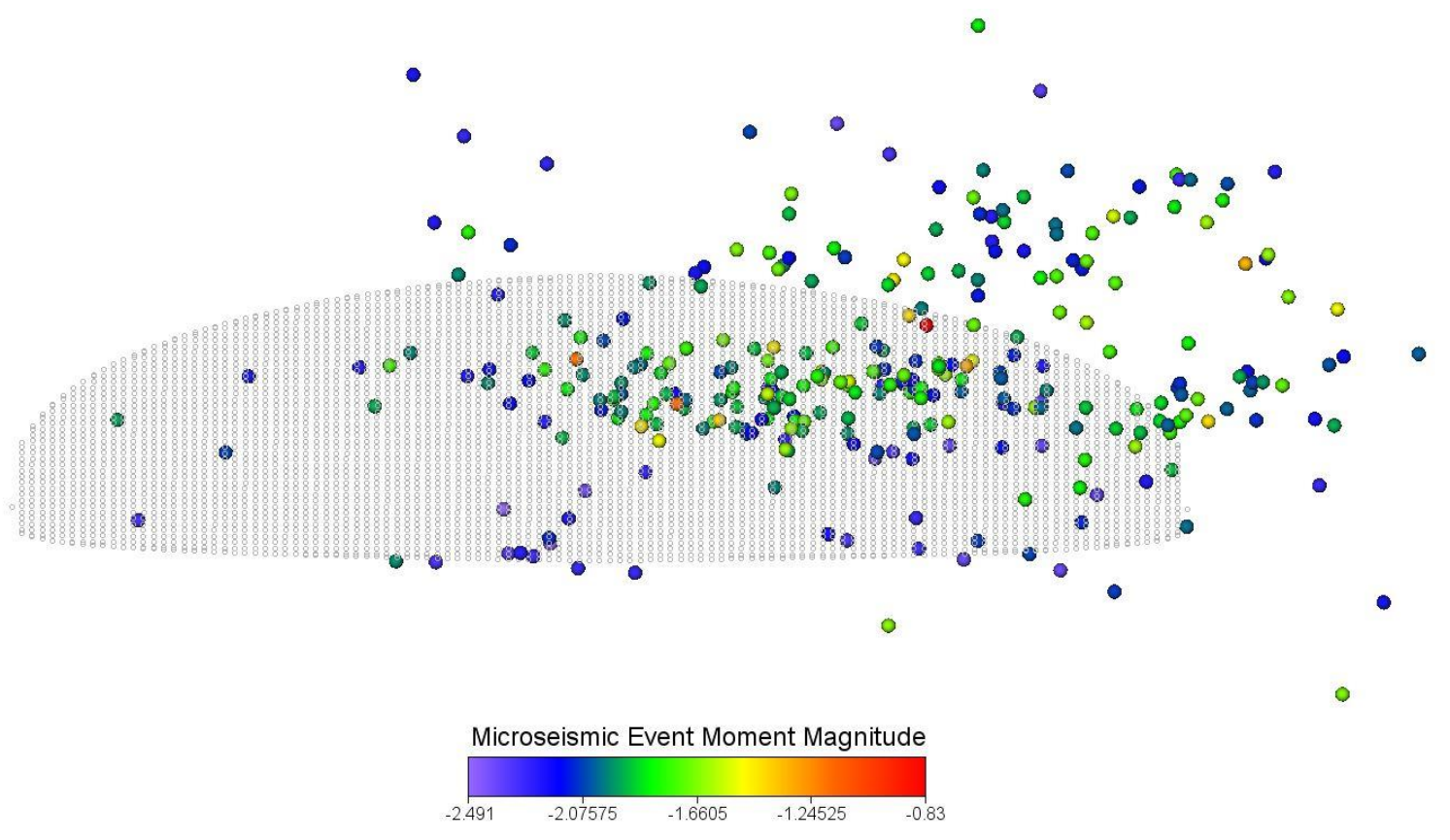

Figure 5.16: Side View of Calculated Hydraulic Fracture and Measured Microseismic Events and Magnitudes for Stage 7 - MIP 3H 


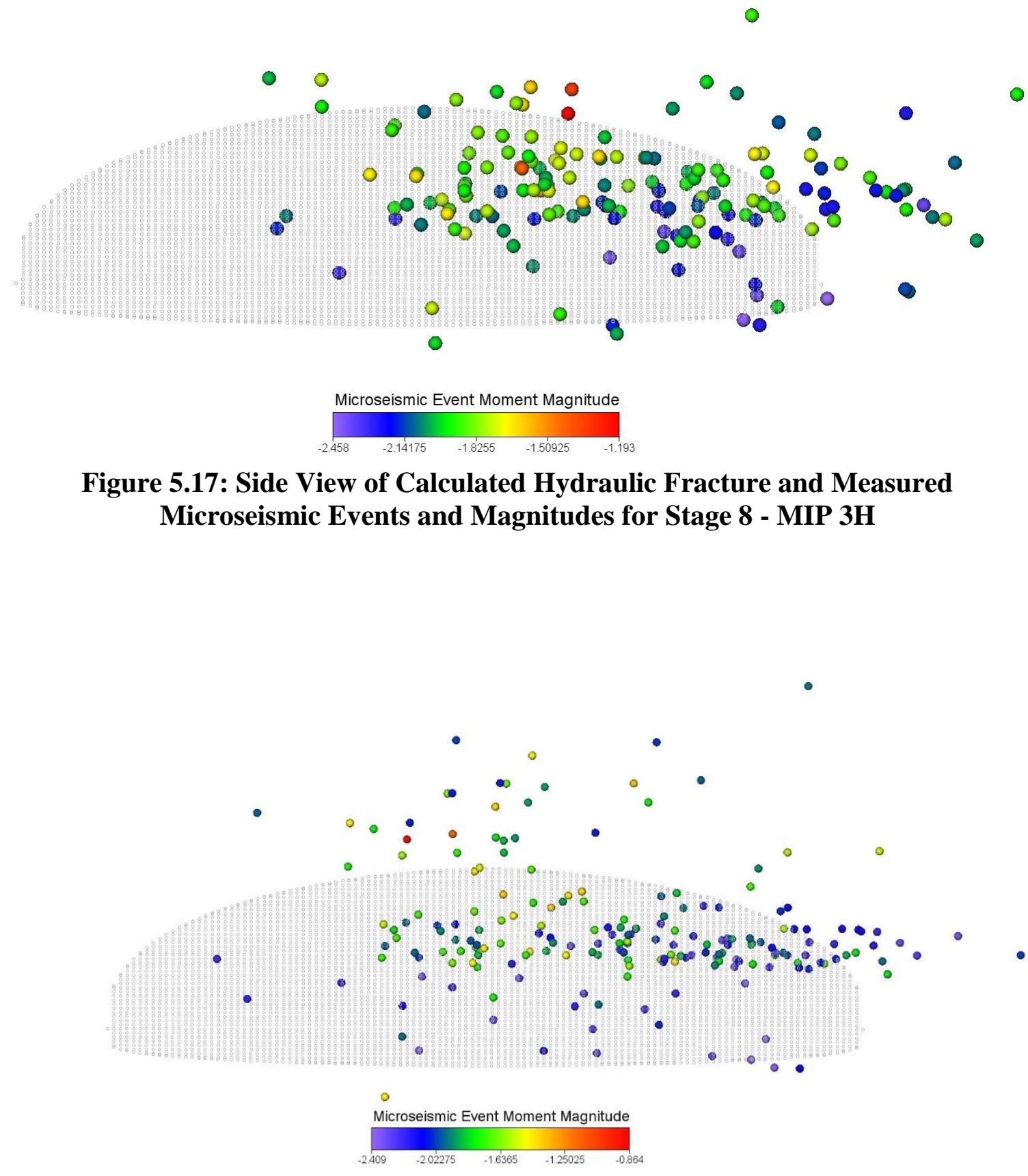

Figure 5.18: Side View of Calculated Hydraulic Fracture and Measured Microseismic Events and Magnitudes for Stage 9 - MIP 3H 

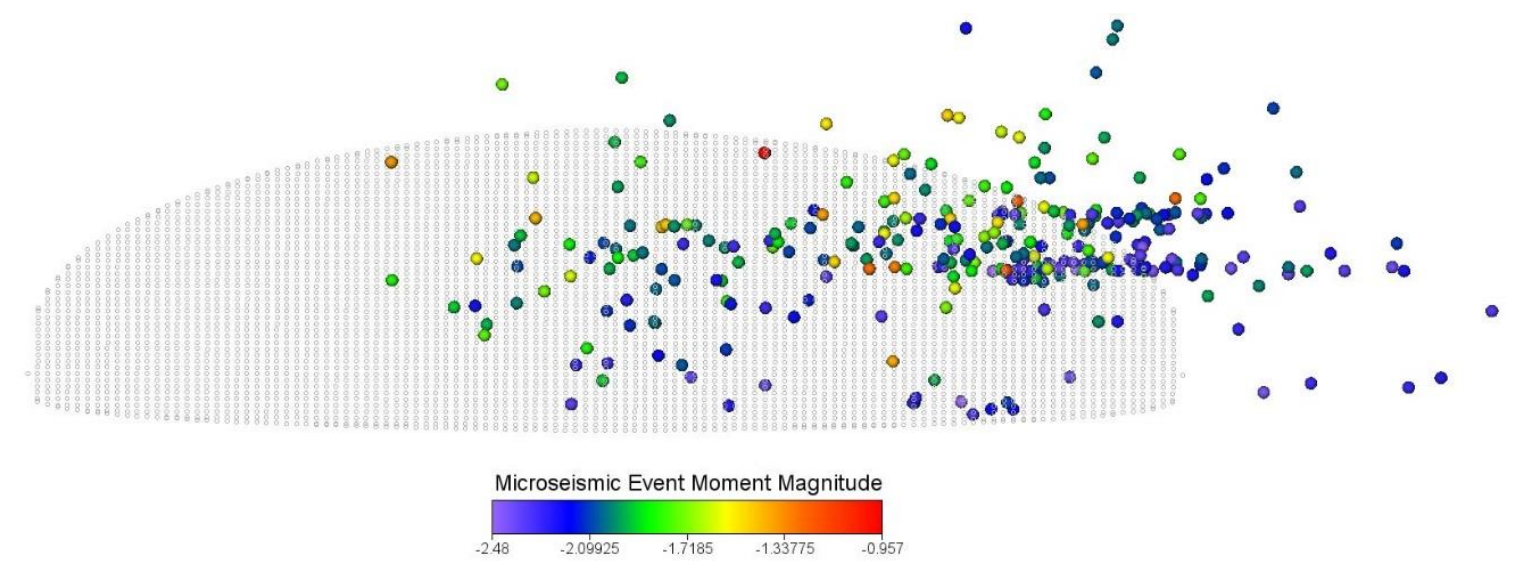

Figure 5.19: Side View of Calculated Hydraulic Fracture and Measured Microseismic Events and Magnitudes for Stage 10 - MIP 3H

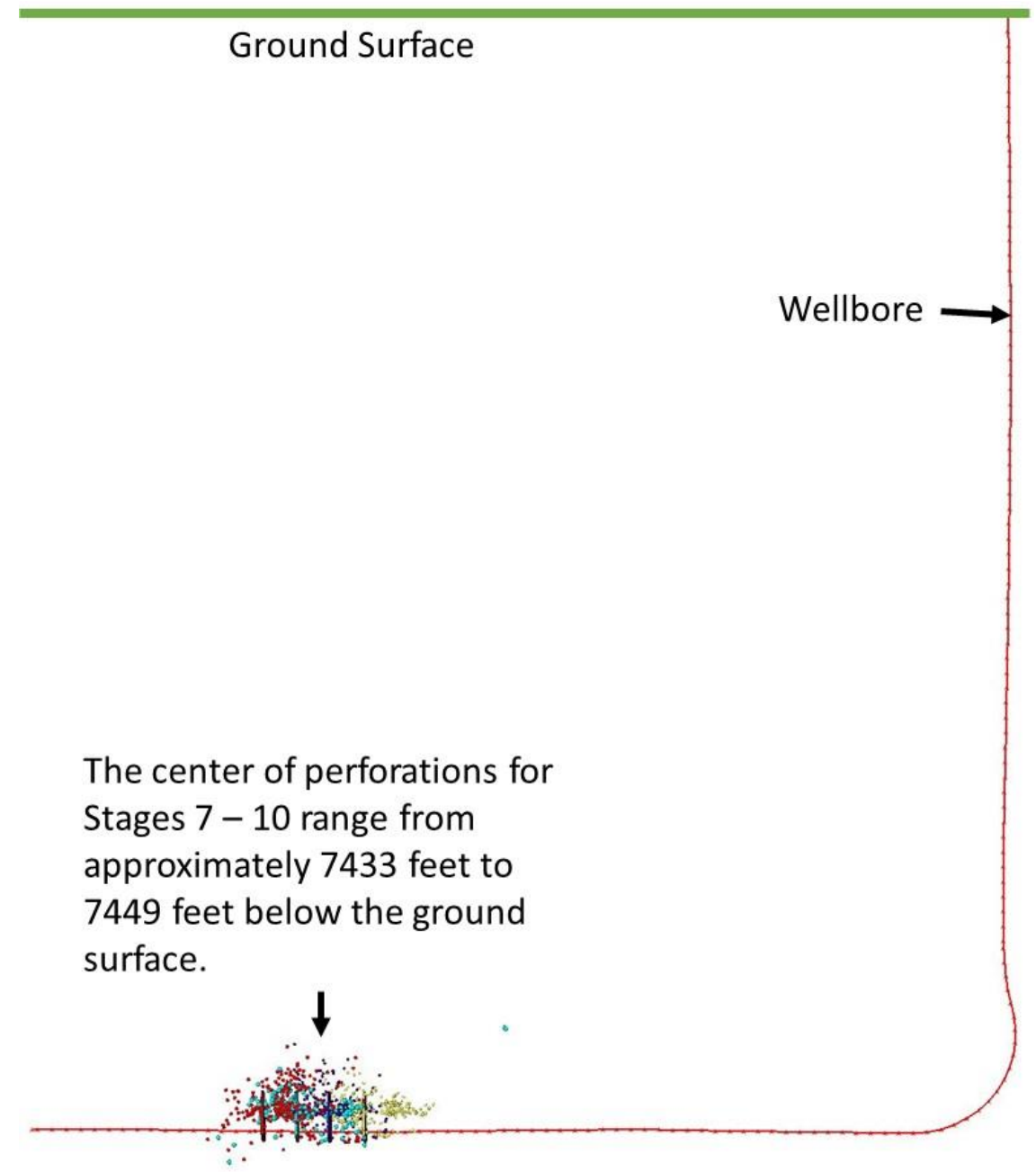

Figure 5.20: Overview of Calculated Hydraulic Fracture Geometries, Measured Microseismic Events, and Entire Wellbore for Stage 7 through Stage 10 - MIP $3 H$ 


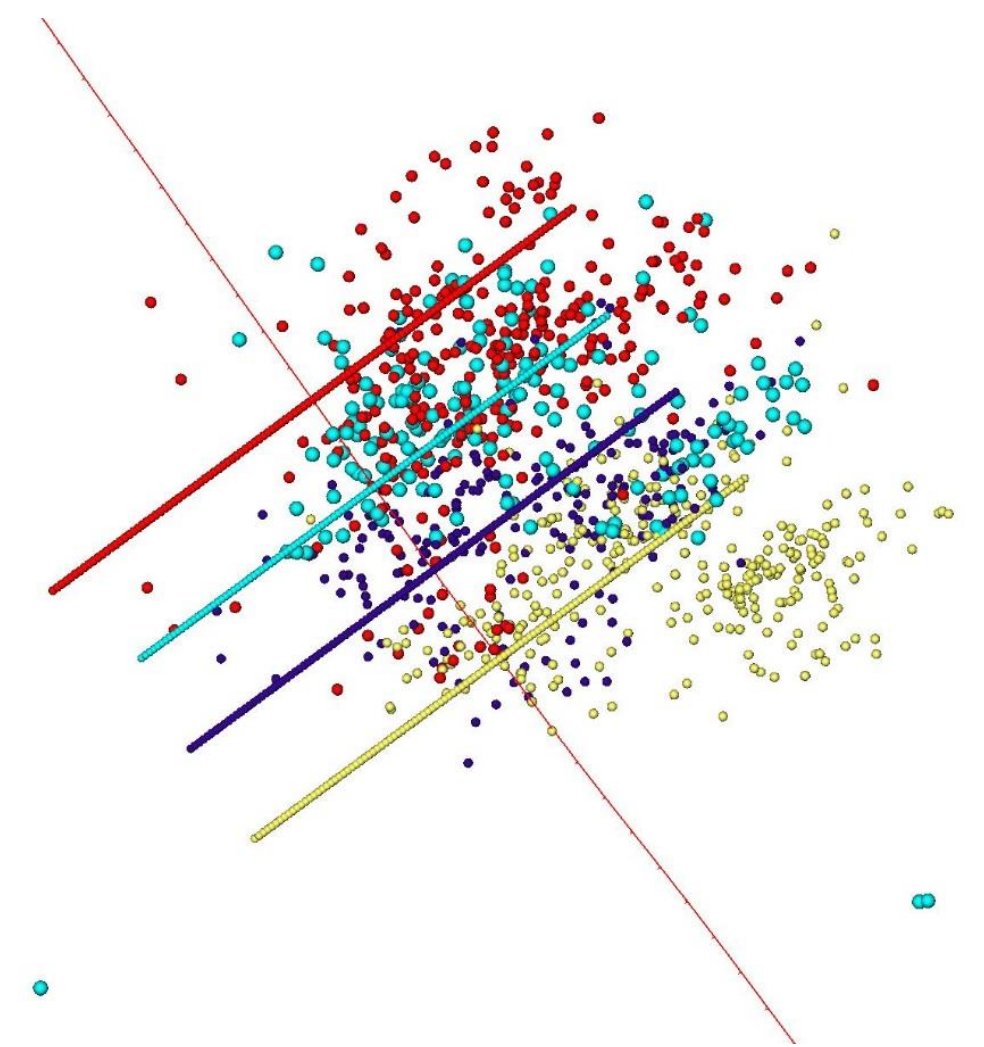

Figure 5.21: Top View of Calculated Hydraulic Fracture Geometries, Measured Microseismic Events, and Nearby Wellbore for Stage 7 through Stage 10 - MIP $3 H$

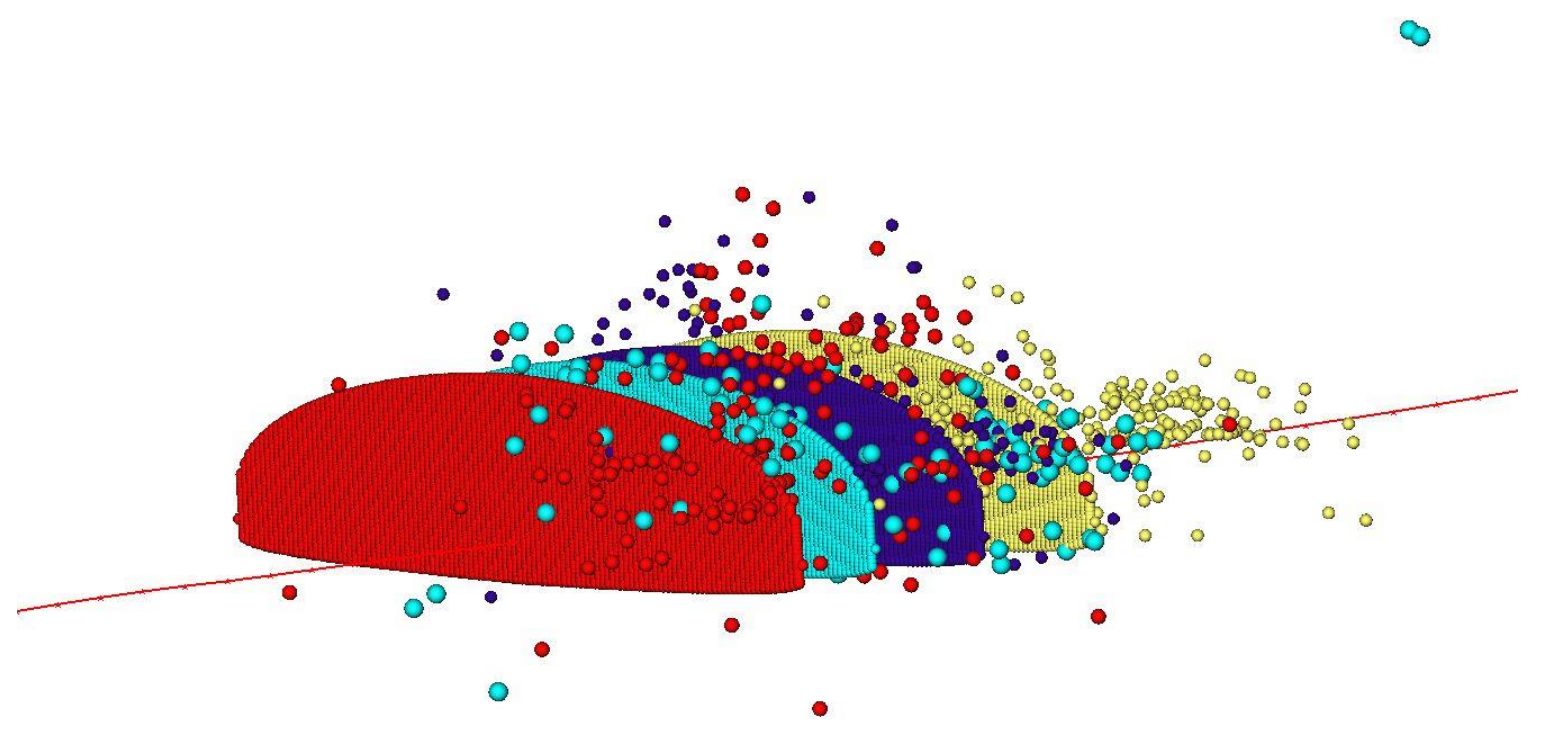

Figure 5.22: Orthogonal View of Calculated Hydraulic Fracture Geometries, Measured Microseismic Events, and Nearby Wellbore for Stage 7 through Stage 10 - MIP 3H 
Table 5.3: Calculated Fracture Geometry Data - MIP-3H

\begin{tabular}{|c|c|c|c|}
\hline STAGE & Fracture Half-Length (ft) & Calculated Fracture Height (ft) & Average Fracture Width (in) \\
\hline 1 & 705.0 & 348.0 & 0.028474 \\
\hline 2 & 647.6 & 306.7 & 0.026497 \\
\hline 3 & 659.7 & 329.9 & 0.02899 \\
\hline 4 & 684.7 & 326.9 & 0.027285 \\
\hline 5 & 594.6 & 300.1 & 0.016779 \\
\hline 6 & 698.7 & 326.5 & 0.026389 \\
\hline 7 & 687.1 & 329 & 0.027577 \\
\hline 8 & 615.5 & 355.2 & 0.021193 \\
\hline 9 & 656.7 & 335.6 & 0.029723 \\
\hline 10 & 649.6 & 332.4 & 0.03001 \\
\hline 11 & 631.3 & 328.8 & 0.030164 \\
\hline 12 & 649.1 & 325.2 & 0.022762 \\
\hline 13 & 597.8 & 316.2 & 0.028964 \\
\hline 14 & 552.4 & 445.8 & 0.023985 \\
\hline 15 & 740.7 & 341.9 & 0.03174 \\
\hline 16 & 660.9 & 316 & 0.033038 \\
\hline 17 & 580.4 & 322.3 & 0.018099 \\
\hline 18 & 644.1 & 318.9 & 0.033231 \\
\hline 19 & 676.1 & 333.1 & 0.033314 \\
\hline 20 & 597.2 & 319.4 & 0.023954 \\
\hline 21 & 623.8 & 314.8 & 0.029267 \\
\hline 22 & 651.9 & 349.6 & 0.028956 \\
\hline 23 & 701.8 & 343.5 & 0.033113 \\
\hline 24 & 609.3 & 327 & 0.02406 \\
\hline 25 & 638.6 & 331.1 & 0.030619 \\
\hline 26 & 615 & 325.5 & 0.031456 \\
\hline 27 & 585.2 & 313.4 & 0.031126 \\
\hline 28 & 629.9 & 325.5 & 0.032047 \\
\hline
\end{tabular}


Table 5.4: Calculated Fracture Geometry Data - MIP-5H

\begin{tabular}{|c|c|c|c|}
\hline STAGE & Fracture Half-Length (ft) & Calculated Fracture Height (ft) & Average Fracture Width (in) \\
\hline 1 & 591.9 & 294.3 & 0.029143 \\
\hline 2 & 547.9 & 295.6 & 0.020782 \\
\hline 3 & 511.5 & 285.7 & 0.022435 \\
\hline 4 & 449.7 & 285.2 & 0.016648 \\
\hline 5 & 517.1 & 289.9 & 0.020991 \\
\hline 6 & 574.1 & 310.6 & 0.021193 \\
\hline 7 & 600.1 & 304 & 0.018286 \\
\hline 8 & 564.5 & 309.1 & 0.021027 \\
\hline 9 & 558 & 306 & 0.02078 \\
\hline 10 & 606.6 & 316.7 & 0.027322 \\
\hline 11 & 592 & 310.4 & 0.026447 \\
\hline 12 & 609.4 & 317.3 & 0.026012 \\
\hline 13 & 665.6 & 310.4 & 0.025469 \\
\hline 14 & 592.6 & 314.3 & 0.025875 \\
\hline 15 & 603.5 & 316.7 & 0.026851 \\
\hline 16 & 560.4 & 307.7 & 0.02186 \\
\hline 17 & 616.2 & 316.3 & 0.027175 \\
\hline 18 & 602.8 & 308.2 & 0.024703 \\
\hline 19 & 610.9 & 317.9 & 0.027597 \\
\hline 20 & 596 & 314.2 & 0.027018 \\
\hline 21 & 598.6 & 316.6 & 0.027016 \\
\hline 22 & 620.5 & 319.5 & 0.027759 \\
\hline 23 & 540.2 & 297.8 & 0.02795 \\
\hline 24 & 583.6 & 312.4 & 0.027346 \\
\hline 25 & 590.1 & 316.1 & 0.026846 \\
\hline 26 & 618.4 & 323.7 & 0.027296 \\
\hline 27 & 617.7 & 316.5 & 0.025959 \\
\hline 28 & 599.4 & 318.5 & 0.025006 \\
\hline 29 & 644.6 & 329.5 & 0.030494 \\
\hline 30 & 644.1 & 336.8 & 0.03046 \\
\hline
\end{tabular}


Microseismic event clouds were observed from field estimations using passive monitoring devices (discussed in Chapter 3) during hydraulic fracturing of most stages at wells MIP-3H and MIP-5H. The microseismic event locations were processed and estimations were determined for microseismic event cloud heights and lengths by a commercial organization who also work in the MSEEL project. This microseismic event cloud geometric estimation data is presented in Table 5.5 for well MIP-3H and in Table 5.6 for well MIP-5H. Figure 5.23 shows the comparison of calculated primary hydraulic heights with estimated microseismic event cloud estimated heights for all available stages at wells MIP-3H and MIP-5H. Figure 5.24 shows the comparison of calculated primary hydraulic lengths with estimated microseismic event cloud estimated lengths for all available stages at wells MIP-3H and MIP-5H. Calculated surface pressure data was also compared with measured surface pressure data in order to make an additional comparison. Figure 5.25 shows the comparison of calculated surface pressure data and measured surface pressure data for wells MIP-3H and MIP-5H. Surface pressure values used in this study were taken from averages over a similar period of time during hydraulic fracturing operations. As the times varied for each of the stages across both wells, it was not possible to use the same time period for every stage; however, the same time range and part of the fracturing stage was used for finding the average for each pair of measured data and calculated data. Comparing the numerical model calculations with the estimated fracture heights and lengths, as well as the measured surface pressures show that there are discrepancies between calculations and estimates/measurements, especially with regards to the fracture heights. In order to potentially address these discrepancies, a sensitivity analysis study was conducted and will be detailed in the following section. 
Table 5.5: Microseismic Event Cloud Geometry Estimate* Data - Well MIP-3H

\begin{tabular}{|c|c|c|}
\hline STAGE & Estimated Fracture Height (ft) & Estimated Fracture Total Length (ft) \\
\hline 1 & No Data Available & No Data Available \\
\hline 2 & No Data Available & No Data Available \\
\hline 3 & No Data Available & No Data Available \\
\hline 4 & No Data Available & No Data Available \\
\hline 5 & No Data Available & No Data Available \\
\hline 6 & No Data Available & No Data Available \\
\hline 7 & 470 & 1390 \\
\hline 8 & 410 & 1100 \\
\hline 9 & 555 & 1160 \\
\hline 10 & 380 & 1250 \\
\hline 11 & 530 & 1230 \\
\hline 12 & 560 & 1450 \\
\hline 13 & 560 & 1920 \\
\hline 14 & 550 & 1570 \\
\hline 15 & 725 & 1510 \\
\hline 16 & 710 & 1570 \\
\hline 17 & 405 & 1580 \\
\hline 18 & 515 & 1500 \\
\hline 19 & 510 & 1550 \\
\hline 20 & 495 & 1850 \\
\hline 21 & 480 & 1510 \\
\hline 22 & 490 & 1580 \\
\hline 23 & 515 & 1610 \\
\hline 24 & 405 & 2410 \\
\hline 25 & 420 & 1680 \\
\hline 26 & 475 & 2050 \\
\hline 27 & 470 & 1670 \\
\hline 28 & 305 & 1370 \\
\hline
\end{tabular}

* Estimates were made by a commercial organization who also worked in the MSEEL project. 
Table 5.6: Microseismic Event Cloud Geometry Estimate* Data - Well MIP-5H

\begin{tabular}{|c|c|c|}
\hline STAGE & Estimated Fracture Height (ft) & Estimated Fracture Total Length (ft) \\
\hline 1 & No Data Available & No Data Available \\
\hline 2 & 575 & 1000 \\
\hline 3 & No Data Available & No Data Available \\
\hline 4 & No Data Available & No Data Available \\
\hline 5 & 425 & 500 \\
\hline 6 & 840 & 1035 \\
\hline 7 & 640 & 1090 \\
\hline 8 & 655 & 1140 \\
\hline 9 & 745 & 790 \\
\hline 10 & 605 & 1560 \\
\hline 11 & 725 & 1205 \\
\hline 12 & 675 & 1145 \\
\hline 13 & 690 & 1440 \\
\hline 14 & 585 & 1495 \\
\hline 15 & 475 & 1660 \\
\hline 16 & 515 & 1355 \\
\hline 17 & 460 & 1155 \\
\hline 18 & 485 & 1210 \\
\hline 19 & 390 & 1200 \\
\hline 20 & 445 & 1760 \\
\hline 21 & 400 & 1515 \\
\hline 22 & 430 & 1420 \\
\hline 23 & 645 & 1295 \\
\hline 24 & 430 & 1190 \\
\hline 25 & 405 & 1125 \\
\hline 26 & 370 & 1350 \\
\hline 27 & 380 & 1445 \\
\hline 28 & 470 & 1195 \\
\hline 29 & 485 & 775 \\
\hline 30 & 555 & 1335 \\
\hline
\end{tabular}

* Estimates were made by a commercial organization who also worked in the MSEEL project. 
Calculated vs Estimated Fracture Height - MIP-3H and MIP-5H

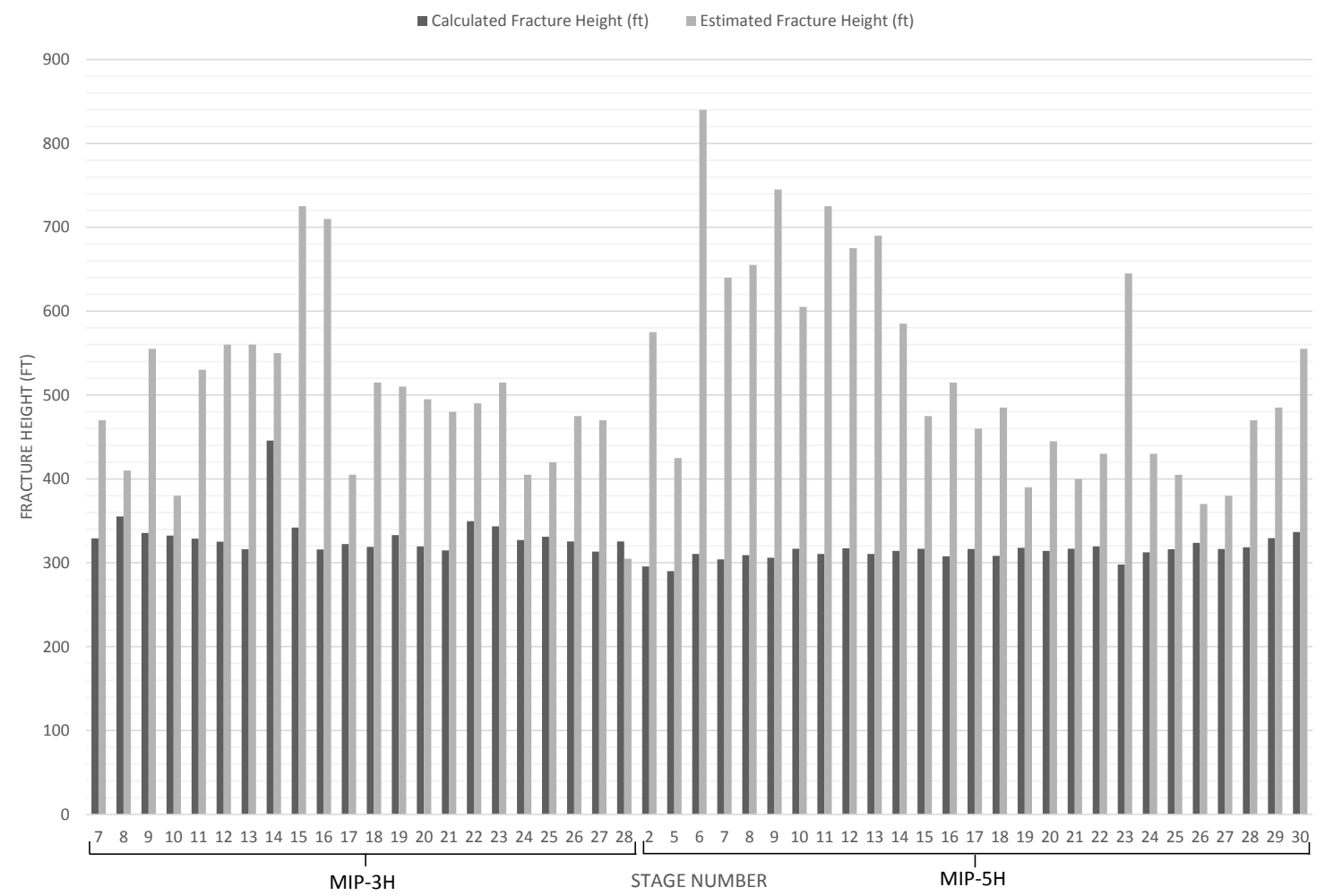

Figure 5.23: Calculated vs Available Estimated* Hydraulic Fracture Heights for wells MIP-3H and MIP-5H

* Estimates were made by a commercial organization who also work in the MSEEL project. 
Calculated vs Estimated Fracture Length - MIP-3H and MIP-5H

- Calculated Fracture Length (ft) Estimated Fracture Length (ft)

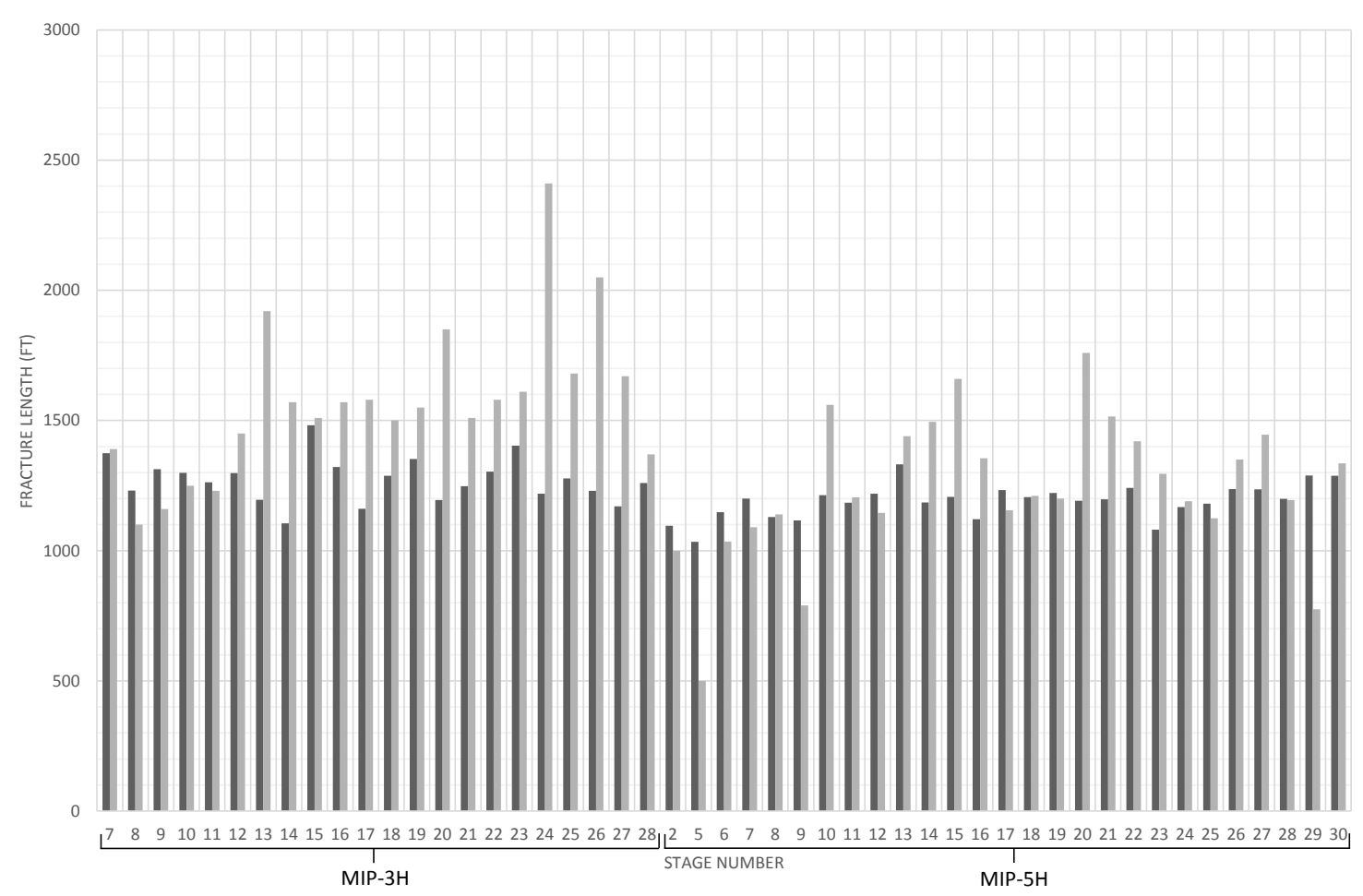

Figure 5.24: Calculated vs Available Estimated* Hydraulic Fracture Lengths for wells MIP-3H and MIP-5H

* Estimates were made by a commercial organization who also work in the MSEEL project. 


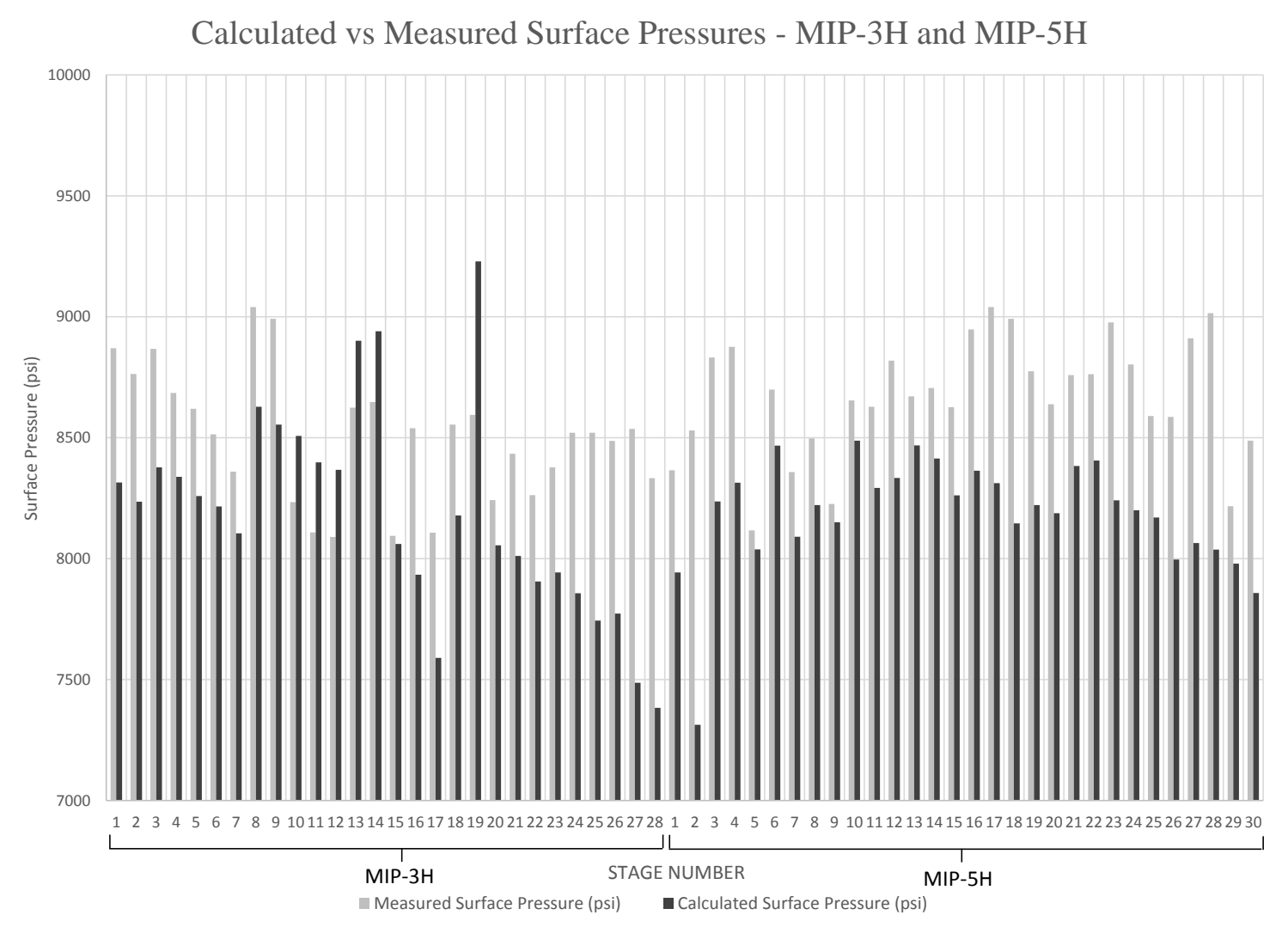

Figure 5.25: Numerical Model Calculations versus Measurements for Surface Pressures - Wells MIP-3H and MIP-5H 


\subsection{Sensitivity Analysis and Results}

From the results of the numerical modeling, it can be seen that the calculated primary hydraulic fracture heights agree less with estimated microseismic event cloud heights than the calculated primary hydraulic fracture lengths do with estimated microseismic event cloud lengths. In an attempt to better match numerical model calculations of the primary hydraulic fracture heights with the observed microseismic event cloud heights, a sensitivity study was performed using a stage from MIP-5H to determine how parametric changes would affect the primary hydraulic fracture height. If significant changes are observed in fracture height from changing geomechanical/fluid flow properties within reasonable ranges, perhaps this could address numerical model calculation discrepancies. Geomechanical and fluid flow properties were modified from the base properties for each layer interacting with the modeled hydraulic fracture. The following geomechanical/fluid flow properties were modified: horizontal stress gradient, Young's Modulus, Poisson's ratio, and fluid leakoff coefficient. Each of these properties was modified plus and minus $10 \%$ from the base property value. The following layers were used to modify their properties for the purposes of this study: Tully Limestone, Hamilton Shale, Upper Marcellus Shale, Cherry Valley Limestone, Lower Marcellus Shale, and the Onondaga Limestone. A total of 48 cases to modify the previously mentioned properties in these layers were numerically modeled. The results of this sensitivity study are presented in Table 5.7. These results were then sorted by percent change from the base case (sorted from greatest positive percentage change to greatest negative percentage change) and are presented in Table 5.8 . 
As can be seen in the sorted Table 5.8, this study shows that the horizontal stress gradient has the greatest impact on the percentage change in primary hydraulic fracture height from the base case (both positive and negative). The average positive percentage change in primary hydraulic fracture height due to the horizontal stress gradient is $9.3 \%$. The average negative percentage change in primary hydraulic fracture height due to the horizontal stress gradient is $-5.8 \%$. The Young's Modulus can be seen to have the second greatest impact on primary hydraulic fracture height. The average positive percentage change in primary hydraulic fracture height due to the Young's Modulus is $1.1 \%$. The average negative percentage change in primary hydraulic fracture height due to the Young's Modulus is $-0.9 \%$. The fluid leakoff coefficient and Poisson's ratio have the least impact on primary hydraulic fracture height. The positive change in primary hydraulic fracture height due to the Poisson's ratio is $0.2 \%$ and the negative change is $-0.3 \%$. The positive change in primary hydraulic fracture height due to the fluid leakoff coefficient is $0.2 \%$ and the negative change is $-0.4 \%$. For this study, in the ranges tested, the horizontal stress gradient is, by far, the most sensitive parameter to change and the fluid leakoff coefficient and Poisson's ratio are least sensitive. This does not mean that the fluid leakoff coefficient and Poisson's ratio are not significant in general; this just indicates that for the specific ranges of values tested, they are not as sensitive to change.

The results of this sensitivity analysis study show that the changes induced by modifying the geomechanical and fluid flow properties do not result in significant enough changes to the calculated hydraulic fracture heights to appropriately match with estimated microseismic event cloud heights. In order to further investigate and find a solution to the 
observed discrepancy, a statistical analysis and approach will be employed. The

methodology and results of this will be discussed in the following section.

\section{Table 5.7: Geomechanical/Fluid Flow Property Sensitivity Analysis Study Results - Sorted by Geologic Layer and Property Changed}

\begin{tabular}{|c|c|c|c|c|}
\hline Case & Geomechanical/Fluid Flow Property & Property Modification & Geologic Layer & Change in Fracture Height From Base Case \\
\hline 1 & Horizontal Stress Gradient & Increase $10 \%$ from base & Tully Limestone & $-7.4 \%$ \\
\hline 2 & Horizontal Stress Gradient & Decrease $10 \%$ from base & Tully Limestone & $21.1 \%$ \\
\hline 3 & Young's Modulus & Increase $10 \%$ from base & Tully Limestone & $0.6 \%$ \\
\hline 4 & Young's Modulus & Decrease $10 \%$ from base & Tully Limestone & $-0.7 \%$ \\
\hline 5 & Poisson's Ratio & Increase $10 \%$ from base & Tully Limestone & $0.1 \%$ \\
\hline 6 & Poisson's Ratio & Decrease $10 \%$ from base & Tully Limestone & $-0.1 \%$ \\
\hline 7 & Leakoff Coefficient & Increase $10 \%$ from base & Tully Limestone & $0.0 \%$ \\
\hline 8 & Leakoff Coefficient & Decrease $10 \%$ from base & Tully Limestone & $0.0 \%$ \\
\hline 9 & Horizontal Stress Gradient & Increase $10 \%$ from base & Hamilton Shale & $-8.7 \%$ \\
\hline 10 & Horizontal Stress Gradient & Decrease $10 \%$ from base & Hamilton Shale & $7.1 \%$ \\
\hline 11 & Young's Modulus & Increase $10 \%$ from base & Hamilton Shale & $2.1 \%$ \\
\hline 12 & Young's Modulus & Decrease $10 \%$ from base & Hamilton Shale & $-2.3 \%$ \\
\hline 13 & Poisson's Ratio & Increase $10 \%$ from base & Hamilton Shale & $0.2 \%$ \\
\hline 14 & Poisson's Ratio & Decrease $10 \%$ from base & Hamilton Shale & $-0.2 \%$ \\
\hline 15 & Leakoff Coefficient & Increase $10 \%$ from base & Hamilton Shale & $-0.3 \%$ \\
\hline 16 & Leakoff Coefficient & Decrease $10 \%$ from base & Hamilton Shale & $0.3 \%$ \\
\hline 17 & Horizontal Stress Gradient & Increase $10 \%$ from base & Upper Marcellus & $13.9 \%$ \\
\hline 18 & Horizontal Stress Gradient & Decrease $10 \%$ from base & Upper Marcellus & $-5.8 \%$ \\
\hline 19 & Young's Modulus & Increase $10 \%$ from base & Upper Marcellus & $0.5 \%$ \\
\hline 20 & Young's Modulus & Decrease $10 \%$ from base & Upper Marcellus & $-1.3 \%$ \\
\hline 21 & Poisson's Ratio & Increase $10 \%$ from base & Upper Marcellus & $-0.2 \%$ \\
\hline 22 & Poisson's Ratio & Decrease $10 \%$ from base & Upper Marcellus & $-0.2 \%$ \\
\hline 23 & Leakoff Coefficient & Increase $10 \%$ from base & Upper Marcellus & $-0.9 \%$ \\
\hline 24 & Leakoff Coefficient & Decrease $10 \%$ from base & Upper Marcellus & $0.1 \%$ \\
\hline 25 & Horizontal Stress Gradient & Increase $10 \%$ from base & Cherry Valley & $9.0 \%$ \\
\hline 26 & Horizontal Stress Gradient & Decrease $10 \%$ from base & Cherry Valley & $-6.3 \%$ \\
\hline 27 & Young's Modulus & Increase $10 \%$ from base & Cherry Valley & $-0.6 \%$ \\
\hline 28 & Young's Modulus & Decrease $10 \%$ from base & Cherry Valley & $-0.5 \%$ \\
\hline 29 & Poisson's Ratio & Increase $10 \%$ from base & Cherry Valley & $-0.4 \%$ \\
\hline 30 & Poisson's Ratio & Decrease $10 \%$ from base & Cherry Valley & $-0.3 \%$ \\
\hline 31 & Leakoff Coefficient & Increase $10 \%$ from base & Cherry Valley & $-0.1 \%$ \\
\hline 32 & Leakoff Coefficient & Decrease $10 \%$ from base & Cherry Valley & $-0.4 \%$ \\
\hline 33 & Horizontal Stress Gradient & Increase $10 \%$ from base & Lower Marcellus & $4.4 \%$ \\
\hline 34 & Horizontal Stress Gradient & Decrease $10 \%$ from base & Lower Marcellus & $-4.8 \%$ \\
\hline 35 & Young's Modulus & Increase $10 \%$ from base & Lower Marcellus & $-0.4 \%$ \\
\hline 36 & Young's Modulus & Decrease $10 \%$ from base & Lower Marcellus & $-0.5 \%$ \\
\hline 37 & Poisson's Ratio & Increase $10 \%$ from base & Lower Marcellus & $-0.2 \%$ \\
\hline 38 & Poisson's Ratio & Decrease $10 \%$ from base & Lower Marcellus & $-0.2 \%$ \\
\hline 39 & Leakoff Coefficient & Increase $10 \%$ from base & Lower Marcellus & $-0.1 \%$ \\
\hline 40 & Leakoff Coefficient & Decrease $10 \%$ from base & Lower Marcellus & $-0.3 \%$ \\
\hline 41 & Horizontal Stress Gradient & Increase $10 \%$ from base & Onondaga Limestone & $-2.1 \%$ \\
\hline 42 & Horizontal Stress Gradient & Decrease $10 \%$ from base & Onondaga Limestone & $0.2 \%$ \\
\hline 43 & Young's Modulus & Increase $10 \%$ from base & Onondaga Limestone & $0.0 \%$ \\
\hline 44 & Young's Modulus & Decrease $10 \%$ from base & Onondaga Limestone & $-0.6 \%$ \\
\hline 45 & Poisson's Ratio & Increase $10 \%$ from base & Onondaga Limestone & $-0.4 \%$ \\
\hline 46 & Poisson's Ratio & Decrease $10 \%$ from base & Onondaga Limestone & $-0.5 \%$ \\
\hline 47 & Leakoff Coefficient & Increase $10 \%$ from base & Onondaga Limestone & $-0.9 \%$ \\
\hline 48 & Leakoff Coefficient & Decrease $10 \%$ from base & Onondaga Limestone & $-0.2 \%$ \\
\hline
\end{tabular}


Table 5.8: Geomechanical/Fluid Flow Property Sensitivity Analysis Study Results Sorted by Percent Change in Fracture Height from Base Case (positive to negative)

\begin{tabular}{|c|c|c|c|c|}
\hline Case & Geomechanical/Fluid Flow Property & Property Modification & Geologic Layer & Change in Fracture Height From Base Case \\
\hline 2 & Horizontal Stress Gradient & Decrease $10 \%$ from base & Tully Limestone & $21.1 \%$ \\
\hline 17 & Horizontal Stress Gradient & Increase $10 \%$ from base & Upper Marcellus & $13.9 \%$ \\
\hline 25 & Horizontal Stress Gradient & Increase $10 \%$ from base & Cherry Valley & $9.0 \%$ \\
\hline 10 & Horizontal Stress Gradient & Decrease $10 \%$ from base & Hamilton Shale & $7.1 \%$ \\
\hline 33 & Horizontal Stress Gradient & Increase $10 \%$ from base & Lower Marcellus & $4.4 \%$ \\
\hline 11 & Young's Modulus & Increase $10 \%$ from base & Hamilton Shale & $2.1 \%$ \\
\hline 3 & Young's Modulus & Increase $10 \%$ from base & Tully Limestone & $0.6 \%$ \\
\hline 19 & Young's Modulus & Increase $10 \%$ from base & Upper Marcellus & $0.5 \%$ \\
\hline 16 & Leakoff Coefficient & Decrease $10 \%$ from base & Hamilton Shale & $0.3 \%$ \\
\hline 13 & Poisson's Ratio & Increase $10 \%$ from base & Hamilton Shale & $0.2 \%$ \\
\hline 42 & Horizontal Stress Gradient & Decrease $10 \%$ from base & Onondaga Limestone & $0.2 \%$ \\
\hline 5 & Poisson's Ratio & Increase $10 \%$ from base & Tully Limestone & $0.1 \%$ \\
\hline 24 & Leakoff Coefficient & Decrease $10 \%$ from base & Upper Marcellus & $0.1 \%$ \\
\hline 8 & Leakoff Coefficient & Decrease $10 \%$ from base & Tully Limestone & $0.0 \%$ \\
\hline 43 & Young's Modulus & Increase $10 \%$ from base & Onondaga Limestone & $0.0 \%$ \\
\hline 7 & Leakoff Coefficient & Increase $10 \%$ from base & Tully Limestone & $0.0 \%$ \\
\hline 39 & Leakoff Coefficient & Increase $10 \%$ from base & Lower Marcellus & $-0.1 \%$ \\
\hline 6 & Poisson's Ratio & Decrease $10 \%$ from base & Tully Limestone & $-0.1 \%$ \\
\hline 31 & Leakoff Coefficient & Increase $10 \%$ from base & Cherry Valley & $-0.1 \%$ \\
\hline 48 & Leakoff Coefficient & Decrease $10 \%$ from base & Onondaga Limestone & $-0.2 \%$ \\
\hline 14 & Poisson's Ratio & Decrease $10 \%$ from base & Hamilton Shale & $-0.2 \%$ \\
\hline 22 & Poisson's Ratio & Decrease $10 \%$ from base & Upper Marcellus & $-0.2 \%$ \\
\hline 38 & Poisson's Ratio & Decrease $10 \%$ from base & Lower Marcellus & $-0.2 \%$ \\
\hline 21 & Poisson's Ratio & Increase $10 \%$ from base & Upper Marcellus & $-0.2 \%$ \\
\hline 37 & Poisson's Ratio & Increase $10 \%$ from base & Lower Marcellus & $-0.2 \%$ \\
\hline 40 & Leakoff Coefficient & Decrease $10 \%$ from base & Lower Marcellus & $-0.3 \%$ \\
\hline 15 & Leakoff Coefficient & Increase $10 \%$ from base & Hamilton Shale & $-0.3 \%$ \\
\hline 30 & Poisson's Ratio & Decrease $10 \%$ from base & Cherry Valley & $-0.3 \%$ \\
\hline 45 & Poisson's Ratio & Increase $10 \%$ from base & Onondaga Limestone & $-0.4 \%$ \\
\hline 29 & Poisson's Ratio & Increase $10 \%$ from base & Cherry Valley & $-0.4 \%$ \\
\hline 32 & Leakoff Coefficient & Decrease $10 \%$ from base & Cherry Valley & $-0.4 \%$ \\
\hline 35 & Young's Modulus & Increase $10 \%$ from base & Lower Marcellus & $-0.4 \%$ \\
\hline 28 & Young's Modulus & Decrease $10 \%$ from base & Cherry Valley & $-0.5 \%$ \\
\hline 36 & Young's Modulus & Decrease $10 \%$ from base & Lower Marcellus & $-0.5 \%$ \\
\hline 46 & Poisson's Ratio & Decrease $10 \%$ from base & Onondaga Limestone & $-0.5 \%$ \\
\hline 27 & Young's Modulus & Increase $10 \%$ from base & Cherry Valley & $-0.6 \%$ \\
\hline 44 & Young's Modulus & Decrease $10 \%$ from base & Onondaga Limestone & $-0.6 \%$ \\
\hline 4 & Young's Modulus & Decrease $10 \%$ from base & Tully Limestone & $-0.7 \%$ \\
\hline 23 & Leakoff Coefficient & Increase $10 \%$ from base & Upper Marcellus & $-0.9 \%$ \\
\hline 47 & Leakoff Coefficient & Increase $10 \%$ from base & Onondaga Limestone & $-0.9 \%$ \\
\hline 20 & Young's Modulus & Decrease $10 \%$ from base & Upper Marcellus & $-1.3 \%$ \\
\hline 41 & Horizontal Stress Gradient & Increase $10 \%$ from base & Onondaga Limestone & $-2.1 \%$ \\
\hline 12 & Young's Modulus & Decrease $10 \%$ from base & Hamilton Shale & $-2.3 \%$ \\
\hline 34 & Horizontal Stress Gradient & Decrease $10 \%$ from base & Lower Marcellus & $-4.8 \%$ \\
\hline 18 & Horizontal Stress Gradient & Decrease $10 \%$ from base & Upper Marcellus & $-5.8 \%$ \\
\hline 26 & Horizontal Stress Gradient & Decrease $10 \%$ from base & Cherry Valley & $-6.3 \%$ \\
\hline 1 & Horizontal Stress Gradient & Increase $10 \%$ from base & Tully Limestone & $-7.4 \%$ \\
\hline 9 & Horizontal Stress Gradient & Increase $10 \%$ from base & Hamilton Shale & $-8.7 \%$ \\
\hline
\end{tabular}




\subsection{Statistical Analysis Approach}

After conducting the sensitivity analysis study discussed in the previous section, a different approach was necessary to compare calculated fracture geometry data and surface pressures with estimated microseismic cloud geometry data and measured surface pressures. It was also necessary to devise a methodology to better predict microseismic cloud geometries and measured surface pressures from numerical model results. Integrating microseismic monitoring results, fracture modeling, and reservoir simulation are required for estimating the effective stimulated reservoir volume (SRV), which is used to estimate expected production volumes (Cipolla et. al., 2012). If geometric microseismic monitoring results can be estimated from numerical modeling, this can potentially save significant time and money involved in the process of obtaining microseismic data.

In order to address the discrepancy between numerical model calculations and available microseismic data, a method known as Linear Scaling Bias Correction (LSBC) was employed. LSBC is taken from the field of hydrology/climate science, where it is commonly used in predicting climate change through the modeling of future rainfall and temperatures around the world (Adams, 2017; Bennett et. al., 2014; Fang et. al., 2015). This method (bias correction in general) has seen limited use in relation to the areas hydraulic fracturing and microseismicity. The closest literature found related to this study was conducted by Zhang et. al. (2014). In these authors' work, bias correction was used in relation to correcting detection-range biases from geophysical microseismic moment magnitude data measurements.

The goal of LSBC is to match the mean of the calculated values with the mean of the estimated/measured values. When used in climate science, bias correction methods, 
such as LSBC, are used because climate numerical models display systematic error (or bias) related to limited spatial data being available for use in the model, along with simplified physics, among other limitations. This can be related to the conditions experience in the numerical modeling of hydraulic fractures in a complex geologic environment with relatively low three-dimensional spatial data resolution and highly localized data availability. Using a similar methodology as is used in hydrology/climate science, LSBC can be applied to data calibration in hydraulic fracturing.

LSBC was applied in the current study to calibrate numerical model calculated primary hydraulic fracture heights, primary hydraulic fracture lengths, and surface pressures. The following equations (Equation 5.1 and Equation 5.2) were utilized in determining the calibrated primary hydraulic fracture height values:

$$
\begin{gathered}
H_{\text {cor }}=H_{\text {calc }} * C F_{H} \\
C F_{H}=\frac{\mu\left(H_{\text {est }}\right)}{\mu\left(H_{\text {calc }}\right)} .
\end{gathered}
$$

where:

$H_{\text {cor }}$ is the calibrated hydraulic fracture height value for a given stage (in feet)

$H_{\text {calc }}$ is the calculated hydraulic fracture height value for a given stage obtained from the numerical model (in feet)

$C F_{H}$ is the calibration factor for the hydraulic fracture heights

$\mu\left(H_{\text {est }}\right)$ is the mean value of the estimated fracture heights taken from the microseismic event cloud data (in feet)

$\mu\left(H_{\text {calc }}\right)$ is the mean value of the calculated fracture heights obtained from the numerical model (in feet) 
The following equations (Equation 5.3 and Equation 5.4) were utilized in determining the calibrated primary hydraulic fracture length values:

$$
\begin{gathered}
L_{\text {cor }}=L_{\text {calc }} * C F_{L} \\
C F_{L}=\frac{\mu\left(L_{\text {est }}\right)}{\mu\left(L_{\text {calc }}\right)} .
\end{gathered}
$$

where:

$L_{\text {cor }}$ is the calibrated hydraulic fracture length value for a given stage (in feet)

$L_{\text {calc }}$ is the calculated hydraulic fracture length value for a given stage obtained from the numerical model (in feet)

$C F_{L}$ is the calibration factor for the hydraulic fracture lengths

$\mu\left(L_{e s t}\right)$ is the mean value of the estimated fracture lengths taken from the microseismic event cloud data (in feet)

$\mu\left(L_{\text {calc }}\right)$ is the mean value of the calculated fracture lengths obtained from the numerical model (in feet)

The following equations (Equation 5.5 and Equation 5.6) were utilized in determining the calibrated surface pressure values:

$$
\begin{gathered}
S P_{\text {cor }}=S P_{\text {calc }} * C F_{S P} \\
C F_{S P}=\frac{\mu\left(S P_{m}\right)}{\mu\left(S P_{\text {calc }}\right)} \ldots
\end{gathered}
$$

where:

$S P_{c o r}$ is the calibrated surface pressure value for a given stage (in psi)

$S P_{\text {calc }}$ is the calculated surface pressure value for a given stage obtained from the numerical model (in psi)

$C F_{S P}$ is the calibration factor for the surface pressures 
$\mu\left(S P_{m}\right)$ is the mean value of the measured surface pressures taken from the field data (in psi)

$\mu\left(S P_{\text {calc }}\right)$ is the mean value of the calculated surface pressures obtained from the numerical model (in psi)

Equation 5.1 through Equation 5.6 were used to calculate calibrated numerical model primary fracture heights, primary fracture lengths, and surface pressures. The results of these calculations are presented in the following section. Next, in an attempt to remove outlying data points, approximately 20 to 25 percent of data points were removed from each of the three data sets (fracture height, fracture length, and surface pressure data sets). The results of the estimated microseismic fracture height versus calculated primary hydraulic fracture height produced a negative correlation, so a second correction needed to be implemented in order to generate a positive correlation between the two data sets. The fracture height data was normalized, in order to produce values between 0 and 1 on both axes. Next, the calculated primary hydraulic fracture heights were inverted by subtracting each value from one. After performing this inversion step, the data was converted back to non-normalized values.

A statistical value known as Kendall's Tau Coefficient or Kendall's Rank Correlation Coefficient (Kendall, 1970) was calculated in order to evaluate the data. The Kendall's Tau Coefficient value is used as part of a statistical approach for determining the rank correlation or association between two random variables from any bivariate population (Gibbons and Chakraborti, 2003). A rank correlation coefficient, such as Kendall's Tau, can be used to determine the significance of a relationship. Kendall's Tau coefficient is part of a non-parametric statistical method. A non-parametric statistical 
method makes no assumption about the probability distribution of the variables being analyzed. Non-parametric tests are quite robust when compared to parameteric tests, which are only valid if a number of assumptions are met, including that a certain probability distribution is appropriate for use. Non-parametric tests, such as the Kendall Tau, only require very general assumptions and are often about as good as other parametric tests, especially for smaller sample sizes (Gibbons and Chakraborti, 2003).

The assumptions made for the Kendall Tau test are very general and are met by the data sets used in the study presented in this paper. The data must be a bivariate population with independent pairs. This current data set includes a bivariate population with independent pairs of fracture heights, fracture lengths, and surface pressures. Kendall Tau makes no assumption with respect to the continuity of the population, as well, so this this not an issue in the current study. As these general assumptions are met in the current study, Kendall's Tau coefficient can be used with the data sets presented in this paper.

The formulation for calculating Kendall's Tau Coefficient is based on counting the number of $(\mathrm{i}, \mathrm{j})$ pairs $($ when $\mathrm{i}<\mathrm{j})$ that are concordant. Concordance occurs when $X_{a, i}-$ $X_{a, j}$ and $Y_{b, i}-Y_{b, j}$ have the same sign. $X$ is the matrix of the first set of data, $Y$ is the matrix of the second set of data, $X_{a, i}$ is the ith element in column a of matrix $X, X_{a, j}$ is the $\mathrm{jth}$ element in column a of matrix $X, Y_{b, i}$ is the ith element in column b of matrix $Y$, and $Y_{b, j}$ is the jth element in column b of matrix $Y$. For column $X_{a}$ in matrix $X$ and column $Y_{b}$ in matrix $Y$, Kendall's Tau Coefficient is defined as follows (Mathworks, 2019):

$$
\tau=\frac{2 K}{n(n-1)}
$$

where

$$
K=\sum_{i=1}^{n-1} \sum_{j=i+1}^{n} \xi^{*}\left(X_{a, i}, X_{a, j}, Y_{b, i}, Y_{b, j}\right)
$$




$$
\xi^{*}\left(X_{a, i}, X_{a, j}, Y_{b, i}, Y_{b, j}\right)=\left\{\begin{array}{c}
1 \text { if }\left(X_{a, i}-X_{a, j}\right)\left(Y_{b, i}-Y_{b, j}\right)>0 \\
0 \text { if }\left(X_{a, i}-X_{a, j}\right)\left(Y_{b, i}-Y_{b, j}\right)=0 \\
-1 \text { if }\left(X_{a, i}-X_{a, j}\right)\left(Y_{b, i}-Y_{b, j}\right)<0
\end{array}\right.
$$

\section{$\tau$ is Kendall's Tau Coefficient}

$\mathrm{n}$ is the length of each column

Kendall's Tau Coefficient can have values ranging from +1 to -1 . A value of -1 indicates that there is a reverse ranking between columns from the two matrices. A value of 0 indicates that there is no relationship between the columns from the two matrices. A value of +1 indicates that the rankings of the columns from the two matrices are the same (Mathworks, 2019). The closer the coefficient value is to +1 , the stronger the relationship between the columns from the two matrices. Thus, the results from Kendall's Tau Coefficient value can be thought of in a similar manner to $\mathrm{R}^{2}$ calculation results. Kendall Tau Coefficient calculations were performed using MATLAB for all three data sets and these results are shown in the following section.

A P value was also calculated for each of the three data sets. The P value, also called the probability value, associated probability, or the significance probability, is defined as the probability, when the null hypothesis is assumed to be true, that a sample result as extreme as, or more extreme than, the observed sample result is obtained (Gibbons and Chakraborti, 2003). The null hypothesis is the assumption that there is no relationship between two data sets. If the calculated $\mathrm{P}$ value is small enough, one can assume that the data sample being tested is particularly rare when assuming the null hypothesis. Thus, the null hypothesis is inconsistent with the data sample being tested and the null hypothesis should be rejected (Gibbons and Chakraborti, 2003). In order to test this $\mathrm{P}$ value for statistical significance and the rejection and the null hypothesis, a value needs to be selected 
as a maximum bound for rejecting the null hypothesis. This value will be called alpha, $\alpha$. If the $\mathrm{P}$ value obtained for each data set is less than or equal to $\alpha$, the null hypothesis is rejected. If the $\mathrm{P}$ value obtained for each data set is greater than $\alpha$, the null hypothesis will not be rejected. Commonly, values of 0.01 or 0.05 are used for $\alpha$ (Gibbons and Chakraborti, 2013; Mathworks, 2019). P value calculations were performed using MATLAB for all three data sets and the results are shown in the following section. 


\subsection{Statistical Analysis of Numerical Modeling Results}

The first step in the statistical analysis of numerical model results was to find the mean values of the estimated/measured data and the calculated data. After these means were found, the calibration factors $C F_{H}$ (height), $C F_{L}$ (length), and $C F_{S P}$ (surface pressure) were calculated. The following values were found for these calibration factors:

$$
\begin{gathered}
C F_{H}=1.61 \\
C F_{L}=1.13 \\
C F_{S P}=1.05
\end{gathered}
$$

Using these calibration factors with the methodology which was described in the previous section, updated results were obtained for the three data sets which compare the estimates/measurements with calculated values. Figure 5.26 shows the updated results for the fracture height data, Figure 5.27 shows the updated results for the fracture length data, and Figure 5.28 shows the updated results for the surface pressure data. As can be seen in these updated graphs, there appears to be a correlation between calculations and field estimates/measurements. 


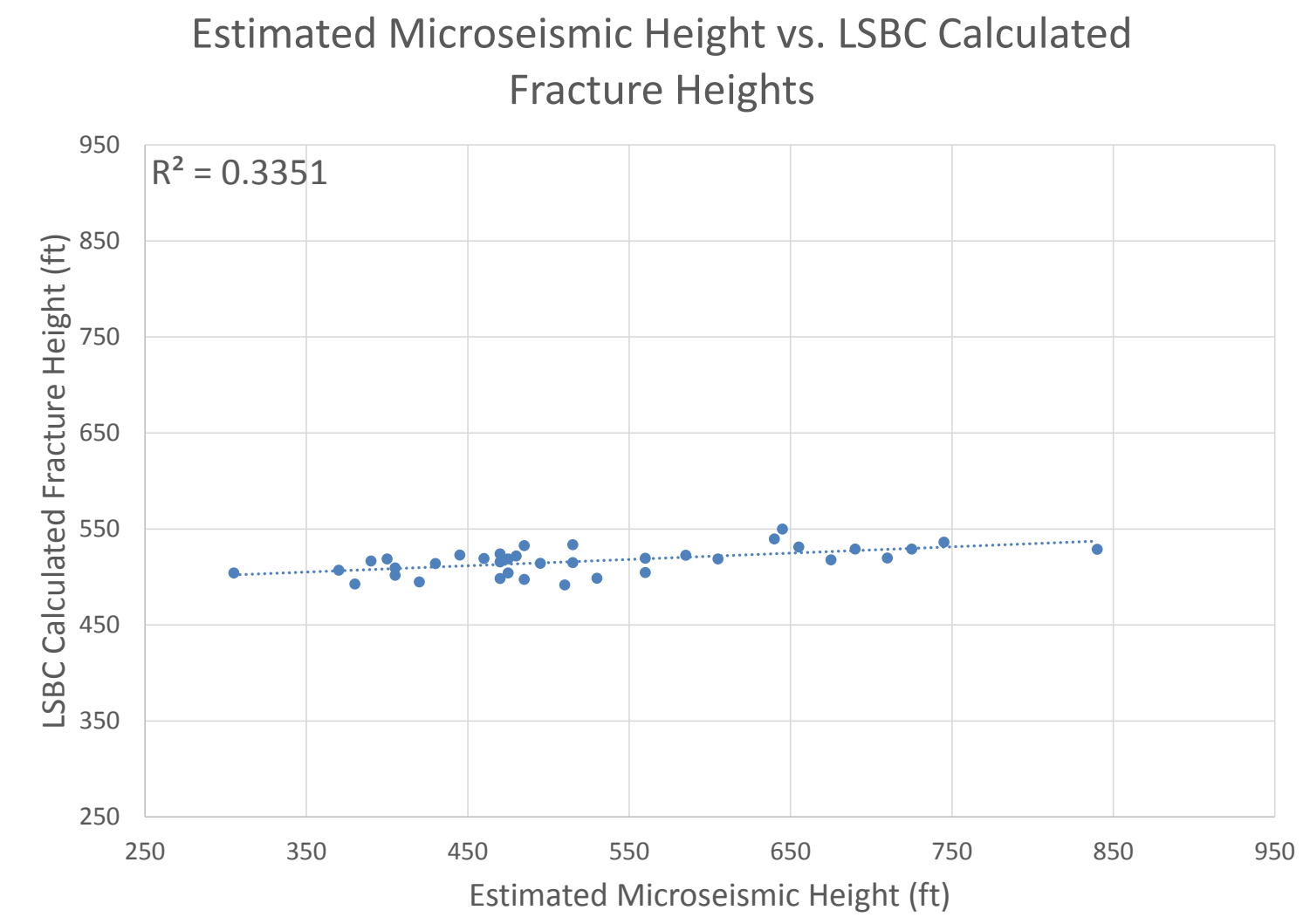

Figure 5.26: Estimated* Microseismic Heights vs. LSBC Calculated Primary Hydraulic Fracture Heights - Wells MIP-3H and MIP-5H

* Estimates were made by a commercial organization who also work in the MSEEL project. 


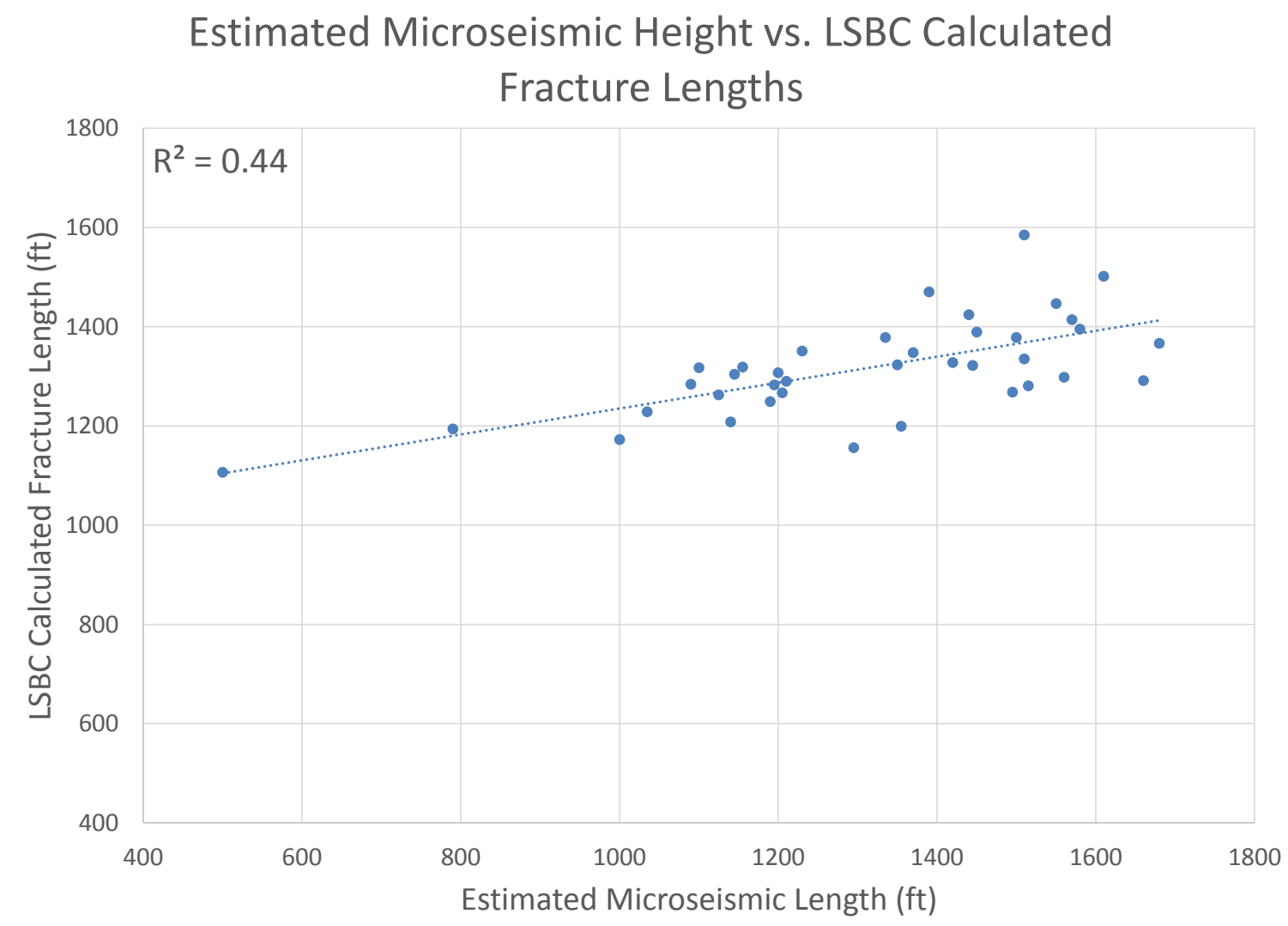

Figure 5.27: Estimated* Microseismic Lengths vs. LSBC Calculated Primary Hydraulic Fracture Lengths - Wells MIP-3H and MIP-5H

* Estimates were made by a commercial organization who also work in the MSEEL project. 


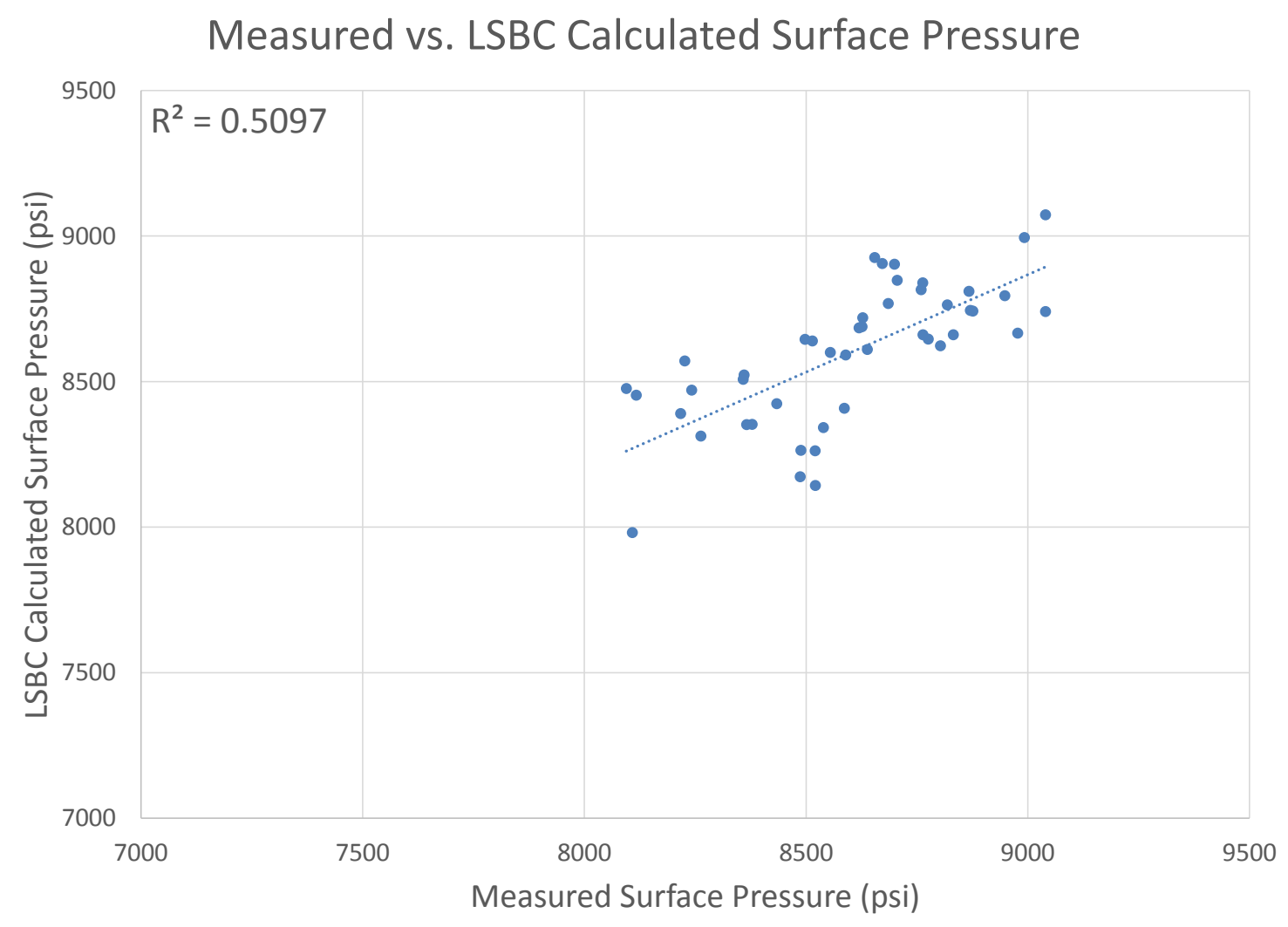

Figure 5.28: Measured Surface Pressures vs. LSBC Calculated Surface Pressures Wells MIP-3H and MIP-5H 
Finally, Kendall's Tau Coefficient and the corresponding P value was calculated for each of the three data sets. These values were calculated using the methodology detailed in the previous section. Table 5.9 shows the results obtained for Kendall's Tau Coefficient values and $\mathrm{P}$ values for each of the three aforementioned data sets.

Table 5.9: Kendall's Tau Coefficients and $P$ Values for Height, Length, and Surface Pressure Data Sets

\begin{tabular}{|c|c|c|}
\hline & Kendall's Tau Coefficient & P Value \\
\hline Height & 0.395 & $6.64 \mathrm{E}-04$ \\
\hline Length & 0.480 & $2.39 \mathrm{E}-05$ \\
\hline Surface Pressure & 0.523 & $7.08 \mathrm{E}-08$ \\
\hline
\end{tabular}

From the resulting Kendall's Tau Coefficients, it can be noted that each data pair exhibits some degree of correlation. For the complexity of the geologic setting and the numerous variables involved in prediction of these quantities, these can be considered a good match. With respect to the $\mathrm{P}$ values, each is very small and well below (by a minimum of two orders of magnitude) the commonly used upper bounds, $\alpha$, of 0.05 and 0.01 . Since all of the $\mathrm{P}$ values are less than the $\alpha$ values, the null hypothesis can be rejected for all three data sets. Thus, there must be a significant relationship between the data sets, as shown in Figure 5.26 through Figure 5.28. 


\subsection{Future Work}

This work was limited to one field site with two wells and 58 stages. Also, not all of the stages at both of the wells were microseismically monitored. Due to these limitations, further field studies should be carried out and should be combined with numerical modeling to determine applicability to other geologic environments. Further studies can refine the calibration factors and draw better correlations between numerical modeling calculations, microseismic estimations, and surface pressure measurements. With an increased amount of data points, additional statistical methods can be applied to determine correlation and any potentially appropriate distributions that the data may fit. In the current study, the limited amount of data points restricted the statistical analysis to a degree.

In this work and in most studies, propped fracture lengths have not been used due to the lack of comparative data. Recently, a new conductive coating has been developed for proppant which allows for the use of electromagnetic testing to potentially determine the extent of proppant within created fractures (Palisch et. al., 2016). The proppant coating and detection methodology are still being developed and are not yet widely used. In the future, this work could be extended to conduct a comparison of field measurements of propped fracture lengths and heights with numerical model calculations of propped fracture lengths and heights. The same methodology developed in this paper of using Linear Scaling Bias Correction (LSBC) and calibration factors to calculate field measurements of propped fracture dimensions could be employed in the future. Also, the same or a similar statistical analysis methodology can be used to draw comparisons and determine the statistical significance of these data sets, depending upon the number of hydraulic fracturing stages studied. 


\section{CHAPTER 6 : SUMMARY AND CONCLUSIONS}

An ability to predict the extent of hydraulic fracture growth in the complex subsurface geologic environment is essential to ensure that induced hydraulic fractures are located at a safe distance below groundwater aquifers. The geometry of propped hydraulic fractures is the controlling factor for natural gas production rates; thus, the predictability of hydraulic fracture growth is critical for determining the economic viability of the fracturing operation. This research aimed to address these issues.

The objectives of this research were as follows:

- The primary goal of this research was to calibrate a commercially-available (MShale, Baker Hughes Reservoir Software, 2015) pseudo three-dimensional (P3D) numerical model and use a statistical approach to predict the extent of microseismic events in shale reservoirs in order to ensure both safe distances between fractures and groundwater aquifers and the efficient determination of microseismic geometric dimensions and surface pressures. Microseismic measurements are costly and the use of P3D numerical modeling to predict the extent of hydraulic fractures can save both time and money.

- Assess and develop the geologic, geomechanical, and treatment parameters based on available field data for numerical modeling of the MSEEL field site (Northeast Natural Energy, 2015). Develop a methodology for converting large amounts of measured field treatment data into smaller sections of data appropriate for numerical modeling. Use available literature to find appropriate geologic and geomechanical properties that are not available from field data for use in numerical 
modeling. Analyze available microseismic data collected by others at the MSEEL site from the VSI geophone array used to compare with computed hydraulic fracture geometries for all available stages at both wells (MIP-3H and MIP-5H) at the MSEEL project site.

- Build the numerical model from available literature and field data for the MSEEL project site. Compute primary hydraulic fracture geometries for all stages at both wells (MIP-3H and MIP-5H) at the MSEEL project site.

- Investigate any observed discrepancy between calculated hydraulic fracture geometries and reported microseismic event clouds. Potentially modify geomechanical properties in order to better match microseismic events.

- Use a statistical method to obtain a better match between field estimates and measurements with numerical model calculations.

A hydraulic fracturing field site was selected as a research site (MSEEL, 2019). This field site is known as the Marcellus Shale Energy and Environment Laboratory (MSEEL). The MSEEL project site is a collaboration between two universities, the National Energy and Technology Laboratory (NETL) in Morgantown, WV (a DOE laboratory), a commercial energy company (responsible for managing well site daily operations), and a commercial fracturing contractor (responsible for completions and microseismic monitoring). All of these collaborators worked together to accomplish the project objective set forth at the project start. The overall project objective is "to provide a long-term field site to develop and validate new knowledge and technology to improve 
recovery efficiency and minimize environmental implications of unconventional resource development.” (MSEEL, 2019)

The field site already has two previously drilled horizontal wells, which are still currently producing hydrocarbons (MIP-4H and MIP-6H). No microseismic monitoring data was available from MIP-4H and MIP-6H. Two new horizontal wells, MIP-3H and MIP-5H, have been drilled especially for the MSEEL research project at the same site. These wells have been completed and are currently producing natural gas. A science well was also drilled in a separate location nearby to monitor microseismic events, among other objectives. The science well incorporated an array of twelve geophones to monitor microseismic events produced during hydraulic fracturing operations for wells MIP-3H and MIP-5H. The geophones used were Versatile Seismic Imagers (VSIs), which capture seismic waveforms produced during hydraulic fracturing (Schlumberger, 2004). The collected data was processed and interpreted by other members of the research team to determine the locations and magnitudes of the microseismically-detected events.

The primary objective of the current work was to perform numerical modeling of hydraulic fracturing operations at wells MIP-3H and MIP-5H, perform comparisons with microseismic events, and use a statistical methodology to match and determine correlation with field measurements/estimates. Available geologic, geomechanical, and treatment data was acquired from available literature and/or field data to build the numerical model for the MSEEL project site. Numerical modeling of all stages at the MSEEL project site (28 stages at well MIP-3H and 30 stages at well MIP-5H) was performed in order to determine the geometries of induced hydraulic fractures/discrete fracture networks. Available 
microseismic data was utilized in making comparisons with hydraulic fracture numerical modeling results and to improve the numerical model.

The statistical methodology was employed through the use of Linear Scaling Bias Correction (LSBC) to form better agreement with field measurements and estimates. After using the methodology, which included bias correction, a better match was obtained between estimated/measured and calculated heights, lengths, and surface pressures. Finally, in order to test for correlation and statistical significance, Kendall's Tau Coefficients and $\mathrm{P}$ values were calculated for each of the three data sets analyzed. These resulting calculated values showed that there was a degree of correlation between the data sets and that the correlation was statistically significant, as the null hypothesis was rejected. The methodology developed in this study can be applied to other field sites in other geologic environments. Calibration factors can be developed to better match numerical model calculations with field estimates/measurements. 


\section{REFERENCES}

1. Adachi, J., Detournay, E., and Peirce, A. 2010. Analysis of the classical pseudo-3D model for hydraulic fracture with equilibrium height growth across stress barriers. International Journal of Rock Mechanics and Mining Sciences, 47: 625 - 639.

2. Adams, E. 2017. Introduction on Bias Correction Methods. NASA Training. Nairobi, Kenya.

3. Arthur, J., Bohm, B., and Layne, M. 2008. Hydraulic Fracturing Considerations for Natural Gas Wells of the Marcellus Shale. The Ground Water Protection Council. Cincinatti, $\mathrm{OH}$.

4. Baker Hughes Reservoir Software. 2015. MFrac Suite User's Guide. MFrac Suite 10 Hydraulic Fracturing Software. Build 1981 (64-bit), built 2015-07-27.

5. Bazan, L. 2012. Personal Communication at MFrac Training Session. Pittsburgh, PA.

6. Belyadi, H., Fathi, E., and Belyadi, F. 2017. Hydraulic Fracturing in Unconventional Reservoirs - Theories, Operations, and Economic Analysis. Elsevier. Online version available at: https://app.knovel.com/hotlink/toc/id:kpHFURTOE1/hydraulicfracturing/hydraulic-fracturing

7. Bennett, J., Grose, M., Corney, S., White, C., Holz, G., Katzfey, J., Post, D., and Bindoff, N. 2014. Performance of an empirical bias-correction of a high-resolution climate dataset. Int. J. Climatol. 34: 2189 - 2204.

8. Bird, R.B, Stewart, W.E., Lightfoot, E.N. 1965. Transport Phenomena, J. Wiley \& Sons Inc., NY, page 204. 
9. Blanton, T. An Experimental Study of Interaction Between Hydraulically Induced and Pre-Existing Fractures. SPE/DOE Unconventional Gas Recovery Symposium. Pittsburgh, PA, May $16-18$.

10. Brady, B., Elbel, J., Mack, M., Morales, H., Nolte, K., and Poe, N. 1992. Cracking rock: Progress in fracture treatment design. Oilfield Review, October: 4 - 17.

11. Brasier, K., Filteau, M., McLaughlin, D., Jacquet, J., Stedman, R., Kelsey, T., and Goetz, S. 2011. Redidents' Perceptions of Community and Environmental Impacts from Development of Natural Gas in the Marcellus Shale: A Comparison of Pennsylvania and New York Cases. Journal of Rural Social Sciences: 26(1), p. 32.

12. Busby, Mattha. 2018. Minor earthquakes detected near fracking site in Lancashire. The Guardian. October 20, 2018. Web. October 23, 2018. https://www.theguardian.com/environment/2018/oct/20/minor-earthquakesdetected-near-cuadrilla-fracking-site-in-lancashire

13. Carr, T., Martin, A., Ameri, S., Aminian, K., Barnes, M., Bilgesu, H.I., Carney, B.J., Cole, D., Daniels, J., Darrah, T., et. al. 2014. Marcellus Shale Energy and Environment Laboratory. Project Narrative Proposal. FOA Number DE-FOA0001076. June, 25.

14. Carter, R. 1957. Optimum fluid characteristics for fracture extension. In: Howard, G., Fast, C. (eds.) Drilling and Production Practices, 261-270. American Petroleum Institute.

15. Cipolla, C., Maxwell, S., and Mack, M. 2012. Engineering Guide to the Application of Microseismic Interpretations. SPE Hydraulic Fracturing Technical Conference. The Woodlands, TX, USA. 6 - 8 February. 
16. Committee on Induced Seismicity Potential in Energy Technologies, 2013. Induced seismicity potential in energy technologies. Washington, D.C., U.S.A: The National Academies Press.

17. Considine, T., Watson, R., Entler, R. and Sparks, J. 2009. An emerging giant: Prospects and economic impacts of developing the Marcellus shale natural gas play. University Park, PA: The Pennsylvania State University, Dept. of Energy and Mineral Engineering. August.

18. Cooper, N. 2002. Geophone Arrays in Today's World of 2D and 3D. J. Can. Soc. Explor. Geophys. pp.1 -2 .

19. Cruz, L., Fu, P., Izadi, G., Moos, D., Sheridan, J., Settgast, R., and Ryerson, F. 2016. The Role of Natural Fractures (Joints) in the Marcellus Shale During Hydraulic Fracture Stimulation Using Full 3D Modeling. Unconventional Resources Technology Conference. San Antonio, TX.

20. Daniels, J., Waters, G., LeCalvez, J., Lassek, J., and Bentley, D. 2007. Contacting More of the Barnett Shale Through an Integration of Real-Time Microseismic Monitoring, Petrophysics and Hydraulic Fracture Design. SPE Annual Technical Conference and Exhibition. Anaheim, CA, USA. October 12-14.

21. Davies, R., Mathias, S., Moss, J., Hustoft, S., and Newport, L. 2012. Hydraulic fractures: How far do they go? Marine and Petroleum Geology 37: 1 - 6 .

22. Davies, R. Foulger, G., Bindley, A., and Styles, P. 2013. Induced seismicity and hydraulic fracturing for the recovery of hydrocarbons. Marine and Petroleum Geology 45: $171-185$. 
23. Detring, J. and Williams-Stroud, S., 2013. The use of microseismicity to understand subsurface-fracture systems and to increase the effectiveness of completions: Eagle Ford shale, Texas. SPE Reservoir Eval. Eng. September.

24. Dontsov, E. and Peirce, A. 2015. An enhanced pseudo-3D model for hydraulic fracturing accounting for viscous height growth, non-local elasticity, and lateral toughness. Engineering Fracture Mechanics, 142: 116 - 139.

25. Dunn-Norman, S., Hufford, W., and Almond, S.W. 2018. A Summary of the US Environmental Protection Agency's Multiyear Study of the Potential Impacts of Hydraulic Fracturing on Drinking Water Resources. SPE Hydraulic Fracturing Technology Conference and Exhibition. The Woodlands, TX.

26. Engelder, T. and Lash, G. 2008. Marcellus Shale Play's Vast Resource Potential Creating Stir in Appalachia. The American Oil \& Gas Reporter. May.

27. Engelder, T., Lash, G. G., and Uzcátegui, R. S., 2009. Joint sets that enhance production from Middle and Upper Devonian gas shales of the Appalachian Basin. AAPG bulletin 93(7), 857-889.

28. Estrada, E., Roberts, N., Weijers, L., Riebel, and Logan, S. 2009. Fracture Mapping in the San Juan Basin, New Mexico. SPE annual Technical Conference and Exhibition. New Orleans, LA.

29. Fang, G., Yang, J., Chen, Y., and Zammit, C. 2015. Comparing bias correction methods in downscaling meteorological variables for a hydrologic impact study in an arid area in China. Hydrol. Earth Syst. Sci., 19, 2547 - 2559.

30. Fisher, K. and Warpinski, N. 2012. Hydraulic-Fracture-Height Growth: Real Data. SPE Production \& Operations, $8-19$, February. 
31. Fontaine, J., Johnson, N., and Schoen, D. 2008. Design, execution, and evaluation of a "typical" Marcellus Shale slickwater stimulation: A case history. 2008 Eastern Regional/AAPG Eastern Section Joint Meeting, Pittsburgh, Pennsylvania, October 11-15, Society of Petroleum Engineers Paper No. 117772, 11 p.

32. Fu, P, Johnson, S., and Carrigan, C. 2013. An explicitly coupled hydrogeomechanical model for simulating hydraulic fracturing in arbitrary discrete fracture networks. Int. J. Numer. Anal. Meth. Geomech. 37: 2278 - 2300.

33. Geertsma, J., \& de Klerk, F. 1969. A Rapid Method of Predicting Width and Extent of Hydraulically Induced Fractures. Journal of Petroleum Technology, 1571-1581.

34. Geertsma, J., \& Haafkens, R. 1979. A Comparison of the Theories for Predicting Width and Extent of Vertical Hydraulically Induced Fractures. Journal of Energy Resources Technology, 8-19.

35. Gibbons, J., and Chakraborti, S. 2003. Nonparametric Statistical Inference. 4th ed. M. Dekker, New York. ISBN: 0-8247-4052-1.

36. Hill, E. and Ma, L. 2017. Shale gas development and drinking water quality. American Economic Review: 107(5), pp.522-25.

37. Hu, H., A. Li, and R. Zavala-Torres. 2017. Long-period long-duration seismic events during hydraulic fracturing: Implications for tensile fracture development, Geophys. Res. Lett., 44, 4814-4819. doi:10.1002/2017GL073582.

38. Hubbert, M.K. and Willis, D.G. 1957. Mechanics of Hydraulic Fracturing. M 18: Underground Waste Management and Environmental Implications. 239 - 257.

39. Hyman, J.D. et. al. 2016. Understanding hydraulic fracturing: a multi-scale problem. Phil. Trans. R. Soc. A. 374: 20150426. 
40. Jackson, R., Vengosh, A., Darrah, T., Warner, N., Down, A., Poreda, R., Osborn, S., Zhao, K., and Karr, J.D. 2013. Increased stray gas abundance in a subset of drinking water wells near Marcellus shale gas extraction. Proceedings of the National Academy of Sciences: 110(28), 11250 - 11255.

41. Jacot, R., Bazan, L., and Meyer, B. 2010. Technology Integration: A Methodology to Enhance Production and Maximize Economics in Horizontal Marcellus Shale Wells. SPE Annual Technical Conference and Exhibition. Florence, Italy. September. Society of Petroleum Engineers.

42. Jadidzadeh, A. and Serletis, A. 2017. How does the US natural gas market react to demand and supply shocks in the crude oil market? Energy Economics: 63, pp. 66 $-74$.

43. Kargbo, D., Wilhelm, R., and Campbell, D. 2010. Natural Gas Plays in the Marcellus Shale: Challenges and Potential Opportunities. Environmental Science and Technology: 44(15), pp.5679-5684.

44. Keller, D., Horwitz, R., Mead, J., and Belton, T. 2017. Natural gas drilling in the Marcellus Shale region: well pad densities and aquatic communities. Hydrobiologia: 795(1), pp.49-64.

45. Kendall, M. 1970. Rank Correlation Methods. Griffin.

46. Khristianovic, S. and Zheltov, Y. 1955. Formation of Vertical Fractures by Means of Highly Viscous Liquid. Proceedings Fourth World Petroleum Congress Section II/T.O.P. 
47. King, G. 2012. Hydraulic Fracturing 101: What Every Representative, Environmentalist, Regulator, Reporter, Investigator, University Researcher, Neighbor and Engineer Should Know About Estimating Frac Risk and Improving Frac Performance in Unconventional Gas and Oil Well. SPE Hydraulic Fracturing Technology Conference. The Woodlands, TX.

48. Kresse, O., Weng, X., Gu, H., and Wu, R. 2013. Numerical modeling of hydraulic fractures interaction in complex naturally fractured formations. Rock mechanics and rock engineering, 46(3), pp. $555-568$.

49. Kumar, A., Zorn, E., Hammack, R., and Harbert, William. 2016. Surface Seismic Monitoring of Hydraulic Fracturing Activity in Pennsylvania and West Virginia. Unconventional Resources Technology Conference. San Antonio, TX.

50. Lei, Q., Latham, J-P., and Tsang, C-F. 2017. The use of discrete fracture networks for modelling coupled geomechanical and hydrological behavior of fracture rocks. Computers and Geotechnics 85: 151 - 176.

51. Llewellyn, G., Dorman, F., Westland, J., Yoxtheimer, D., Grieve, P, Sowers, T., Humston-Fulmer, E., and Brantley, S. 2015. Evaluating a groundwater supply contamination incident attributed to Marcellus Shale gas development. Proceedings of the National Academy of Sciences: 112(20): $6325-6330$.

52. Marcellus Center for Outreach and Research, 2010. Wet-Dry Gas - Depth to Marcellus Shale Base. University Park, PA, U.S.A. Retrieved from http://www.marcellus.psu.edu/resources/maps.php on June 6, 2017.

53. Marcellus Center for Outreach and Research, 2018. Marcellus Shale Thickness. $\begin{array}{lllll}\text { University } & \text { Park, } & \text { PA, } & \text { USA. } & \text { Retrieved }\end{array}$ 
http://www.marcellus.psu.edu/resources/images/marcellus-thickness.gif

February 15, 2018.

54. Mathworks. 2019. Kendall's Tau Coefficient. MATLAB R2018b Documentation. Found in "corr" function definition documentation. Accessed on March 11, 2019. https://www.mathworks.com/help/stats/corr.html\#mw_e263787a-88e2-46038e9b-a3d5600c2a19

55. Mayerhofer, M.J., Lolon, E.P., Youngblood, J.E., and Heinze, J.R. 2006. Integration of Microseismic Fracture Mapping Results with Numerical Fracture Network Production Modeling in the Barnett Shale. SPE Annual Technical Conference and Exhibition. San Antonio, TX, USA. 24 - 27 September.

56. Meyer, B. 1986. Design Formulae for 2-D and 3-D Vertical Hydraulic Fractrures: Model Comparison and Parametric Studies. Unconventional Gas Technology Symposium of the Society of Petroleum Engineers. Louisville, KY, USA.

57. Meyer, B., \& Hagel, M. 1989. Simulated mini-frac analysis. Journal of Canadaian Petroleum Technology, 63-73.

58. Meyer, B. and Bazan, L. 2011. A discrete fracture network model for hydraulically induced fractures-theory, parametric and case studies. SPE Hydraulic Fracturing Technology Conference. The Woodlands, TX, USA. January. Society of Petroleum Engineers.

59. MSEEL Database Development Team. 2015. Quarterly Research Performance Progress Report. Figure 1.2. Period ending: 6/30/2015. July 31, 2015.

60. MSEEL. 2019. Accessed on March 14, 2019 from: http://mseel.org 
61. Nolte, K. 1986. Determination of Proppant and Fluid Schedules from FracturingPressure Decline. SPE Production Engineering, July: 255-265.

62. Nordgren, R. 1972. Propagation of a Vertical Hydraulic Fracture. Society of Petroleum Engineers Journal , 306-314.

63. Northeast Natural Energy. 2015. Completions Procedure MIP 3H Monongalia County West Virginia. Ian Costello. November 5.

64. Osborn, S., Vengosh, A., Warner, N., and Jackson, R. 2011. Methane contamination of drinking water accompanying gas-well drilling and hydraulic fracturing. Proceedings of the National Academy of Sciences: 108(20), pp.8172 8176.

65. OSHA. 2019. Illustrated Glossary. Retrieved February 18, 2019 from Occupational $\begin{array}{llll}\text { Safety } & \& & \text { Health } & \text { Administration }\end{array}$ https://www.osha.gov/SLTC/etools/oilandgas/illustrated_glossary.html

66. Osman, T.M., and Bilgesu, H.I. 2015. Impact of Geo-Mechanical Properties on the Fracture Treatment of Utica Shale. SPE Eastern Regional Meeting. Morgantown, WV, USA. 13 - 15 Octboer.

67. Palisch, T., Al-Taiji, W., Bartel, L., Cannan, C., Czapski, M., and Lynch, K. 2016. Recent Advancements in Far-Field Proppant Detection. SPE Hydraulic Fracturing Technology Conference. The Woodlands, TX, USA. 9 - 11 February.

68. Palmer, I, Moschovidis, Z., and Schaefer, A. 2013. Microseismic Clouds: Modeling and Implications. SPE Americas Unconventional Resources Conference, Pittsburgh, PA. June $5-7$. 
69. Peirce, A. and Detournay, E. 2008. An implicit level set method for modeling hydraulically driven fractures. Comput. Methods Appl. Mech. Engrg. 197: 2858 2885.

70. Peirce, A. 2015. Modeling multi-scale processes in hydraulic fracture propagation using the implicit level set algorithm. Comput. Methods Appl. Mech. Engrg. 283: 881- 908.

71. Perkins, T., \& Kern, L. 1961. Widths of Hydraulic Fractures. Journal of Petroleum Technology, 937-949.

72. Peters, J. and Hertel, T. 2017. Achieving the Clean Power Plan 2030 CO2 target with the new normal in natural gas prices. The Energy Journal: 38(5), $23-50$.

73. Raziperchikolaee, S., Alvarado, V., and Yin, S. 2014. Microscalemodeling of fluid flow-geomechanics-seismicity: Relationship between permeability and seismic source response in deformed rock joints. J. Geophys. Res. Solid Earth, 119: 69586975.

74. Roussel, N., Florez, H., Rodriguez, A., and Agrawal, S. 2018. Method for Determining Hydraulic Fracture Orientation and Dimension. United States Patent No. US 9,988,895 B2.

75. Rozell, D. and Reaven, S. 2012. Water pollution risk associated with natural gas extraction from the Marcellus Shale. Risk Analysis, 32(8): 1382 - 1393.

76. Savalli, L. and Engelder, T. 2005. Mechanisms controlling rupture shape during subcritical growth of joints in layered rocks. Geological Society of America Bulletin. March/April. 
77. Schlumberger. 2004. VSI Versatile Seismic Imager. Product Information Sheet. $\begin{array}{lllll}\text { Accessed } & \text { on } & \text { February } & \text { 16, } & 2018 \text { from: }\end{array}$ https://www.slb.com/ /media/Files/seismic/product_sheets/vsi_ds.pdf

78. Schlumberger. 2014. Sapphire VF. Guar-free viscoelastic fracturing fluid. Product Information Sheet. Available online: 08/11/2014. Accessed on February 26, 2018 from:

https://www.slb.com/resources/other_resources/product_sheets/stimulation/sapphi re_vf_ps.aspx

79. Shakiba, M. and Sepehrnoori, K. 2015. Using Embedded Discrete Fracture Model (EDFM) and Microseismic Monitoring Data to Characterize the Complex Hydraulic Fracture Networks. SPE Annual Technical Conference and Exhibition. Houston, TX. September $28-30$.

80. Shemeta, J.E., Maxwell, S., Warpinski, N.R., Quimby, S., Riebel, T., Phillips, Z., Kinser, J.R., Hinds, G., Green, T.W., and Waltman, C.K. 2007. Stacking Seismograms To Improve Microseismic Images. SPE Rocky Mountain Oil \& Gas Technology Symposium. Denver, Colorado.

81. Sneddon, I. 1973. Integral Transform Methods. In Mechanics of fracture I, Methods of analysis and solutions of crack problems. Leyden: G.C. Nordhoff International.

82. Soeder, D. and Kappel, W. 2009. Water resources and natural gas production from the Marcellus Shale. pp. 1-6. Reston, Virginia: US Department of the Interior, US Geological Survey.

83. Starr, J. 2011. Closure stress gradient estimation of the Marcellus Shale from seismic data. In 2011 SEG Annual Meeting. Society of Exploration Geophysicists. 
84. Stolyarov, S. and Sookprasong, A. 2013. Multi-Stage Large Scale Hydraulic Fracturing in Horizontal Well, a First in India. SPE Unconventional Resources Conference and Exhibition - Asia Pacific. Brisbane, Australia. 11 - 13 November. 85. U.S. Energy Information Administration. 2016. Updated geologic maps provide greater detail for Marcellus formation. [Press Release]. Retrieved from https://www.eia.gov/todayinenergy/detail.php?id=20612.

86. U.S. Energy Information Administration. 2018. Annual Energy Outlook 2018 with projections to 2050. Published February 6, 2018. Available from: https://www.eia.gov/aeo

87. U.S. EPA. 2016. Hydraulic Fracturing for Oil and Gas: Impacts from the Hydraulic Fracturing Water Cycle on Drinking Water Resources in the United States (Final Report). U.S. Environmental Protection Agency, Washington, DC, EPA/600/R$16 / 236 \mathrm{~F}$.

88. U.S. Silica. 2010. Ottawa White Frac Sand Series. Product Data Sheet. Available on: 10/15/2010. Accessed on: 02/26/2018 from: http://www.ussilica.com/sites/ussilica.com/uploads/files/product-datasheets/location/ottawa/Ottawa-White-Frac-Sand-Series.pdf

89. Valko, P., and Economides, M. J., 1995. Hydraulic Fracture Mechanics. West Sussex: John Wiley \& Sons Ltd.

90. Veatch, R.W., King, G.E., and Holditch, S.A. 2017. Essentials of Hydraulic Fracturing: Vertical and Horizontal Wellbores. Tulsa, OK: PennWell Corp.

91. Warpinski, N., Wright. T., Uhl, J., Drozda, P., Peterson, R., and Branagan, P. 1996. Microseismic Monitoring of the B-Sand Hydraulic Fracture Experiment at the 
DOE/GRI Multi-Site Project. SPE Annual Technical Conference and Exhibition. Denver, CO. October 6 - 9.

92. Warpinski, N., Branagan, P., Peterson, R., Fix, J., Uhl, J., Engler, B., and Wilmer, R. 1997. Microseismic and Deformation Imaging of Hydraulic Fracture Growth and Geometry in the C Sand Interval, GRI/DOE M-Site Project. SPE Annual Technical Conference and Exhibition. San Antonio, TX. October 5 - 8.

93. Warpinski, N. 2013. Understanding Hydraulic Fracture Growth, Effectiveness, and Safety Through Microseismic Monitoring, Effective and Sustainable Hydraulic Fracturing, Dr. Rob Jeffrey (Ed.), InTech, DOI: 10.5772/55974. Available from: https://www.intechopen.com/books/effective-and-sustainable-hydraulicfracturing/understanding-hydraulic-fracture-growth-effectiveness-and-safetythrough-microseismic-monitoring

94. Warpinski, N., and Wolhart, S. 2016. A Validation Assessment of Microseismic Monitoring. SPE Hydraulic Fracturing Technology Conference. The Woodlands, TX, USA. February $9-11$.

95. Weng, X. 1992. Incorporation of 2D fluid flow into a pseudo-3D hydraulic fracturing simulator. SPE Production Engineering, 4: 331-337.

96. Weng, X. 2015. Modeling of complex hydraulic fractures in naturally fractured formation. Journal of Unconventional Oil and Gas Resources, 9: 114 - 135.

97. Westaway, R. 2016. The importance of characterizing uncertainty in controversial geoscience applications: induced seismicity associated with hydraulic fracturing for shale gas in northwest England. Proceedings of the Geologists' Association. 127: 1 $-17$. 
98. Wilson, M.P., Foulger, G.R., Gluyas, J.G., Davies, R.J., and Julian, B.R. 2017. HiQuake: The Human-Induced Earthquake Database. Seismological Research Letters, 88(6): $1560-1565$.

99. Wrightstone, G. 2009. Marcellus Shale-Geologic Controls on Production. In AAPG Annual Convention, Denver, CO, Jun 7-10.

100. WV GIS Technical Center. 2014. Unconventional Hydrocarbon Resources. Developed by the West Virginia GIS Technical Center (WVGISTC). http://www.unconventionalenergyresources.org/

101. Zagorski, W., Wrightstone, G., and Bowman, D. 2012. The Appalachian Basin Marcellus gas play: Its history of development, geologic controls on production, and future potential as a world-class reservoir, in J. A. Breyer, ed., Shale reservoirs - Giant resources for the 21st century: AAPG Memoir 97, p. 172 $-200$.

102. Zhang, X., Holland, M., van der Zee, W., and Moos, D. 2014. Microseismic Estimates of Stimulated Rock Volume Using a Detection-Range Bias Correction: Theory and Case Study. SPE Hydraulic Fracturing Technology Conference. The Woodlands, TX, USA. 4 - 6 February.

103. Zhang, X., Wu, B., Dontsov, E., Jeffrey, R., Han, Y., and Quinlan, K. 2017. A new pseudo-3D model for hydraulic fracture height growth in multilayered rocks. $51^{\text {st }}$ US Rock Mechanics/Geomechanics Symposium. San Fransisco, CA, USA. 2528 June.

104. Zhu, H., Lin, Y., Meng, Y., Zhao, S, Liu, D., and Luo, F. 2010. Influence of Relevant Parameters on Hole Cleaning and Pipe String Erosion in Air Drilling. 
SPE Oil and Gas India Conference and Exhibition. Mumbai, India. January 20 22.

105. Zorn, E., Harbert, W., Hammack, R., and Kumar, A. 2017. Geomechanics of the Microseismic Response in Devonian Organic Shales at the Marcellus Shale Energy and Environment Laboratory (MSEEL) Site, West Virginia. Unconventional Resources Technology Conference. Austin, Texas. July $24-26$. 


\section{APPENDIX A - Numerical Modeling Results for Stages 11-28 at Well MIP-3H and all Stages at Well MIP-5H}

Table A.1 shows the computed fracture geometries for newly modeled MIP-3H stages 11 through 20. Figure A.1 shows the fracture geometry for one of the primary induced hydraulic fractures in stage 20 of well MIP 3H. Figure A.2 shows the cumulative proppant mass versus time (modeled vs measured), Figure A.3 shows the slurry volume injected versus time (modeled vs measured), and Figure A.4 shows the surface pressure versus time (modeled vs measured) for stage 20 of well MIP-3H.

Microseismic data was available for all of the stages modeled in this set. Microseismic, well, and hydraulic fracture geometric data were visualized in three dimensions. Figures A.5 through A.14 show side views of calculated hydraulic fracture geometries and measured microseismic events and magnitudes for stages 11 through 20, respectively, for well MIP-3H. Figure A.15 shows an overview of all 10 modeled hydraulic fracture geometries, microseismic events, and the entire MIP-3H wellbore. Figure A.16 shows a top view of all newly modeled hydraulic fracture geometries, microseismic events, and the nearby section of the MIP-3H wellbore. Figure A.17 shows an orthogonal projection of the newly modeled hydraulic fracture geometries, microseismic events, and the nearby section of the MIP-3H wellbore. 
Table A.1: Computed Fracture Geometries - Stage 11 through Stage 20 - MIP-3H

\begin{tabular}{|c|c|c|c|}
\hline STAGE & Fracture Half-Length $(\mathrm{ft})$ & Fracture Height $(\mathrm{ft})$ & Average Fracture Width (in) \\
\hline 11 & 631.3 & 328.8 & 0.030164 \\
\hline 12 & 649.1 & 325.2 & 0.022762 \\
\hline 13 & 597.8 & 316.2 & 0.028964 \\
\hline 14 & 552.4 & 445.8 & 0.023985 \\
\hline 15 & 740.7 & 341.9 & 0.03174 \\
\hline 16 & 660.9 & 316 & 0.033038 \\
\hline 17 & 580.4 & 322.3 & 0.018099 \\
\hline 18 & 644.1 & 318.9 & 0.033231 \\
\hline 19 & 676.1 & 333.1 & 0.033314 \\
\hline 20 & 597.2 & 319.4 & 0.023954 \\
\hline
\end{tabular}

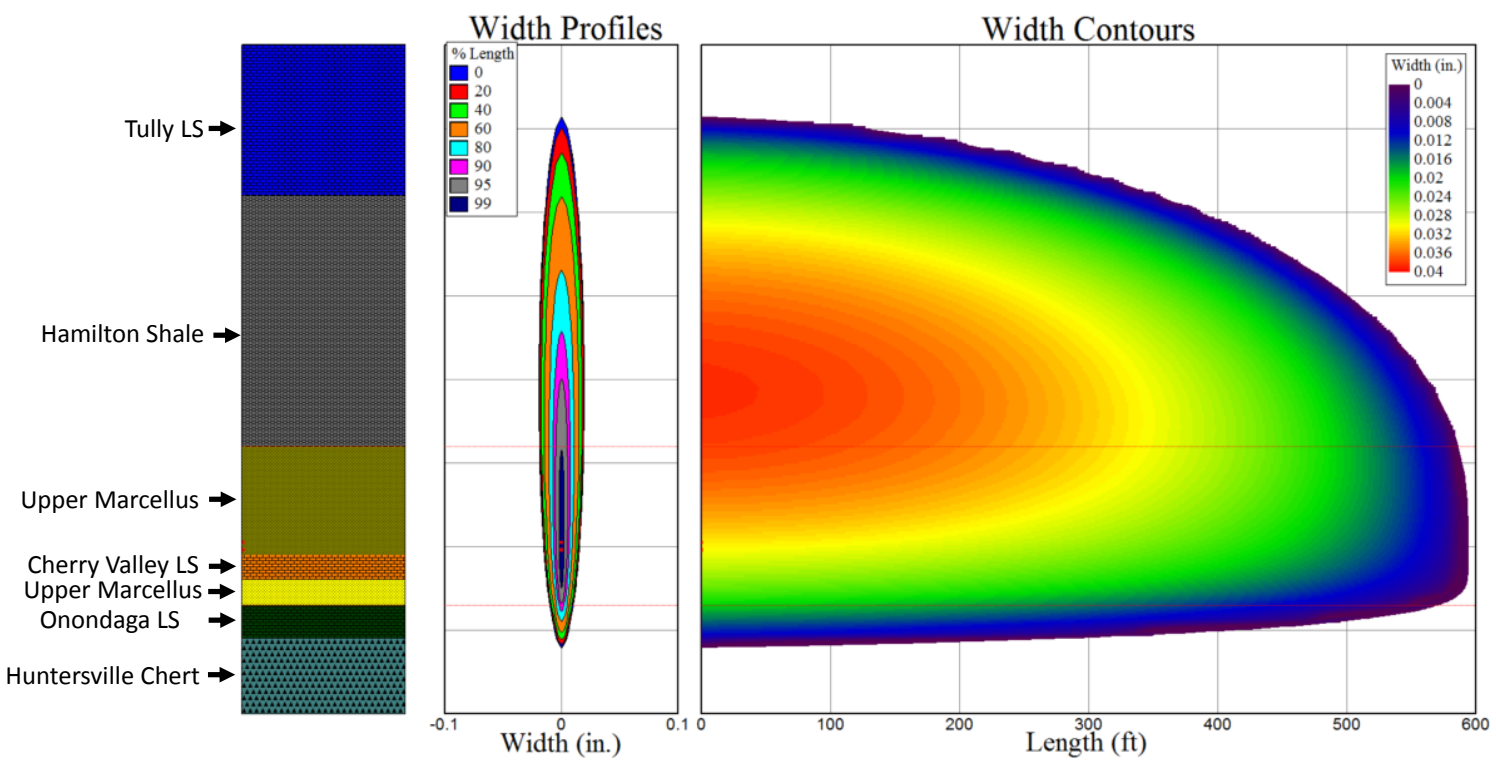

Figure A.1: Fracture Geometry for Stage 20 - MIP-3H 


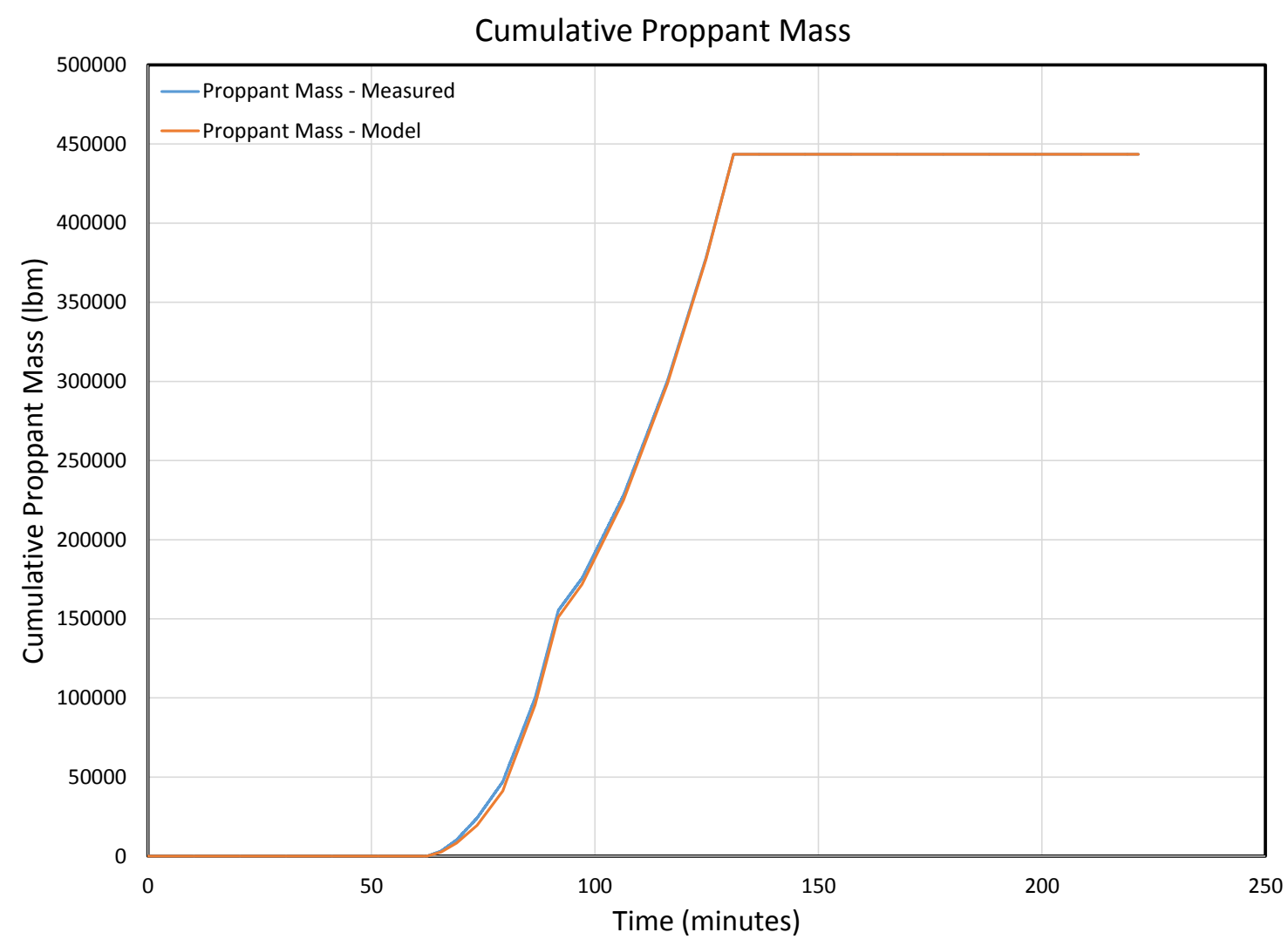

Figure A.2: Cumulative Proppant Mass for Stage 20 - MIP-3H

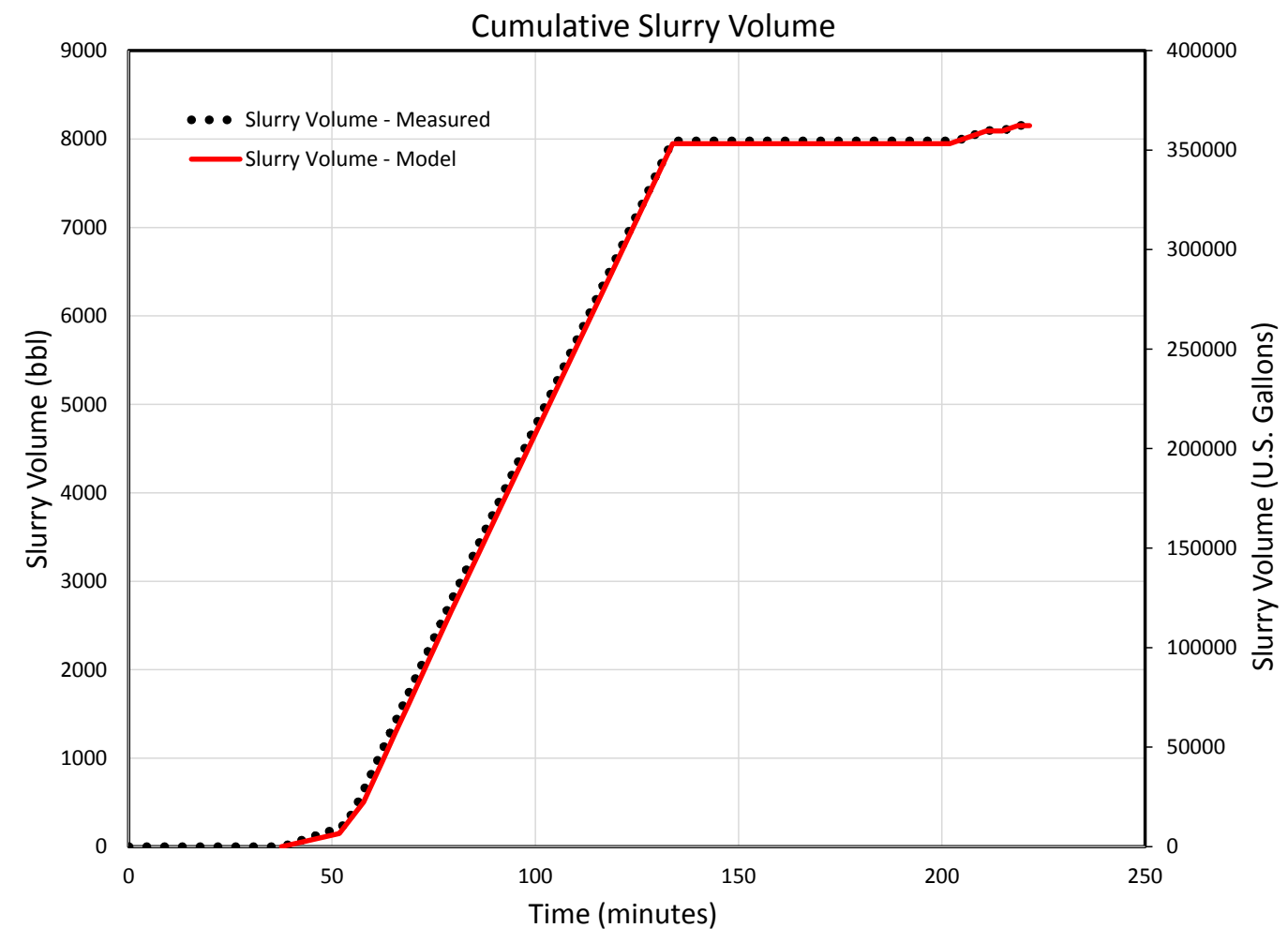


Figure A.3: Cumulative Slurry Volume for Stage 20 - MIP-3H

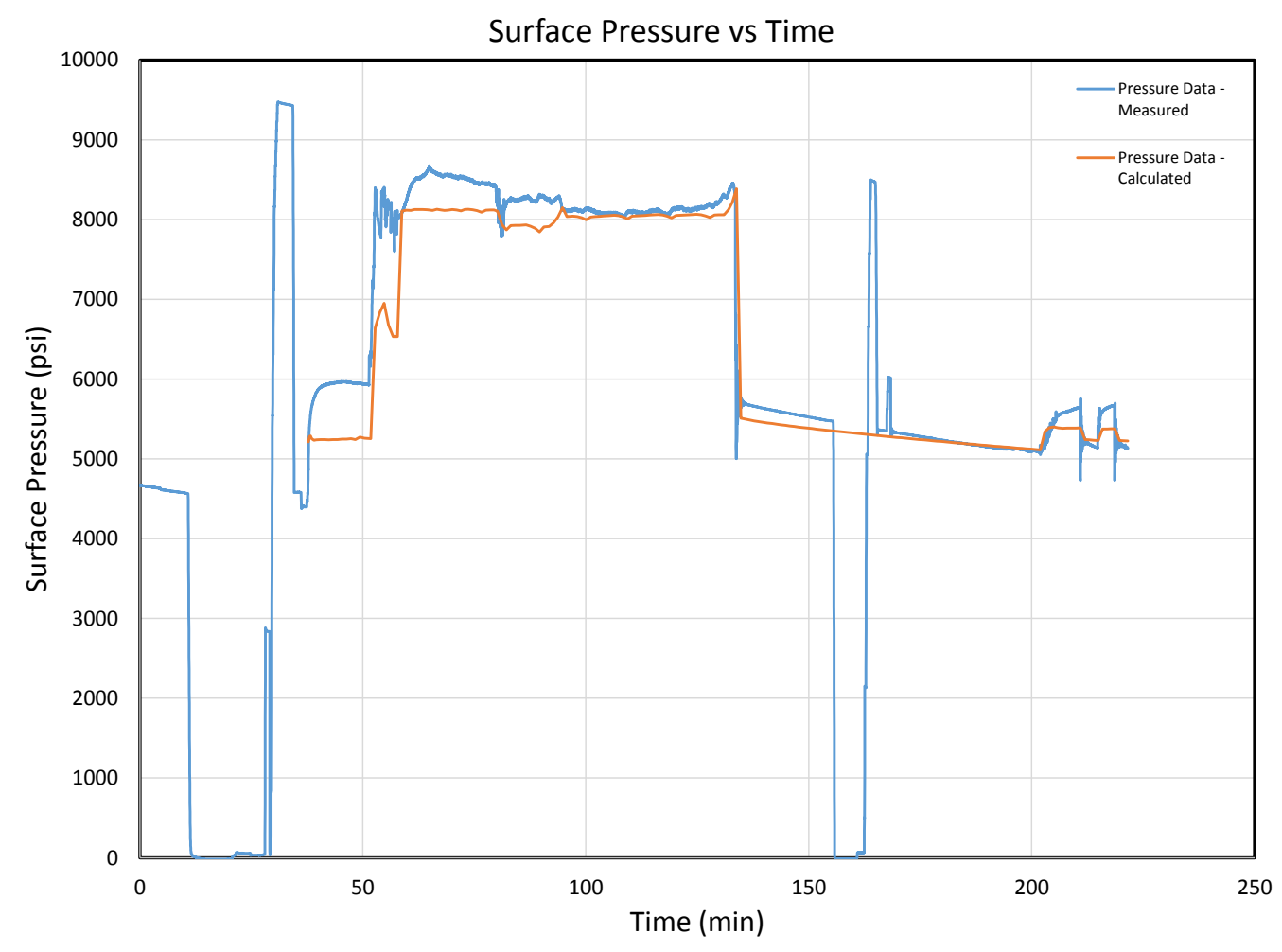

Figure A.4: Surface Pressure versus Time for Stage 20 - MIP-3H

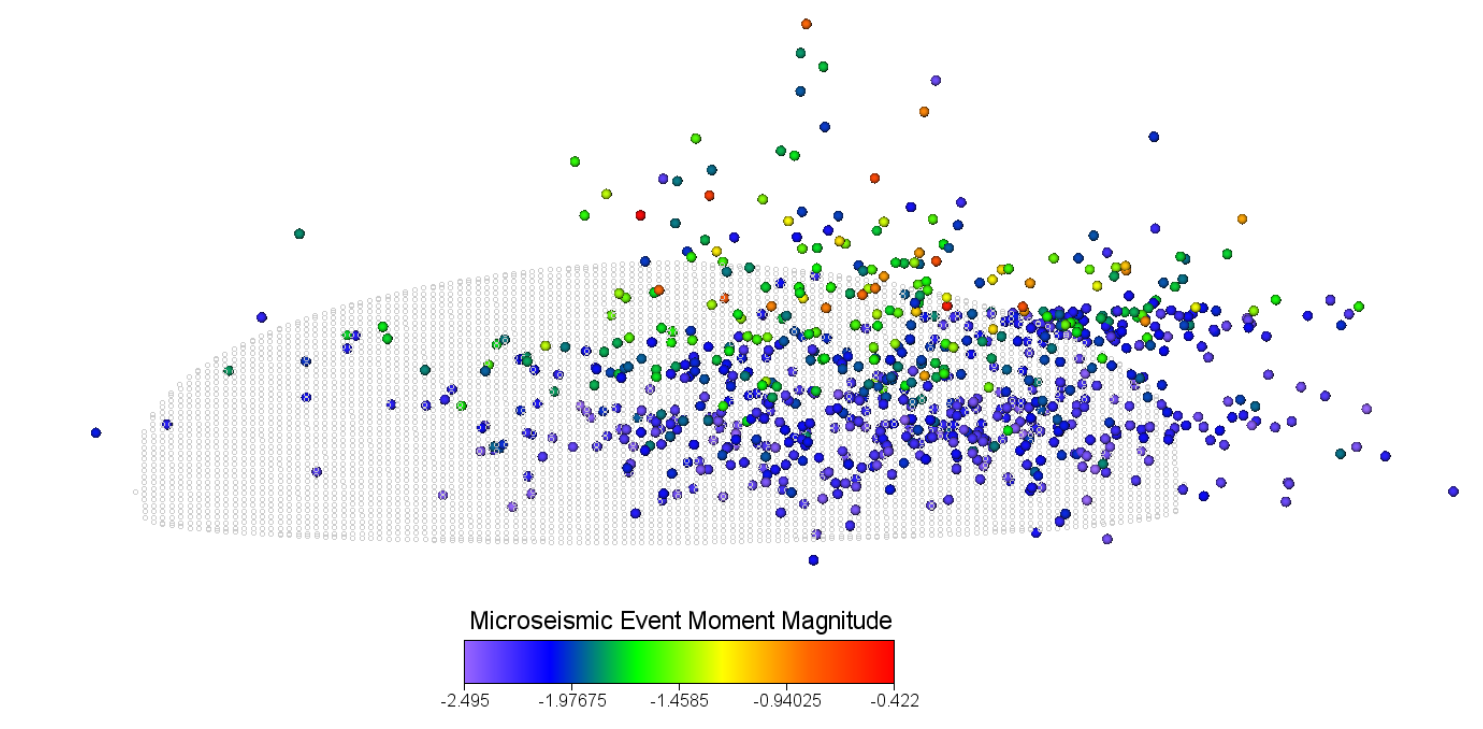

Figure A.5: Side View of Calculated Hydraulic Fracture and Measured Microseismic Events and Magnitudes for Stage 11 - MIP-3H 


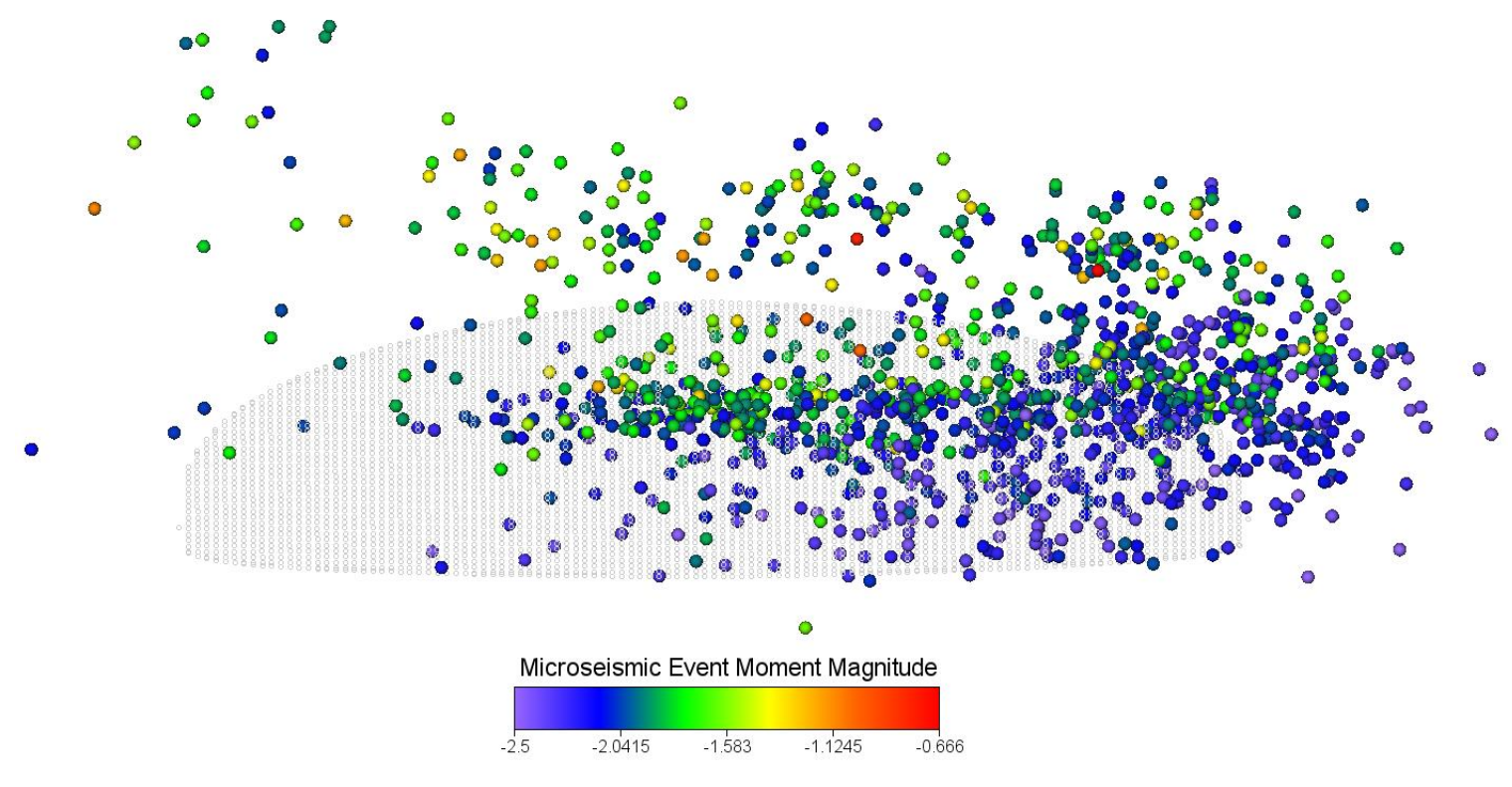

Figure A.6: Side View of Calculated Hydraulic Fracture and Measured Microseismic Events and Magnitudes for Stage 12 - MIP-3H

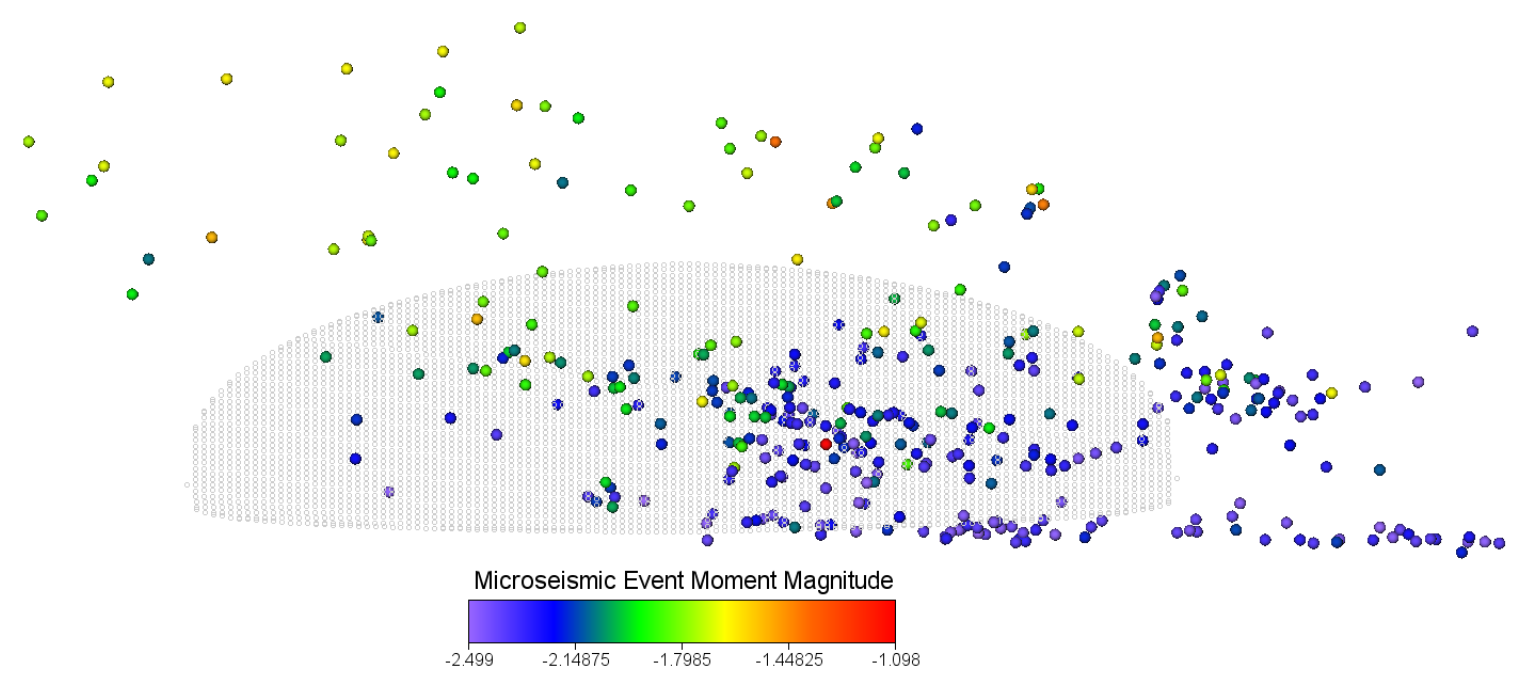

Figure A.7: Side View of Calculated Hydraulic Fracture and Measured Microseismic Events and Magnitudes for Stage 13 - MIP-3H 


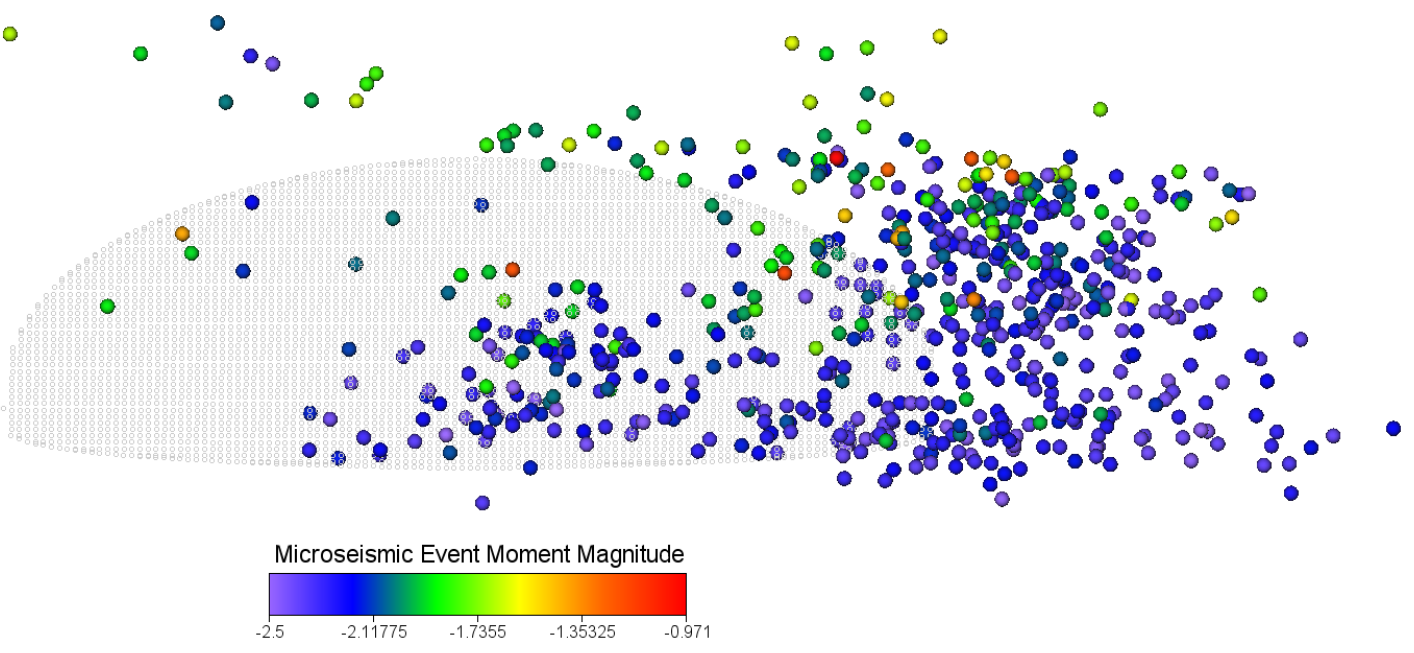

Figure A.8: Side View of Calculated Hydraulic Fracture and Measured Microseismic Events and Magnitudes for Stage 14 - MIP-3H

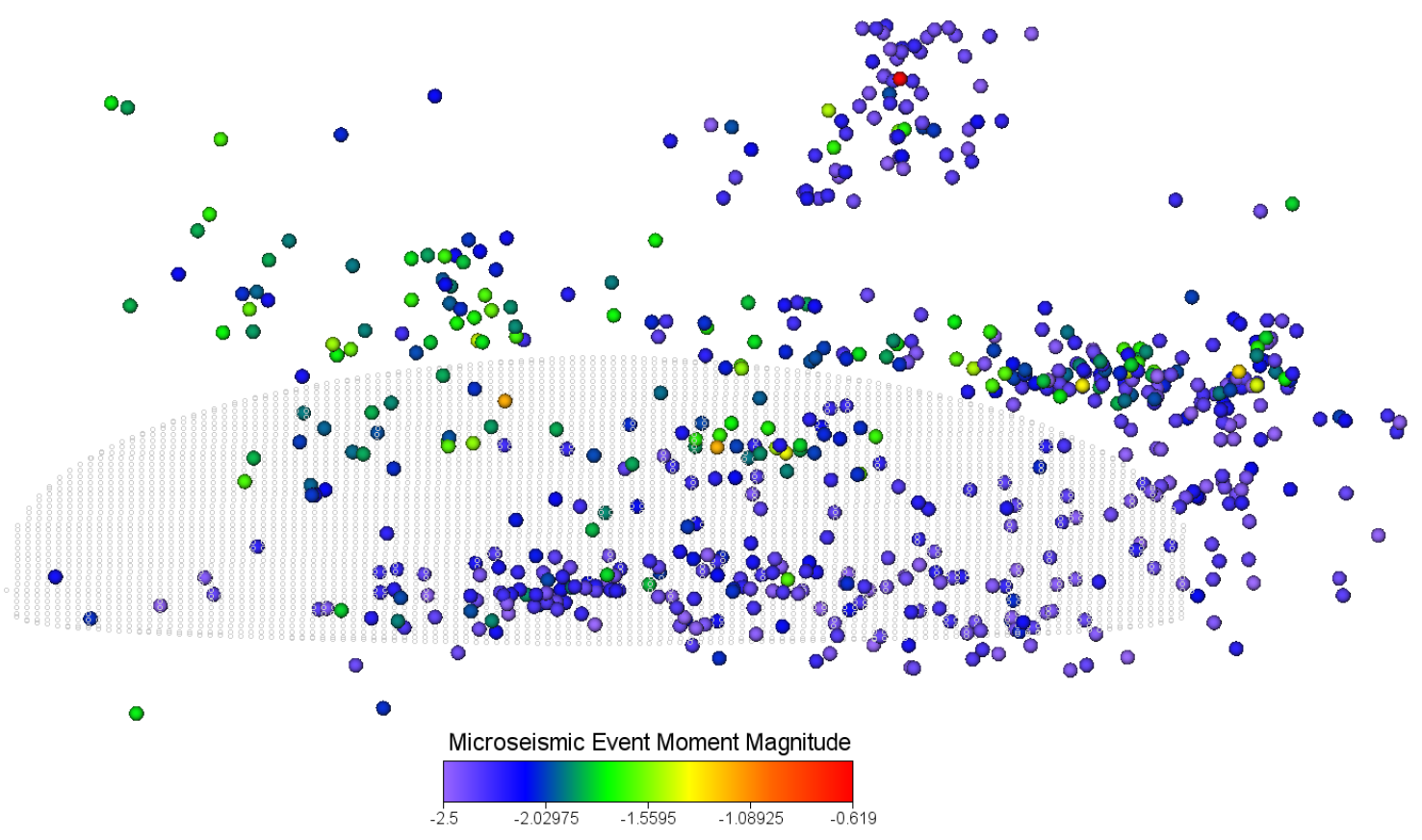

Figure A.9: Side View of Calculated Hydraulic Fracture and Measured Microseismic Events and Magnitudes for Stage 15 - MIP-3H 


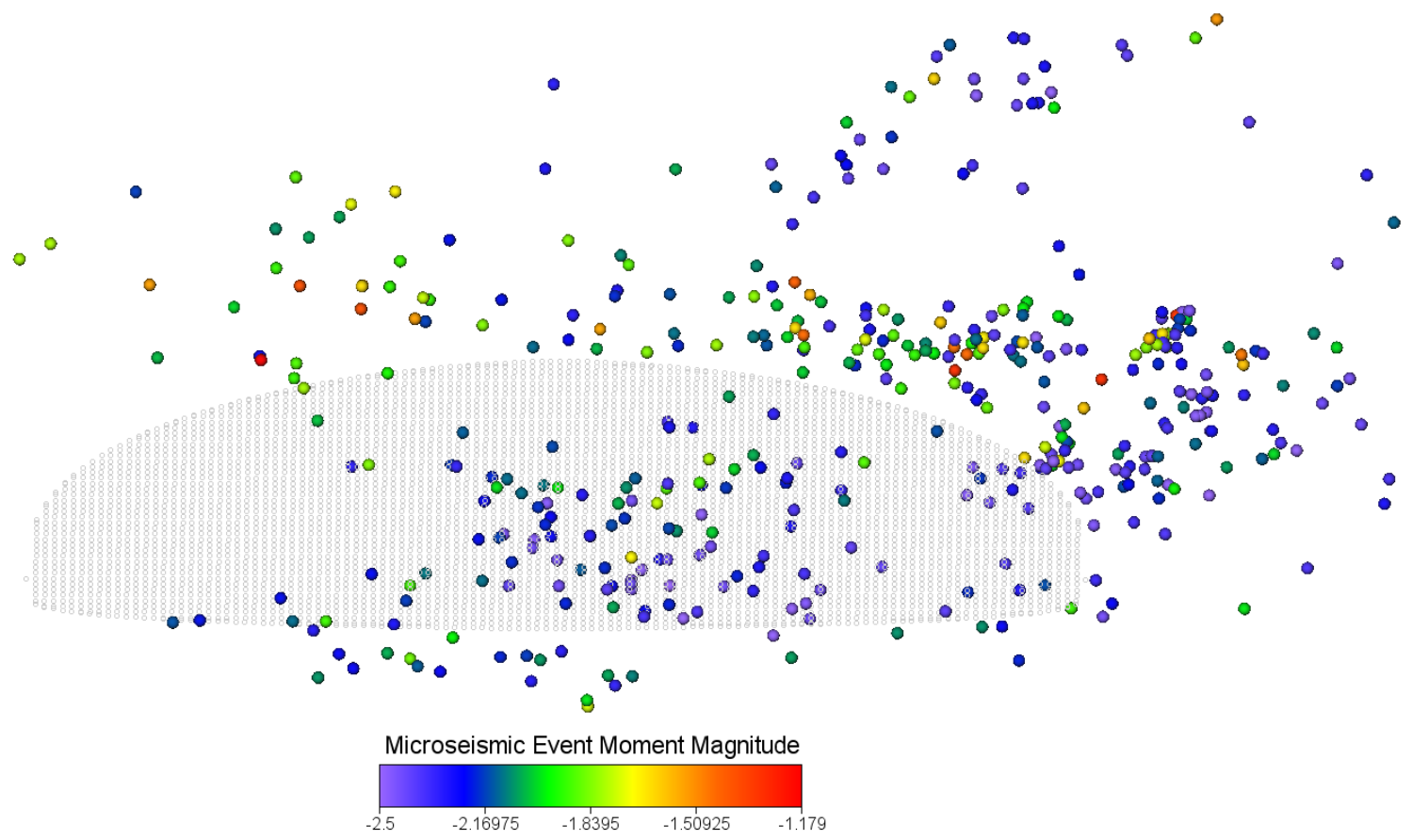

Figure A.10: Side View of Calculated Hydraulic Fracture and Measured

Microseismic Events and Magnitudes for Stage 16-MIP-3H

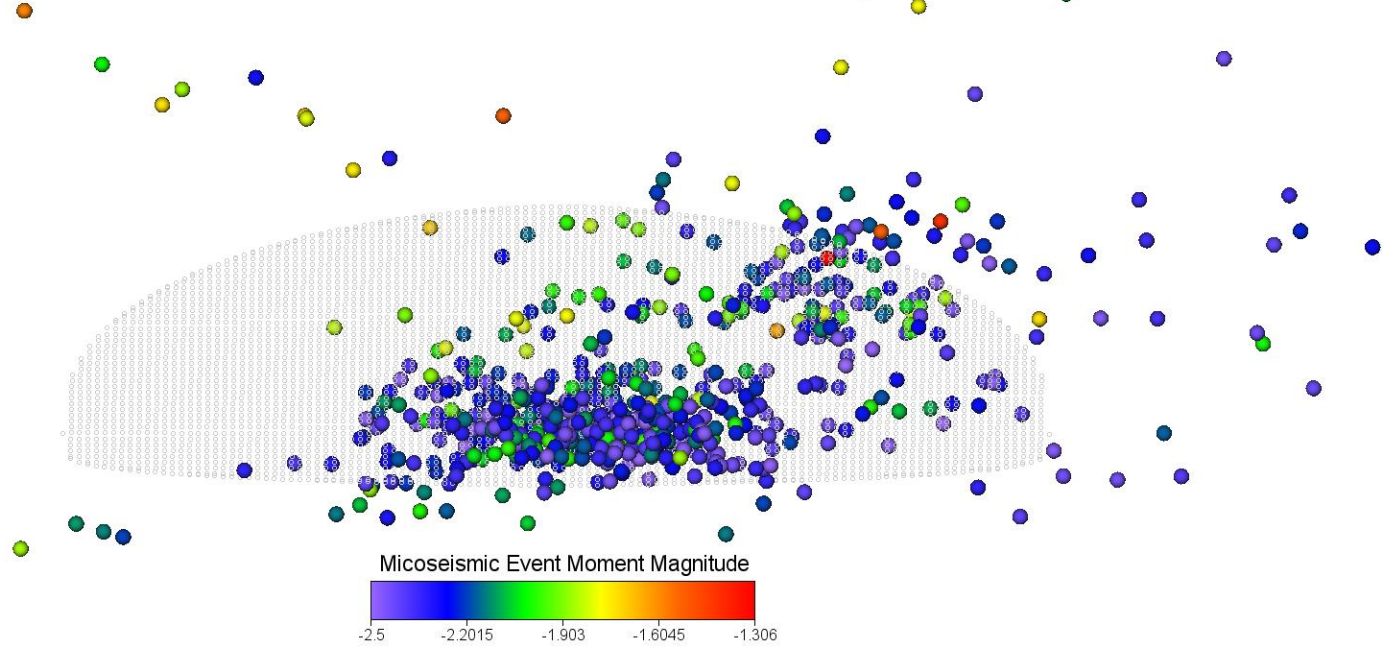

Figure A.11: Side View of Calculated Hydraulic Fracture and Measured Microseismic Events and Magnitudes for Stage 17 - MIP-3H 


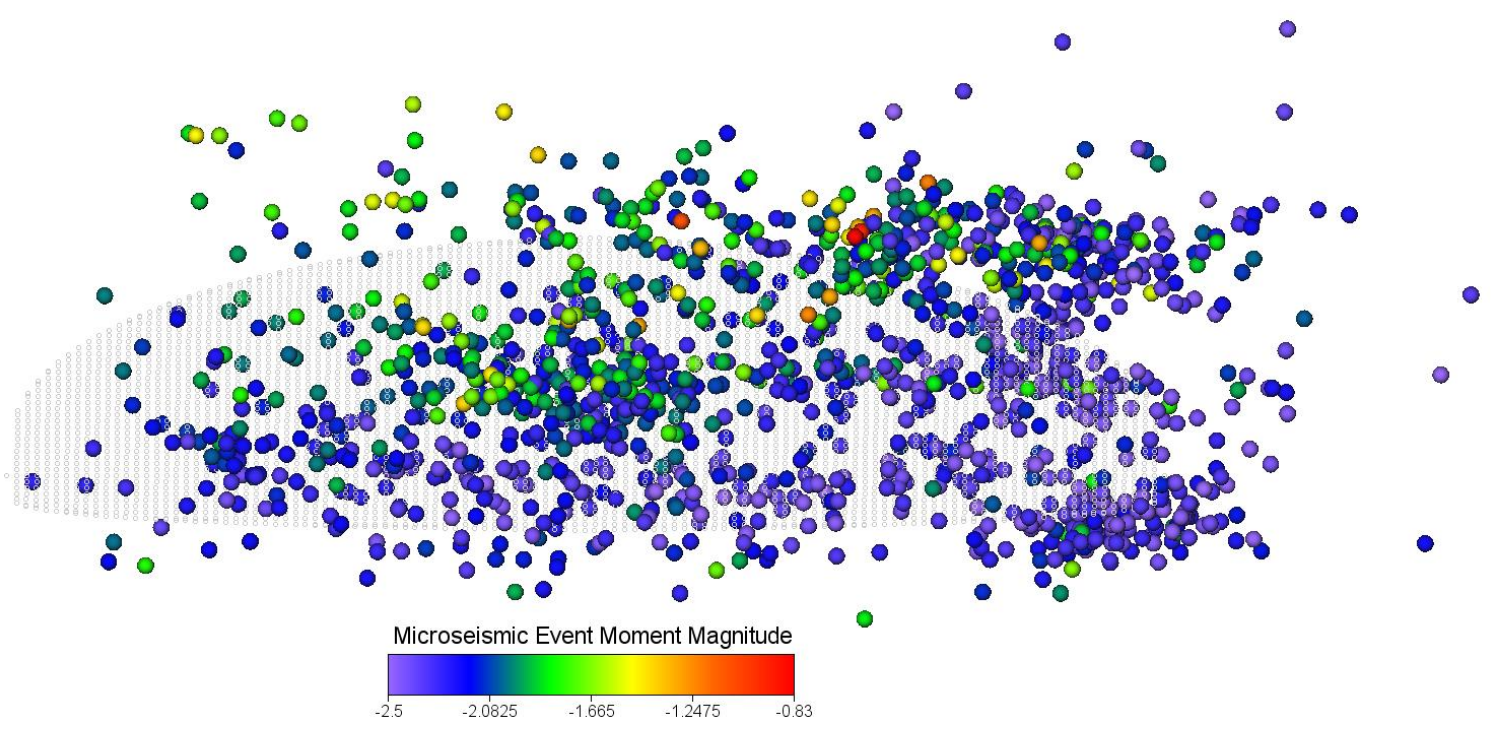

Figure A.12: Side View of Calculated Hydraulic Fracture and Measured Microseismic Events and Magnitudes for Stage 18 - MIP-3H

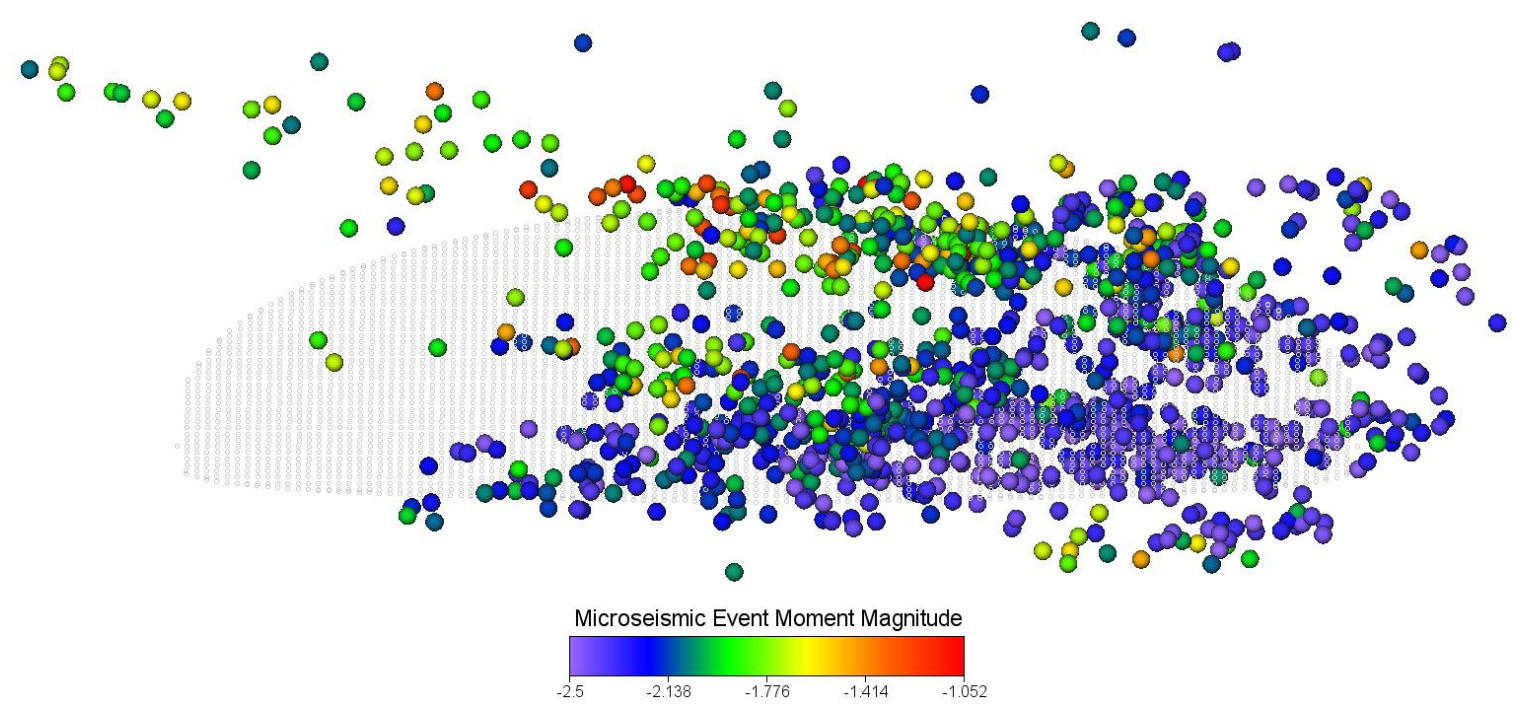

Figure A.13: Side View of Calculated Hydraulic Fracture and Measured

Microseismic Events and Magnitudes for Stage 19 - MIP-3H 


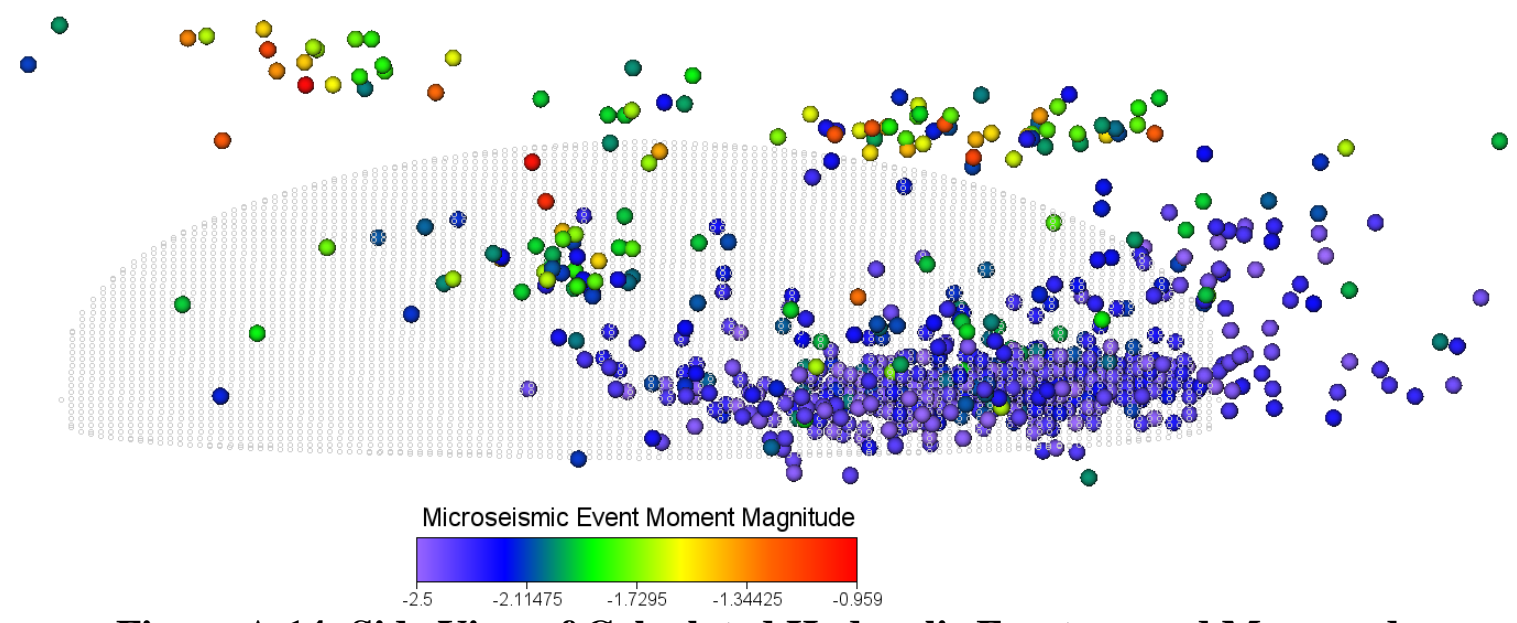

Figure A.14: Side View of Calculated Hydraulic Fracture and Measured

Microseismic Events and Magnitudes for Stage 20 - MIP-3H 


\section{Ground Surface}

The center of perforations for

Stages $11-20$ are approximately

7450 feet below the ground surface.

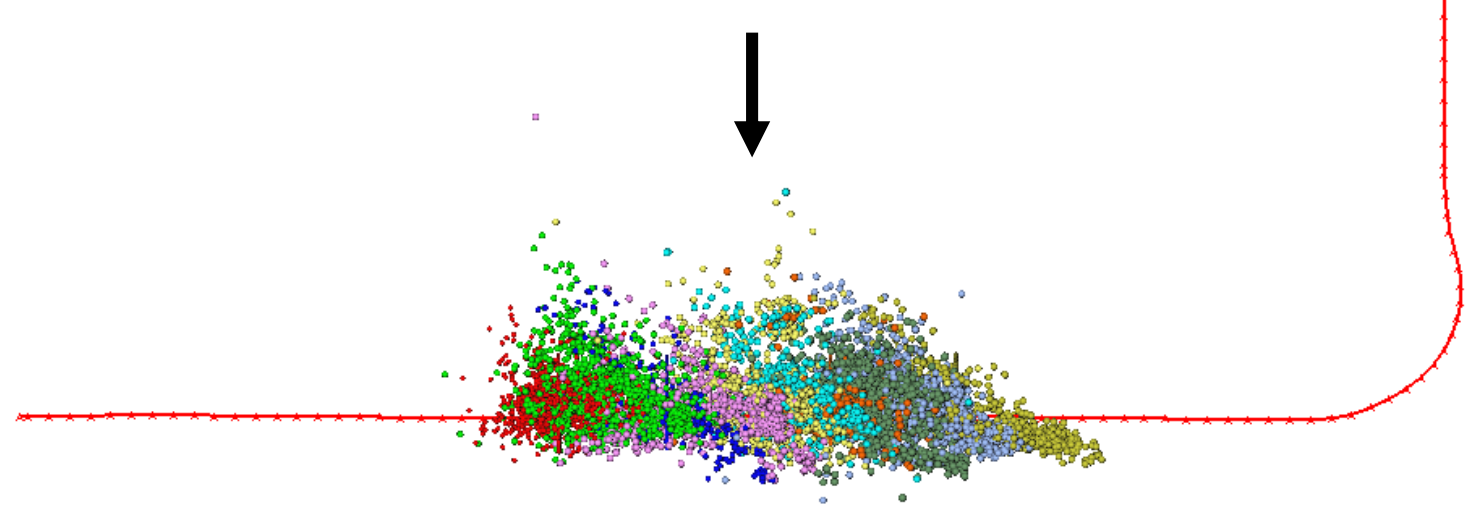

Figure A.15: Overview of Calculated Hydraulic Fracture Geometries, Measured Microseismic Events, and Entire Wellbore for Stage 11 through Stage 20 - MIP-3H 


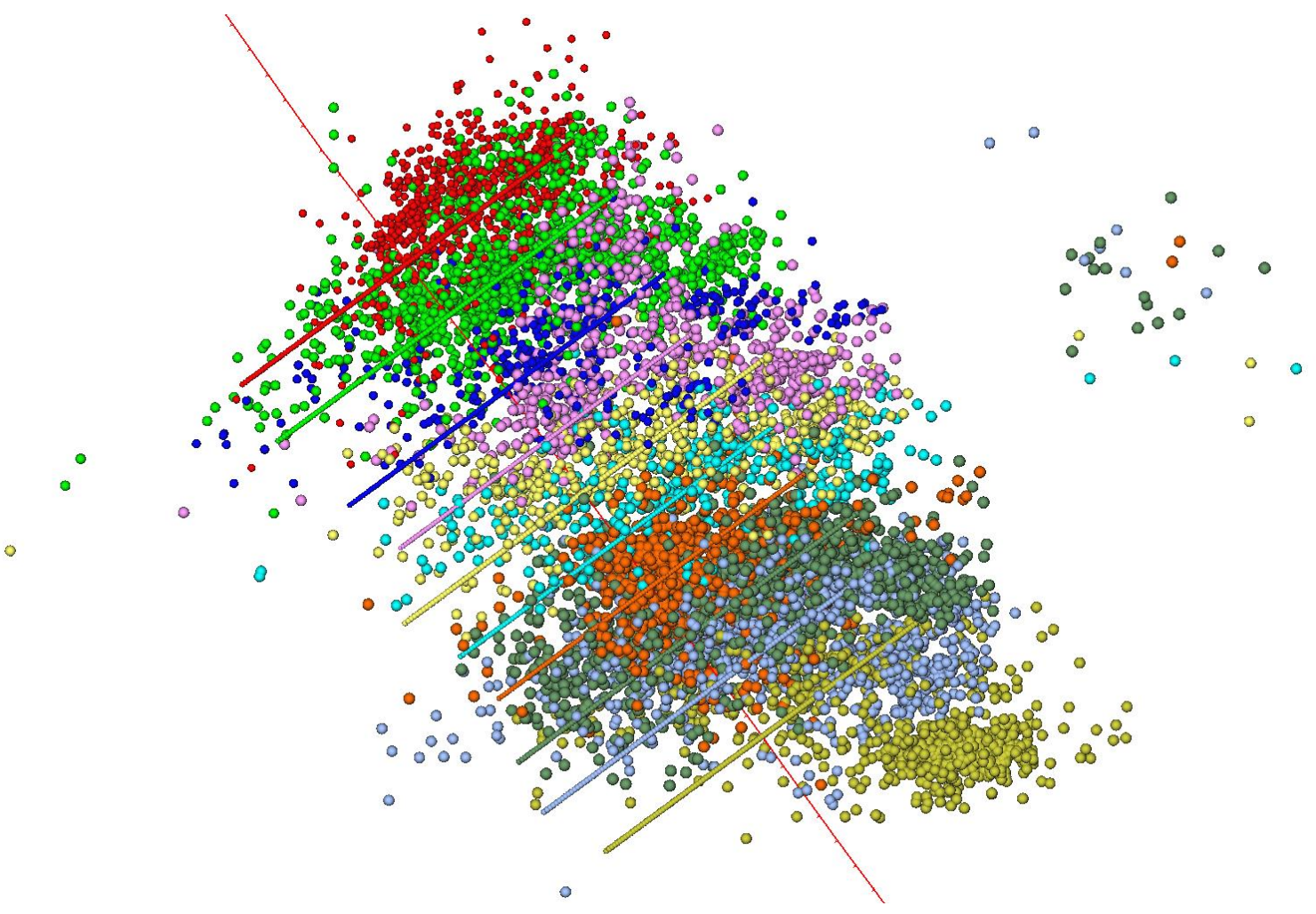

Figure A.16: Top View of Calculated Hydraulic Fracture Geometries, Measured Microseismic Events, and Nearby Wellbore for Stage 11 through Stage 20 - MIP-3H

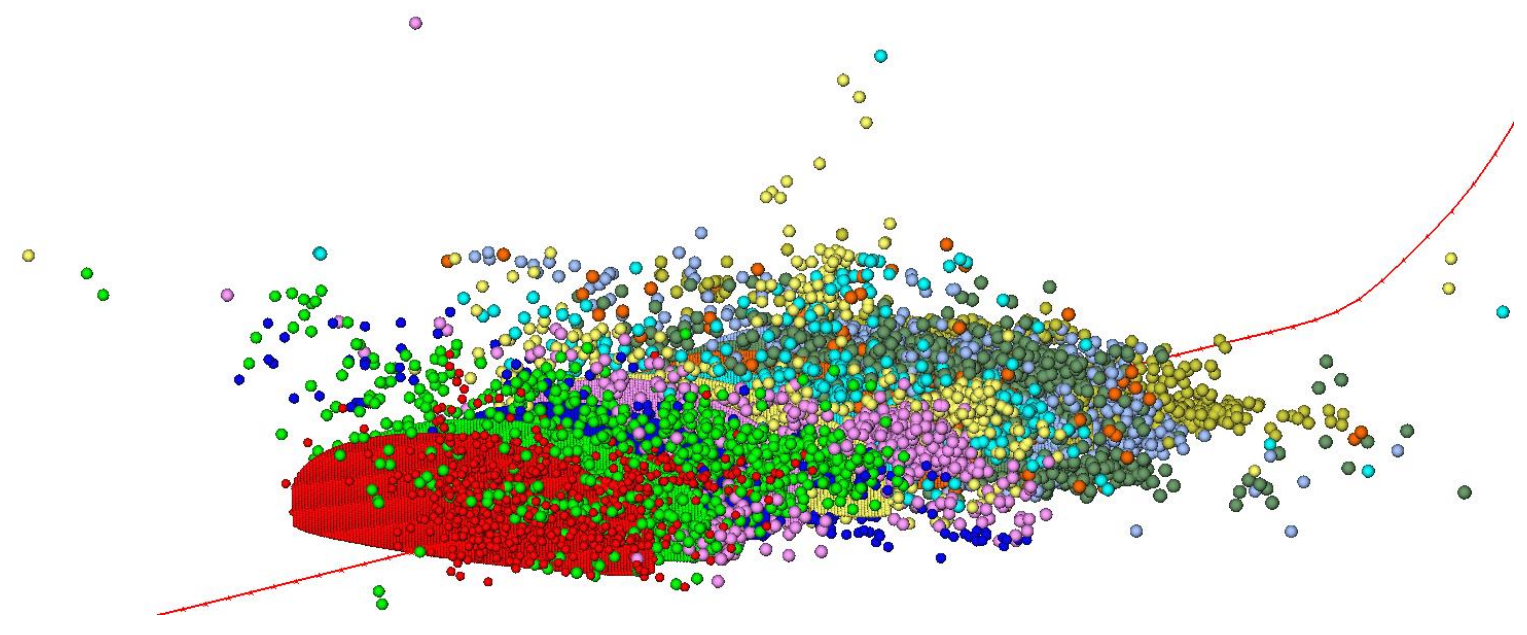

Figure A.17: Orthogonal View of Calculated Hydraulic Fracture Geometries, Measured Microseismic Events, and Nearby Wellbore for Stage 11 through Stage 20 - MIP-3H 
Table A.2 shows the computed fracture geometries for newly modeled MIP-3H stages 21 through 28. Figure A.18 shows the fracture geometry for one of the primary induced hydraulic fractures in stage 28 of well MIP-3H. Figure A.19 shows the cumulative proppant mass versus time (modeled vs measured), Figure A.20 shows the slurry volume injected versus time (modeled vs measured), and Figure A.21 shows the surface pressure versus time (modeled vs measured) for stage 28 of well MIP-3H.

Microseismic data was available for all of the stages modeled in this set. Microseismic, well, and hydraulic fracture geometric data were visualized in three dimensions. Figures A.22 through A.29 show side views of calculated hydraulic fracture geometries and measured microseismic events and magnitudes for stages 21 through 28, respectively, for well MIP-3H. Figure A.30 shows an overview of all 8 modeled hydraulic fracture geometries, microseismic events, and the entire MIP-3H wellbore. Figure A.31 shows a top view of all newly modeled hydraulic fracture geometries, microseismic events, and the nearby section of the MIP-3H wellbore. Figure A.32 shows an orthogonal projection of the newly modeled hydraulic fracture geometries, microseismic events, and the nearby section of the MIP-3H wellbore.

Table A.2: Computed Fracture Geometries - Stage 21 through Stage 28 - MIP-3H

\begin{tabular}{|c|c|c|c|}
\hline STAGE & Fracture Half-Length (ft) & Fracture Height (ft) & Average Fracture Width (in) \\
\hline 21 & 623.8 & 314.8 & 0.029267 \\
\hline 22 & 651.9 & 349.6 & 0.028956 \\
\hline 23 & 701.8 & 343.5 & 0.033113 \\
\hline 24 & 609.3 & 327 & 0.02406 \\
\hline 25 & 638.6 & 331.1 & 0.030619 \\
\hline 26 & 615 & 325.5 & 0.031456 \\
\hline 27 & 585.2 & 313.4 & 0.031126 \\
\hline 28 & 629.9 & 325.5 & 0.032047 \\
\hline
\end{tabular}




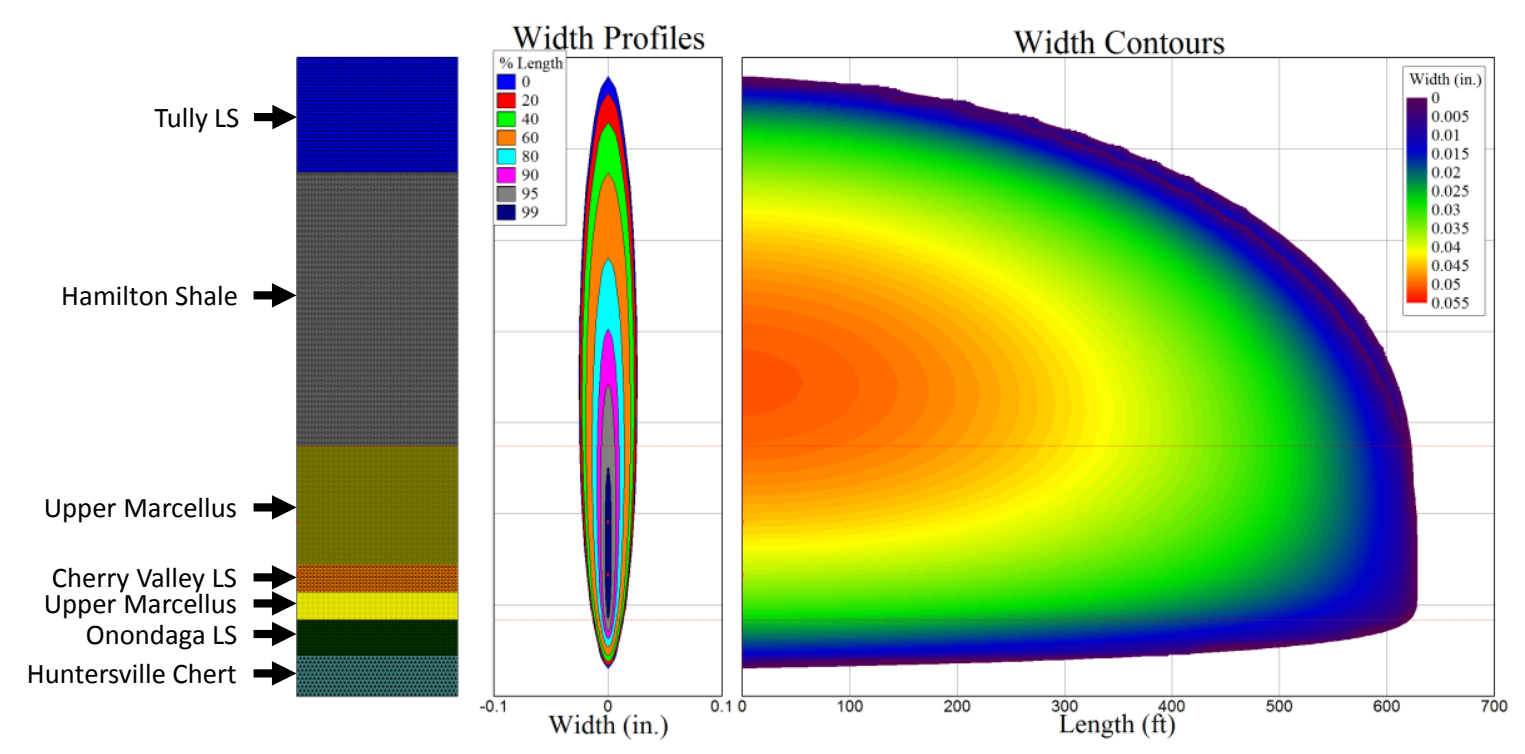

Figure A.18: Fracture Geometry for Stage 28 - MIP-3H

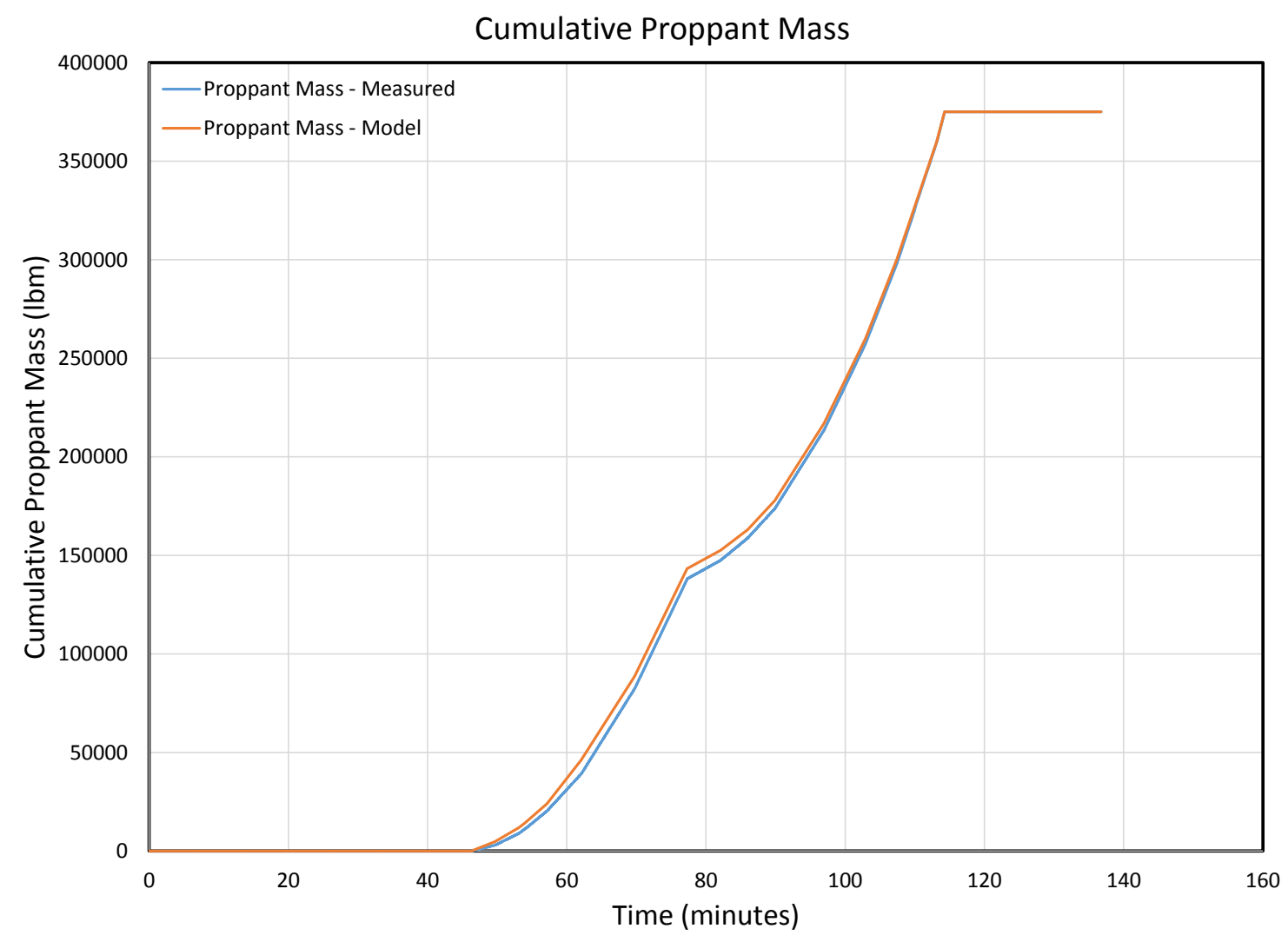

Figure A.19: Cumulative Proppant Mass for Stage 28 - MIP-3H 


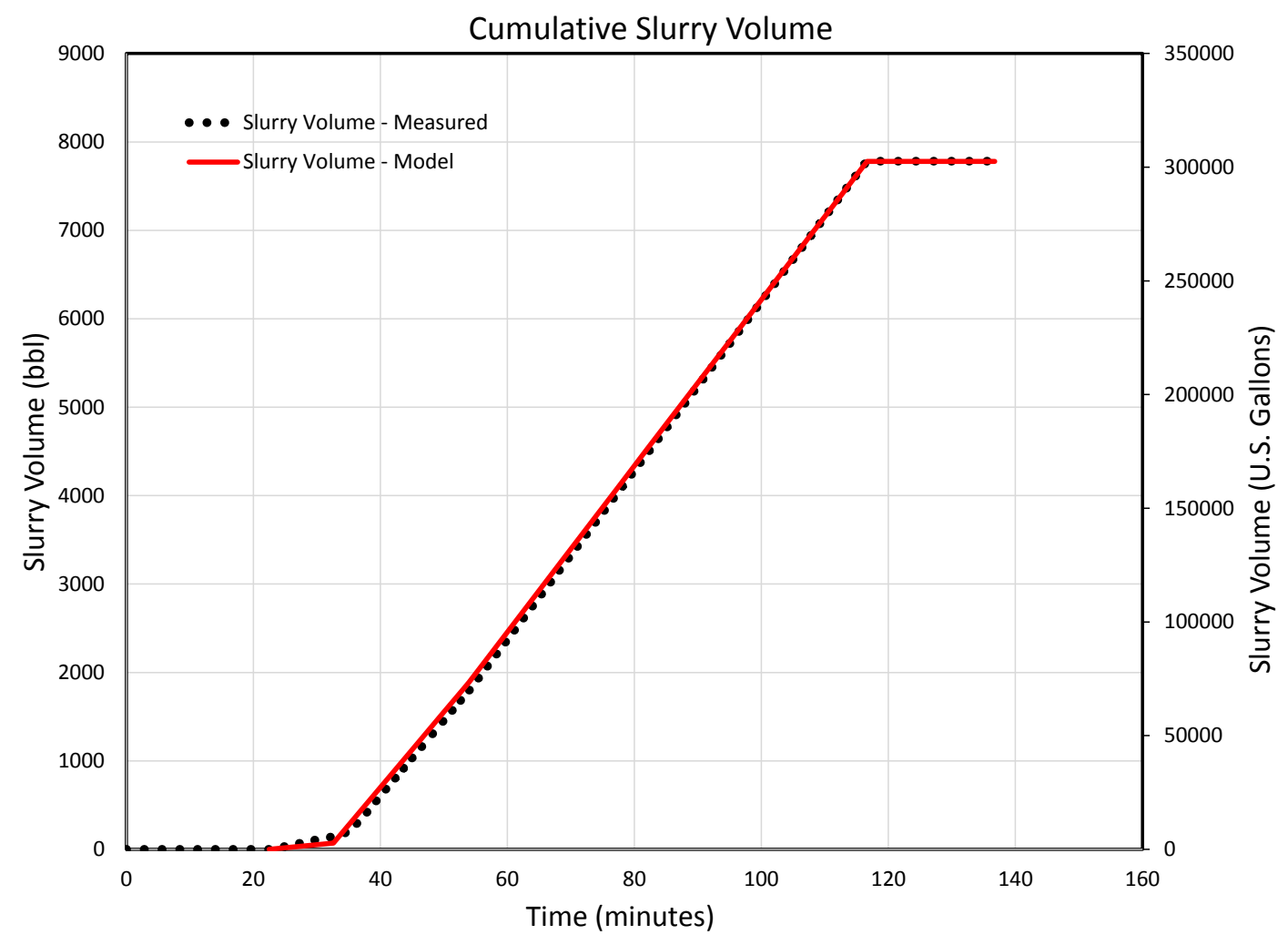

Figure A.20: Cumulative Slurry Volume for Stage 28 - MIP-3H

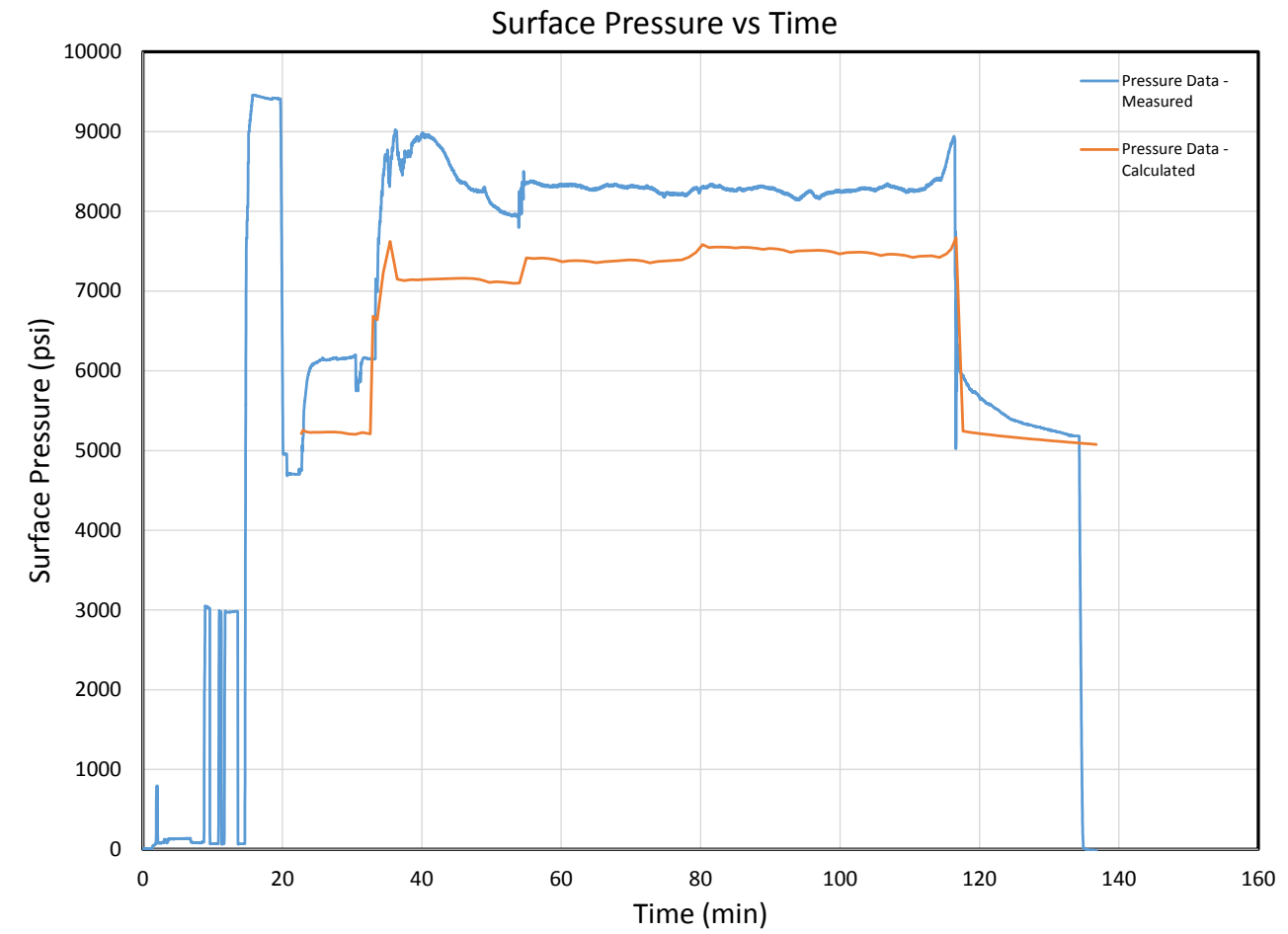

Figure A.21: Surface Pressure versus Time for Stage 28 - MIP-3H 


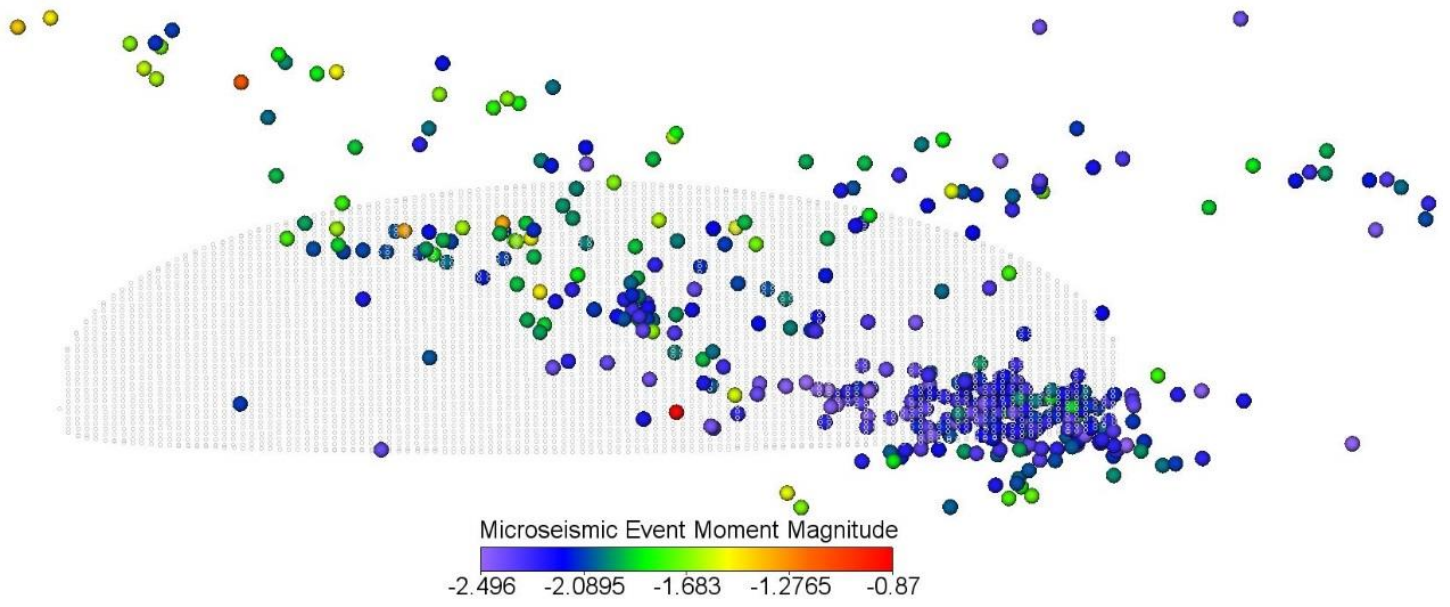

Figure A.22: Side View of Calculated Hydraulic Fracture and Measured

Microseismic Events and Magnitudes for Stage 21 - MIP-3H

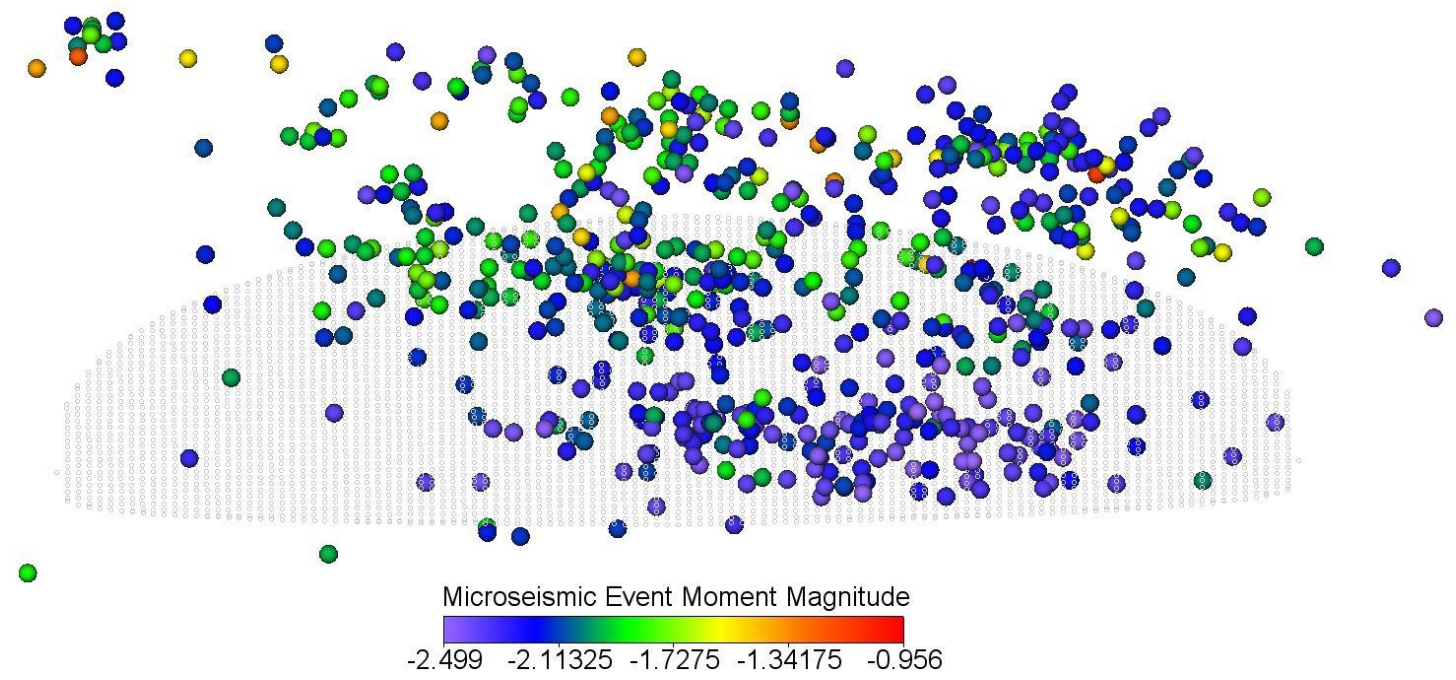

Figure A.23: Side View of Calculated Hydraulic Fracture and Measured

Microseismic Events and Magnitudes for Stage 22 - MIP-3H 


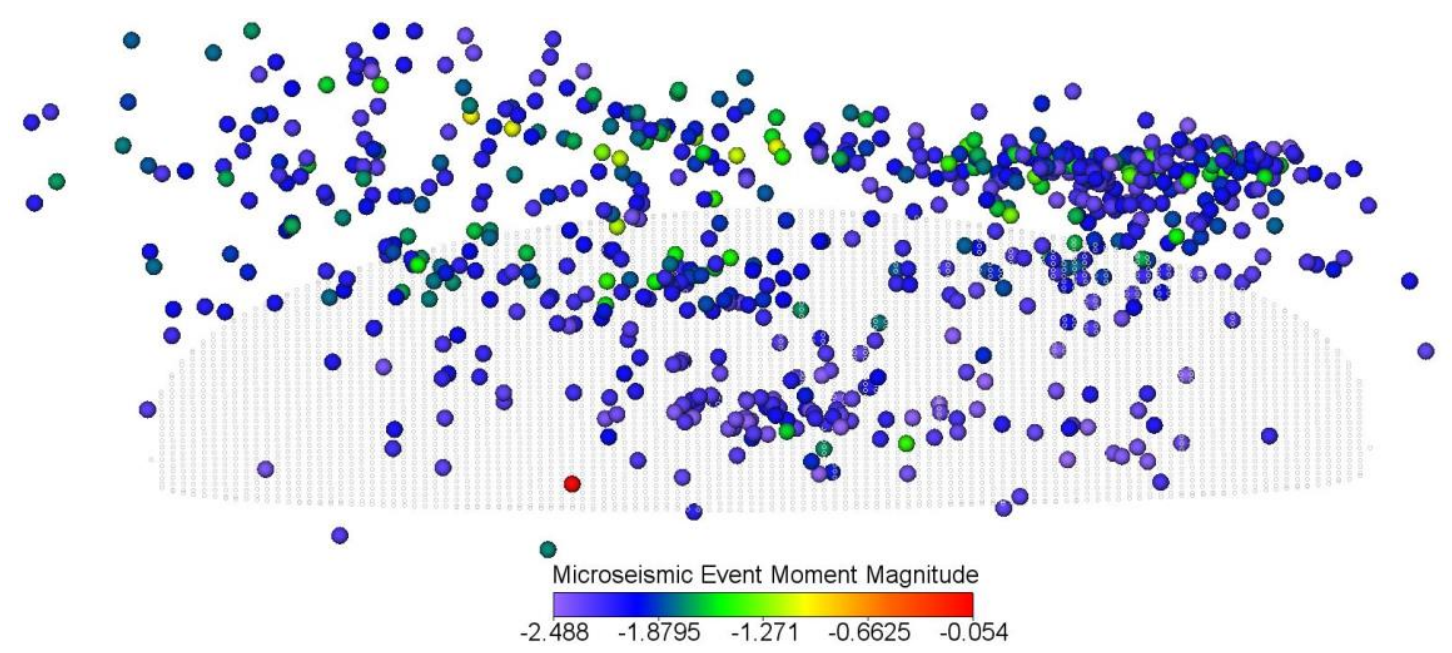

Figure A.24: Side View of Calculated Hydraulic Fracture and Measured Microseismic Events and Magnitudes for Stage 23 - MIP-3H

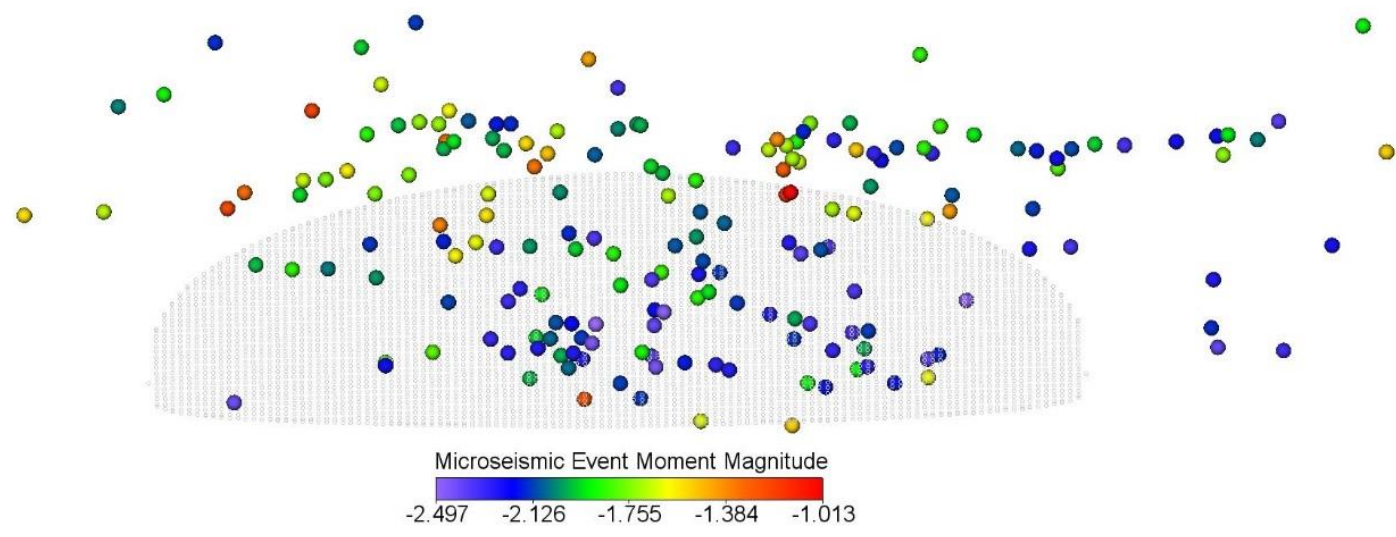

Figure A.25: Side View of Calculated Hydraulic Fracture and Measured Microseismic Events and Magnitudes for Stage 24 - MIP-3H 


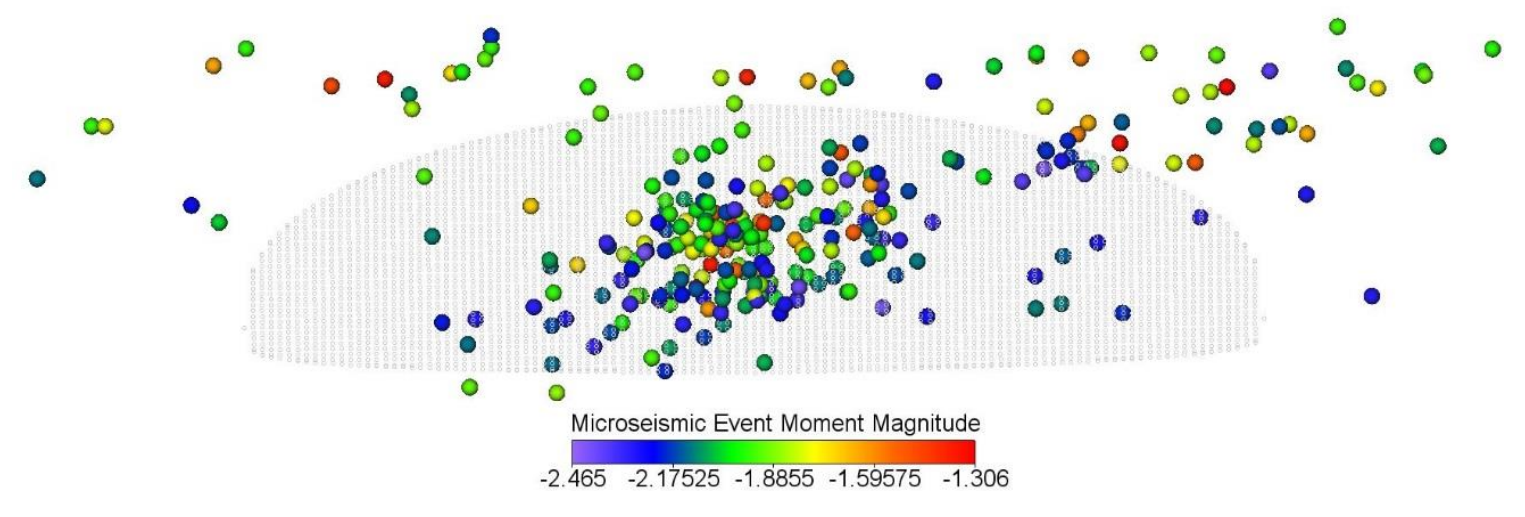

Figure A.26: Side View of Calculated Hydraulic Fracture and Measured Microseismic Events and Magnitudes for Stage 25 - MIP-3H

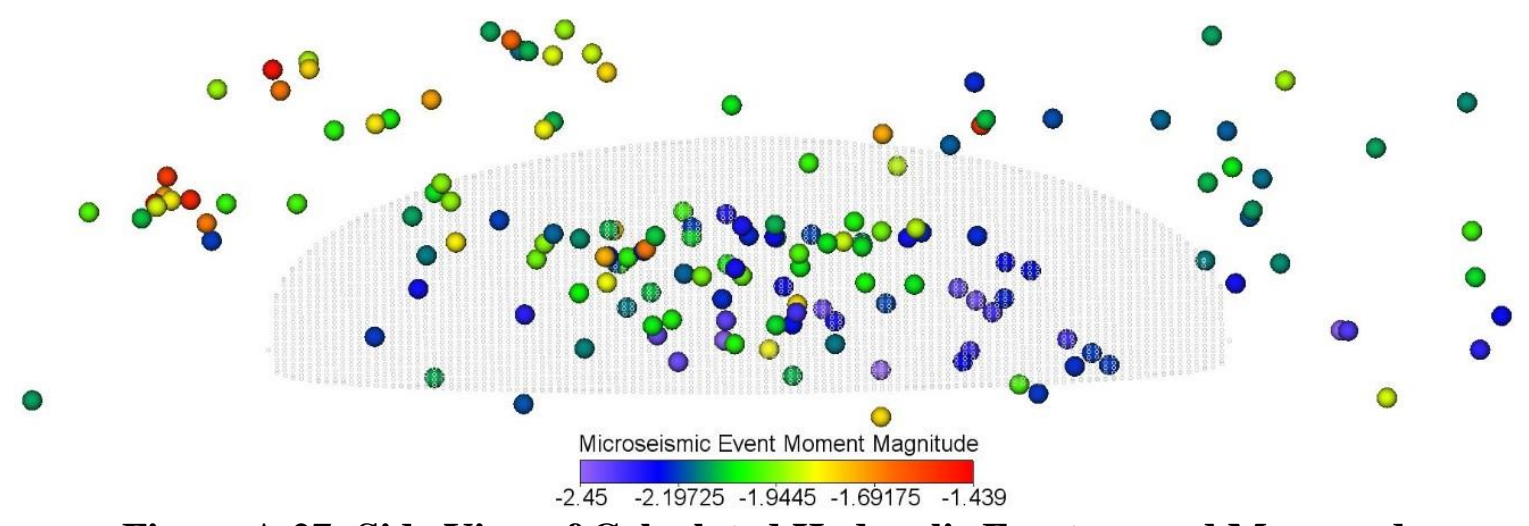

Figure A.27: Side View of Calculated Hydraulic Fracture and Measured Microseismic Events and Magnitudes for Stage 26-MIP-3H 


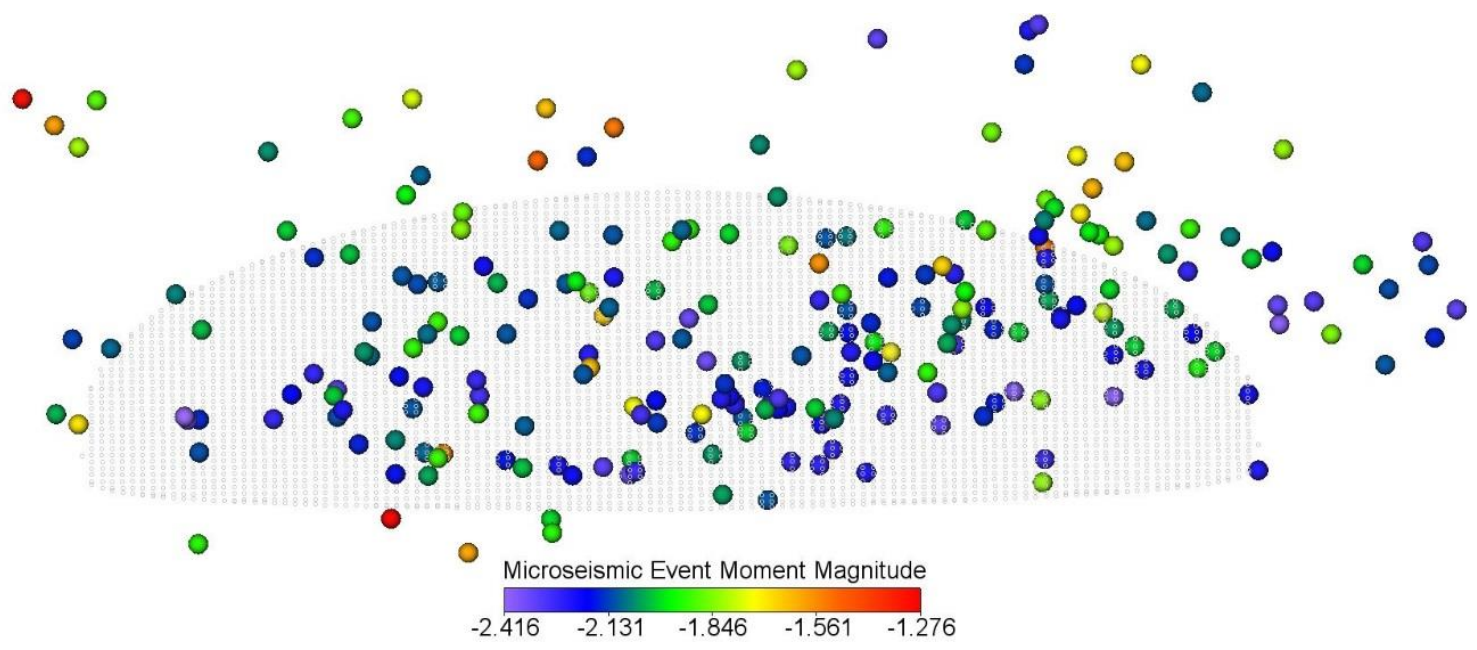

Figure A.28: Side View of Calculated Hydraulic Fracture and Measured

Microseismic Events and Magnitudes for Stage 27 - MIP-3H

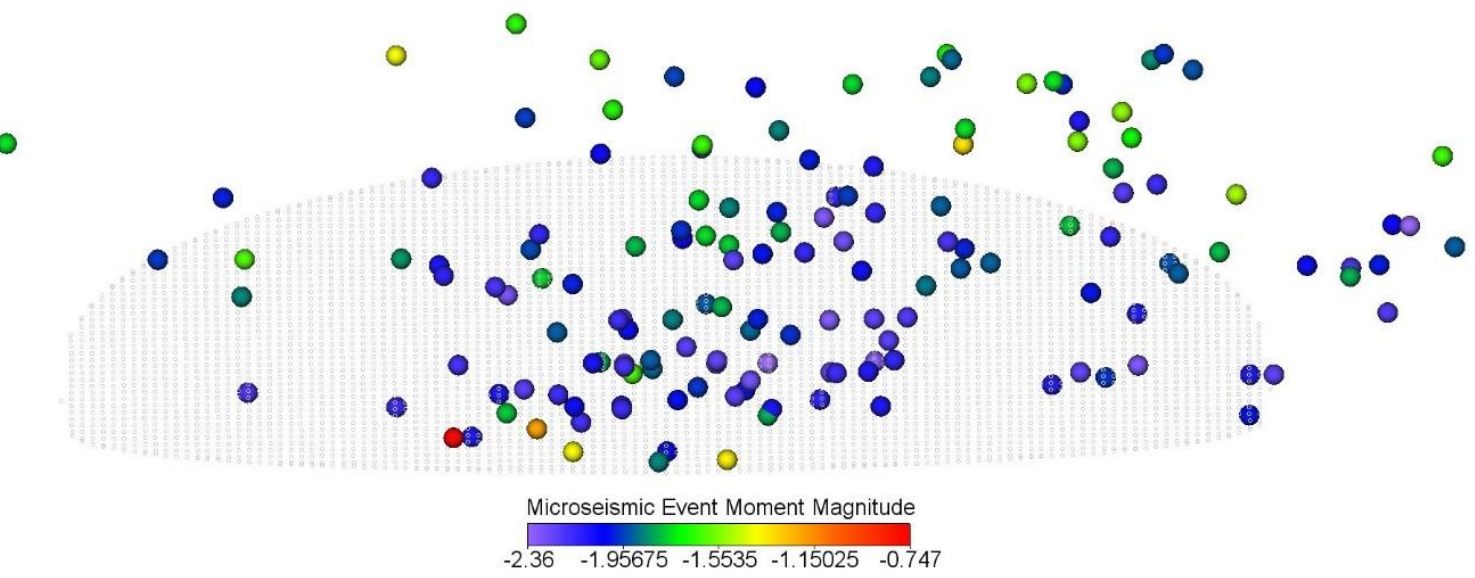

Figure A.29: Side View of Calculated Hydraulic Fracture and Measured

Microseismic Events and Magnitudes for Stage 28 - MIP-3H 


\section{Ground Surface}

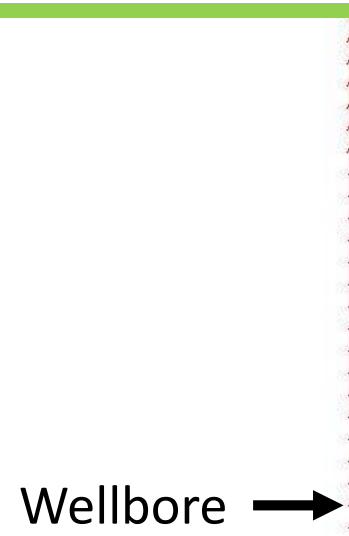

The center of perforations for

Stages $21-28$ are approximately

7470 feet below the ground surface.
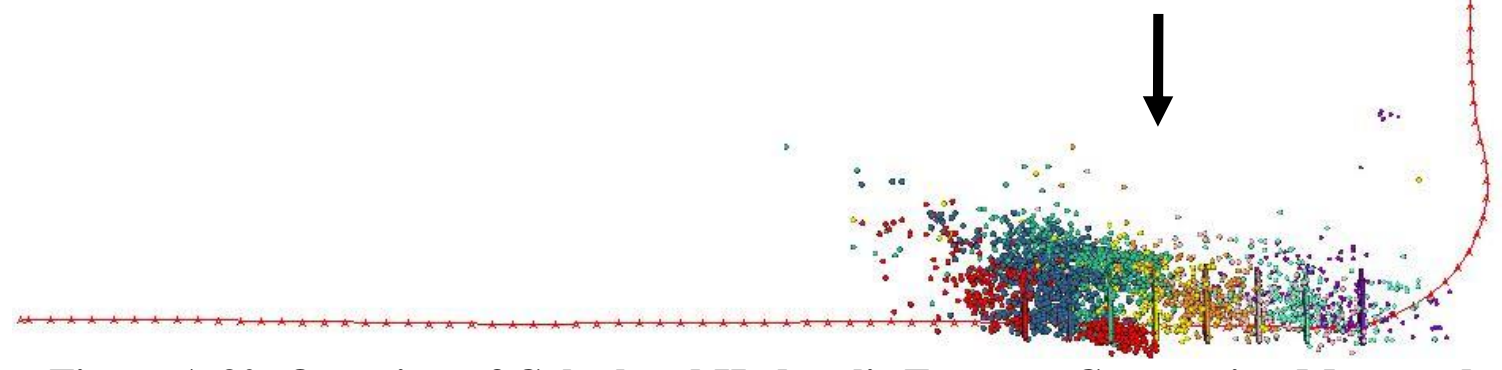

Figure A.30: Overview of Calculated Hydraulic Fracture Geometries, Measured Microseismic Events, and Entire Wellbore for Stage 21 through Stage 28 - MIP-3H 


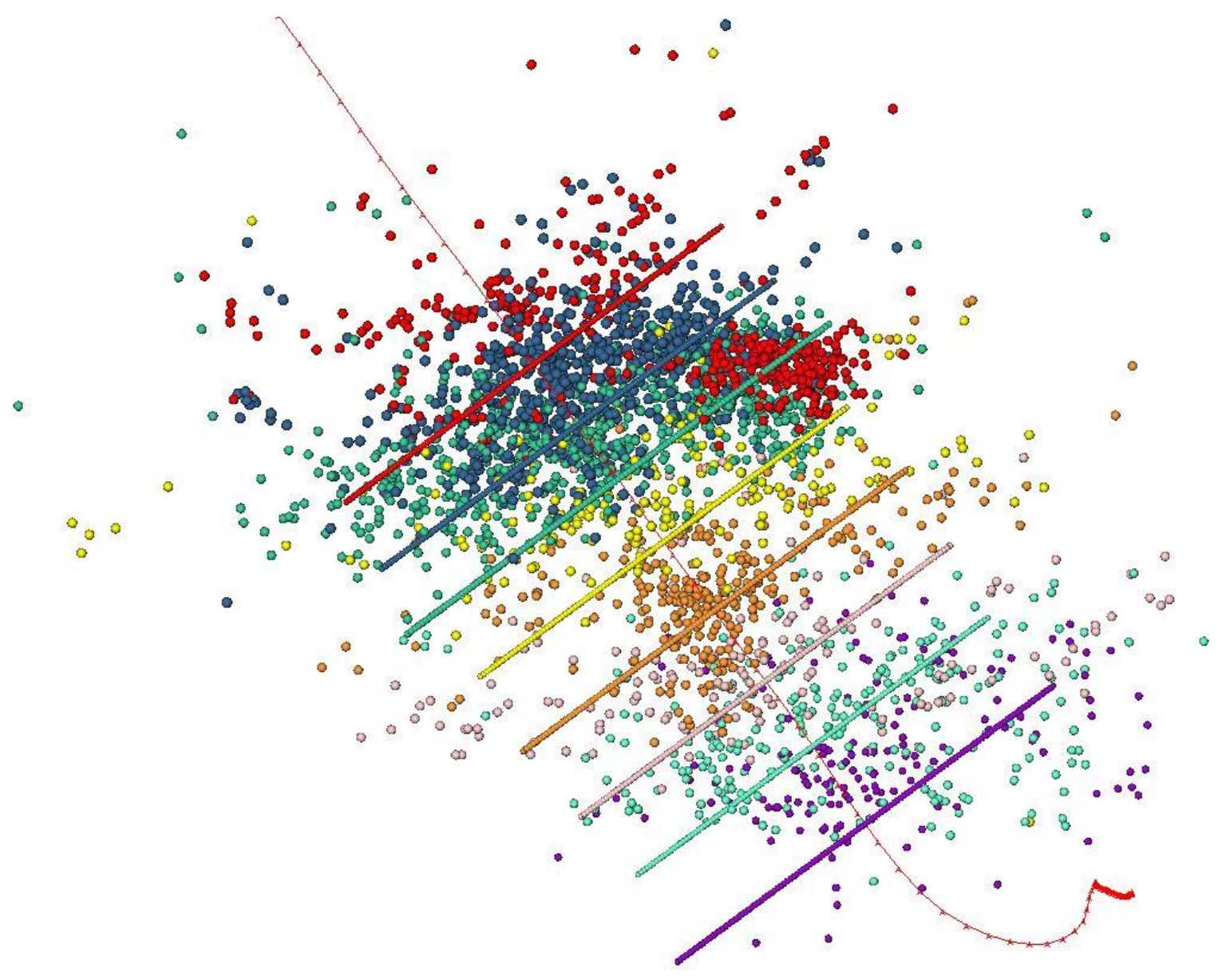

Figure A.31: Top View of Calculated Hydraulic Fracture Geometries, Measured Microseismic Events, and Nearby Wellbore for Stage 21 through Stage 28 - MIP-3H

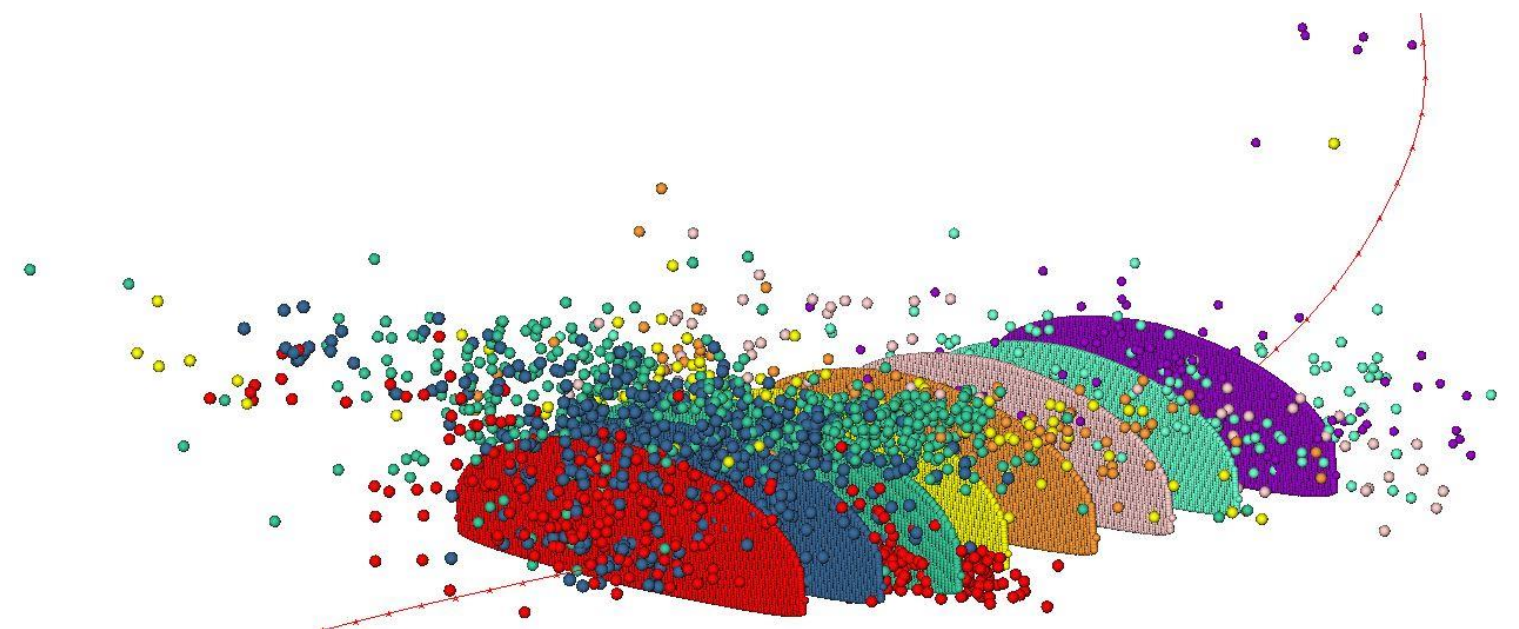

Figure A.32: Orthogonal View of Calculated Hydraulic Fracture Geometries, Measured Microseismic Events, and Nearby Wellbore for Stage 21 through Stage 28 - MIP-3H 
Table A.3 shows the computed hydraulic fracture geometries for MIP-5H stage 1 through stage 10. Figure A.33 shows the hydraulic fracture geometry for one of the primary induced hydraulic fractures in stage 10 of well MIP-5H. Figure A.34 shows the cumulative proppant mass versus time (calculated and measured), Figure A.35 shows the slurry volume injected versus time (calculated and measured), and Figure A.36 shows the surface pressure versus time (calculated and measured) for stage 10 of well MIP-5H.

Microseismic data was available for stage 2 and stage 4 through stage 10 of well MIP-5H. Microseismic, well, and hydraulic fracture geometry data were visualized in three dimensions. Figures A.37 through A.44 show side views of modeled hydraulic fracture geometries and available measured microseismic events and magnitudes for stage 2 , and stages 4 through 10, respectively, for well MIP-5H. Figure A.45 shows an overview of all 8 modeled hydraulic fracture geometries, available microseismic event data, and the entire MIP-5H wellbore. Figure A.46 shows a top view of these modeled hydraulic fracture geometries, available microseismic event data, and the nearby section of the MIP-5H wellbore. Figure A.47 shows an orthogonal projection of these modeled hydraulic fracture geometries, available microseismic event data, and the nearby section of the MIP-5H wellbore. 
Table A.3: Computed Hydraulic Fracture Geometries - Stage 1 through Stage 10 MIP-5H

\begin{tabular}{|c|c|c|c|}
\hline STAGE & Fracture Half-Length (ft) & Fracture Height (ft) & Average Fracture Width (in) \\
\hline 1 & 591.9 & 294.3 & 0.029143 \\
\hline 2 & 547.9 & 295.6 & 0.020782 \\
\hline 3 & 511.5 & 285.7 & 0.022435 \\
\hline 4 & 449.7 & 285.2 & 0.016648 \\
\hline 5 & 517.1 & 289.9 & 0.020991 \\
\hline 6 & 574.1 & 310.6 & 0.021193 \\
\hline 7 & 600.1 & 304 & 0.018286 \\
\hline 8 & 564.5 & 309.1 & 0.021027 \\
\hline 9 & 558 & 306 & 0.02078 \\
\hline 10 & 606.6 & 316.7 & 0.027322 \\
\hline
\end{tabular}

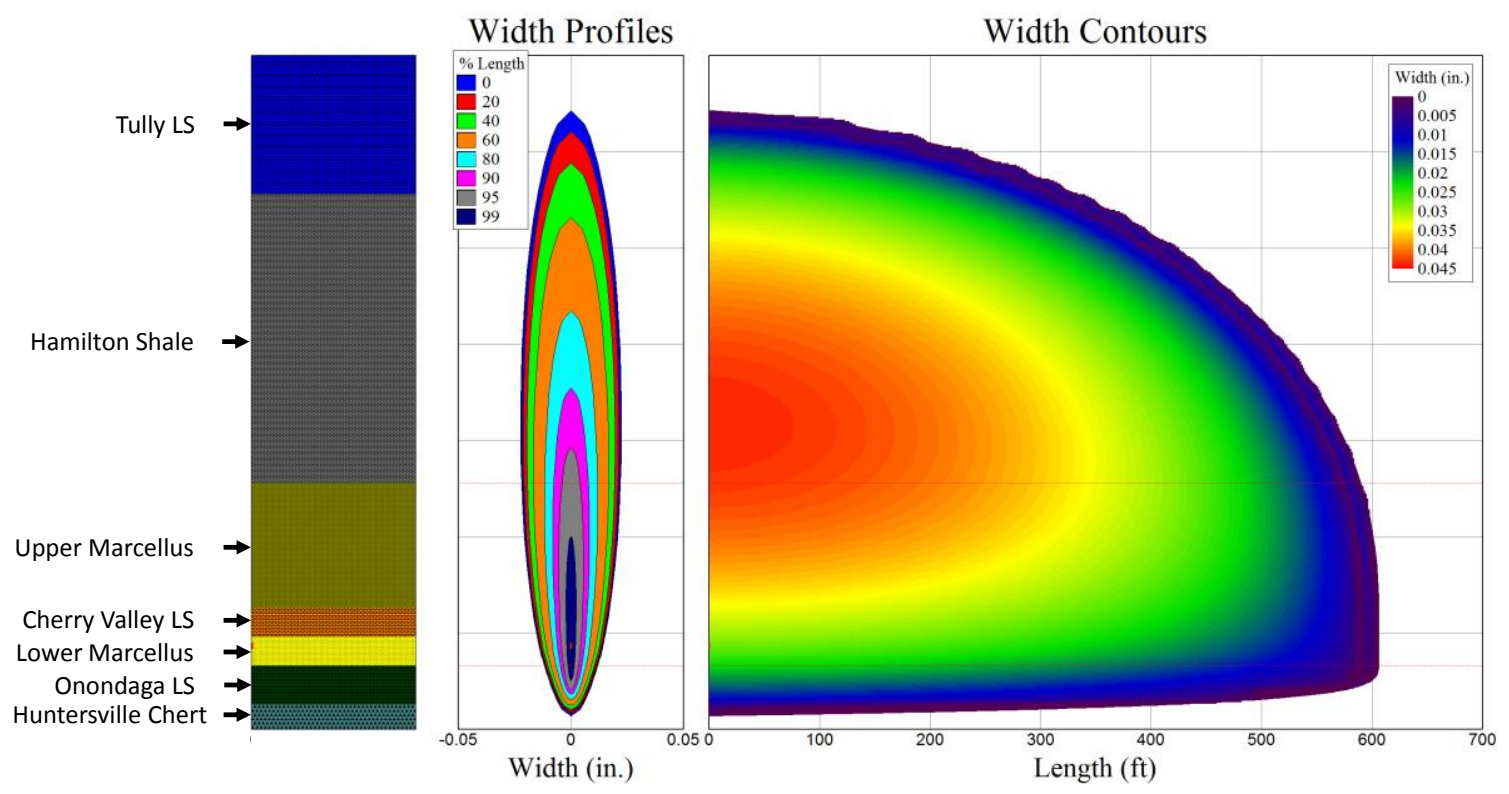

Figure A.33: Primary Hydraulic Fracture Geometry for Stage 10 - MIP-5H 


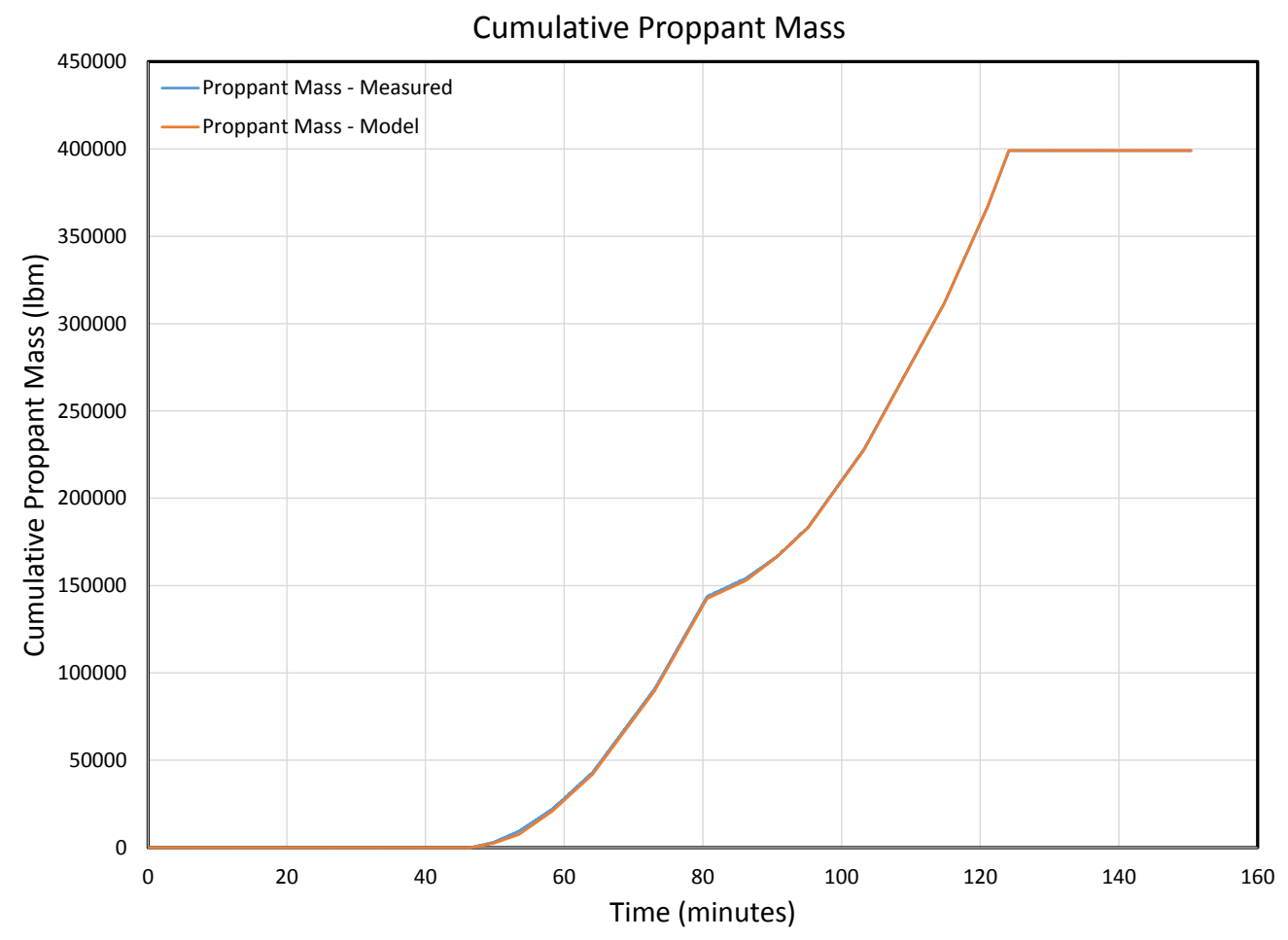

Figure A.34: Cumulative Proppant Mass Injected for Stage 10 - MIP-5H

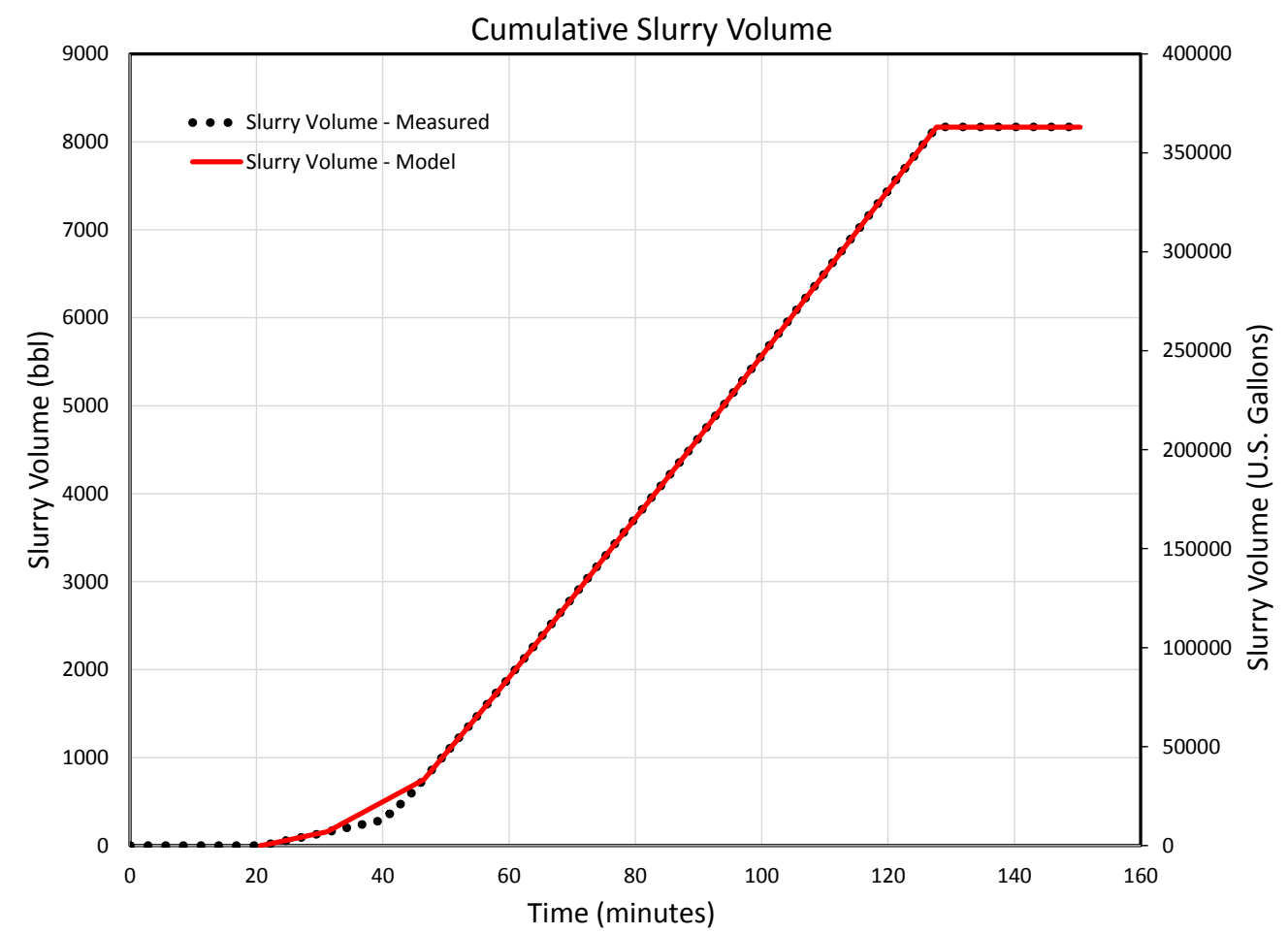

Figure A.35: Cumulative Slurry Volume Injected for Stage 10 - MIP-5H 


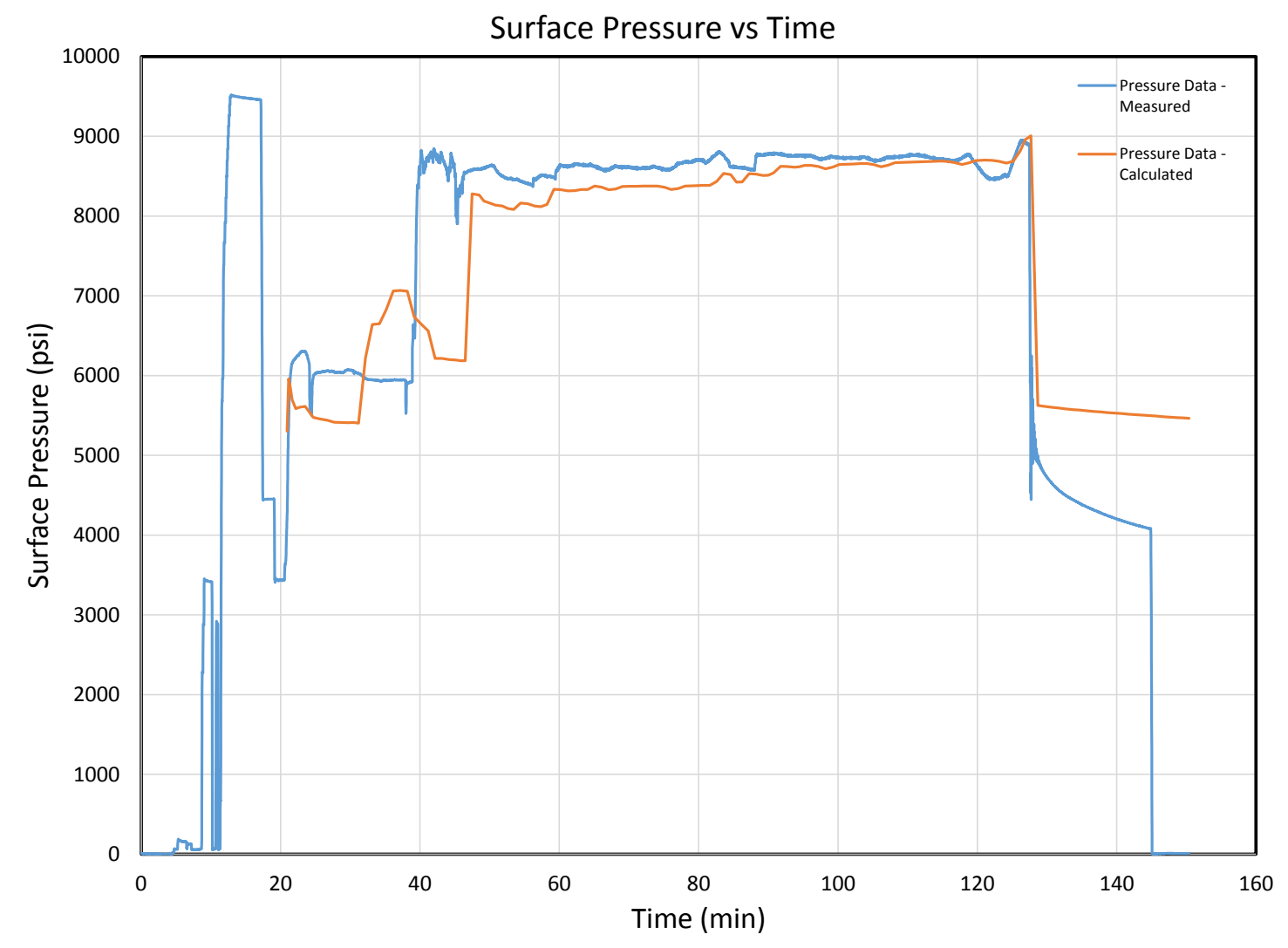

Figure A.36: Surface Pressure versus Time for Stage 10 - MIP-5H 


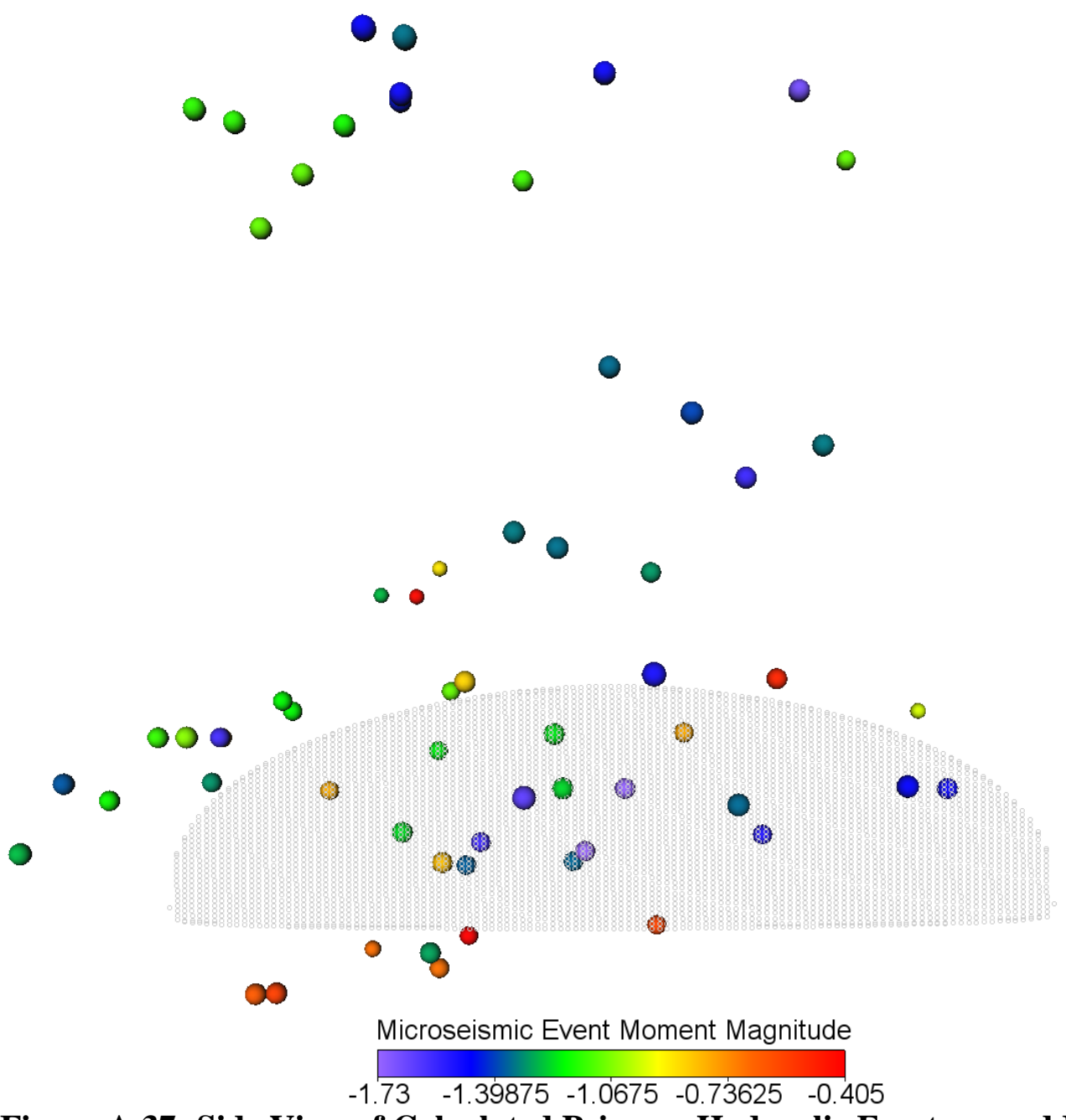

Figure A.37: Side View of Calculated Primary Hydraulic Fracture and Measured

Microseismic Events and Magnitudes for Stage 2 - MIP-5H

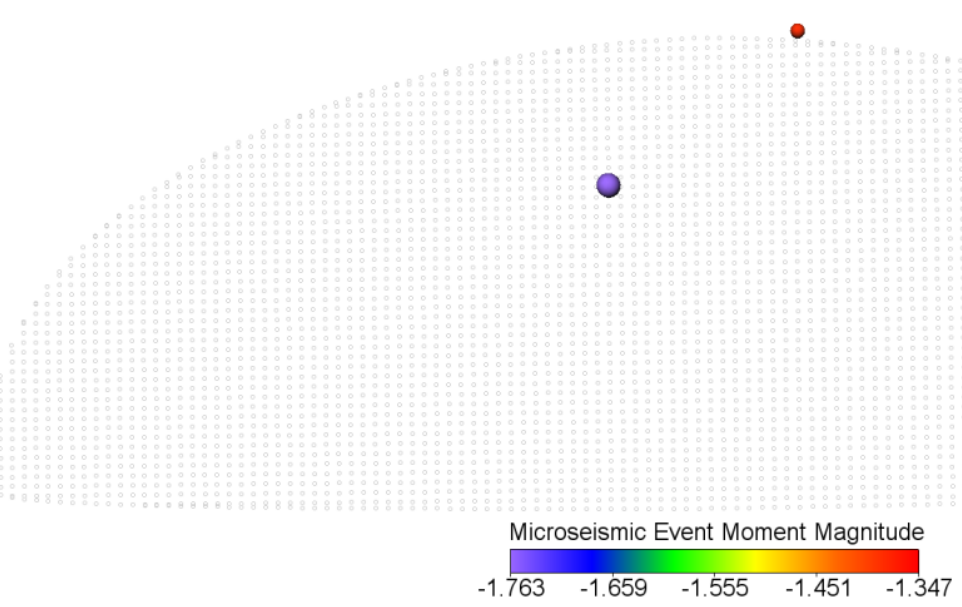

Figure A.38: Side View of Calculated Primary Hydraulic Fracture and Measured Microseismic Events and Magnitudes for Stage 4 - MIP-5H 


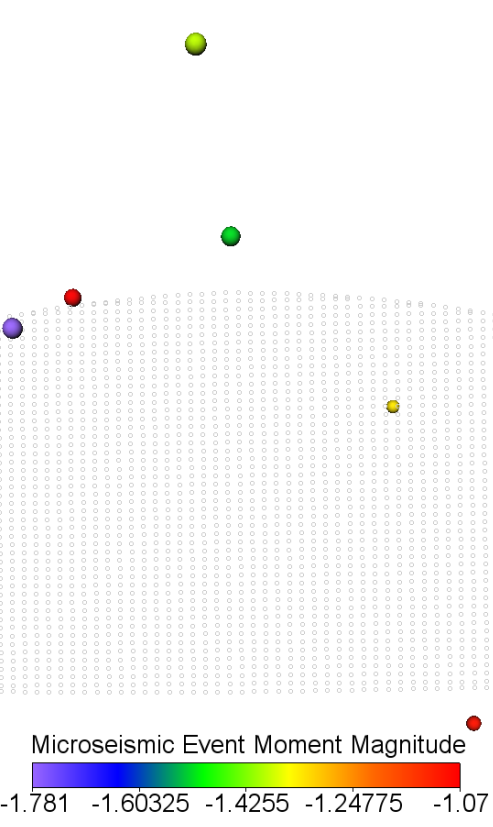

Figure A.39: Side View of Calculated Primary Hydraulic Fracture and Measured Microseismic Events and Magnitudes for Stage 5 - MIP-5H

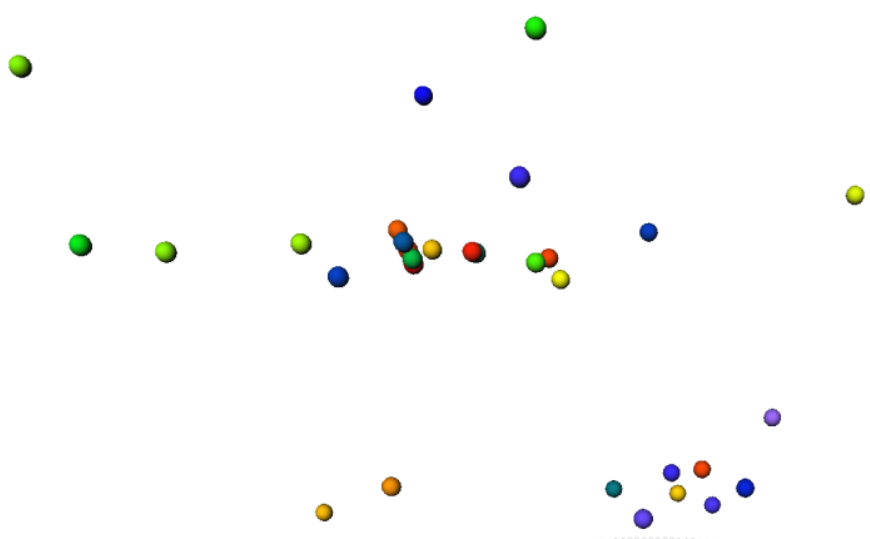

0

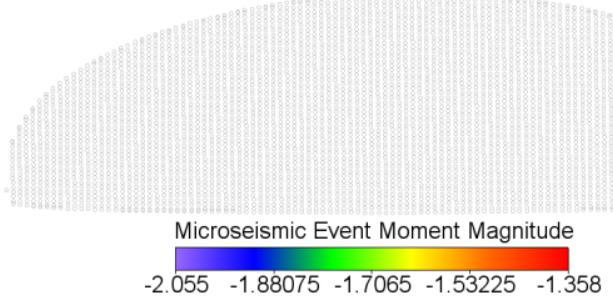

Figure A.40: Side View of Calculated Primary Hydraulic Fracture and Measured Microseismic Events and Magnitudes for Stage 6 - MIP-5H 


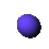

0
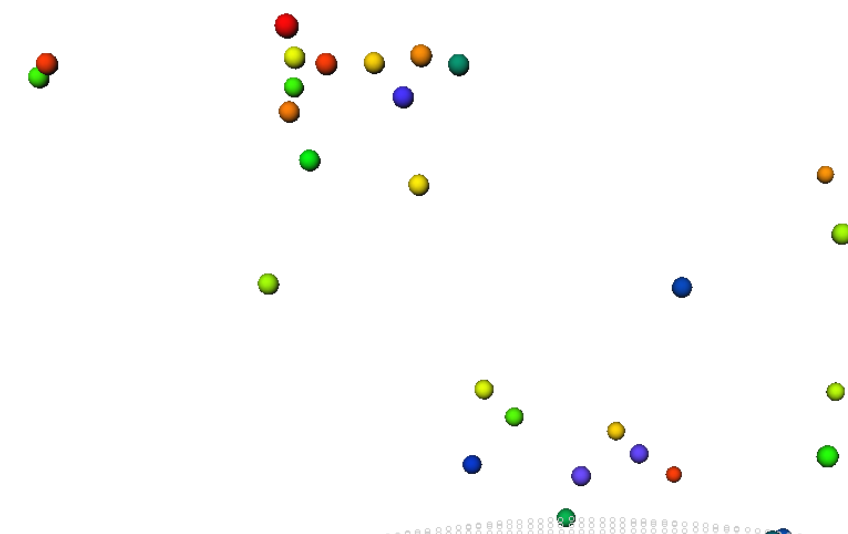

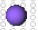

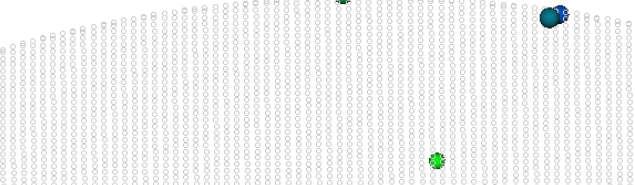

Microseismic Event Moment Magnitude

$-2.061-1.85825-1.6555-1.45275-1.25$

Figure A.41: Side View of Calculated Primary Hydraulic Fracture and Measured Microseismic Events and Magnitudes for Stage 7 - MIP-5H

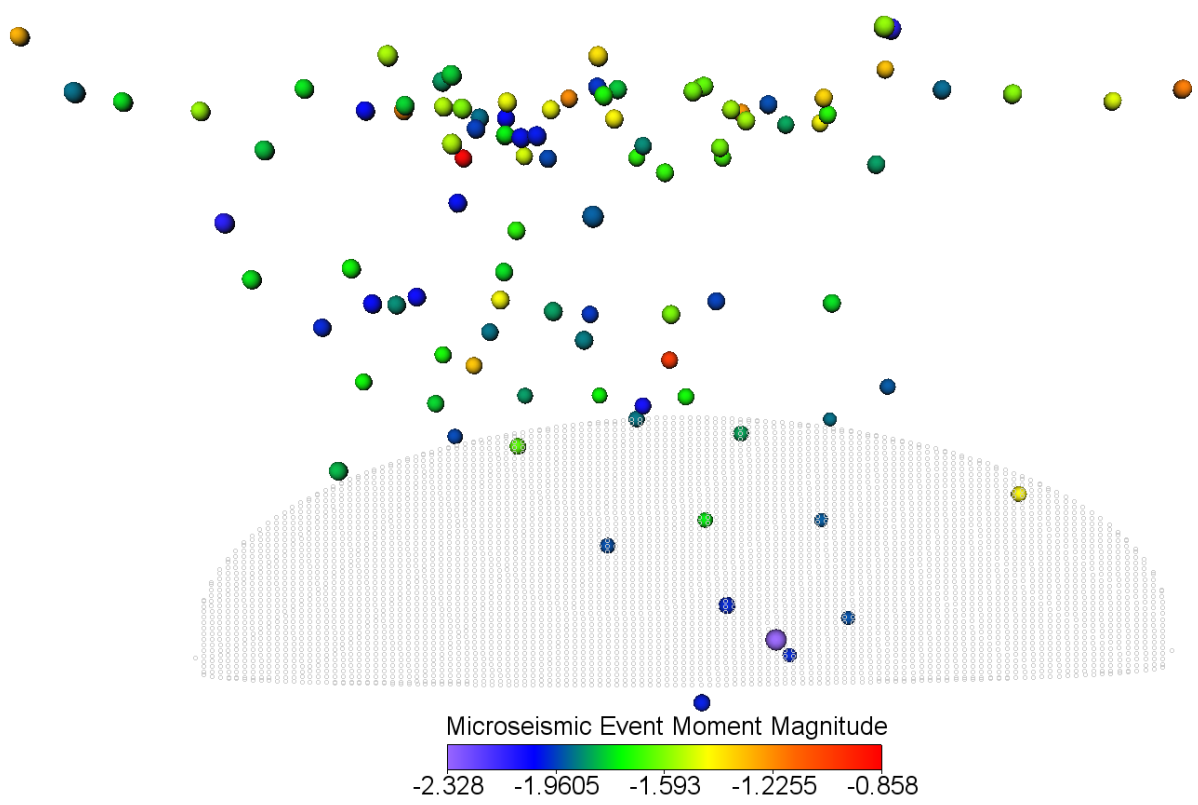

Figure A.42: Side View of Calculated Primary Hydraulic Fracture and Measured Microseismic Events and Magnitudes for Stage 8 - MIP-5H 


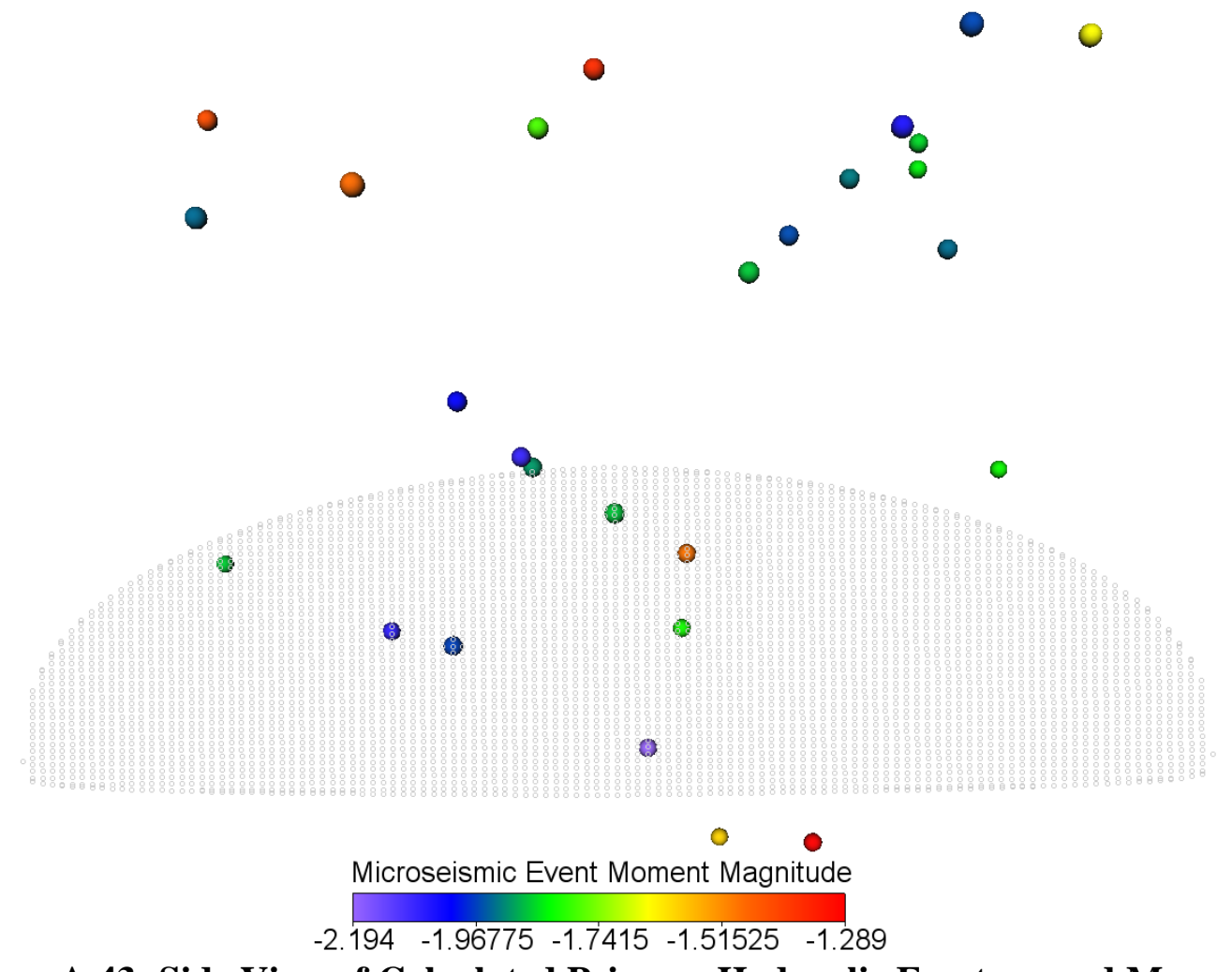

Figure A.43: Side View of Calculated Primary Hydraulic Fracture and Measured Microseismic Events and Magnitudes for Stage 9 - MIP-5H

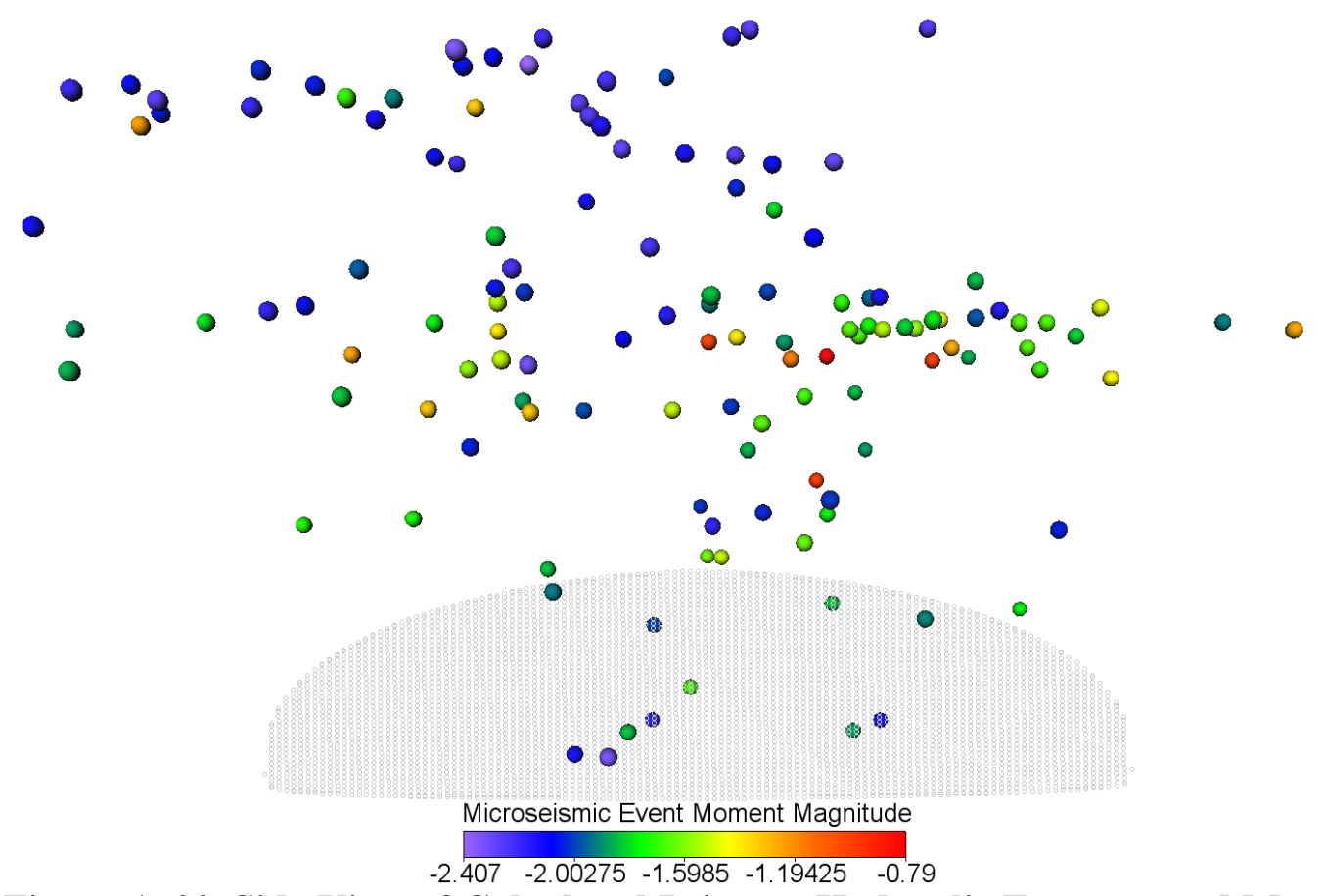

Figure A.44: Side View of Calculated Primary Hydraulic Fracture and Measured Microseismic Events and Magnitudes for Stage 10 - MIP-5H 


\section{Ground Surface}

The center of perforations for

Stages $1-10$ are approximately

7461 feet below the ground surface.

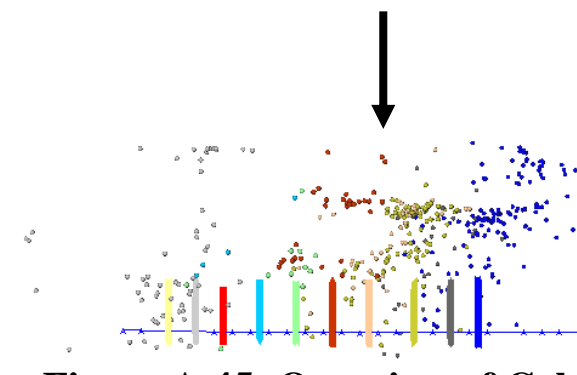

Figure A.45: Overview of Calculated Primary Hydraulic Fracture Geometries, Available Measured Microseismic Events, and Entire Wellbore for Stage 1 through Stage 10 - MIP-5H 


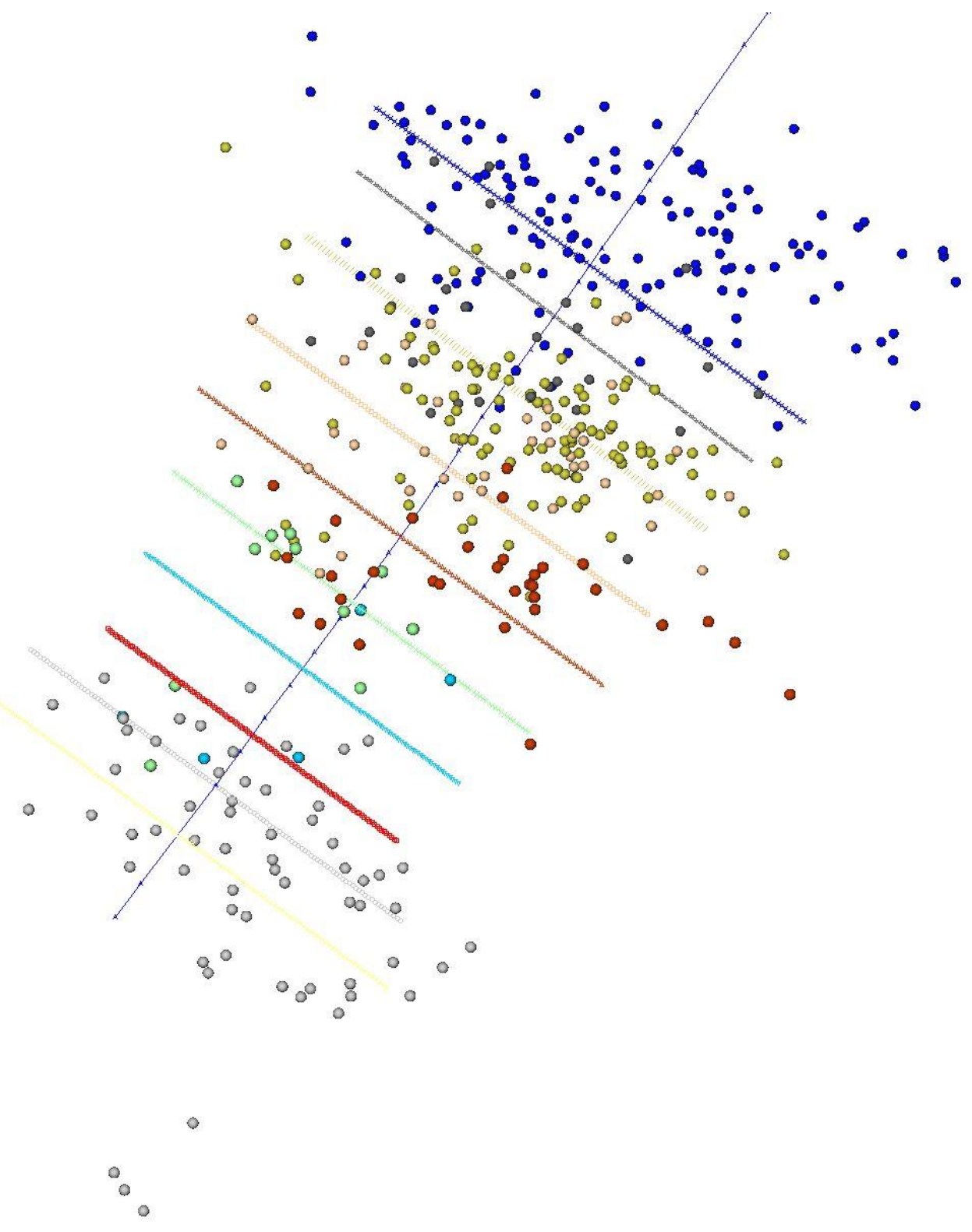

Figure A.46: Top View of Calculated Primary Hydraulic Fracture Geometries, Available Measured Microseismic Events, and Nearby Wellbore for Stage 1 through Stage 10 - MIP-5H 


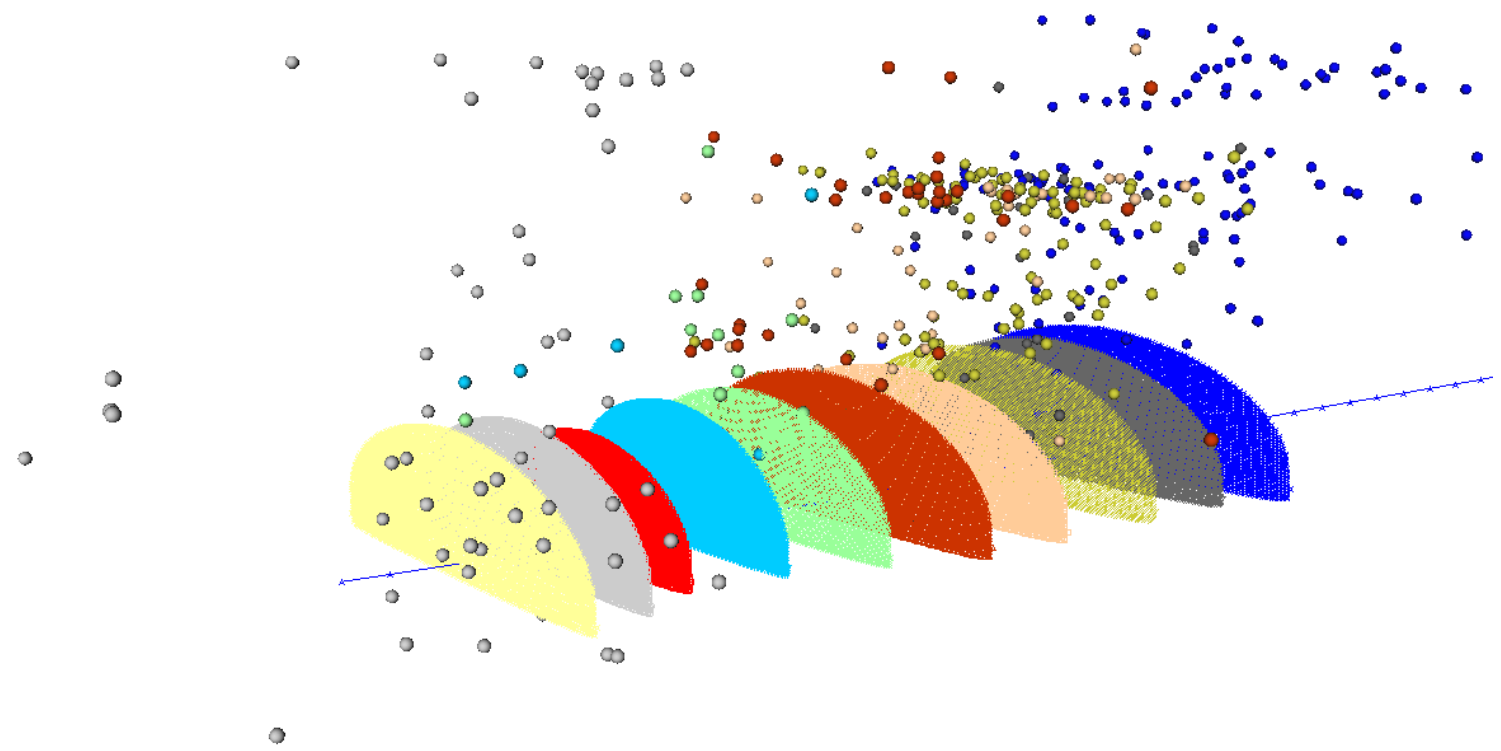

Figure A.47: Orthogonal View of Calculated Primary Hydraulic Fracture Geometries, Available Measured Microseismic Events, and Nearby Wellbore for Stage 1 through Stage 10 - MIP-5H 
Table A.4 shows the computed hydraulic fracture geometries for modeled MIP-5H stage 11 through stage 20. Figure A.48 shows the hydraulic fracture geometry for one of the primary induced hydraulic fractures in stage 20 of well MIP-5H. Figure A.49 shows the cumulative proppant mass versus time (calculated and measured), Figure A.50 shows the slurry volume injected versus time (calculated and measured), and Figure A.51 shows the surface pressure versus time (calculated and measured) for stage 20 of well MIP-5H.

Microseismic, well, and hydraulic fracture geometry data were visualized in three dimensions. Figures A.52 through A.61 show side views of modeled hydraulic fracture geometries and available measured microseismic events and magnitudes for stage 11 through stage 20, respectively, for well MIP-5H. Figure A.62 shows an overview of these modeled hydraulic fracture geometries, available microseismic event data, and the entire MIP-5H wellbore. Figure A.63 shows a top view of these modeled hydraulic fracture geometries, available microseismic event data, and the nearby section of the MIP-5H wellbore. Figure A.64 shows an orthogonal projection of these modeled hydraulic fracture geometries, available microseismic event data, and the nearby section of the MIP-5H wellbore. 
Table A.4: Computed Hydraulic Fracture Geometries - Stage 11 through Stage 20 MIP-5H

\begin{tabular}{|c|c|c|c|}
\hline STAGE & Fracture Half-Length (ft) & Fracture Height (ft) & Average Fracture Width (in) \\
\hline 11 & 592 & 310.4 & 0.026447 \\
\hline 12 & 609.4 & 317.3 & 0.026012 \\
\hline 13 & 665.6 & 310.4 & 0.025469 \\
\hline 14 & 592.6 & 314.3 & 0.025875 \\
\hline 15 & 603.5 & 316.7 & 0.026851 \\
\hline 16 & 560.4 & 307.7 & 0.02186 \\
\hline 17 & 616.2 & 316.3 & 0.027175 \\
\hline 18 & 602.8 & 308.2 & 0.024703 \\
\hline 19 & 610.9 & 317.9 & 0.027597 \\
\hline 20 & 596 & 314.2 & 0.027018 \\
\hline
\end{tabular}

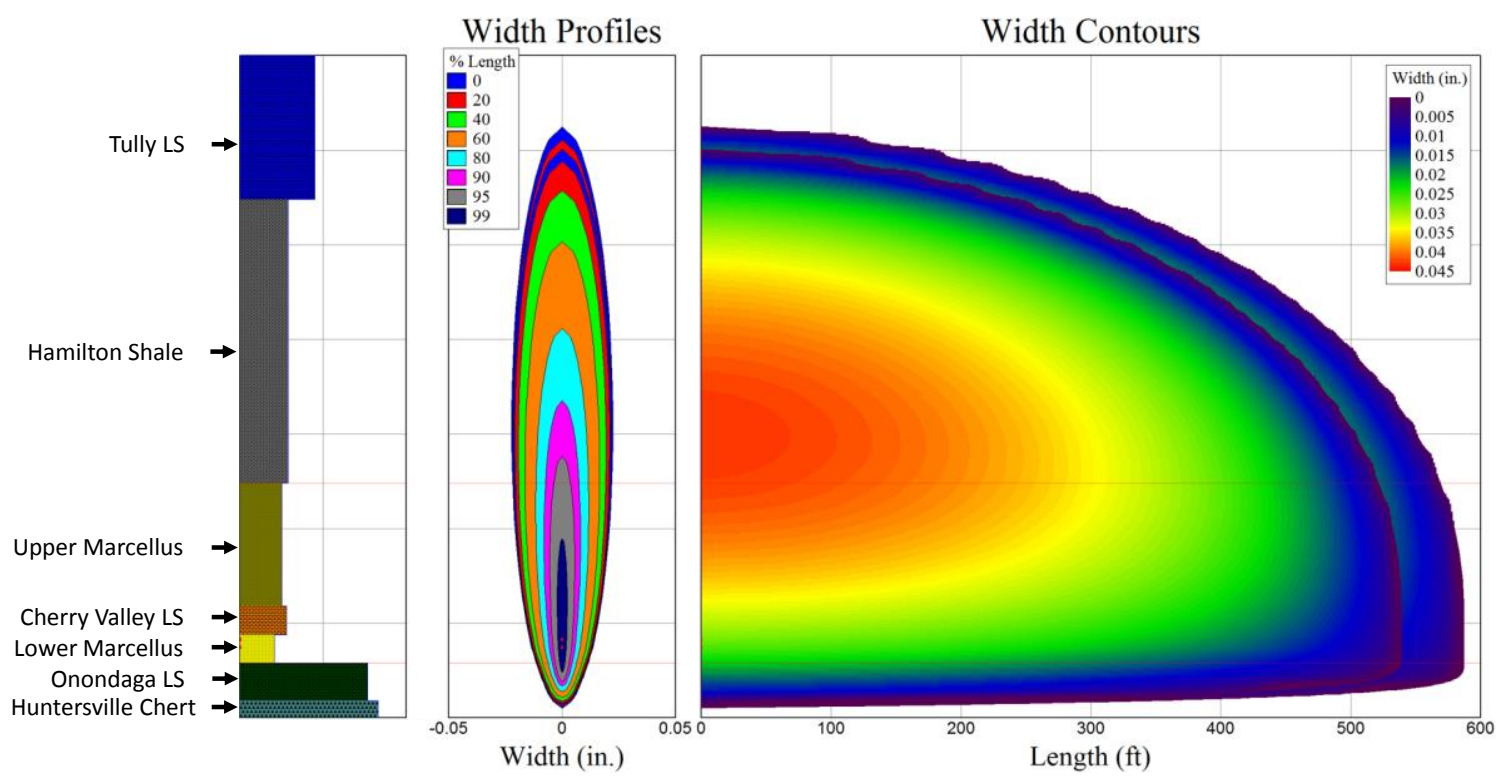

Figure A.48: Primary Hydraulic Fracture Geometry for Stage 20 - MIP-5H 


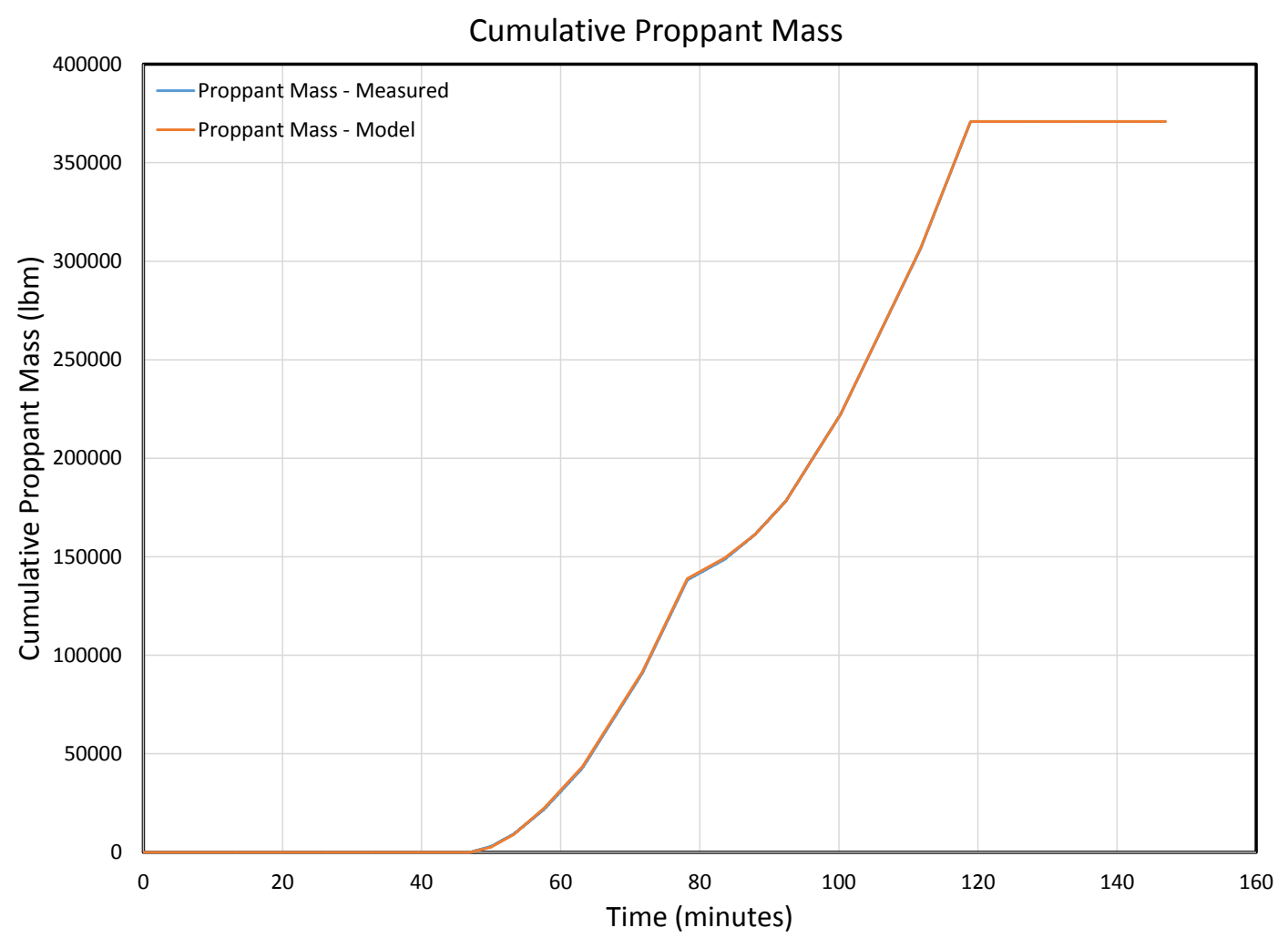

Figure A.49: Cumulative Proppant Mass Injected for Stage 20 - MIP-5H

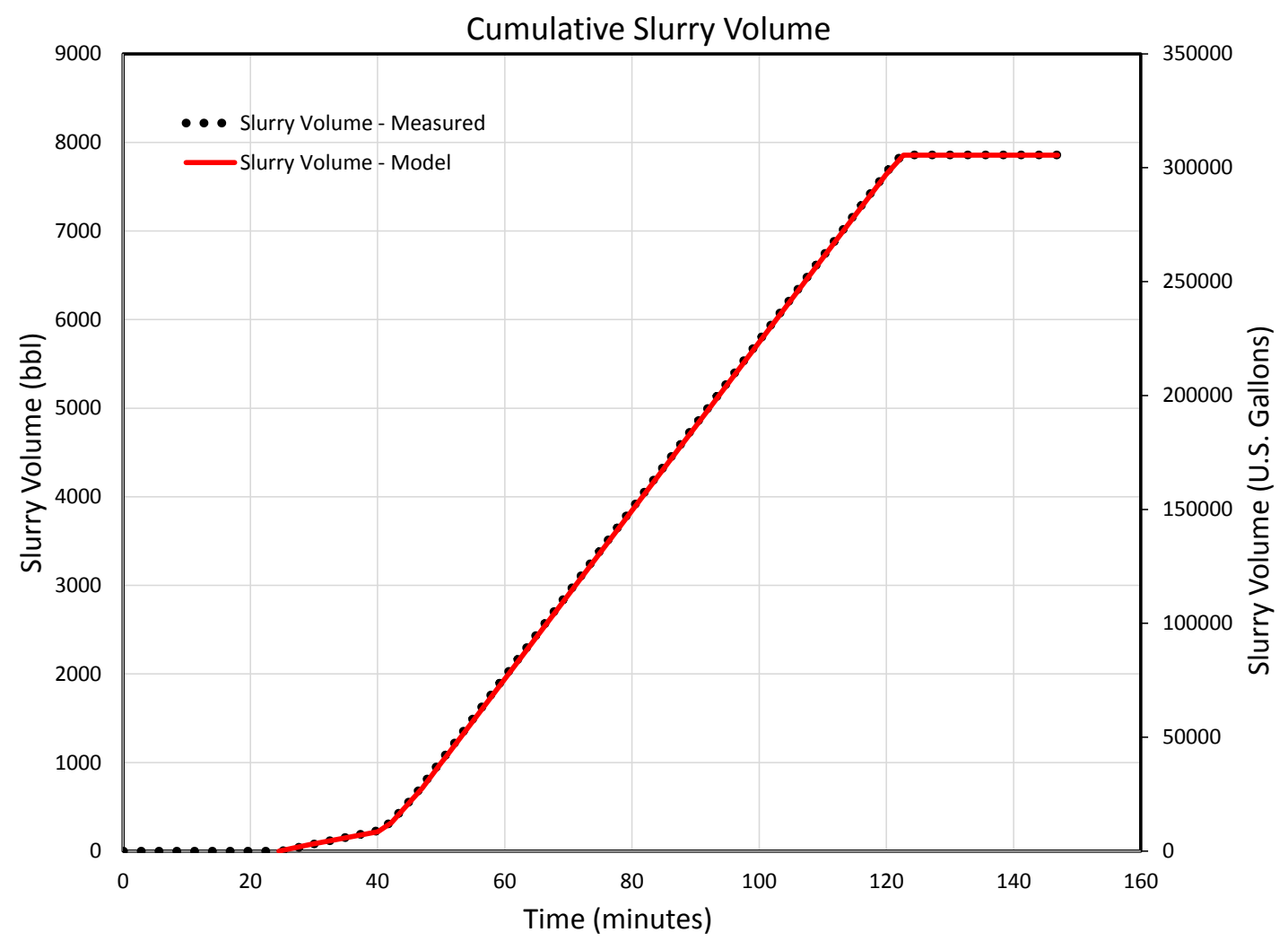

Figure A.50: Cumulative Slurry Volume Injected for Stage 20 - MIP-5H 


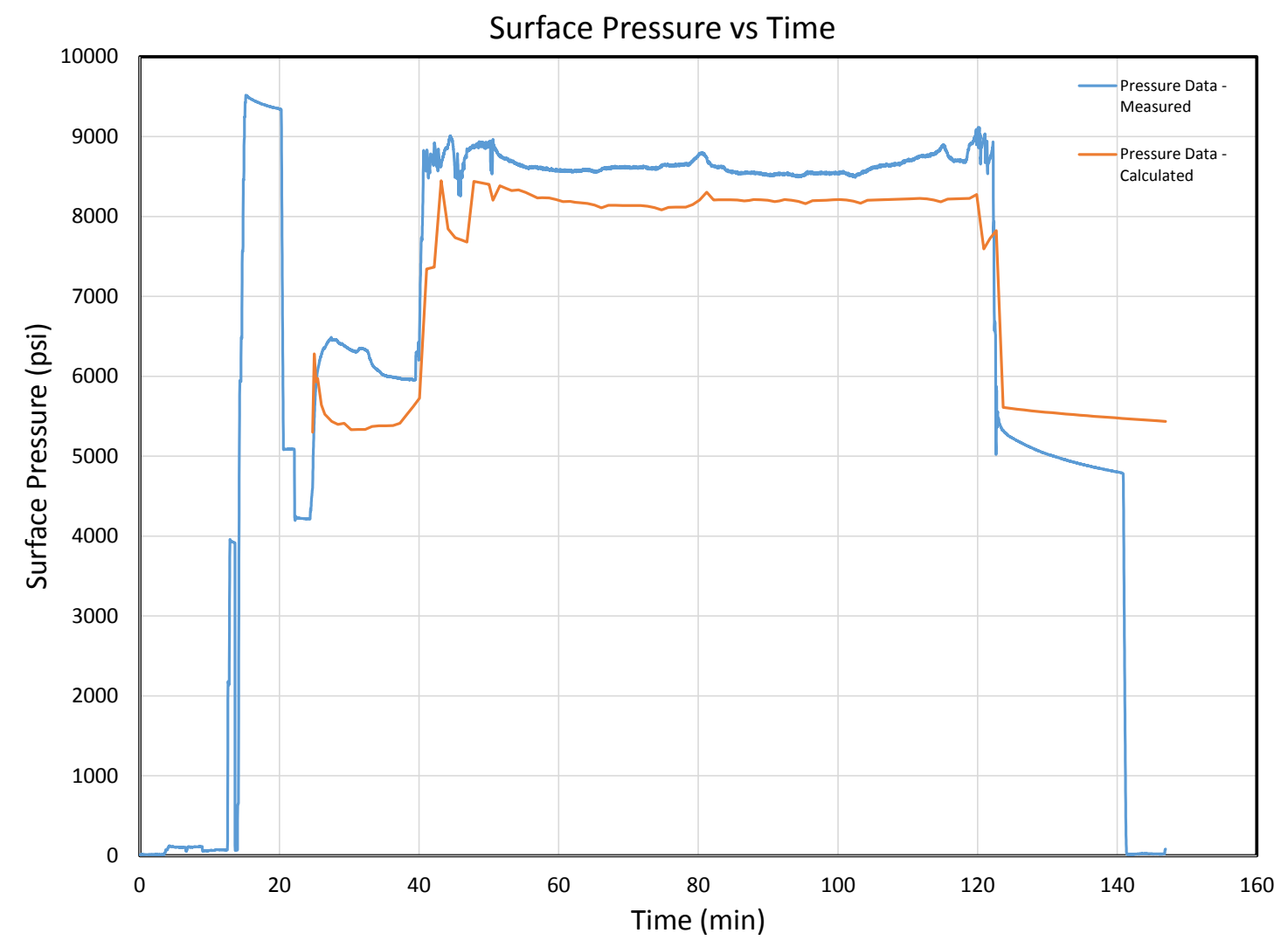

Figure A.51: Surface Pressure versus Time for Stage 20 - MIP-5H 


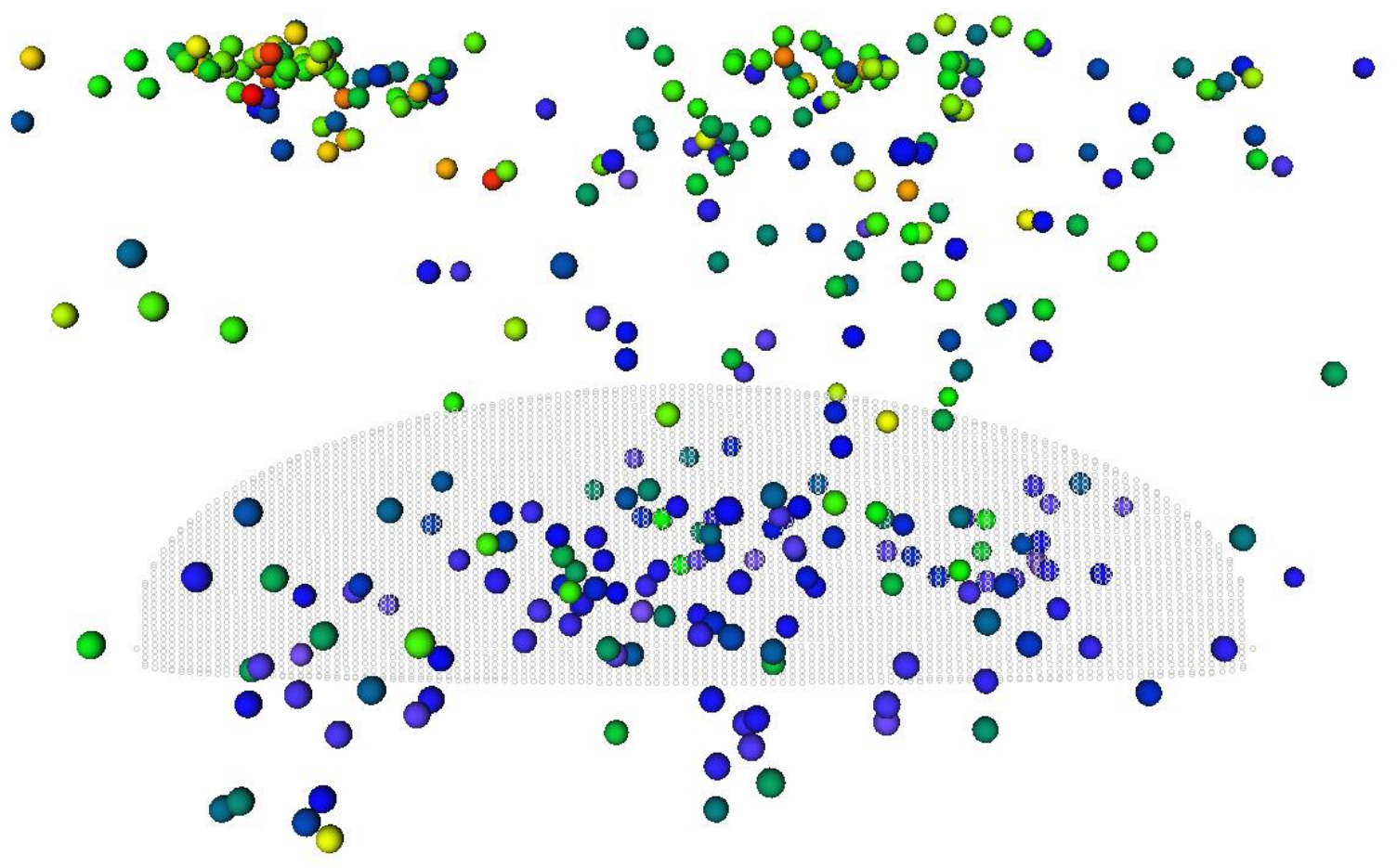

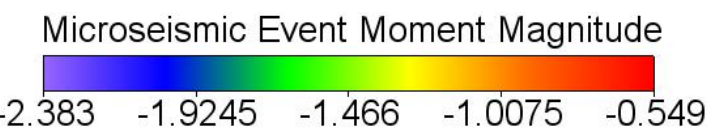

Figure A.52: Side View of Calculated Primary Hydraulic Fracture and Measured Microseismic Events and Magnitudes for Stage 11 - MIP-5H

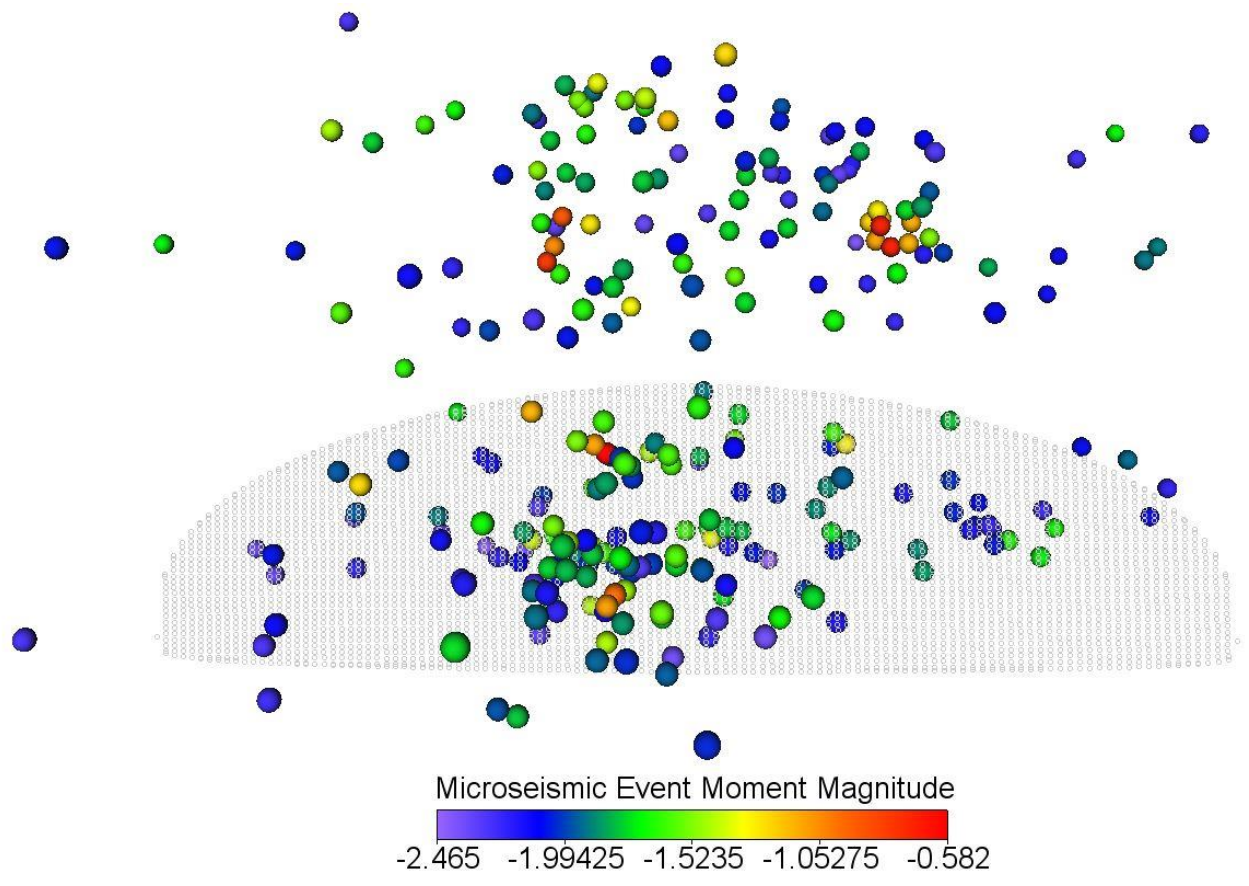

Figure A.53: Side View of Calculated Primary Hydraulic Fracture and Measured Microseismic Events and Magnitudes for Stage 12 - MIP-5H 


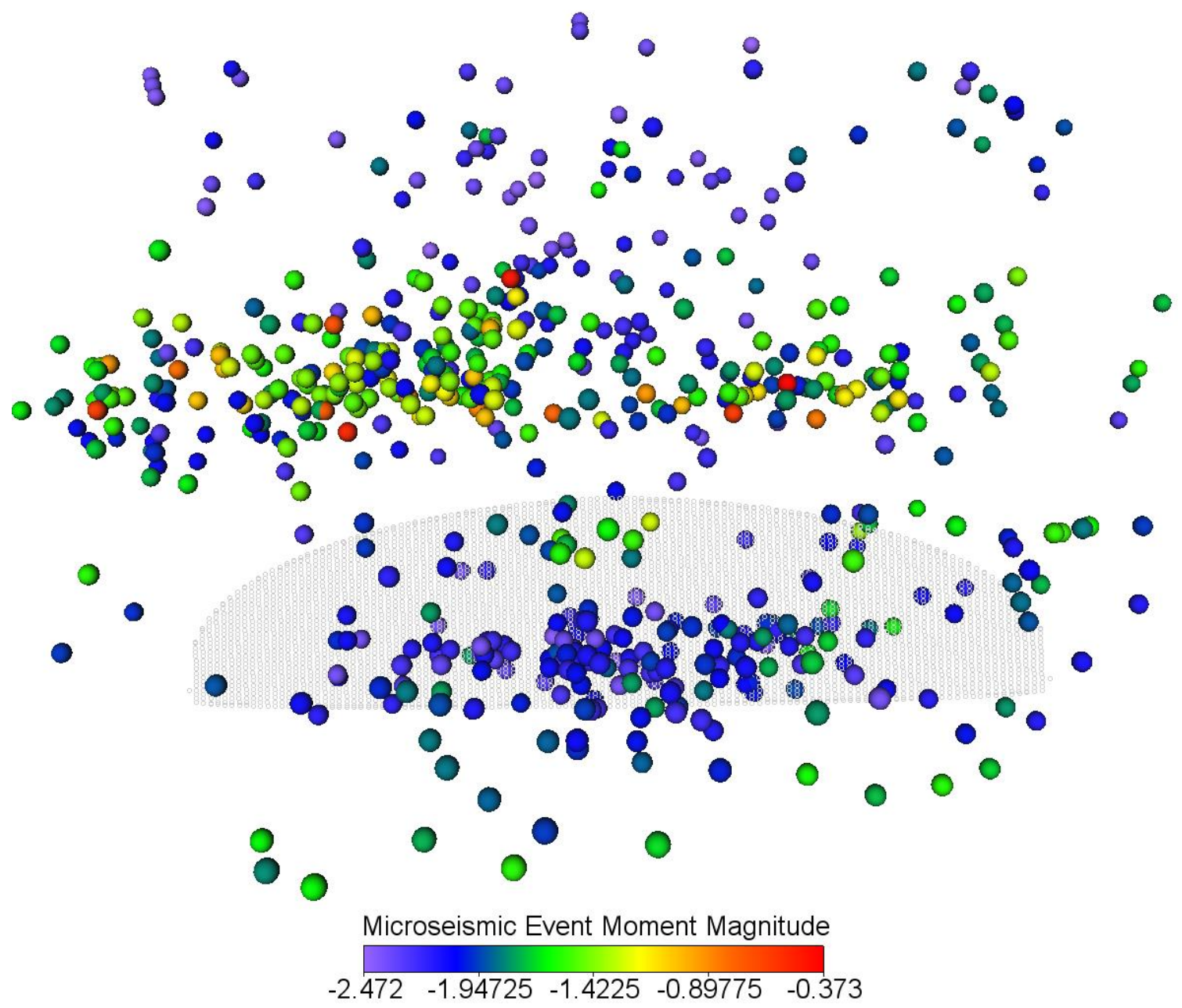

Figure A.54: Side View of Calculated Primary Hydraulic Fracture and Measured Microseismic Events and Magnitudes for Stage 13 - MIP-5H 


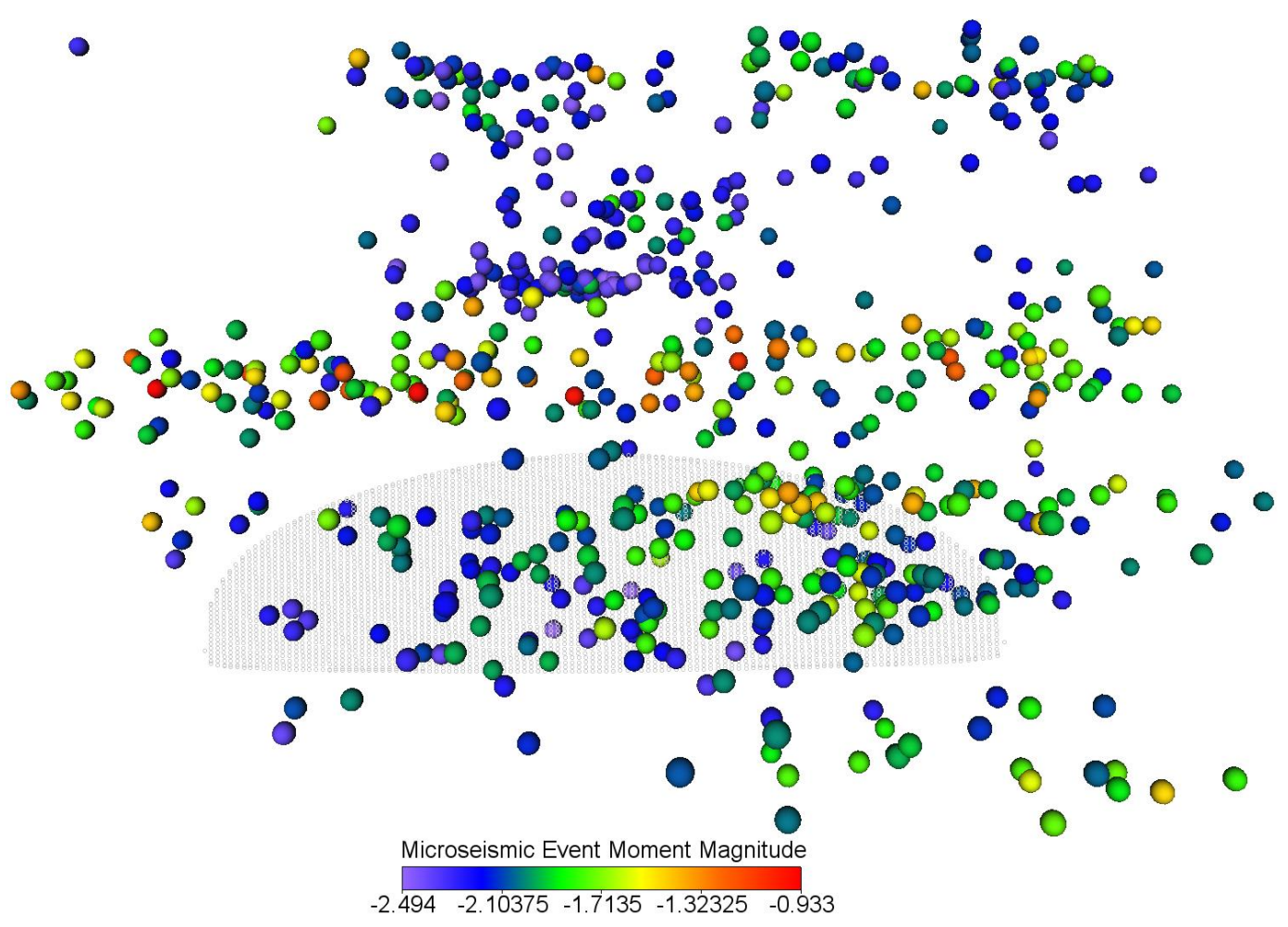

Figure A.55: Side View of Calculated Primary Hydraulic Fracture and Measured Microseismic Events and Magnitudes for Stage 14 - MIP-5H

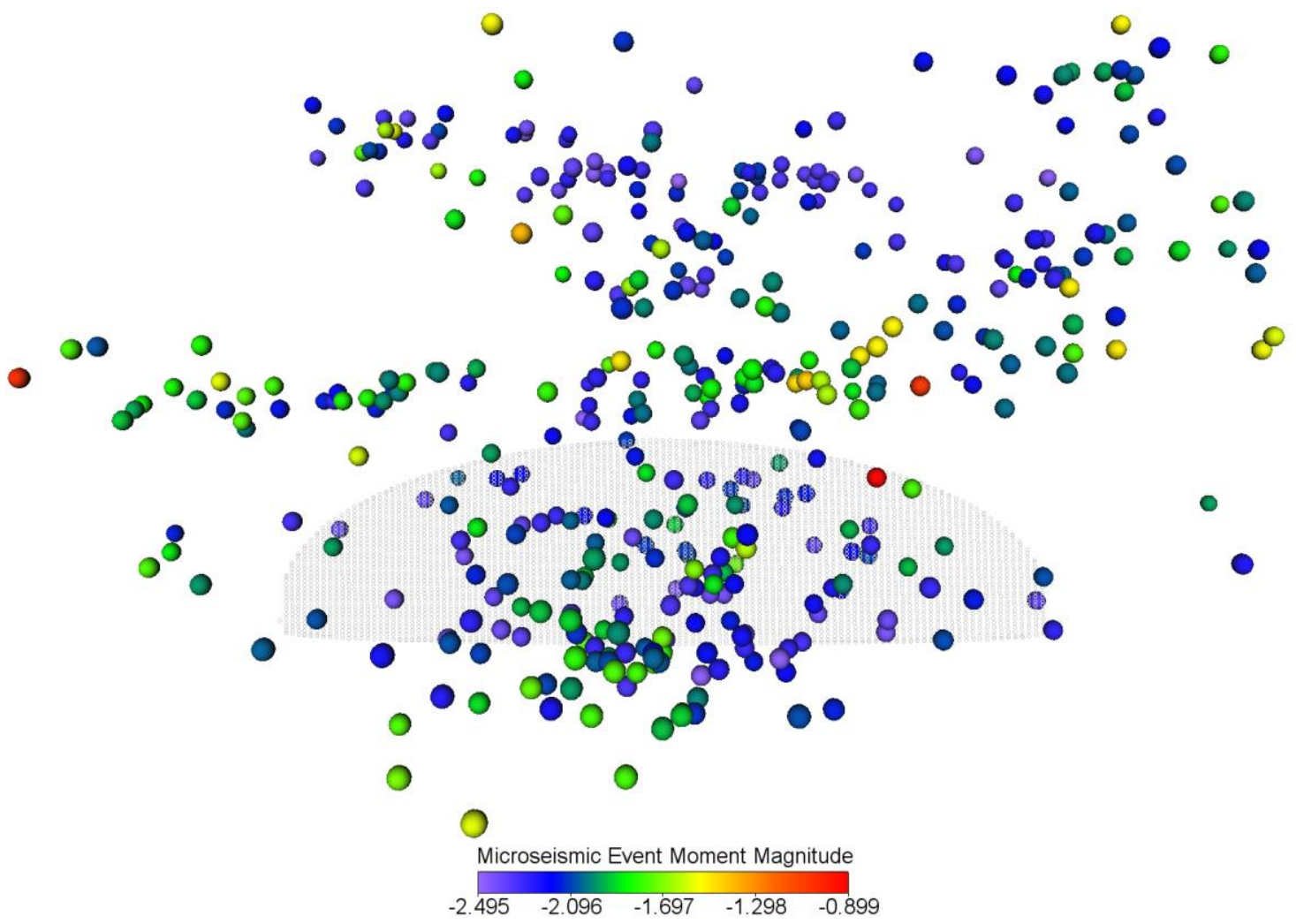

Figure A.56: Side View of Calculated Primary Hydraulic Fracture and Measured Microseismic Events and Magnitudes for Stage 15 - MIP-5H 


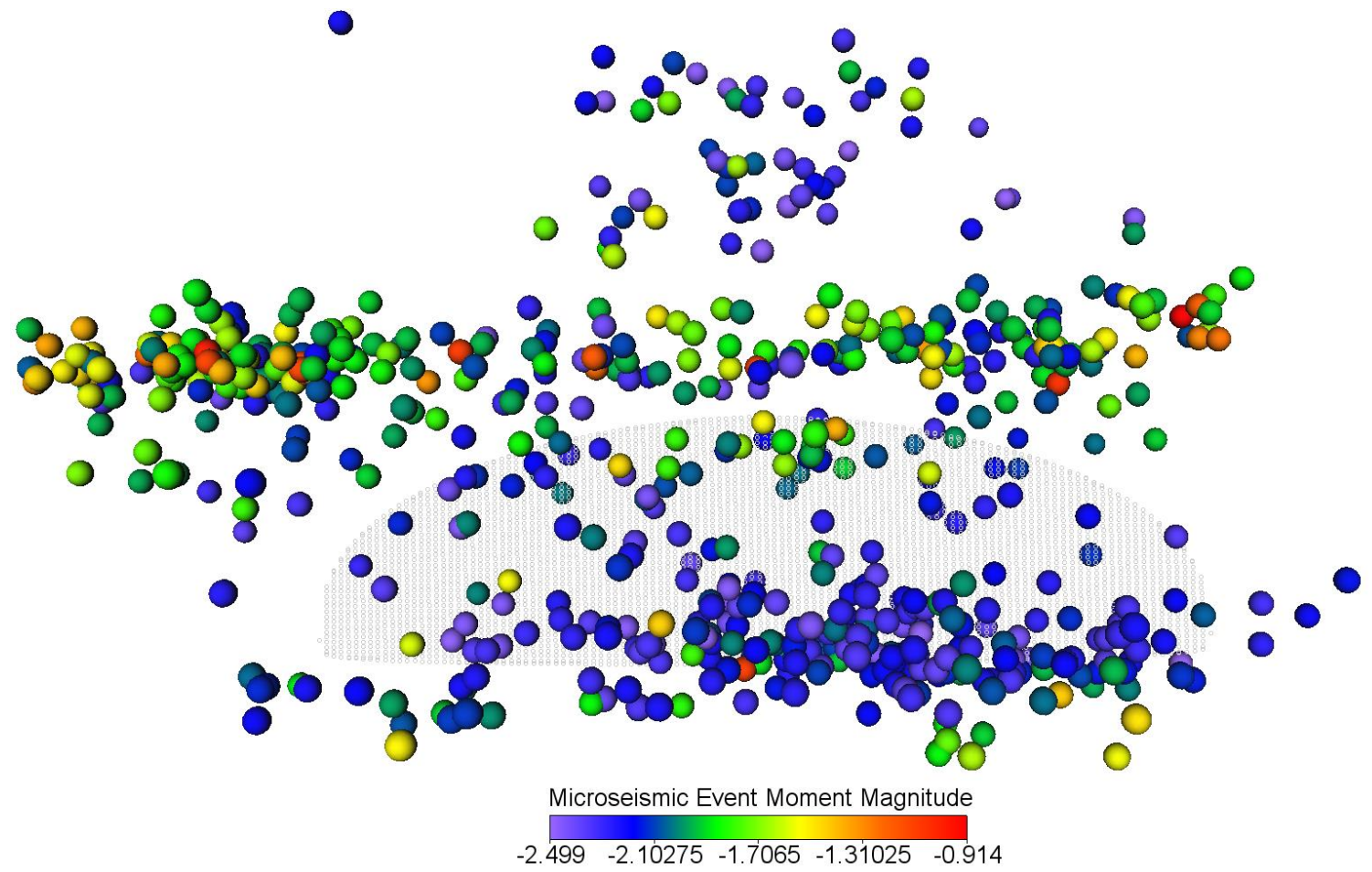

Figure A.57: Side View of Calculated Primary Hydraulic Fracture and Measured Microseismic Events and Magnitudes for Stage 16 - MIP-5H

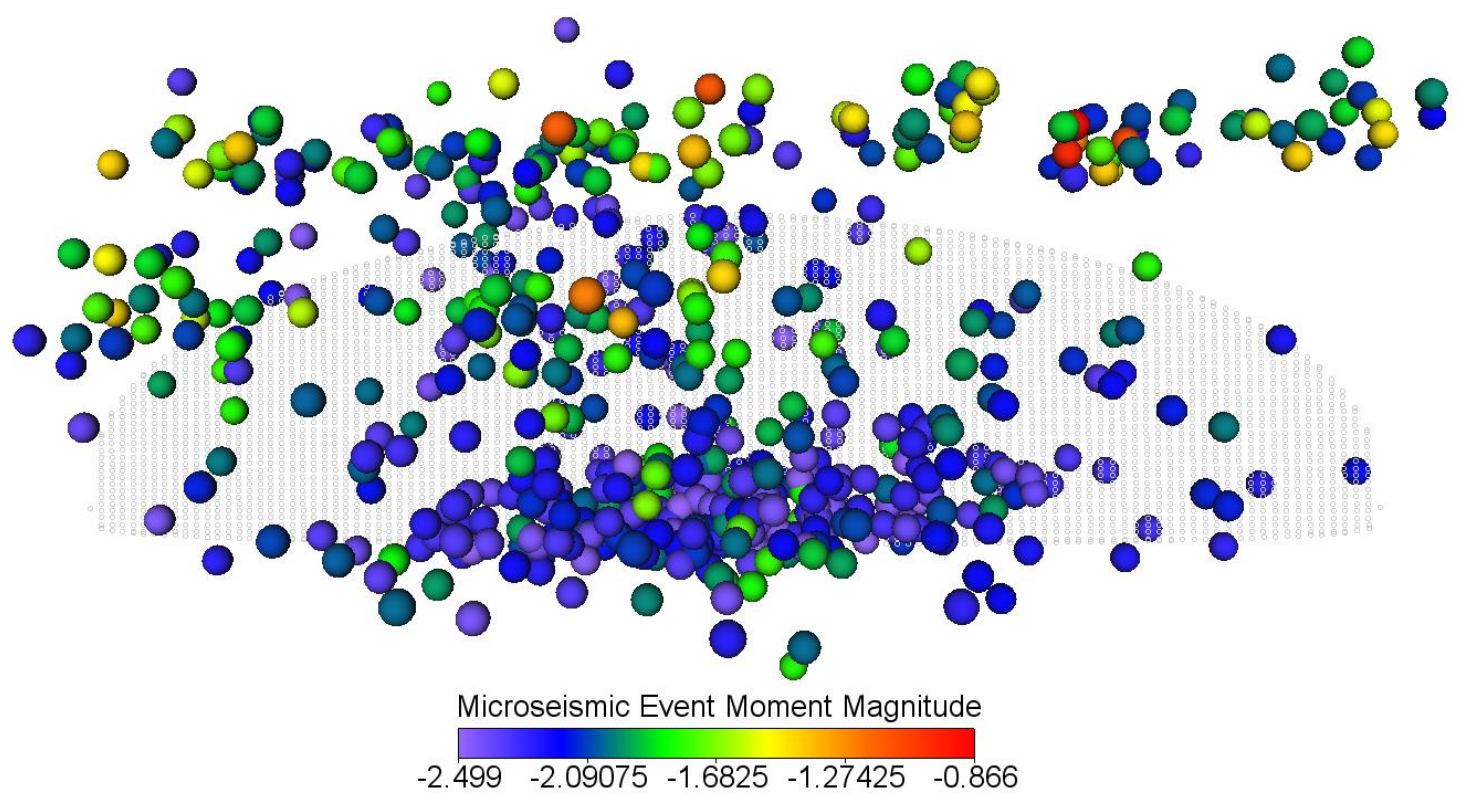

Figure A.58: Side View of Calculated Primary Hydraulic Fracture and Measured Microseismic Events and Magnitudes for Stage 17 - MIP-5H 


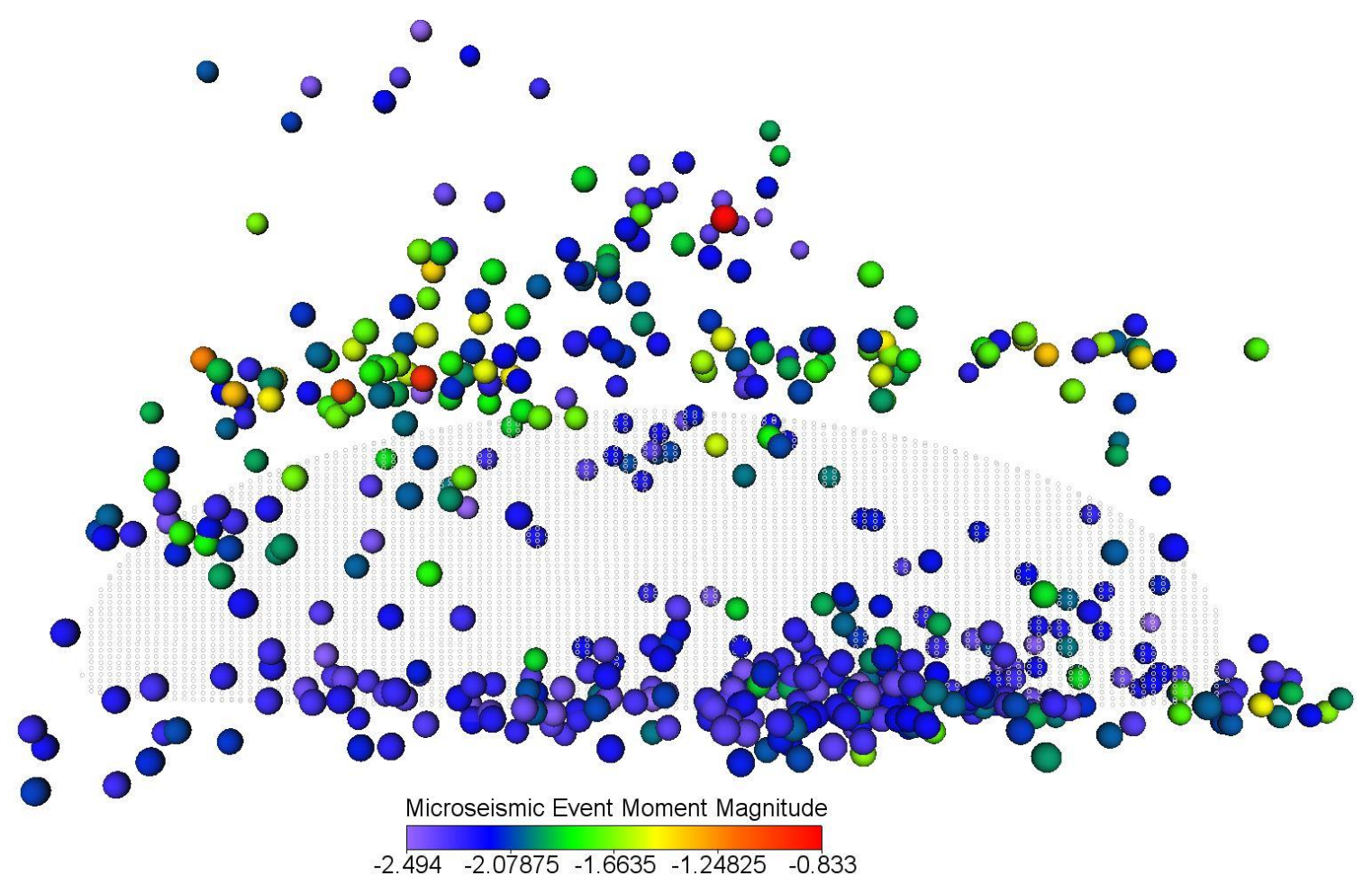

Figure A.59: Side View of Calculated Primary Hydraulic Fracture and Measured Microseismic Events and Magnitudes for Stage 18 - MIP-5H

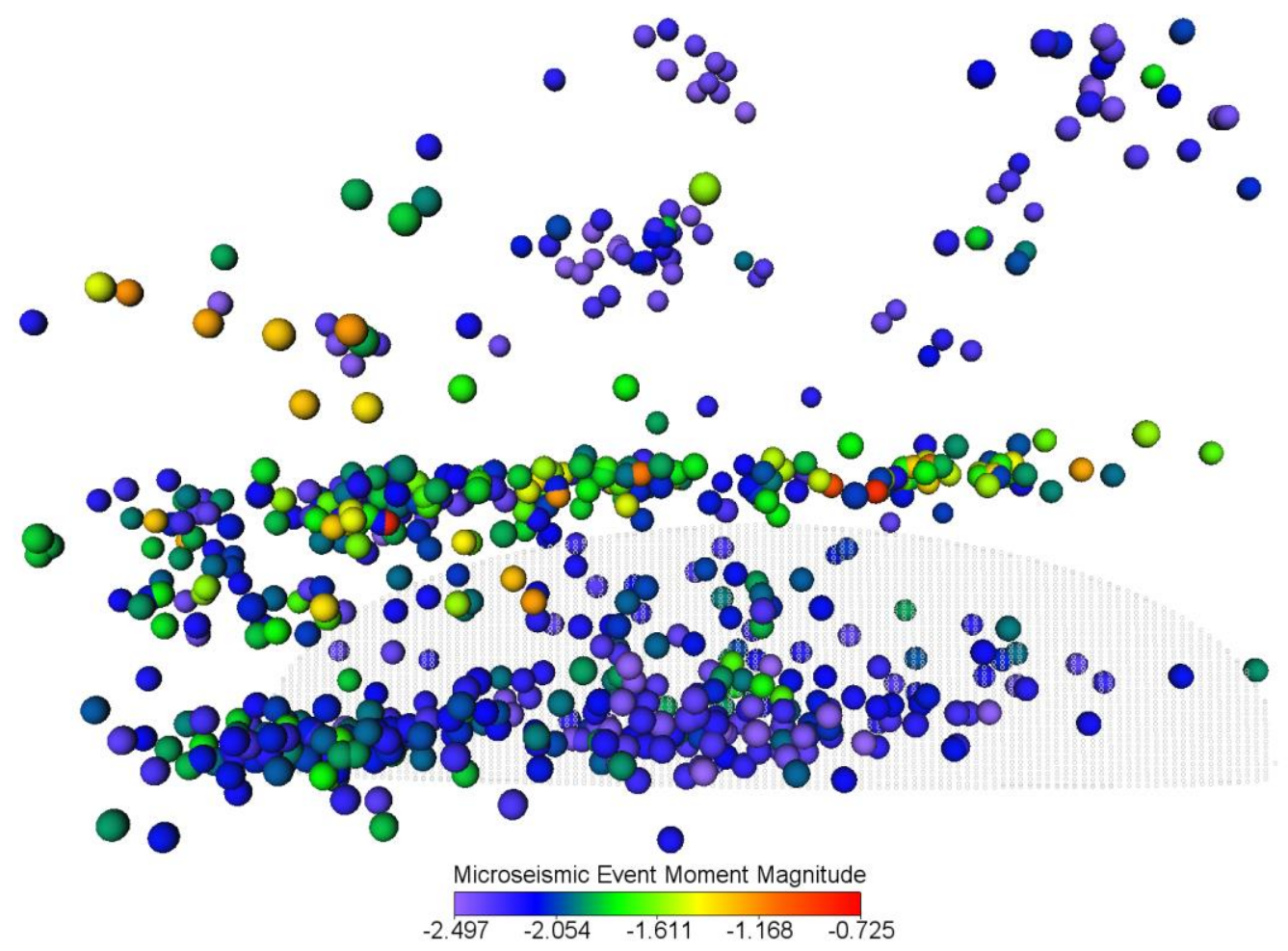

Figure A.60: Side View of Calculated Primary Hydraulic Fracture and Measured Microseismic Events and Magnitudes for Stage 19 - MIP-5H 


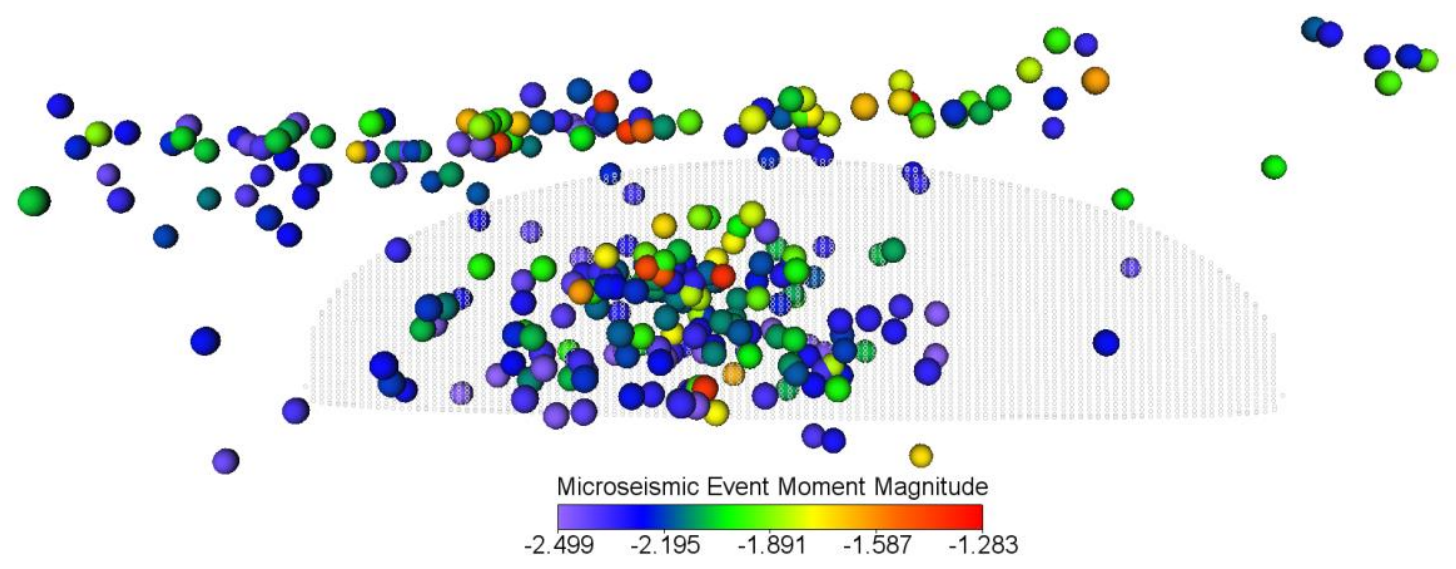

Figure A.61: Side View of Calculated Primary Hydraulic Fracture and Measured Microseismic Events and Magnitudes for Stage 20 - MIP-5H 


\section{Ground Surface}

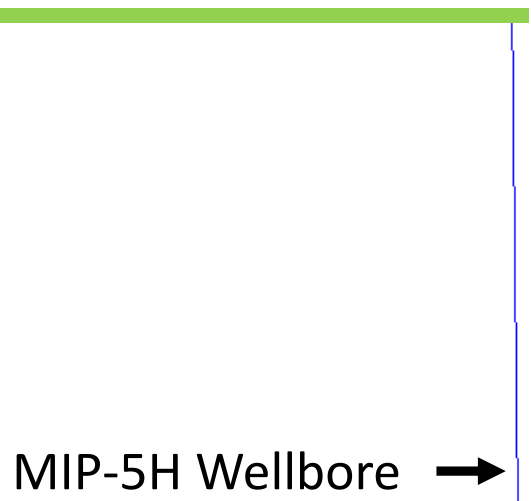

The center of perforations for

Stages $11-20$ are approximately

7453 feet below the ground surface.

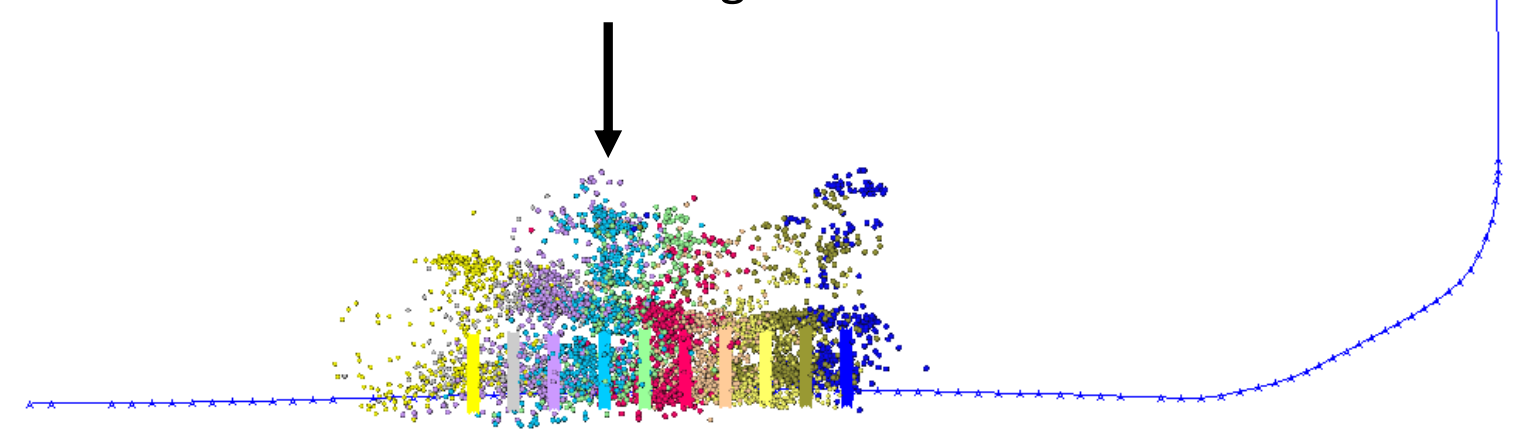

Figure A.62: Overview of Calculated Primary Hydraulic Fracture Geometries, Available Measured Microseismic Events, and Entire Wellbore for Stage 11 through Stage 20 - MIP-5H 


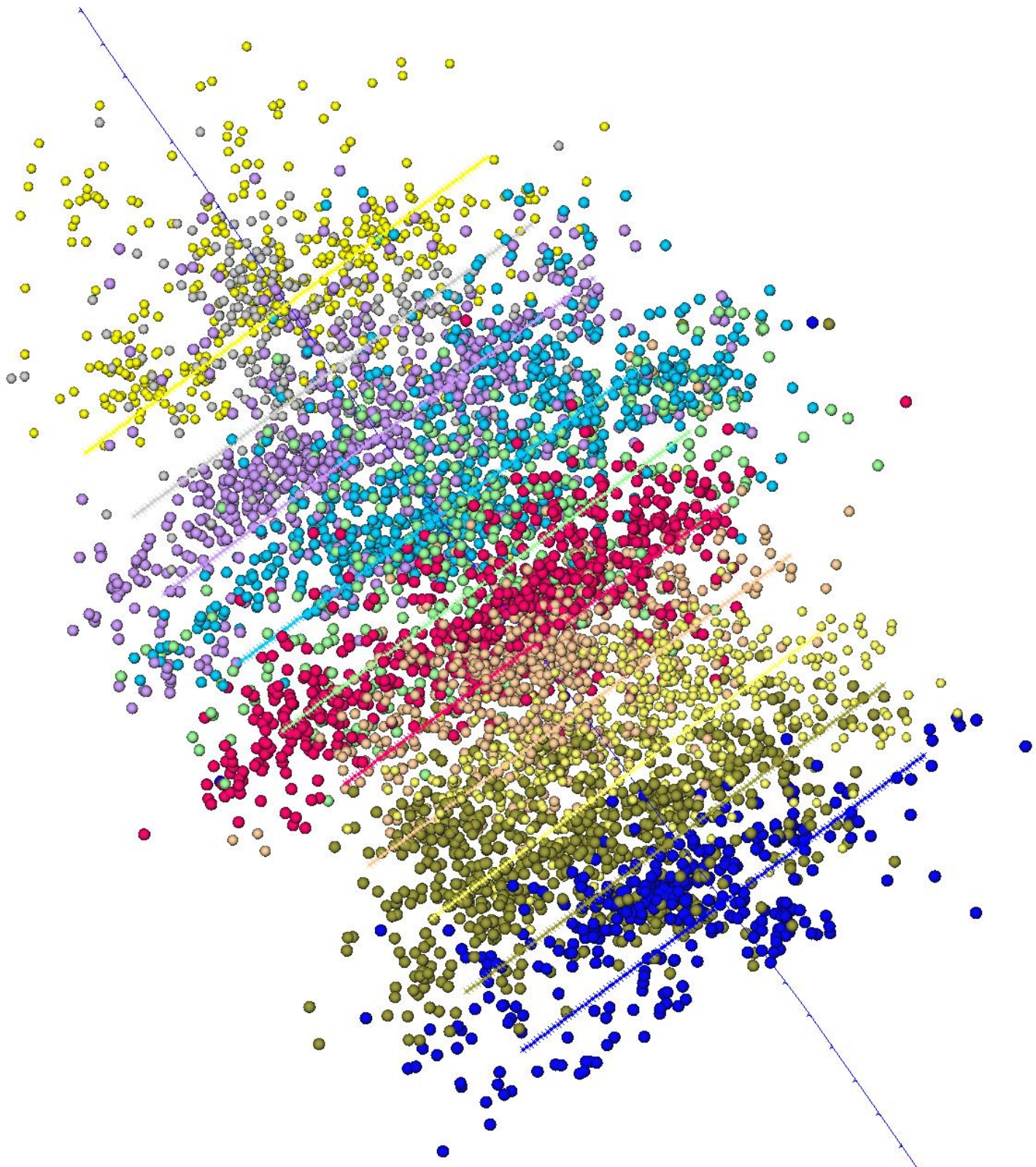

Figure A.63: Top View of Calculated Primary Hydraulic Fracture Geometries, Available Measured Microseismic Events, and Nearby Wellbore for Stage 11 through Stage 20 - MIP-5H 


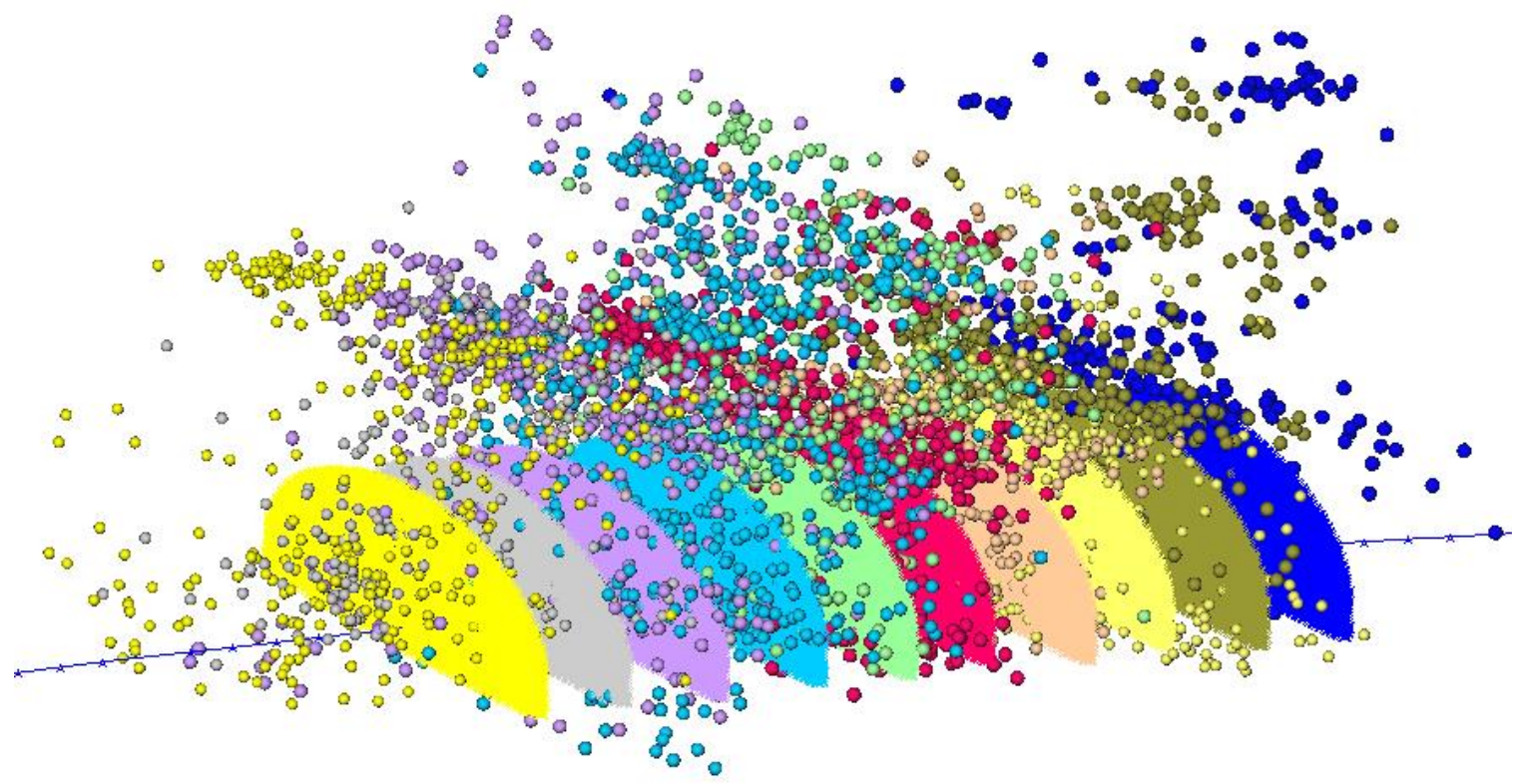

Figure A.64: Orthogonal View of Calculated Primary Hydraulic Fracture Geometries, Available Measured Microseismic Events, and Nearby Wellbore for Stage 11 through Stage 20 - MIP-5H 
Table A.5 shows the computed hydraulic fracture geometries for numerically modeled MIP-5H stage 21 through stage 25. Figure A.65 shows the hydraulic fracture geometry for one of the primary induced hydraulic fractures in stage 25 of well MIP-5H. Figure A.66 shows the cumulative proppant mass versus time (calculated and measured), Figure A.67 shows the slurry volume injected versus time (calculated and measured), and Figure A.68 shows the surface pressure versus time (calculated and measured) for stage 25 of well MIP-5H.

Microseismic, well, and hydraulic fracture geometry data were visualized in three dimensions. Figure A.69 through Figure A.73 show side views of numerically modeled hydraulic fracture geometries and available measured microseismic events and magnitudes for stage 21 through stage 25, respectively, for well MIP-5H. Figure A.74 shows an overview of these hydraulic fractures, as well as available microseismic event data and the entire MIP-5H wellbore. Figure A.75 shows a top view of these numerically modeled hydraulic fracture geometries with available microseismic event data and the nearby section of the MIP-5H wellbore. Figure A.76 shows an orthogonal projection of these numerically modeled hydraulic fracture geometries with available microseismic event data and the nearby section of the MIP-5H wellbore.

Table A.5: Computed Hydraulic Fracture Geometries - Stage 21 through Stage 25 MIP-5H

\begin{tabular}{|c|c|c|c|}
\hline STAGE & Fracture Half-Length (ft) & Fracture Height (ft) & Average Fracture Width (in) \\
\hline 21 & 598.6 & 316.6 & 0.027016 \\
\hline 22 & 620.5 & 319.5 & 0.027759 \\
\hline 23 & 540.2 & 297.8 & 0.02795 \\
\hline 24 & 583.6 & 312.4 & 0.027346 \\
\hline 25 & 590.1 & 316.1 & 0.026846 \\
\hline
\end{tabular}




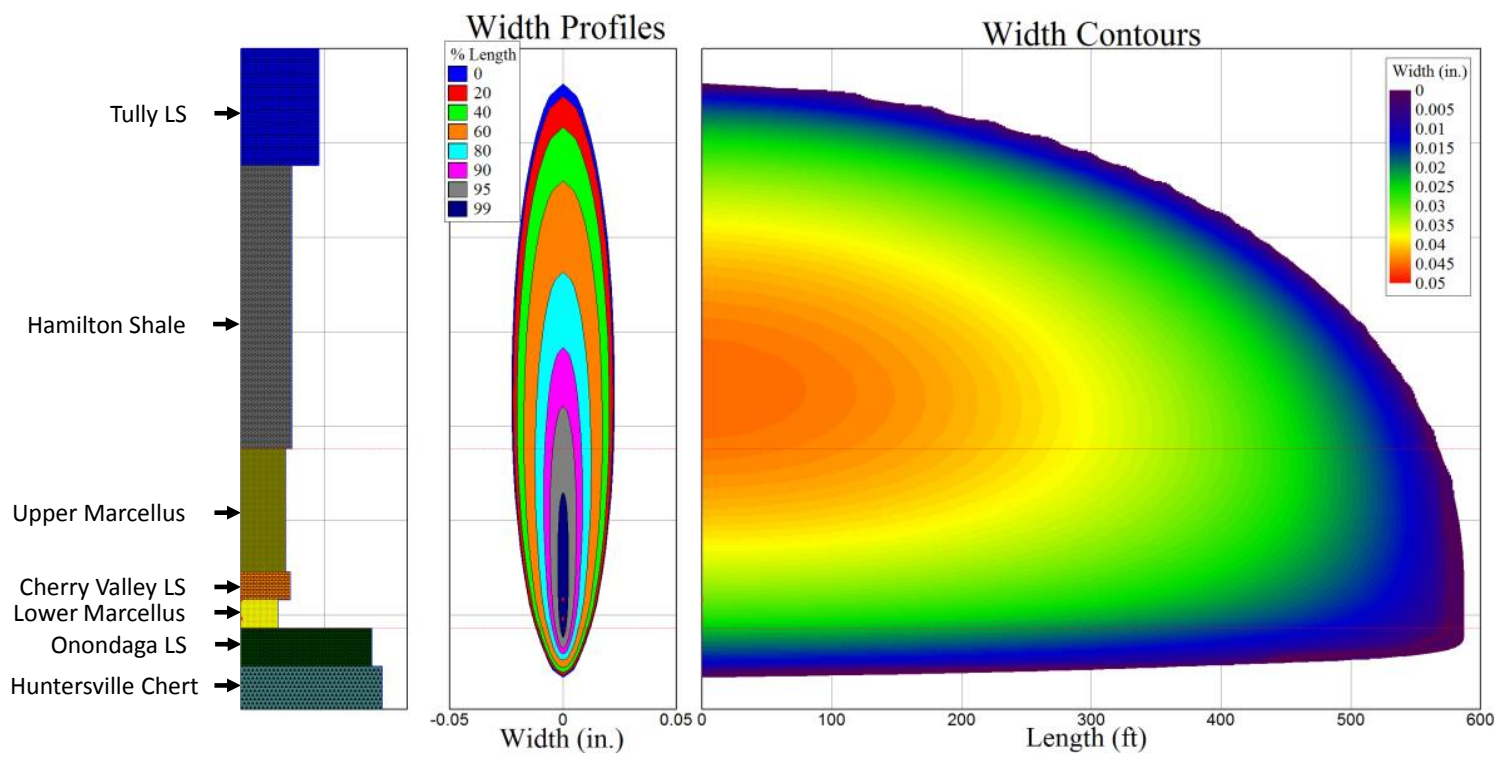

Figure A.65: Primary Hydraulic Fracture Geometry for Stage 25 - MIP-5H

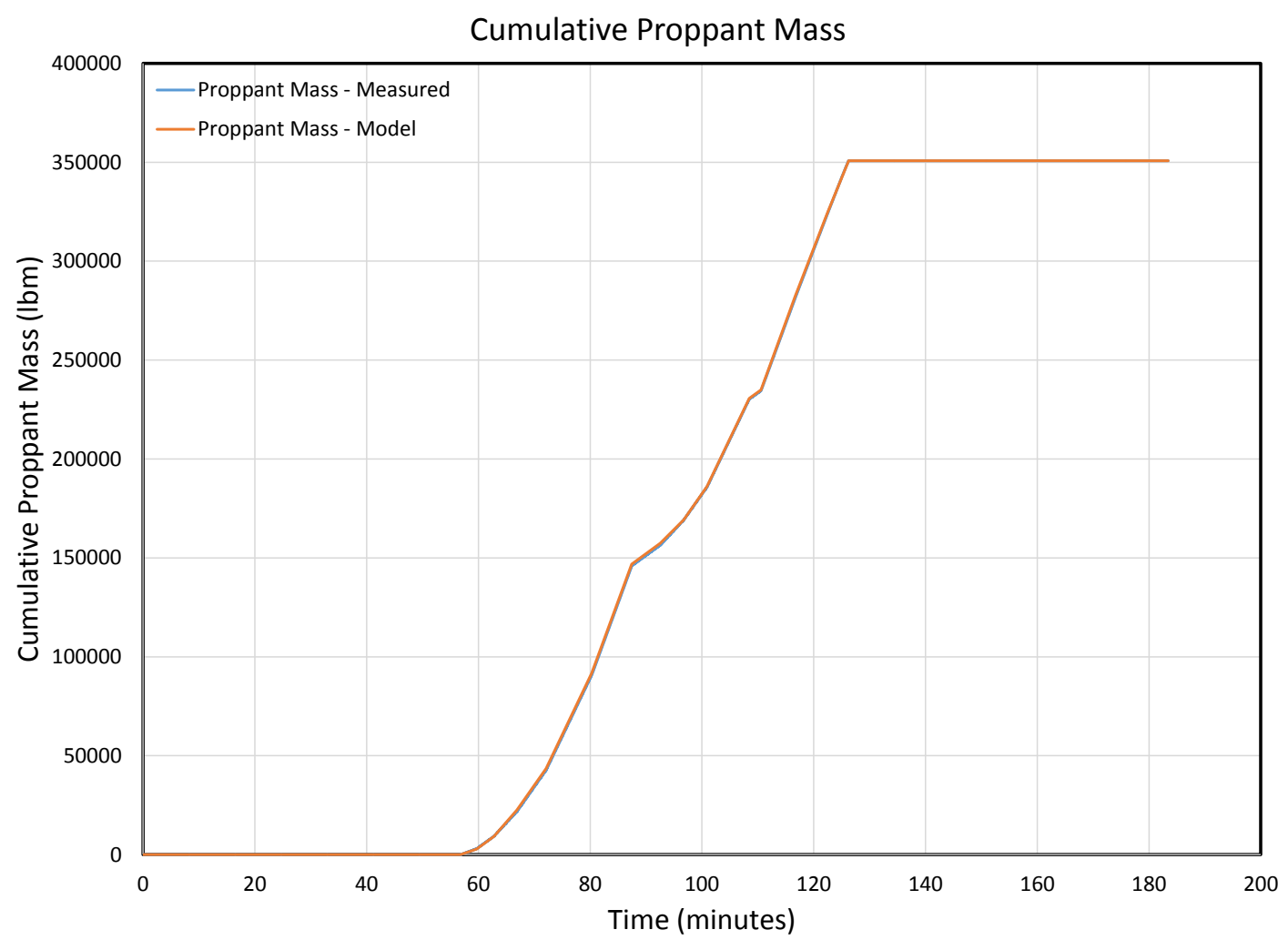

Figure A.66: Cumulative Proppant Mass Injected for Stage 25 - MIP-5H 


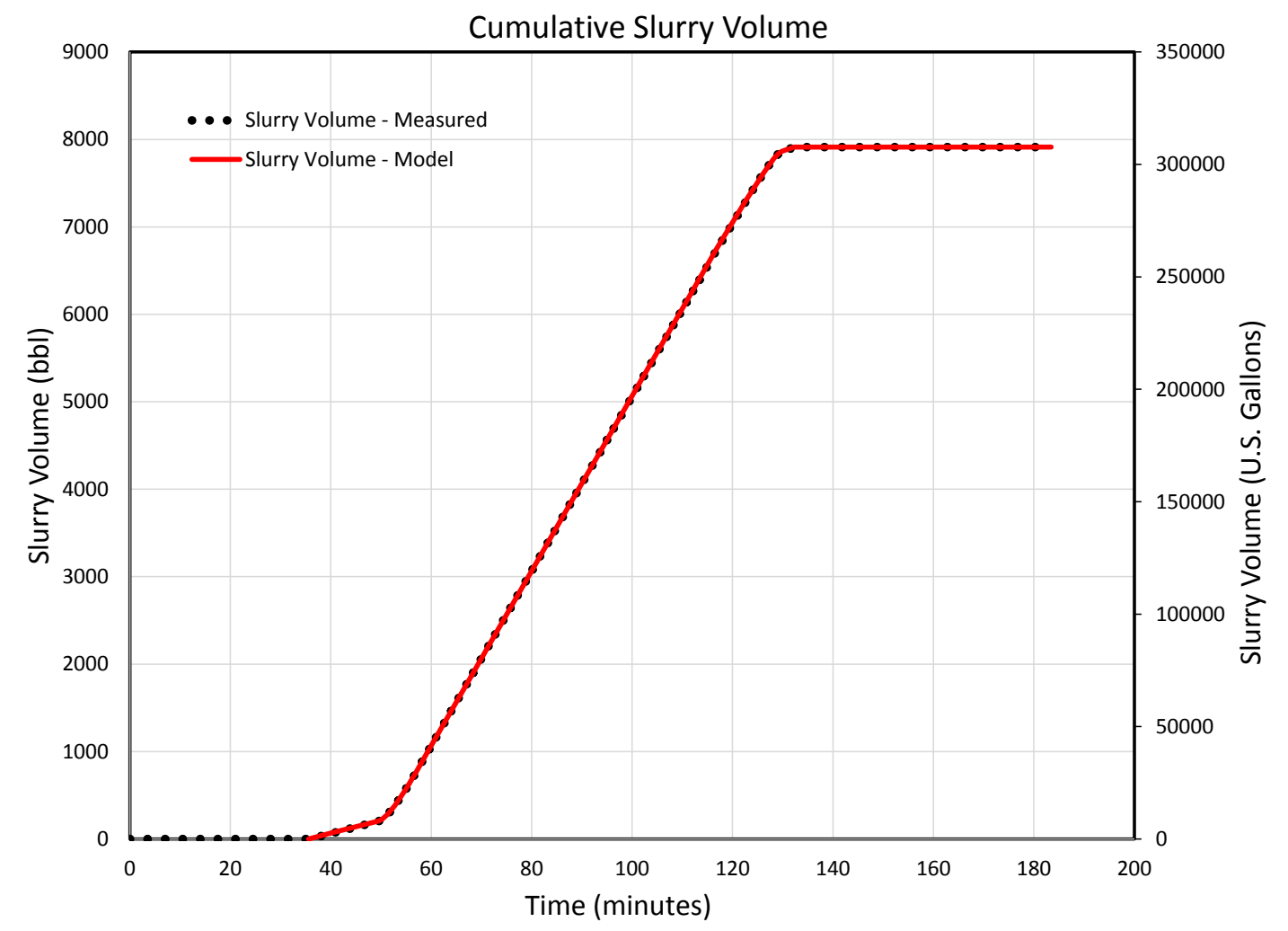

Figure A.67: Cumulative Slurry Volume Injected for Stage 25 - MIP-5H

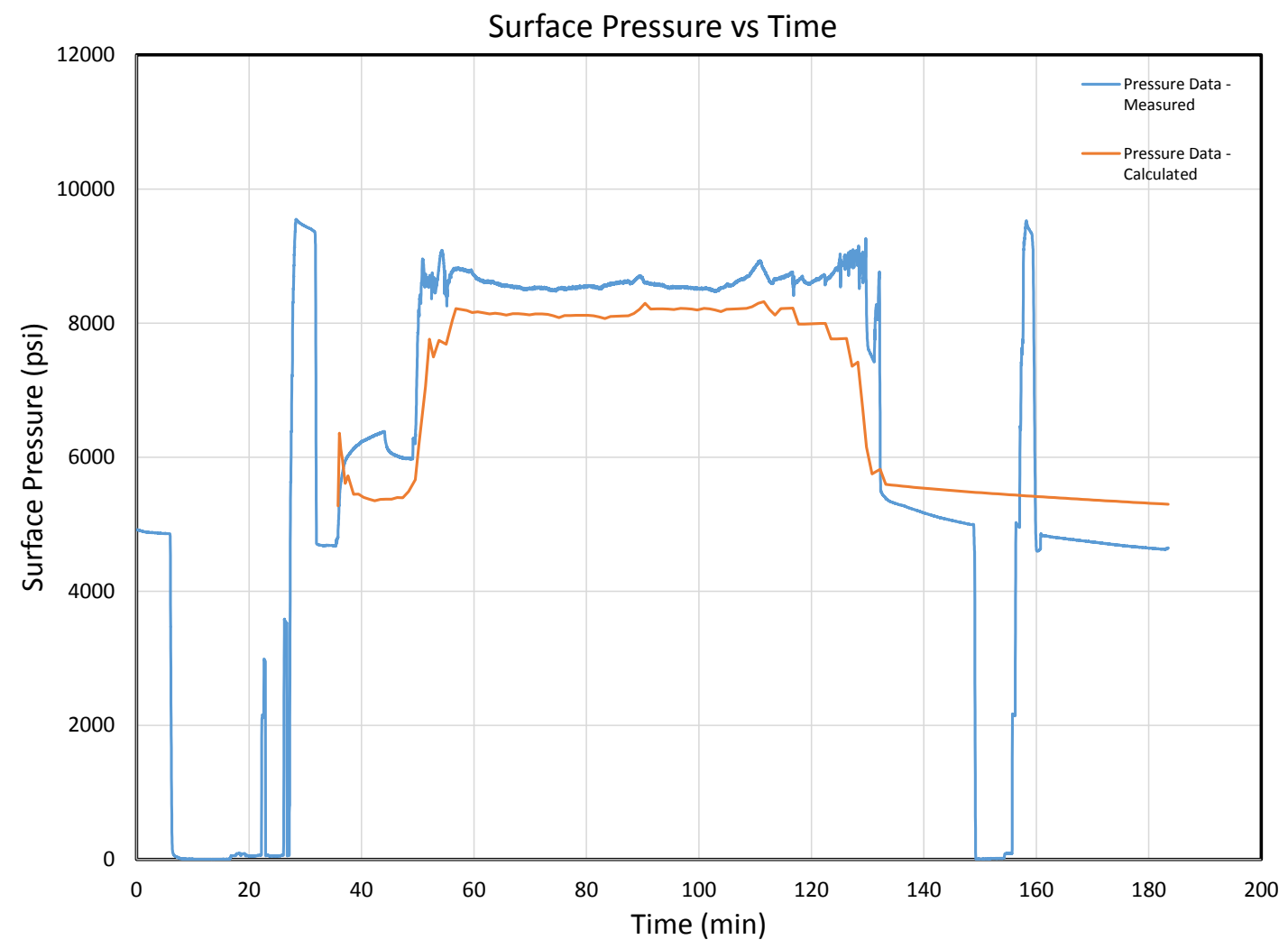

Figure A.68: Surface Pressure versus Time for Stage 25 - MIP-5H 


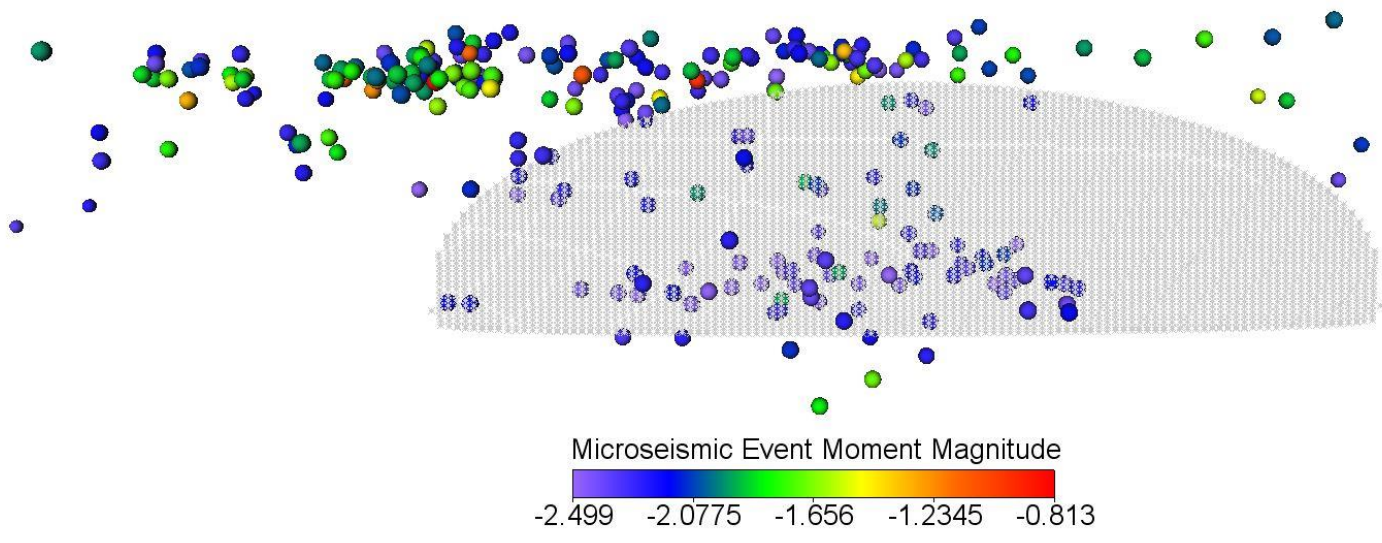

Figure A.69: Side View of Calculated Primary Hydraulic Fracture and Measured Microseismic Events and Magnitudes for Stage 21 - MIP-5H

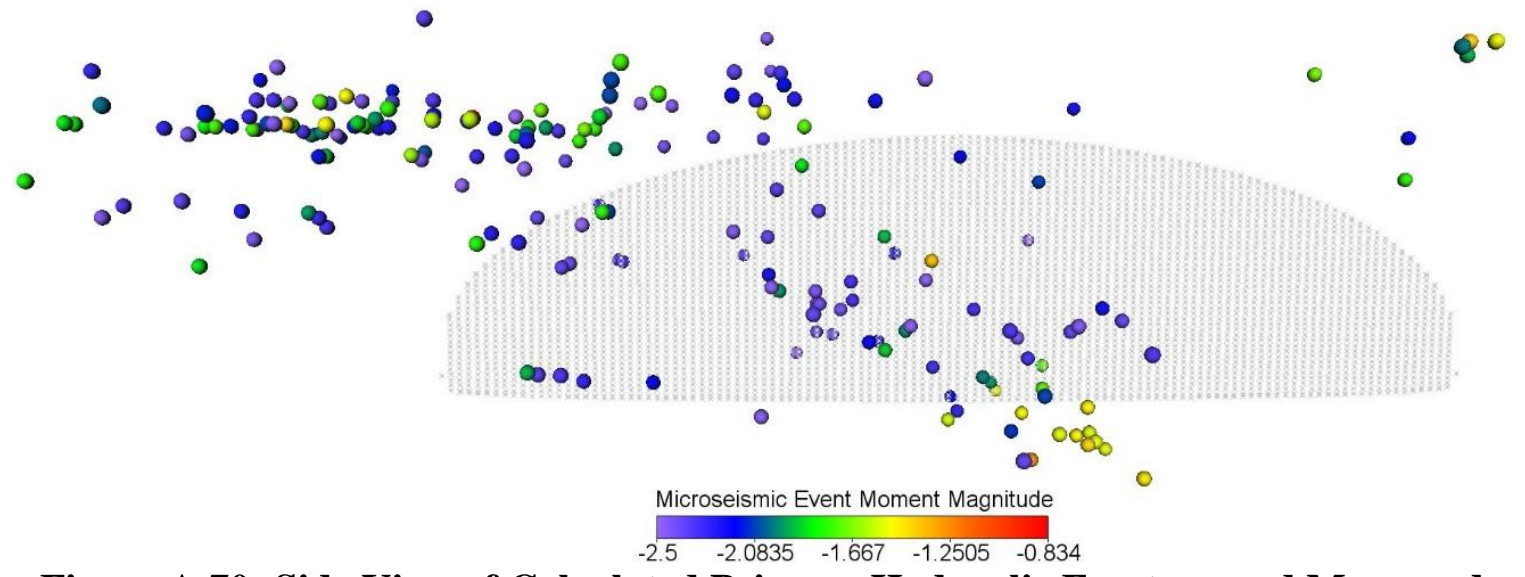

Figure A.70: Side View of Calculated Primary Hydraulic Fracture and Measured Microseismic Events and Magnitudes for Stage 22 - MIP-5H 


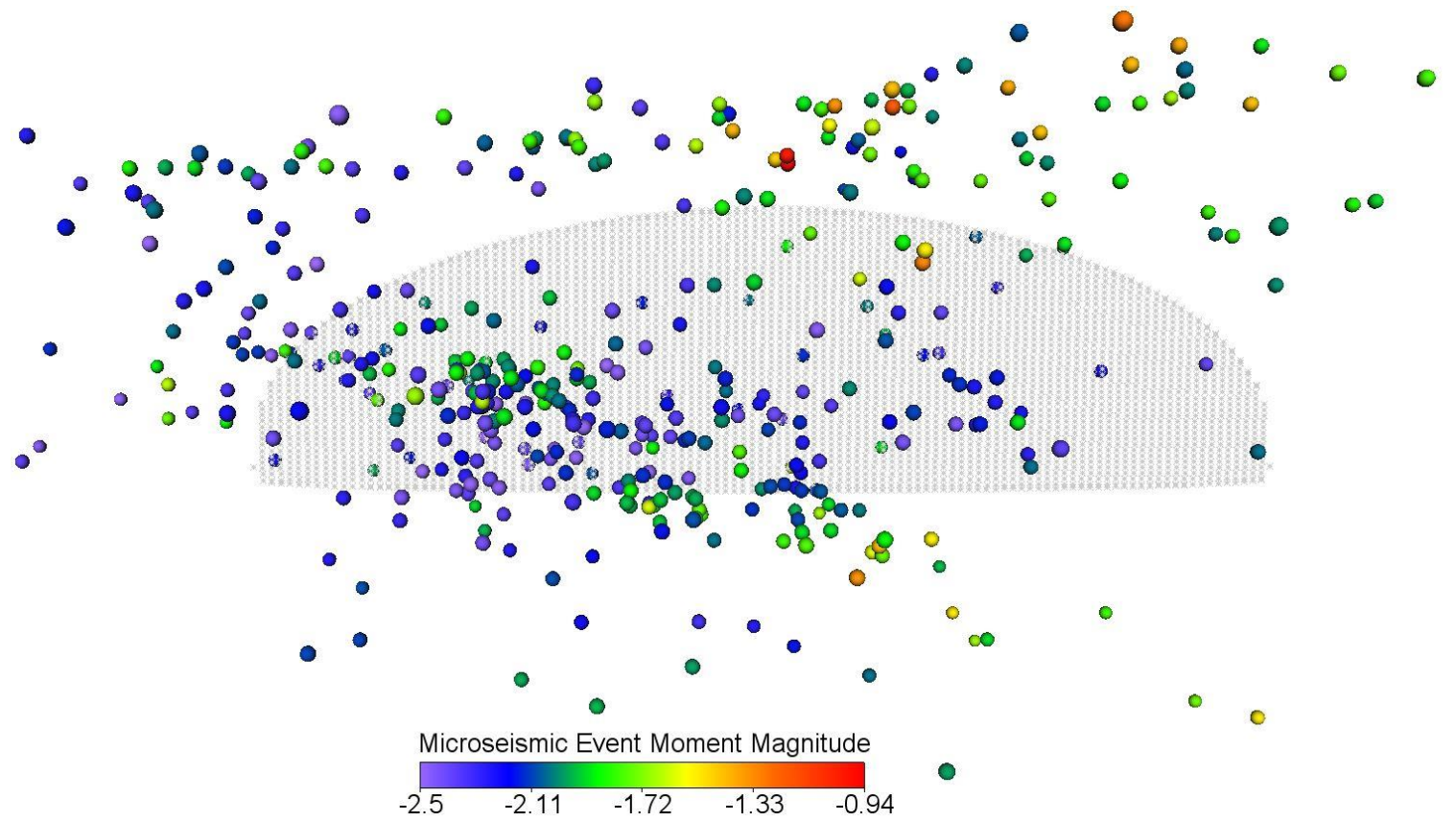

Figure A.71: Side View of Calculated Primary Hydraulic Fracture and Measured Microseismic Events and Magnitudes for Stage 23 - MIP-5H

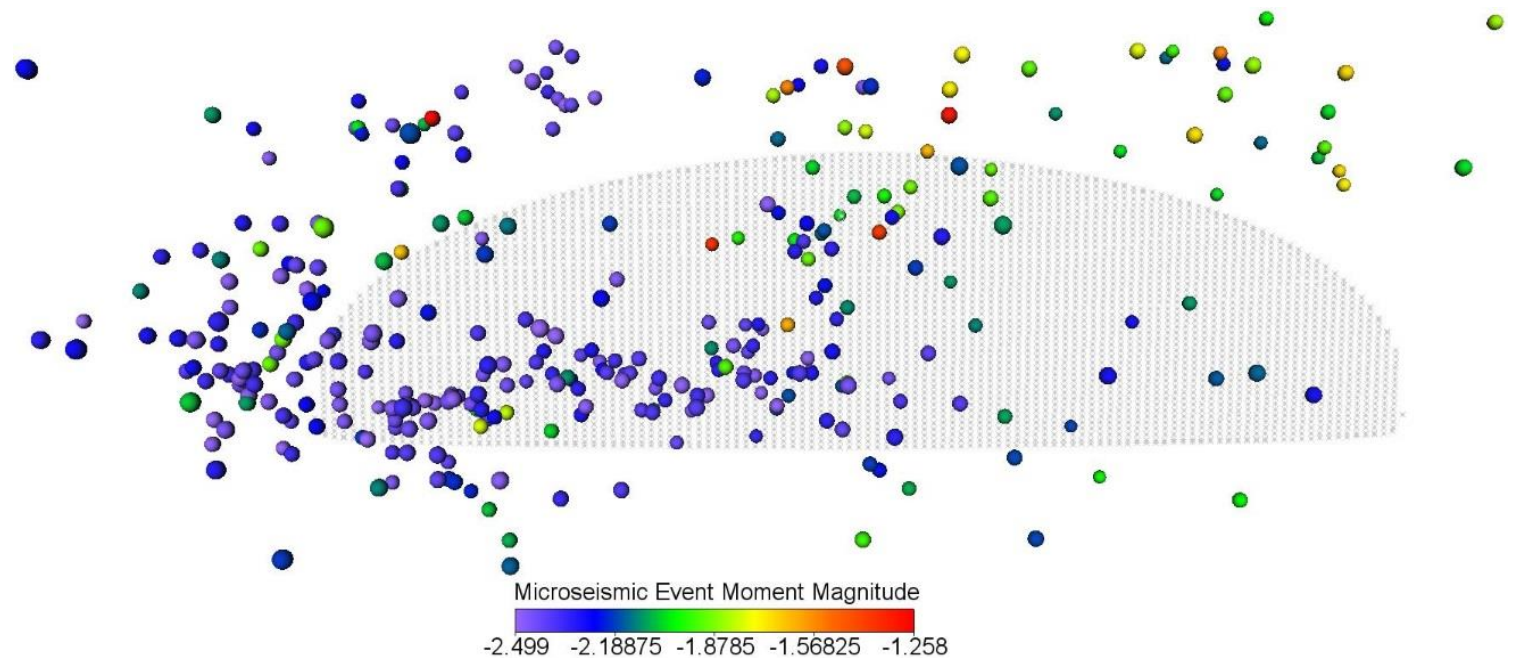

Figure A.72: Side View of Calculated Primary Hydraulic Fracture and Measured Microseismic Events and Magnitudes for Stage 24 - MIP-5H 

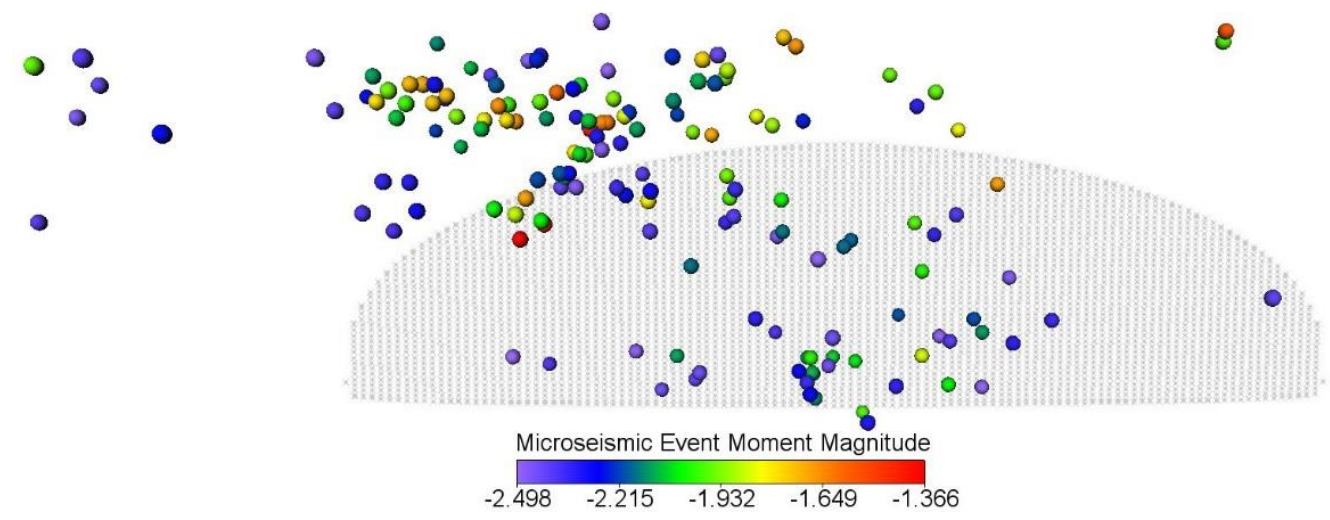

Figure A.73: Side View of Calculated Primary Hydraulic Fracture and Measured Microseismic Events and Magnitudes for Stage 25 - MIP-5H 


\section{Ground Surface}

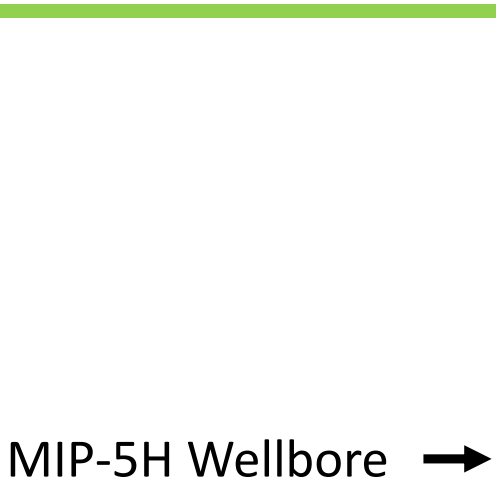

The center of perforations for

Stages $21-25$ are approximately

7482 feet below the ground surface.

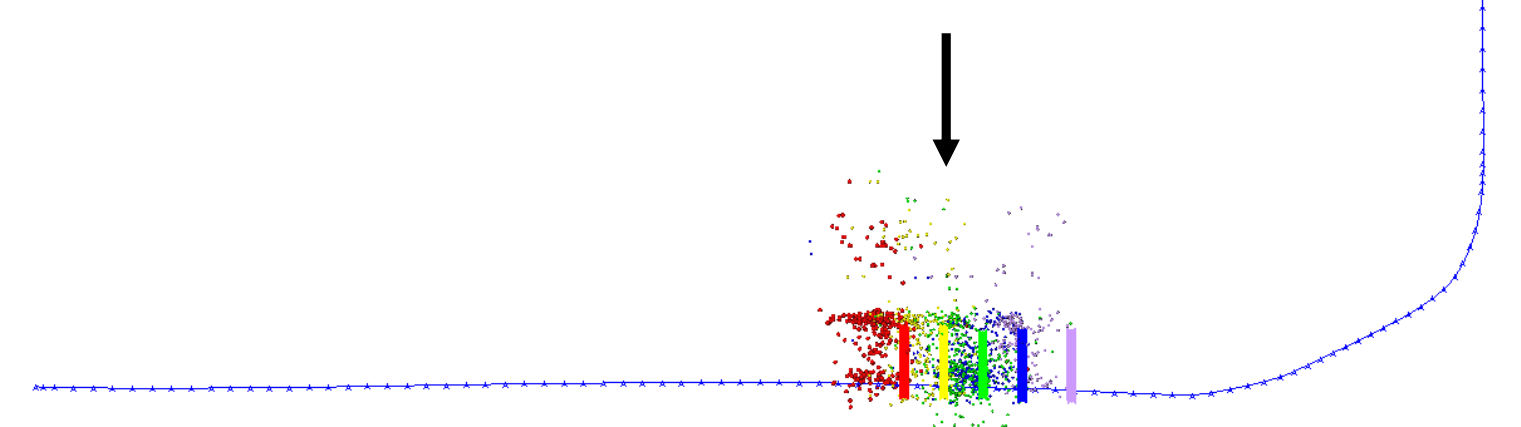

Figure A.74: Overview of Calculated Primary Hydraulic Fracture Geometries, Available Measured Microseismic Events, and Entire Wellbore for Stage 21 through Stage 25 - MIP-5H 


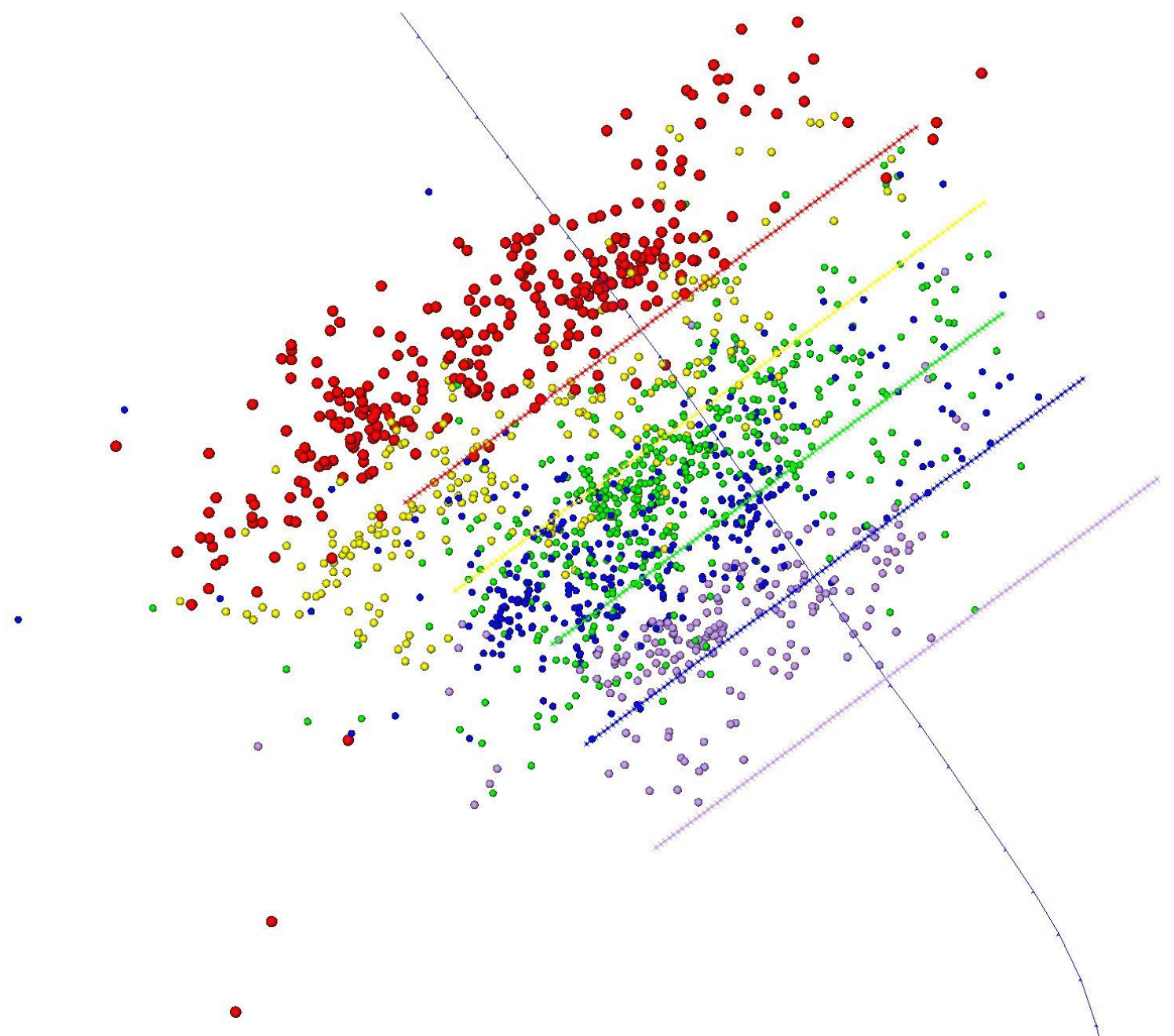

Figure A.75: Top View of Calculated Primary Hydraulic Fracture Geometries, Available Measured Microseismic Events, and Nearby Wellbore for Stage 21 through Stage 25 - MIP-5H 


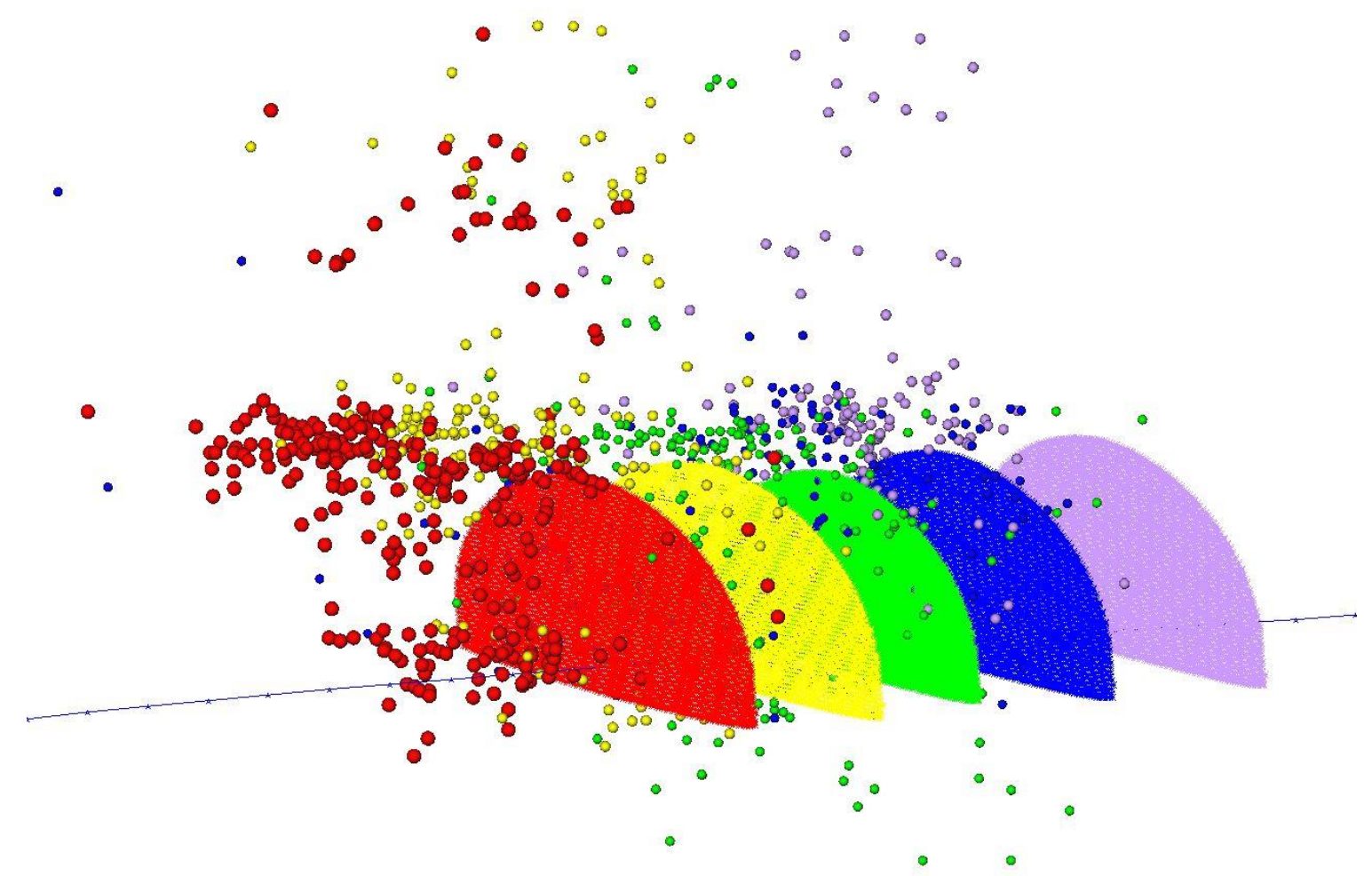

Figure A.76: Orthogonal View of Calculated Primary Hydraulic Fracture Geometries, Available Measured Microseismic Events, and Nearby Wellbore for Stage 21 through Stage 25 - MIP-5H 
Table A.6 shows the computed hydraulic fracture geometries for numerically modeled MIP-5H stage 26 through stage 30. Figure A.77 shows the hydraulic fracture geometry for one of the primary induced hydraulic fractures in stage 30 of well MIP-5H. Figure A.78 shows the cumulative proppant mass versus time (calculated and measured), Figure A.79 shows the cumulative slurry volume injected versus time (calculated and measured), and Figure A.80 shows the surface pressure versus time (calculated and measured) for stage 30 of well MIP-5H.

Microseismic, well, and hydraulic fracture geometry data were visualized in three dimensions. Figure A.81 through Figure A.85 show side views of numerically modeled hydraulic fracture geometries and available measured microseismic events and magnitudes for stage 26 through stage 30, respectively, for well MIP-5H. Figure A.86 shows an overview of these hydraulic fractures, as well as available microseismic event data and the entire MIP-5H wellbore. Figure A.87 shows a top view of all these numerically modeled hydraulic fracture geometries with available microseismic event data and the nearby section of the MIP-5H wellbore. Figure A.88 shows an orthogonal projection of these numerically modeled hydraulic fracture geometries with available microseismic event data and the nearby section of the MIP-5H wellbore.

Table A.6: Computed Hydraulic Fracture Geometries - Stage 26 through Stage 30 MIP-5H

\begin{tabular}{|c|c|c|c|}
\hline STAGE & Fracture Half-Length (ft) & Fracture Height (ft) & Average Fracture Width (in) \\
\hline 26 & 618.4 & 323.7 & 0.027296 \\
\hline 27 & 617.7 & 316.5 & 0.025959 \\
\hline 28 & 599.4 & 318.5 & 0.025006 \\
\hline 29 & 644.6 & 329.5 & 0.030494 \\
\hline 30 & 644.1 & 336.8 & 0.03046 \\
\hline
\end{tabular}




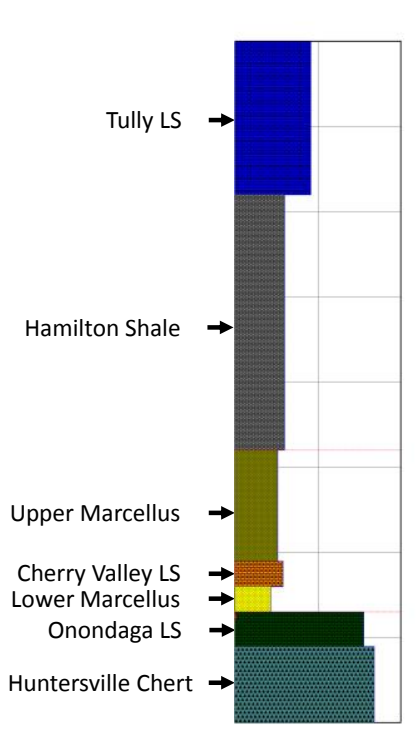

Width Profiles
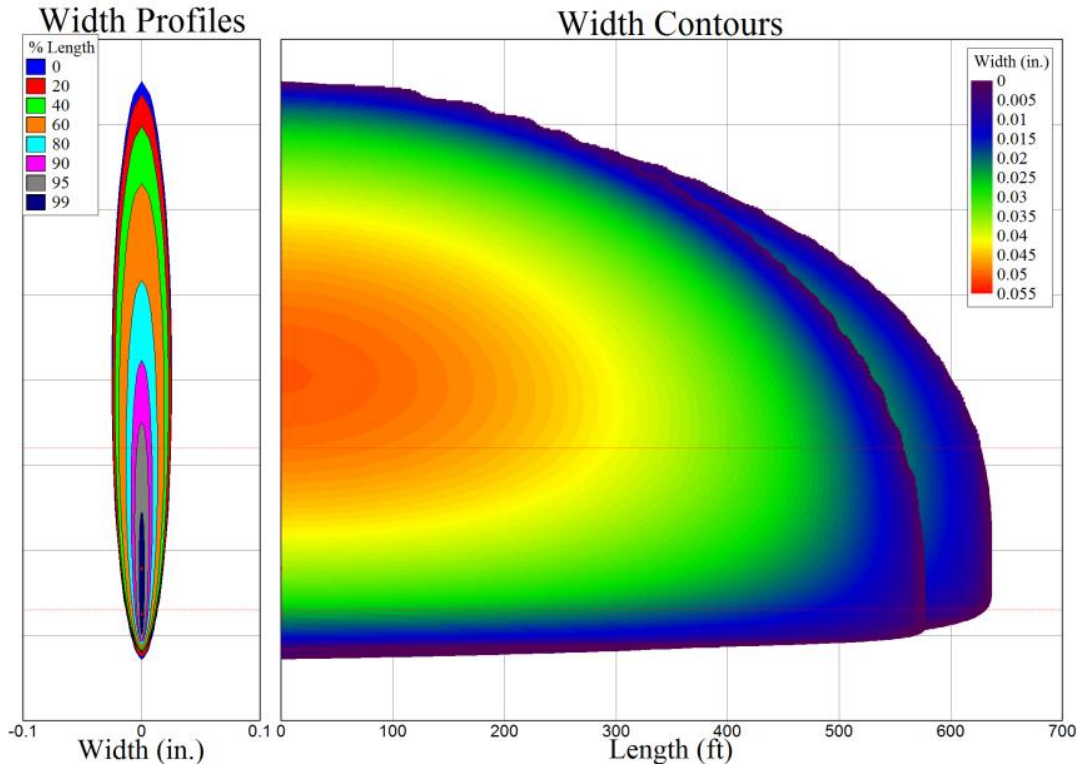

Figure A.77: Primary Hydraulic Fracture Geometry for Stage 30 - MIP-5H

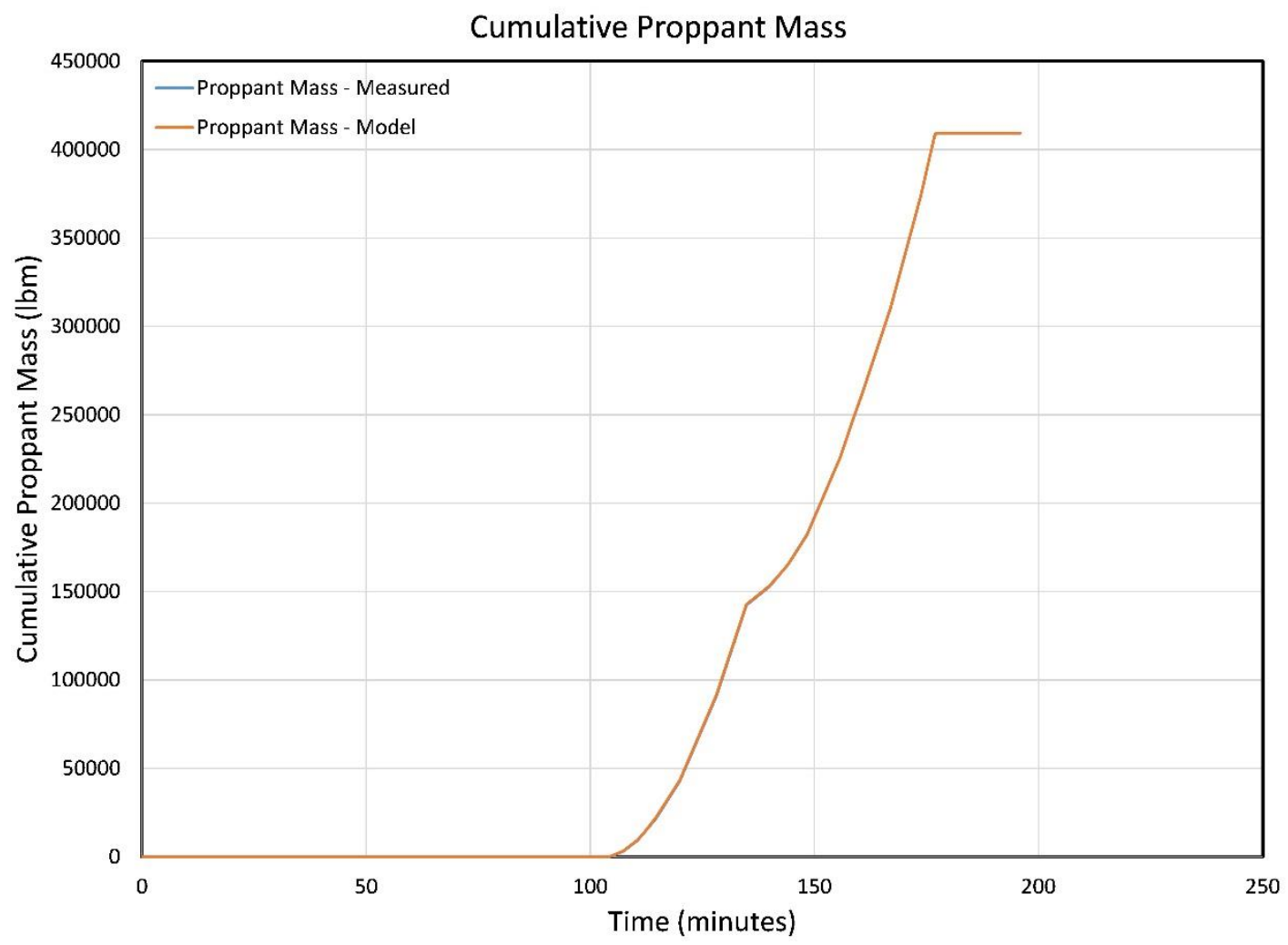

Figure A.78: Cumulative Proppant Mass Injected for Stage 30 - MIP-5H 


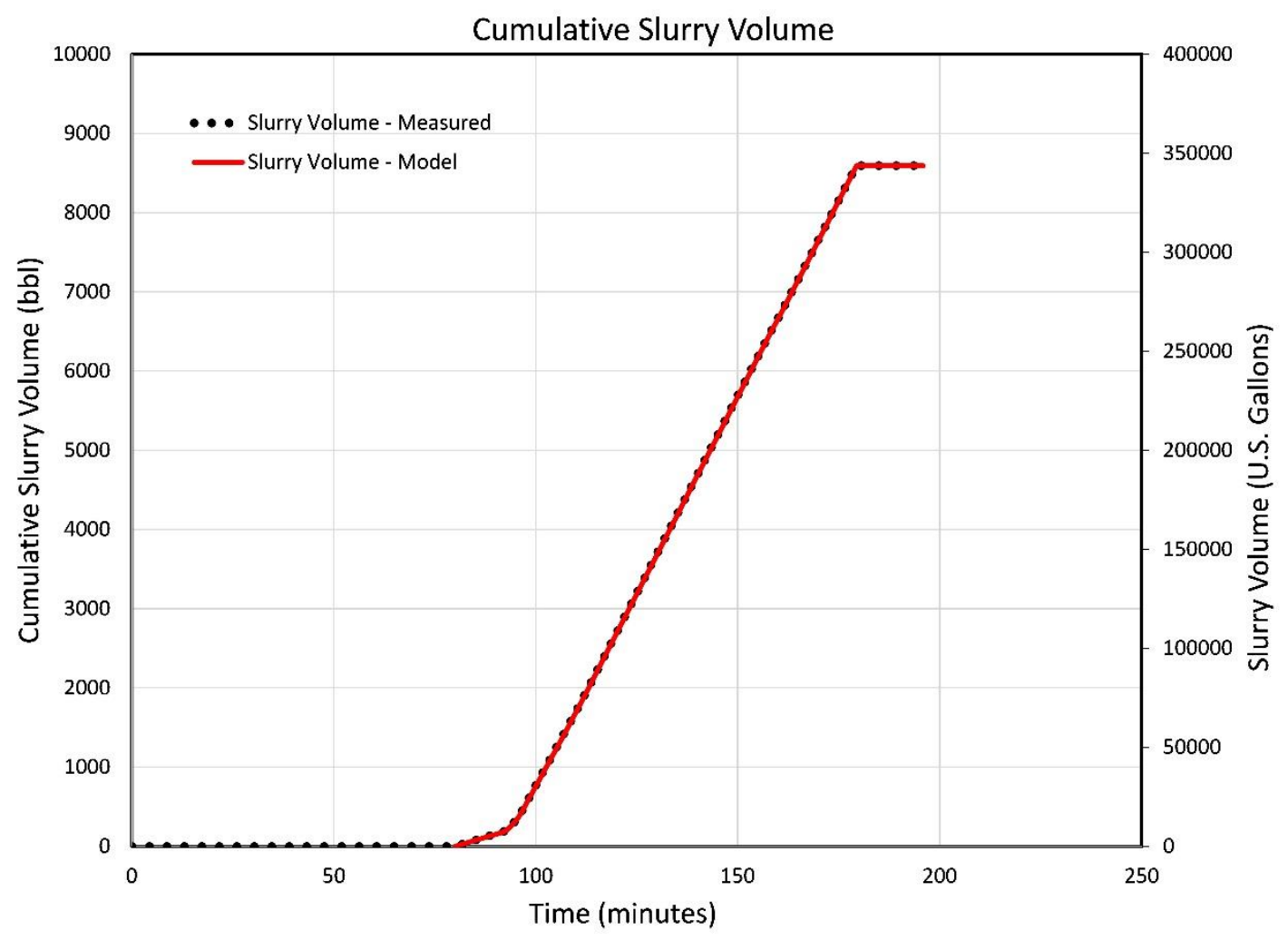

Figure A.79: Cumulative Slurry Volume Injected for Stage 30 - MIP-5H

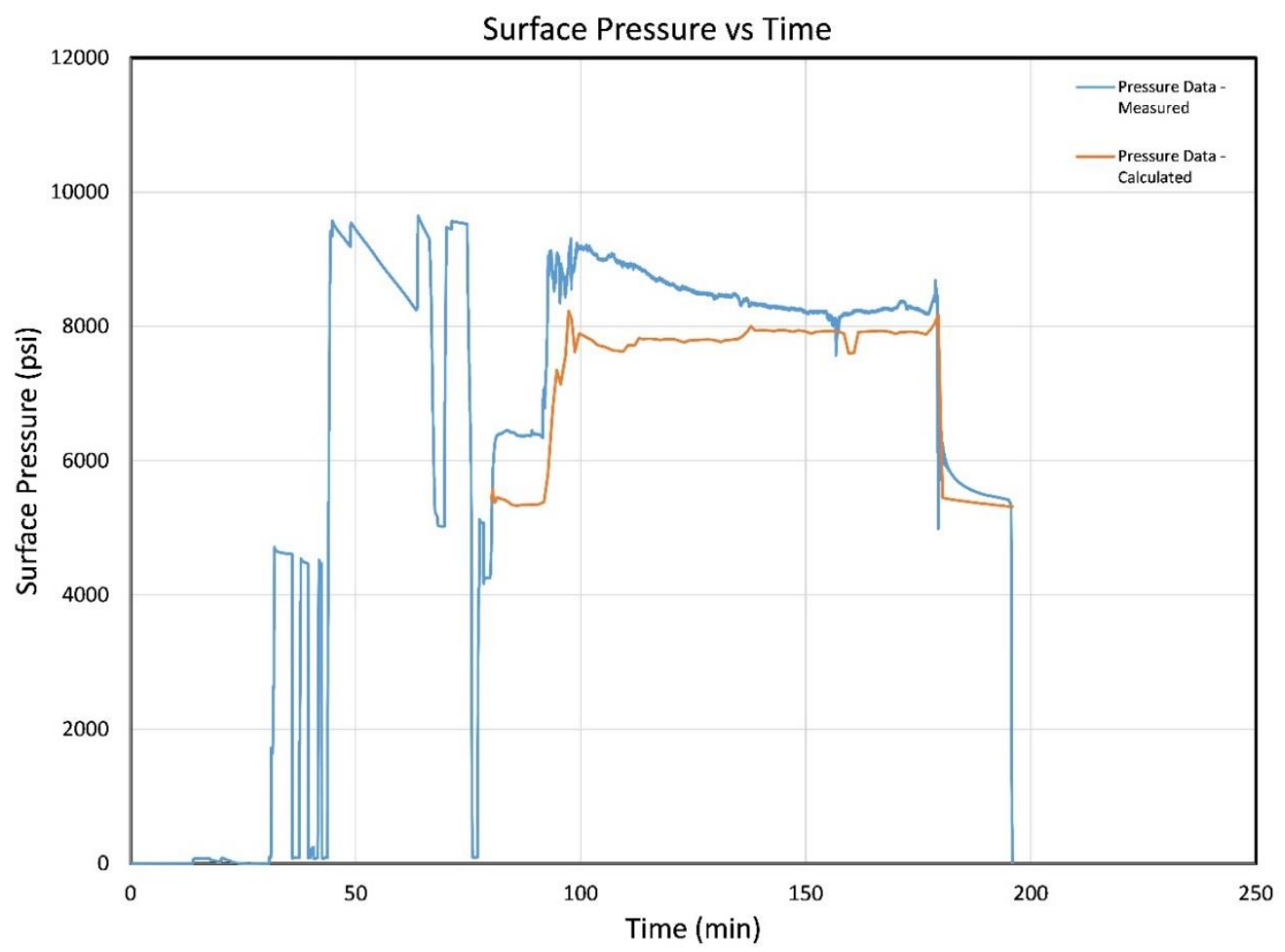

Figure A.80: Surface Pressure versus Time for Stage 30 - MIP-5H 


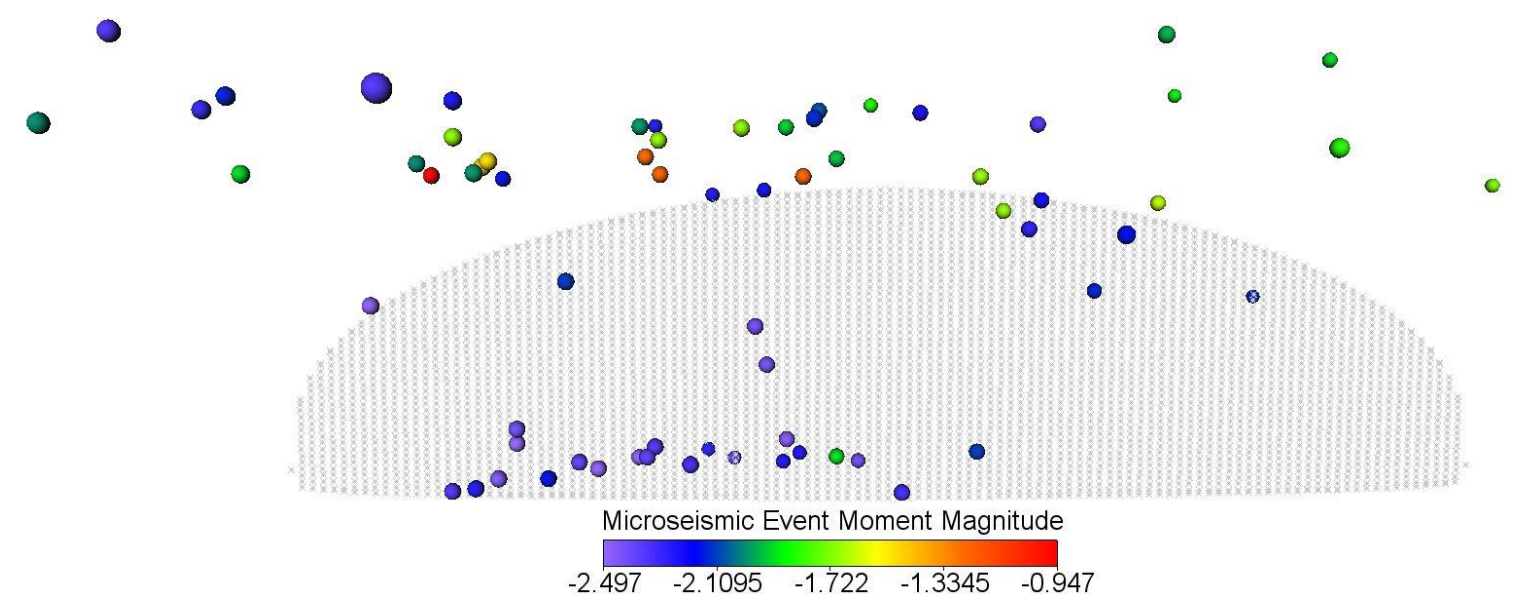

Figure A.81: Side View of Calculated Primary Hydraulic Fracture and Measured Microseismic Events and Magnitudes for Stage 26 - MIP-5H

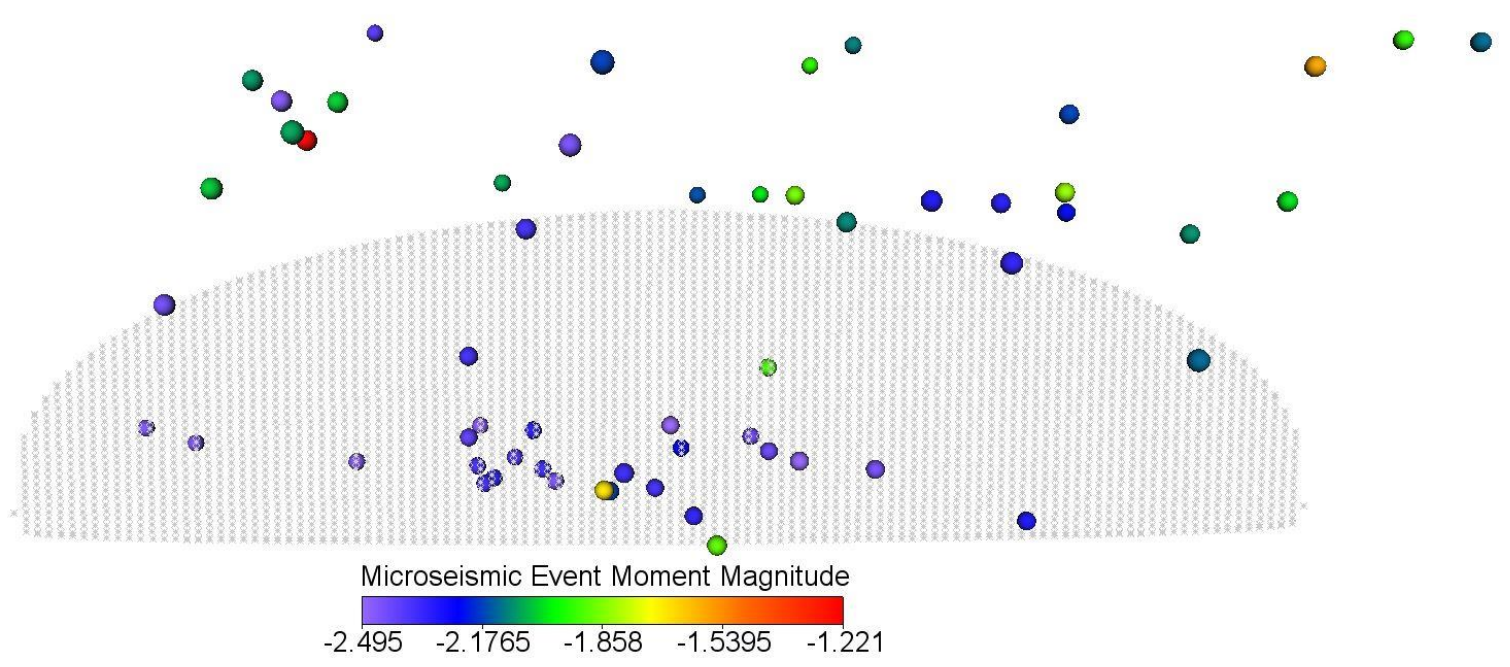

Figure A.82: Side View of Calculated Primary Hydraulic Fracture and Measured Microseismic Events and Magnitudes for Stage 27 - MIP-5H 


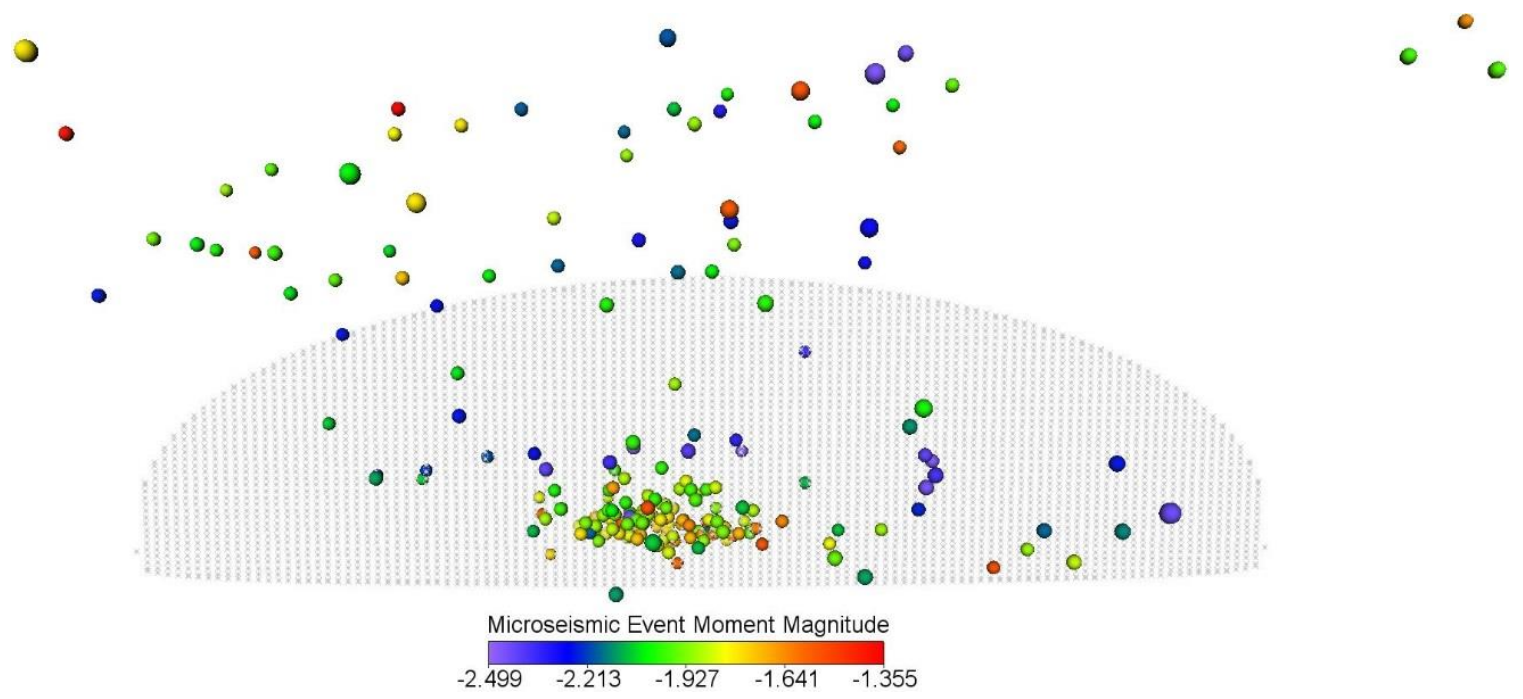

Figure A.83: Side View of Calculated Primary Hydraulic Fracture and Measured Microseismic Events and Magnitudes for Stage 28 - MIP-5H

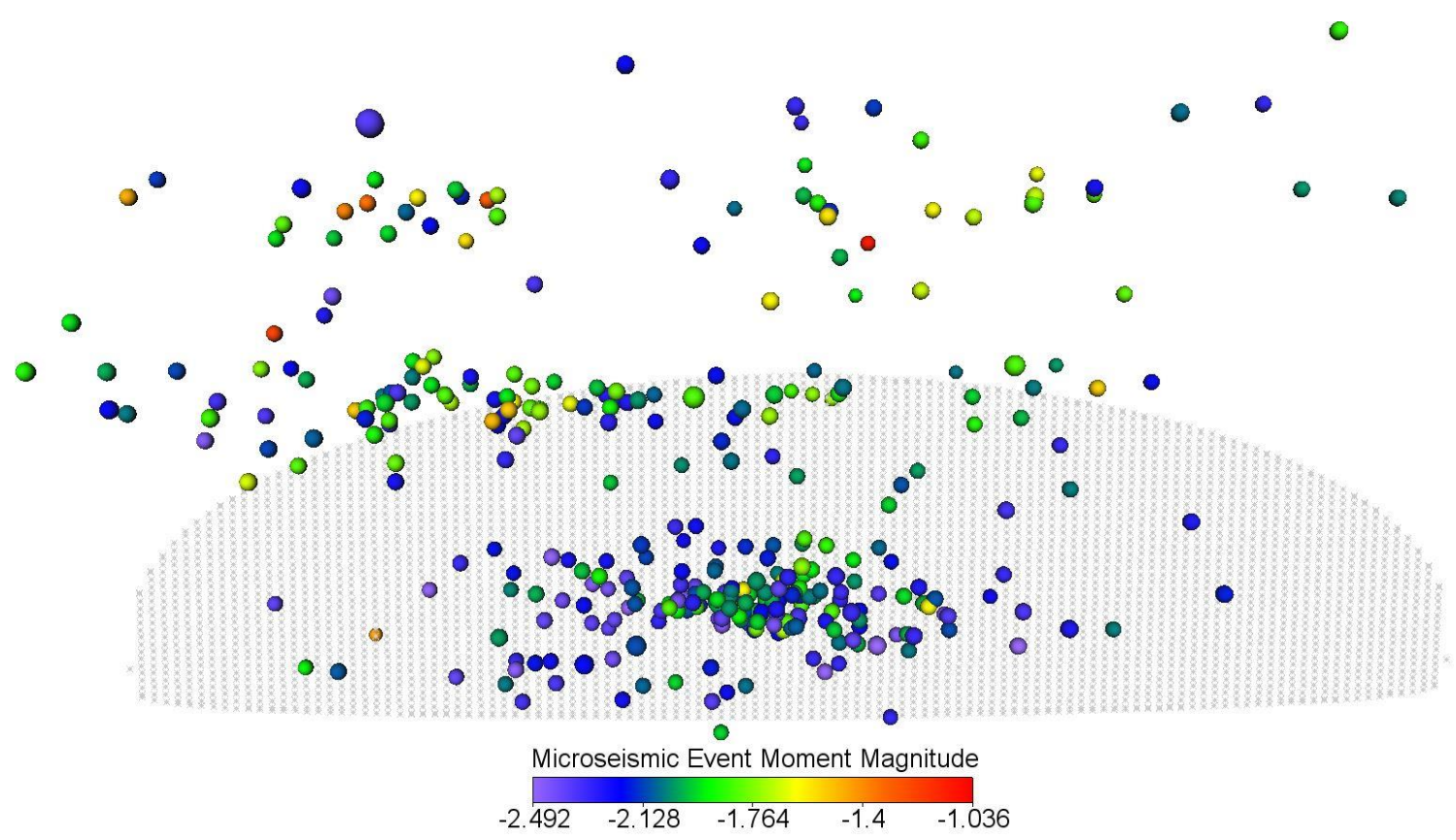

Figure A.84: Side View of Calculated Primary Hydraulic Fracture and Measured Microseismic Events and Magnitudes for Stage 29 - MIP-5H 


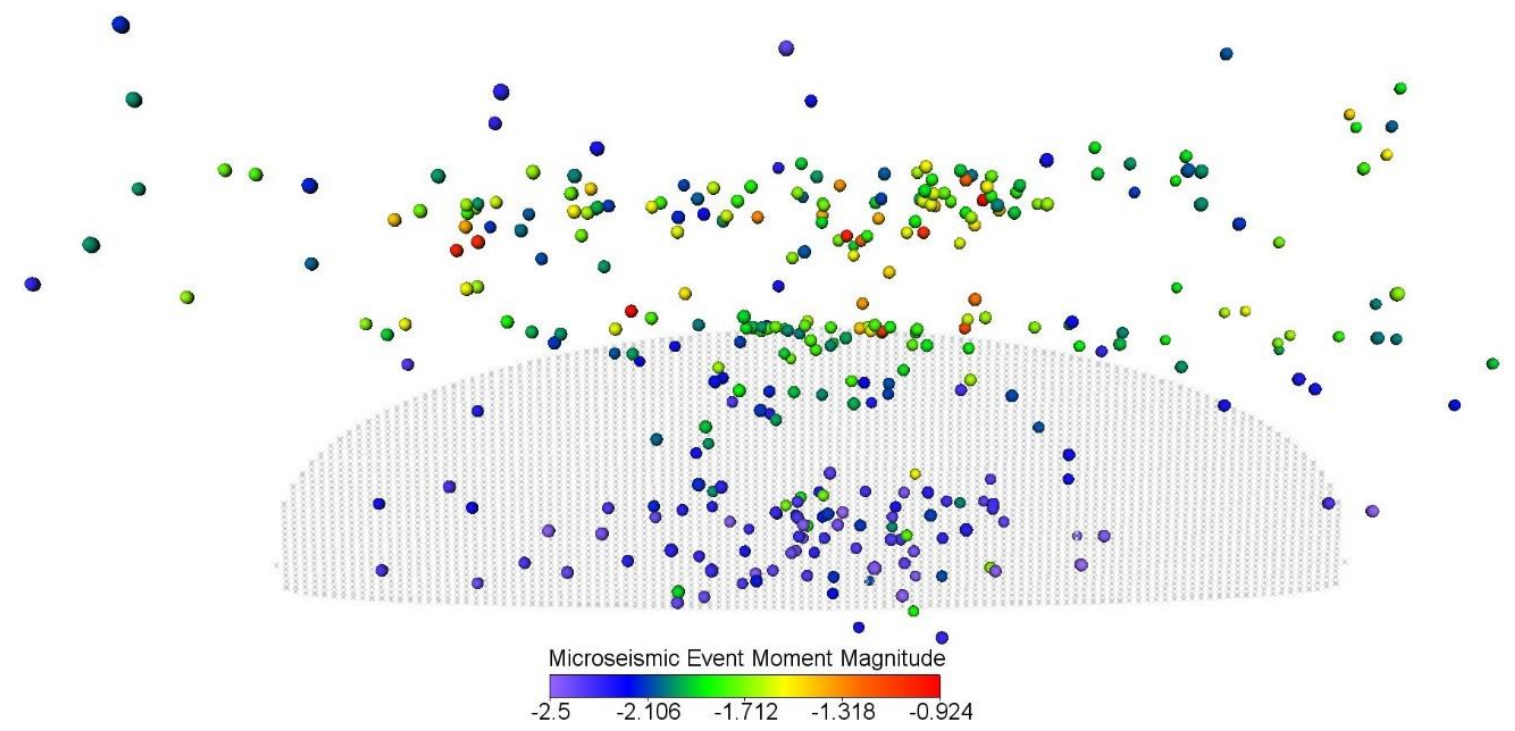

Figure A.85: Side View of Calculated Primary Hydraulic Fracture and Measured Microseismic Events and Magnitudes for Stage 30 - MIP-5H 
The center of perforations for

Stages $26-30$ are approximately 7507 feet below the ground surface.

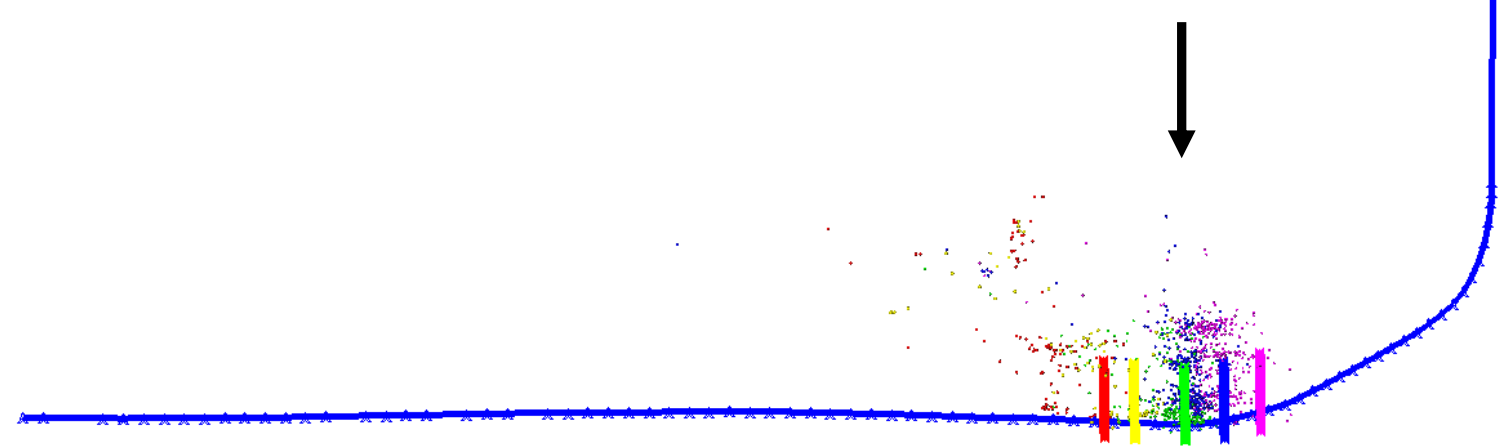

Figure A.86: Overview of Calculated Primary Hydraulic Fracture Geometries, Available Measured Microseismic Events, and Entire Wellbore for Stage 26 through Stage 30 - MIP-5H 


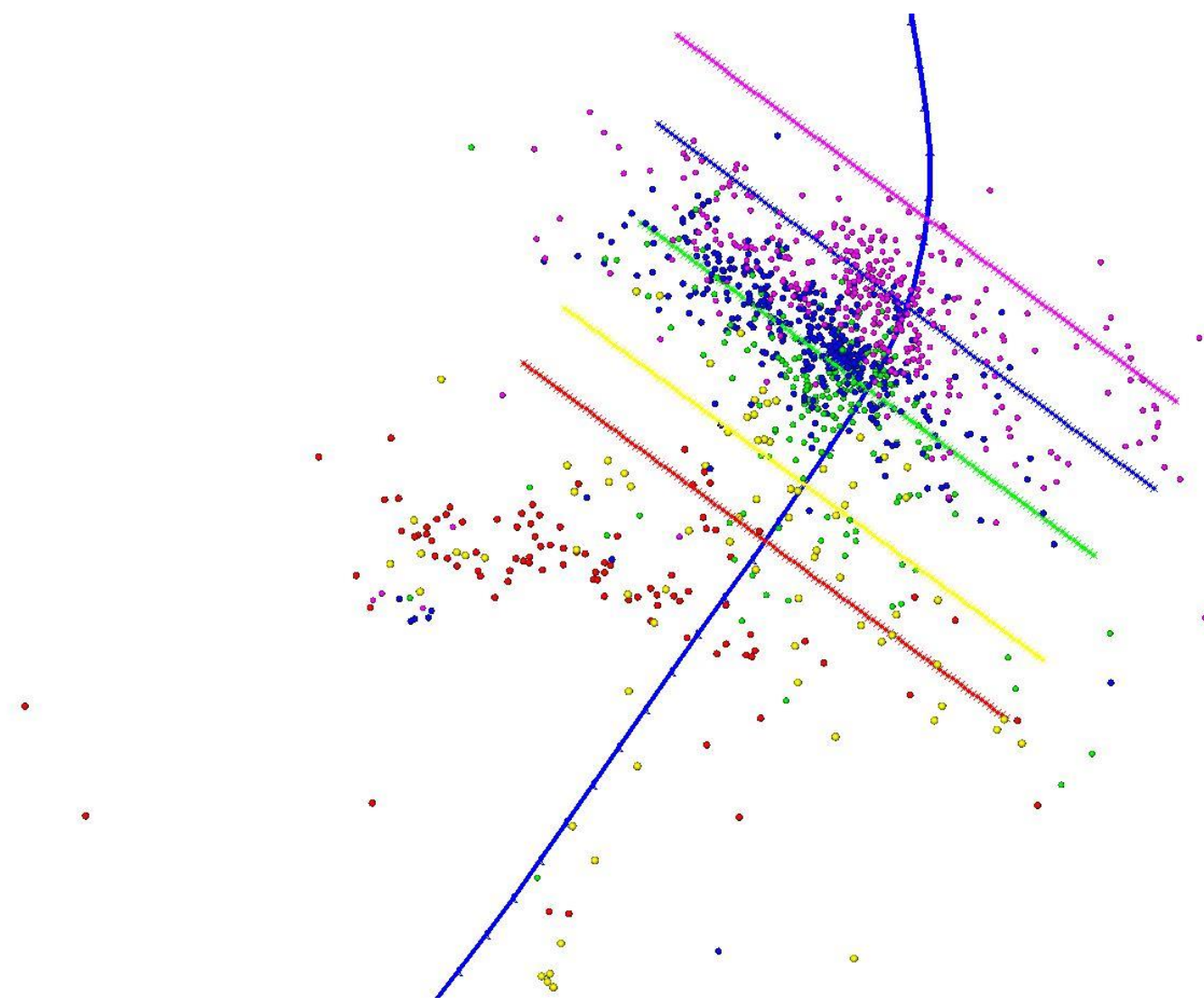

Figure A.87: Top View of Calculated Primary Hydraulic Fracture Geometries, Available Measured Microseismic Events, and Nearby Wellbore for Stage 26 through Stage 30 - MIP-5H 


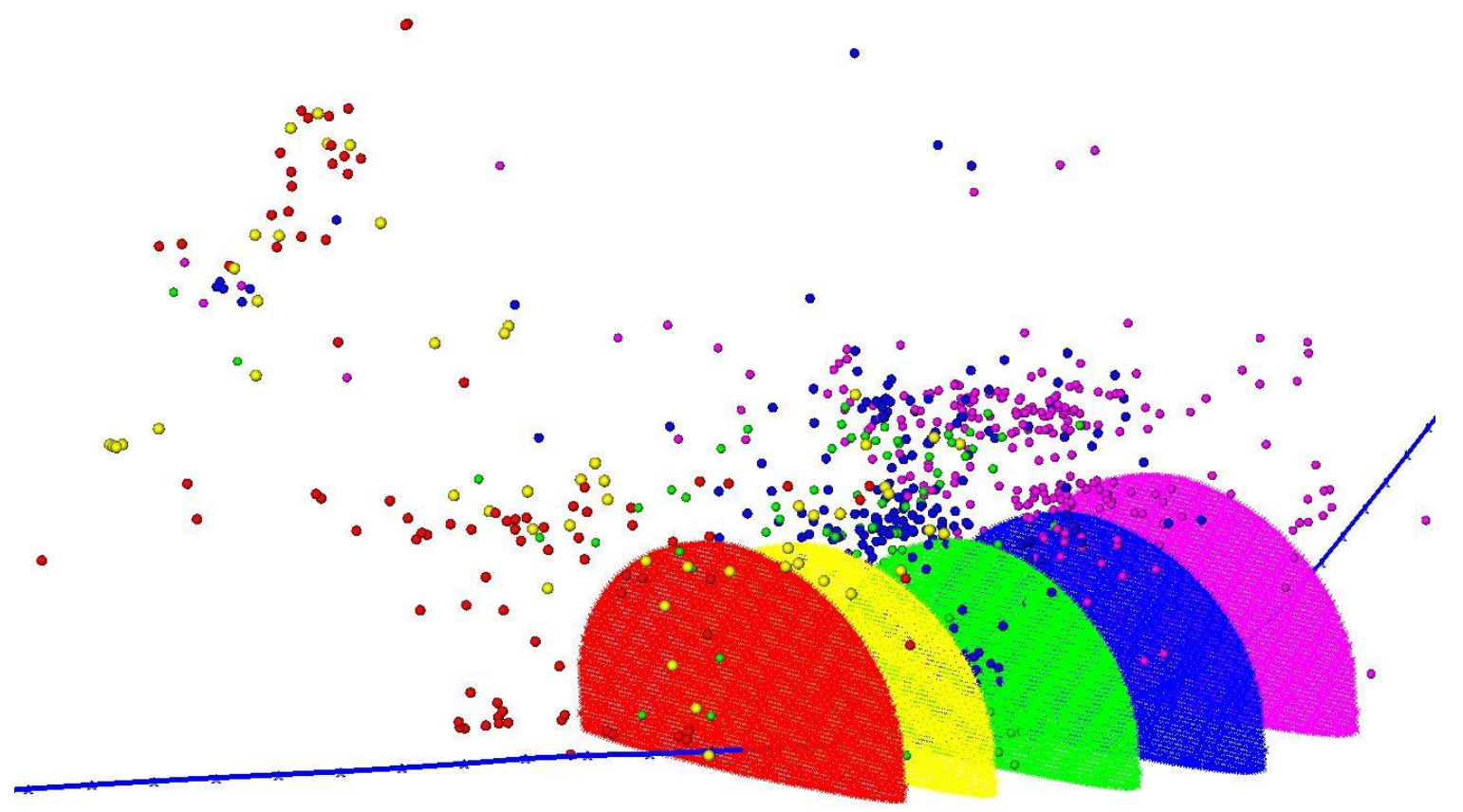

Figure A.88: Orthogonal View of Calculated Primary Hydraulic Fracture Geometries, Available Measured Microseismic Events, and Nearby Wellbore for Stage 26 through Stage 30 - MIP-5H 